\title{
Safety Training and Safe Operating Procedures Written for PBFA II and Applicable to Other Pulsed Power Facilities
}

Guy L. Donovan, Steven A. Goldstein

\section{Prepared by}

Sandia National Laboratories

Albuquerque, New Mexico 87185 and Livermore, California 94550

for the United States Department of Energy

under Contract DE-AC04-76DP00789

\section{When printing a copy of any digitized SAND Report, you are required to update the markings to current standards.}


Issued by Sandia National Laboratories, operated for the United States Department of Energy by Sandia Corporation.

NOTICE: This report was prepared as an account of work sponsored by an agency of the United States Government. Neither the United States Government nor any agency thereof, nor any of their employees, nor any of their contractors, subcontractors, or their employees, makes any warranty, express or implied, or assumes any legal liability or responsibility for the accuracy, completeness, or usefulness of any information, apparatus, product, or process disclosed, or represents that its use would not infringe privately owned cess disclosed, or represents that its use would not infringe privately owned
rights. Reference herein to any specific commercial product, process, or rights. Reference herein to any specific commercial product, process, or
service by trade name, trademark, manufacturer, or otherwise, does not necessarily constitute or imply its endorsement, recommendation, or favoring by the United States Government, any agency thereof or any of their contractors or subcontractors. The views and opinions expressed herein do not necessarily state or reflect those of the United States Government, any agency thereof or any of their contractors or subcontractors.

Printed in the United States of America

Available from

National Technical Information Service

U.S. Department of Commerce

5285 Port Royal Road

Springfield, VA 22161

NTIS price codes

Printed copy: A17

Microfiche copy: A01 
SAND86-2350

UNLIMITED RELEASE

PRINTED ，1986

\begin{abstract}
SAFETY TRAINING AND SAFE OPERATING PROCEDURES WRITTEN FOR PBFA II AND APPLICABLE TO OTHER PULSED POWER FACILITIES
\end{abstract}

Guy L. Donovan and Steven A. Goldstein

Accelerator Experiments Division 1266

Sandia National Laboratories

Albuquerque, N. M. 87185

\begin{abstract}
To ensure that work in advancing pulsed power technology is performed with an acceptably low risk, pulsed power research facilities at Sandia National Laboratories must satisfy general safety guidelines established by the Department of Energy, policies and formats of the Environment, Safety, and Health (ES\&H) Department, and detailed procedures formulated by the Pulsed Power Sciences Directorate. The approach to safety training and to writing safe operating procedures, and the procedures presented here are specific to the Particle Beam Fusion Accelerator II (PBFA II) Facility but are applicable as guidelines to other research and development facilities which have similar hazards.
\end{abstract}


R. R. Johnston presently is in charge of executing the safety and technical training programs at PBFA II and has contributed many ideas to its

administration. Many other members of the Accelerator Experiments Division (formerly the Pulsed Power Operations Division) and the PBFA II Project Team contributed technical input to the component and subsystem safe Operating Procedures and operating Procedures. Special recognition is deserved by the personnel who advise us on specific safety, health physics, industrial hygiene, and fire protection issues and who have reviewed the material presented in this report, viz., A. M. Fine, T. N. Simmons, J. B. Mashburn, J. M. Phelan, and V. L. Duke. 


\section{TABLE OF CONTENTS}

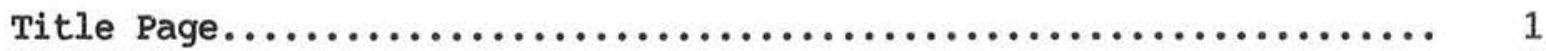

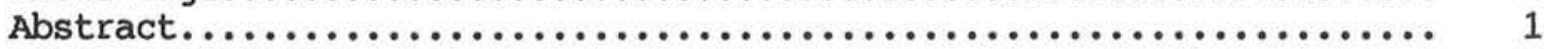

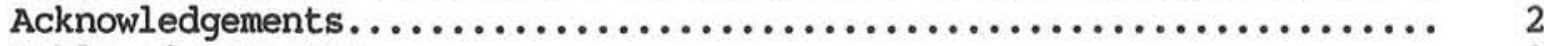

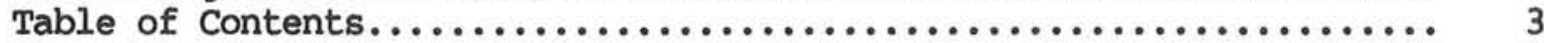

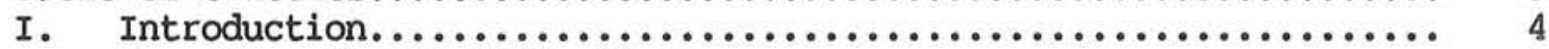

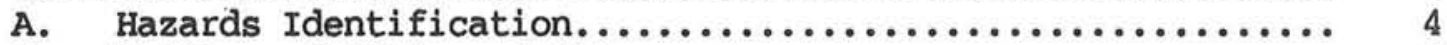

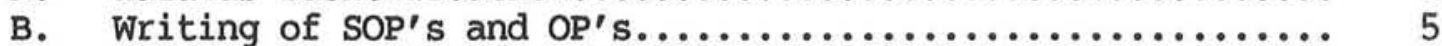

C. Safety and Technical Training...................... 5

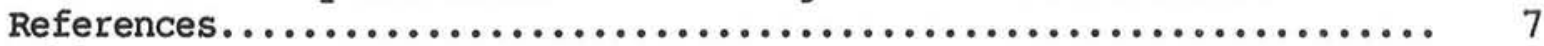

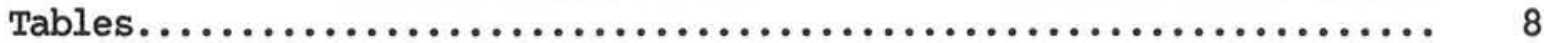

Table 1 - PBFA II Classes of Hazards and Their Potential Areas of Impact................................... 8

Table 2 - PBFA II Operating Procedures Under Development....... 9 9

Table 3 - General Operations Training Requirements............ 10

Table 4 - Division Training Record....................... 11

Table 5 - Pulse Power Technical Training Manual

Table of Contents............................. 12

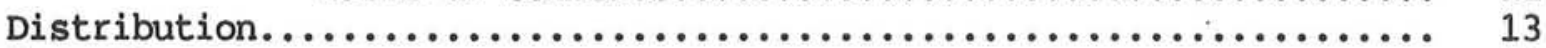

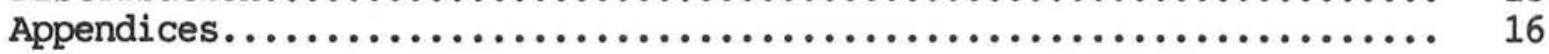


I. INTRODUCTION

\section{A. Hazards Identification}

The identification of hazards for the Particle Beam Fusion Accelerator II (PBFA II) considers conditions and events unique to the equipment and operation of the facility. A hazard is defined as anything with the potential for causing injury or illness to human operators or other personnel or damage to the environment, including the work environment and facility. A hazard control is defined as any device or (in the case of this report) any procedure that eliminates, minimizes, or mitigates a hazard.

At Sandia National Laboratories (for large particle accelerator projects) the general types of hazards are identified during the design and early construction phases and are documented in a Preliminary Safety Analysis Report (PSAR) (1) and, again, after more detailed information is known, in a Final Safety Analysis Report (FSAR) (2), both of which are submitted to and approved by the Department of Energy. In acquiring hazards information, an earlier technique utilized one or two ES\&H personnel and a few key facility individuals to identify hazard origins and severity. Recently, a methodology has been developed by ES\&H personnel (3) and the Project Management Division to acquire a detailed hazard identification and risk evaluation from the accountable and most knowledgeable design engineers during the criteria development and design review stages of R\&D construction projects. This new procedure is expected to greatly aid the timely collection and documentation of safety related information and procedures during both the construction and later operational phases of pulsed power facilities.

A multi-step approach to hazard control is taken at PBFA II. Once hazards have been identified, they may be controlled by the following steps:

* Engineering mechanical and electrical solutions to control the hazard exposure or to mitigate the consequences

* Writing (and following) safe operating procedures (SOP's) covering techniques for safely interacting with the facility and subsystems

* Writing operating procedures ( $\left.O P^{\prime} s\right)$ to define the technically correct methods and approaches to system operations

* Training of personnel in technical areas associated with the hazards

* Training of personnel in safety areas associated with the hazards. 


\section{B. Writing of $S O P^{\prime} s$ and $O P^{\prime} s$}

Note that SOP's and OP's are written separately, for several reasons. First, to stress the difference between technical and safe performance of a job function. While these are interrelated, there are situations where there may be several technical methods for completing a task but only one acceptable way of performing it safely, and vice versa. Second, safe procedures frequently can be, and must be established and fixed earlier in the life of a new facility or subsystem than the optimum, technically correct procedures, since it takes some time to characterize and optimize complex subsystems. Third, the source of information for SOP's and OP's may be different; in the past, the former were originated by ES\&H personnel trained in safety, and the latter frequently were written by subsystem design engineers or operating personnel. Fourth, numerous logistic procedures, checklists, and details required to run a world-class size accelerator like PBFA II need to be documented, but the information frequently does not fit into the format and context of an SOP, which are formally established by Sandia ES\&H requirements.

The general hazards associated with PBFA II, collected from documentation in the PBFA II PSAR and FSAR and shown in Table 1, are generic to many other pulsed power facilities at Sandia and in the R\&D community. The training programs and SOP's developed to address these hazards therefore may be useful as guidelines or models at other facilities and programs either directly or after modification to apply to specific subsystems.

The PBFA II SOP's in the appendices contain the current procedures for controlling hazards now present in the facility as identified by the SAR's and our up-to-date operating experiences. Since PBFA II is a young facility and will continue to evolve in its development, the SOP's and OP's are dynamic; the material in this report therefore is a "snapshot" of what the procedures are now, but they will continue to change, expand, and improve to better control the identified hazards.

While the PBFA II facility SOP's are nearly complete, the OP's are just starting their development phase. It is envisioned that these latter procedures will cover the information categories shown in Table 2.

\section{Safety and Technical Training}

In addition to documenting safe procedures for accomplishing PBFA II operational tasks, a safety training program has been initiated to instruct personnel in various safety technologies. General safety training requirements are dependent on the type of assignment given to personnel; the matrix of assignments and required general training presently used is shown in Table 3 . A specific safety training curriculum, tailored to a person's current assignment and background experience, is established and stored in a personal computer database. A sample format is shown in Table 4. Completion of initial training is documented, and retraining schedules are automatically generated by the database. 
Technical training also is performed in fields applicable to the operation of large pulsed power accelerators and their electromechanical support subsystems to better understand basic operating principles and associated hazards. The contents of a manual of collected technical materials (4) currently used is shown in Table 5.

The documentation of safety and technical training requirements for various accelerator operator functions has become sufficiently important that it has been outlined specifically in the SOP, "Operator Training and Certification at PBFA II, Building 983" (see Appendix). 
1. "Preliminary Safety Analysis Report for Particle Beam Fusion Accelerator II," L. D. Rigdon, et. al., Los Alamos Technical Associates, Inc., June, 1982, SAND81-7148.

2. "Final Safety Analysis Report for Particle Beam Fusion Accelerator II, Sandia National Laboratories," T. M. Rudell, et. al., Los Alamos Technical Associates, Inc., July 1986, SAND867079 .

3. "Guidelines for Risk Evaluation in Project Management (A Guide for Work Package Managers and Functional Representatives)," A. M. Fine, T. N. Simmons, and J. Phelan, Sandia National Laboratories Internal Memorandum, July, 1986.

4. "Pulse Power Technical Training Manual," Sandia National Laboratories Internal Document, July, 1986. 
TABLE 1. PBFA II CLASSES OF HAZARDS AND THEIR POTENTIAL AREAS OF IMPACT

IMPACT

\begin{tabular}{|c|c|c|}
\hline & EMPLOYEE & EMPLOYEE \\
\hline ENVIRONMENT & $\begin{array}{l}\text { SAFETY } \\
\text { mamm }\end{array}$ & 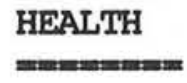 \\
\hline
\end{tabular}

1. Anoxia

SF6, Drowning

EMP, Lasers

Neutrons, X-rays

Gamma-rays

Yes

Yes

Ionizing

3. Radioactive Matl's Activated Metals and Gases from Proton, Neutron, and Gamma Irrad.

Yes

Yes

Yes

4. Toxic/Corrosive SF6, Hexanes, Substances

Acid, Caustic

Personnel Falls

Yes

Yes

Yes

5. Potential Energy

6. Kinetic Energy

Tools, Components

Yes

7. Pressure-Volume

Compressed Gases, Vacuum

Yes

Yes

Maybe

Yes

Yes

Accelerator, Mechanical Systems

Maybe

10. High Voltage

Electrical Subsystems
Yes

Yes 
TABLE 2. PBFA II OPERATING PROCEDURES UNDER DEVELOPMENT

EXPERIMENTAL FIRING LOGISTICS-RELATED OP'S

Shot Procedures

Shot Descriptions

Shot Coordinator Duties

Special Access Control Procedures

PA System Announcement Guide

Marx Generator Operating Procedure

Marx Trigger Generator Operating Procedure

Laser Trigger System Operating Procedure

Plasma Opening Switch System Operating Procedure

Diode Capacitor Bank Operating Procedure

Procedure for Crew Utilization During Shots

Manpower Requirements for Shot Activities

Preshot/Postshot Checkoff Lists

SUPPORT SYSTEMS/MAINTENANCE-RELATED OP'S

Morning Inspection Sheet

Evening Inspection Sheet

Weekend Inspection Sheet

Water Processing/Transfer System Operating Procedure

Transformer Oil Processing/Transfer System Operating Procedure

Insulating Gas System Operating Procedure

Marx Generator Refurbishment Procedure

Rimfire Switch Refurbishment Procedure

Vacuum System Operating/Maintenance Procedure

Energy Storage Section Inspection

Pulse Forming Section Inspection

Power Flow Section Inspection

Vacuum Interface Stack Maintenance Procedure

Vacuum Convolute Maintenance Procedure

Emergency/Auxiliary Generator Testing Procedure 
TABLE 3. GENERAL OPERATIONS TRANINO RECUIREMENTS

\begin{tabular}{|c|c|c|c|c|c|c|c|c|c|c|c|}
\hline JOB ASSIGNMENT & CPR & $\begin{array}{l}\text { First } \\
\text { Ald } \\
\end{array}$ & $\begin{array}{c}\text { Aip } \\
\text { Pack }\end{array}$ & Scuba & \begin{tabular}{|c|}
$\begin{array}{c}\text { Resplipo } \\
\text { ators }\end{array}$ \\
\end{tabular} & $\begin{array}{l}\text { Fork } \\
\text { Lifte } \\
\end{array}$ & $\begin{array}{l}\text { Crane a } \\
\text { Rigging } \\
\end{array}$ & $\begin{array}{l}\text { Fire } \\
\text { Exe. }\end{array}$ & $\begin{array}{l}\text { Laser } \\
\text { Safety }\end{array}$ & $\begin{array}{c}\text { HV } \\
\text { Safoty }\end{array}$ & $\begin{array}{c}\text { Rad } \\
\text { Safoty }\end{array}$ \\
\hline ENERGY STORAGE SECTION & $x$ & $x$ & $x$. & & $x$ & $x$ & $x$ & $x$ & & $x$ & \\
\hline PULSE FORMENG SECTION & $x$ & $x$ & $x$ & $x$ & $x$ & $x$ & $x$ & $x$ & & & \\
\hline $\begin{array}{l}\text { CENTER SECTION } \\
\text { Hardware Rolurb \& install } \\
\text { POS Fabrication \& Prep }\end{array}$ & $\begin{array}{l}x \\
x\end{array}$ & $\begin{array}{l}x \\
x\end{array}$ & $x$ & & $\begin{array}{l}x \\
x\end{array}$ & $\begin{array}{l}x \\
x\end{array}$ & $\begin{array}{l}x \\
x\end{array}$ & $\begin{array}{l}x \\
x\end{array}$ & & $\begin{array}{l}x \\
x\end{array}$ & $\begin{array}{l}x \\
x\end{array}$ \\
\hline VACUUM SECTION & $x$ & $x$ & & & $x$ & $x$ & $x$ & $x$ & & & $x$ \\
\hline $\begin{array}{l}\text { CONTROL MONTOR SECTION } \\
\text { System Programmer } \\
\text { Operator Tecthildan }\end{array}$ & $\begin{array}{l}x \\
x\end{array}$ & $\begin{array}{l}x \\
x\end{array}$ & & & & $x$ & $x$ & $\begin{array}{l}x \\
x\end{array}$ & & $x$ & \\
\hline $\begin{array}{l}\text { DATA ACQUISTION SECTION } \\
\text { Syatom Programmer } \\
\text { Operator Tochniclan }\end{array}$ & $\begin{array}{l}x \\
x\end{array}$ & $\begin{array}{l}x \\
x\end{array}$ & & & & $x$ & $x$ & $\begin{array}{l}x \\
x\end{array}$ & & & \\
\hline PROCESS SYSTEMS & $x$ & $x$ & $x$ & $x$ & $x$ & $x$ & $x$ & $x$ & & & \\
\hline SUPPORT SHOPS & $x$ & $x$ & & & & $x$ & $x$ & $x$ & & & $x$ \\
\hline $\begin{array}{l}\text { LOGISTICS } \\
\text { Software Development } \\
\text { Purchasing, Inventory \& } \\
\text { Material Moving }\end{array}$ & $\begin{array}{l}x \\
x\end{array}$ & $\begin{array}{l}x \\
x\end{array}$ & & & & $x$ & $x$ & $\begin{array}{l}x \\
x\end{array}$ & & & $x$ \\
\hline LASER TRIGGER SECTION & $x$ & $x$ & $x$ & & $x$ & $x$ & $x$ & $x$ & $x$ & $x$ & \\
\hline
\end{tabular}


TABLE 4. Division Training Record

\begin{tabular}{|c|c|c|c|c|c|c|c|c|c|c|c|c|c|c|}
\hline NAME & $\begin{array}{c}\text { Job } \\
\text { Assign. }\end{array}$ & Date & CPR & $\begin{array}{l}\text { First } \\
\text { Aid }\end{array}$ & $\begin{array}{c}\text { Air } \\
\text { Pack }\end{array}$ & Scuba & $\begin{array}{c}\text { Respir- } \\
\text { ators }\end{array}$ & $\begin{array}{c}\text { Fork } \\
\text { Lift }\end{array}$ & \begin{tabular}{|l|} 
Crane \& \\
Rigging \\
\end{tabular} & $\begin{array}{l}\text { Fire } \\
\text { Ext. }\end{array}$ & $\begin{array}{l}\text { Laser } \\
\text { Safety }\end{array}$ & $\begin{array}{c}\text { HV } \\
\text { Safety }\end{array}$ & $\begin{array}{c}\text { Rad } \\
\text { Safety }\end{array}$ & \begin{tabular}{|c|} 
New Hire \\
Briefing
\end{tabular} \\
\hline Jobe, Dan & ESS & Recv'd & $12 / 85$ & $1 / 86$ & $10 / 85$ & & & $10 / 85$ & 7186 & & & & & \\
\hline & & Due & $12 / 86$ & $1 / 88$ & & & YES & $10 / 87$ & $7 / 88$ & YES & & YES & & \\
\hline Johnson, Albert (Red) & POS & Recv'd & & & & & & & $7 / 86$ & & & & $6 / 86$ & \\
\hline & & Due & YES & YES & YES & & YES & YES & $7 / 88$ & YES & & YES & & YES \\
\hline Johnson, Mark & LTS & Recv'd & $7 / 85$ & $1 / 86$ & $10 / 85$ & & $4 / 85$ & $10 / 85$ & $7 / 86$ & & & & & \\
\hline & & Due & $7 / 86$ & $1 / 88$ & & & $7 / 85$ & $10 / 87$ & $7 / 88$ & YES & YES & YES & & YES \\
\hline Johnston, Robert & Facility & Recv'd & Instructor & & $10 / 85$ & & & & $7 / 86$ & & & & & N/A \\
\hline & & Due & & YES & & & YES & YES & $7 / 88$ & YES & & & & \\
\hline Junod, Marcus & DAS Prog. & Recv'd & & & & & & & N/A & & & & & $6 / 86$ \\
\hline & & Due & YES & YES & & & & & & YES & & & & \\
\hline King, Curt & PFS & Recv'd & & $1 / 86$ & & & & $10 / 85$ & $7 / 86$ & & & & & $6 / 86$ \\
\hline & & Due & YES & $1 / 88$ & YES & YES & YES & $10 / 87$ & $7 / 88$ & YES & & & & \\
\hline Lake, Pat & Center & Recv'd & & $1 / 86$ & & & & $10 / 86$ & $7 / 86$ & & & & $6 / 86$ & $5 / 86$ \\
\hline & & Due & YES & $1 / 88$ & YES & & YES & $10 / 87$ & $7 / 88$ & YES & & YES & & \\
\hline Linzmeier, Barbara & C/M Tech & Recv'd & & & & & & & & & & & & $5 / 86$ \\
\hline & & Due & YES & YES & & & & YES & YES & YES & & & & \\
\hline Lundstrom, Joe & Process & Recv'd & $11 / 85$ & $1 / 86$ & $10 / 85$ & & & $10 / 85$ & & & & & & $5 / 86$ \\
\hline & & Due & $11 / 86$ & $1 / 88$ & & YES & YES & $10 / 87$ & YES & YES & & & & \\
\hline Lynch, Jim & Facility & Recv'd & & & & & & & $7 / 86$ & & & & & $6 / 86$ \\
\hline & & Due & YES & YES & & & YES & YES & $7 / 88$ & YES & & & YES & \\
\hline Mattson, Craig & DAS & Recv'd & $11 / 85$ & & & & & & $\mathrm{~N} / \mathrm{A}$ & & & & & $\mathrm{N} / \mathrm{A}$ \\
\hline & & Due & $11 / 86$ & YES & & & & & & YES & & & & \\
\hline McDonnell, John & Vacuum & Recv'd & $11 / 85$ & $1 / 86$ & $8 / 83$ & & $12 / 85$ & $10 / 85$ & $7 / 86$ & & & & $6 / 86$ & $5 / 86$ \\
\hline & & Due & $11 / 86$ & $1 / 88$ & & & $6 / 86$ & $10 / 87$ & $7 / 88$ & YES & & & & \\
\hline McDougal, Cynthia & POS & Recv'd & $11 / 85$ & & & & $3 / 86$ & & & & & & $6 / 86$ & $6 / 86$ \\
\hline & & Due & $11 / 86$ & YES & YES & & $9 / 86$ & YES & YES & YES & & YES & & \\
\hline McGovern, Harry & PFS & Recv'd & $12 / 85$ & $1 / 86$ & $10 / 85$ & & & & $7 / 86$ & & & & & $5 / 86$ \\
\hline & & Due & $12 / 86$ & $1 / 88$ & & YES & YES & YES & $7 / 88$ & YES & & & & \\
\hline Mikkelson, Jim & PFS & Recv'd & & & & & & & $7 / 86$ & & & & & $6 / 86$ \\
\hline & & Due & YES & YES & YES & YES & YES & YES & $7 / 88$ & YES & & & & \\
\hline Mills, Jerry & DAS Tech & Recv'd & & $1 / 86$ & & & & & $7 / 86$ & & & & & \\
\hline & & Due & YES & $1 / 88$ & & & & YES & $7 / 88$ & YES & & & & YES \\
\hline Nations, Dennis & Shot Coord. & Recv'd & Instructor & & & & & & & & & & & $\mathrm{N} / \mathrm{A}$ \\
\hline & & Due & & YES & & & & & YES & YES & & & & \\
\hline Navarro, Mike & Center & Recv'd & & $1 / 86$ & & & $12 / 85$ & $10 / 85$ & $7 / 86$ & & & & $6 / 86$ & $5 / 86$ \\
\hline & & Due & YES & $1 / 88$ & YES & & $6 / 86$ & $10 / 87$ & $7 / 88$ & YES & & YES & & \\
\hline Nielsen, Dan & PFS & Recv'd & & & & & & & $7 / 86$ & & & & & $6 / 86$ \\
\hline & & Due & YES & YES & YES & YES & YES & YES & $7 / 88$ & YES & & & & \\
\hline Orth, Scott & C/M Tech & Recv'd & $11 / 85$ & $1 / 86$ & & & & & $7 / 86$ & & & & & \\
\hline & & Due & $11 / 86$ & $1 / 88$ & & & & YES & $7 / 88$ & YES & & YES & & YES \\
\hline Osborn, Richard & Logis. Tech & Recr'd & $11 / 85$ & $1 / 86$ & & & & $10 / 85$ & $7 / 86$ & & & & $6 / 86$ & $5 / 86$ \\
\hline & & Due & $11 / 86$ & $1 / 88$ & & & & $10 / 87$ & $7 / 88$ & YES & & & & \\
\hline Padilla, Richard & POS & Recv'd & & & & & & & $7 / 86$ & & & & $6 / 86$ & $5 / 86$ \\
\hline & & Due & YES & YES & & & YES & YES & $7 / 88$ & YES & & YES & & \\
\hline
\end{tabular}


TABLE 5.

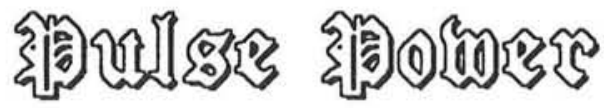

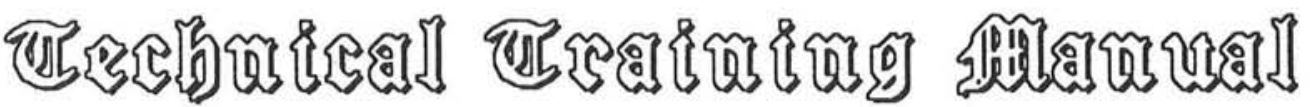

\section{TABLE OF CONTENTS}

1. Some Basic Concepts and Fundamentals of H.V. Generators

2. Lectures on Intense Particle Beams

3. PBFA I Pulse Power Manual

4. The PBFA II Demonstration Experiment DEMON Project Documentation

5. PBFA II Papers Delivered at the 5th IEEE Pulsed Power Conference

6. Circuit and Electromagnetic System Design Notes

- Note 4 - Nanosecond Pulse Techniques

7. Transmission Lines and Pulse Forming Networks Appendix - Energy Storage Capacitors

8. Discharge Circuits and Loads

9. Grounding and Shielding in Pulse Power

10. Effects of High Voltage Pulses on Various Resistors

11. Vacuum Techniques for Beginners

12. Pulsed Power Equations, Formulas, and Rules of Thumb 
US Department of Energy

Office of Inertial Fusion

Attn: M. Sluyter

Mail Station C-404

Washington, DC 20545

US Department of Energy

Albuquerque Operations Office

Attn: M. Charles ESHD

PO Box 5400

Albuquerque, NM 87115

Air Force Weapons Laboratory

Attn: A. H. Guenther, CA

Kirtland AFB, NM 87117

Cornell University (2)

Laboratory for Plasma Studies

Attn: D. Hammer

R. N. Sudan

Ithaca, NY 14853

Pulse Sciences, Inc.

Attn: I. D. Smith

14796 Wickes Blvd.

San Leandro, CA 94557

Texas Tech University

Department of Electrical Engineering

Attn: M. Kristiansen

Lubbock, TX 79409

Massachusetts Inst. of Technology

Physics Department

Attn: G. Bekefi

Mudd Bldg.

Cambridge, MA 02139

Maxwell Laboratories, Inc.

Attn: A. C. Kolb

8835 Balboa Ave.

San Diego, Ca 92123

Naval Research Laboratory

Attn: G. Cooperstein

4555 Overlook Avenue SW

Washington, DC 20390 


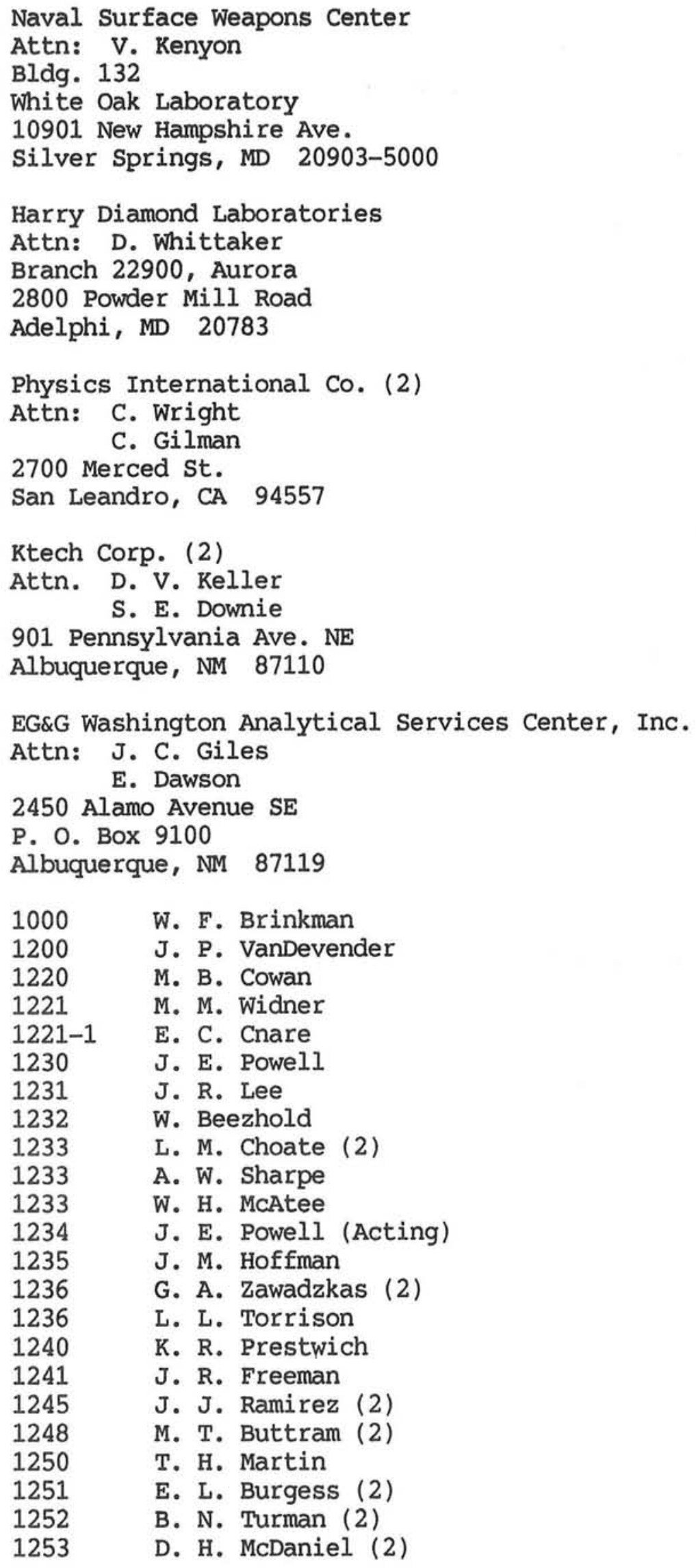




$\begin{array}{ll}1260 & \text { D. L. Cook } \\ 1263 & \text { J. N. Olsen (2) } \\ 1264 & \text { P. A. Miller (2) } \\ 1265 & \text { J. P. Quintenz } \\ 1266 & \text { S. A. Goldstein (5) } \\ 1266 & \text { G. L. Donovan (5) } \\ 1270 & \text { R. B. Miller } \\ 1271 & \text { M. Clauser } \\ 1272 & \text { D. E. Hasti (2) } \\ 1273 & \text { M. K. Matzen (2) } \\ 1274 & \text { R. J. Lipinski (2) } \\ 3141 & \text { Technical Library Process Division (5) } \\ 3151 & \text { Technical Writing Division (3) } \\ 3154-1 & \text { DOE/TIC (28) } \\ 3311 & \text { J. M. Phelan } \\ 3312 & \text { T. N. Simmons } \\ 3312 & \text { J. B. Mashburn } \\ 3316 & \text { A. M. Fine (4) } \\ 7554 & \text { T. S. Edrington, Actg. } \\ 7554 & \text { R. A. White } \\ 7860 & \text { G. W. Barr } \\ 7862 & \text { V. L. Duke } \\ 7866 & \text { J. P. Furaus } \\ 8424 & \text { (1) }\end{array}$




\section{APPENDICES - SAFE OPERATING PROCEDURES}

1. Escorting Visitors

2. Staff Machine Shop at PBFA II, Building 983

3. Operation, Maintenance, and Repair of the Testbed Facility at PBFA II, Building 983

4. Reacting to Emergencies at PBFA II, Building 983

5. Motive Equipment Operation at PBFA II, Building 983

6. Use of Flammable Liquids at PBFA II, Building 983

7. Use of Safety Equipment at PBFA II, Building 983

8. Personnel Access at PBFA II, Building 983

9. Maintenance and Repair in the Oil Section of PBFA II, Building 983

10. Fluid Systems Operation at PBFA II, Building 983

11. Maintenance and Repair in the Water Section of PBFA II, Building 983

12. Gas Switch Pressure Test Vessel at PBFA II, Building 983

13. Ionizing Radiation Hazards at PBFA II, Building 983

14. Underwater Diving at PBFA II, Building 983

15. Laser Trigger System Operation at PBFA II, Building 983

16. Maintenance and Repair in the Center Section of PBFA II, Building 983

17. Applied-B Diode Capacitor Bank at PBFA II, Building 983

18. Welding, Cutting, and Hotwork in Tech Area IV

19. Operator Training and Certification at PBFA II, Building 983

20. High Voltage Monitor Calibration at PBFA II, Building 983 
SAFE OPERATING PROCEDURE

FOR

ESCORTING VISITORS

AT

PBFA II, BUILDING 983

Appendix 1

$1-1-1-2$ 


\section{Table of Contents}

Abstract . . . . . . . . . . . . . . 0

I. Introduction . . . . . . . . . . . . . . . . I

A. General . . . . . . . . . . . . . . l

B. Phases of the PBFA II Project . . . . . . . I

C. Types of Visitor Access . . . . . . . . . . . 2

D. Required Authorizations . . . . . . . . . . . 3

E. Required Escort Indoctrination . . . . . . . . 3

II. Hazards and Safety Considerations . . . . . . . 5

A. Flammable and Combustable Materials . . . . . . 5

B. Motive Equipment and Mechanical Hazards . . . . 5

C. Slips and Falls... . . . . . . . . . . 6

D. Stairs, Ladders, Gratings and Catwalks . . . 6

E. Electrical Hazards . . . . . . . . . . 6

F. Hard Hat Areas . . . . . . . . . . . . . 7

G. Warning Lights and Audible Alarms. . . . . 7

H. Locked Doors . . . . . . . . . . . . . 8

III. Action in Case of Emergency or Injury . . . . . 9

A. Evacuation in Case of Fire . . . . . . . . . . 9

B. Injury or Emergency . . . . . . . . . . 10

II. Appendices . . . . . . . . . . . . . . . . . . . 11

A. 1200 Tour Information Sheet . . . . . . . . 11

B. Entry Points, Tour Routes and No Smoking Areas 12 
SAFE OPERATING PROCEDURE

FOR

ESCORTING VISITORS

$\mathrm{AT}$

PBFA II, BUILDING 983

\begin{abstract}
This SOP outlines proper procedures for conducting tours through the PBFA II complex in Area IV, building 983. Poor coordination of tours in this facility may expose visitors and/or resident personnel to unnecessary safety hazards and may result in lost time to the operation of the facility.
\end{abstract}

J. P. VanDevender, 1200 date

T. H. Martin, 1250 date

S. A. Goldstein, 1254 date

Distribution: (rev. 9/84)

0400 C. Winter

1000 W. F. Brinkman

$1000 \mathrm{~A}$ D. L. Hughes

1200 J. P. VanDevender

1200 A S. A. Ross

1201 G. W. Barr

1220 M. B. Cowan

1230 J. E. Powell

1230 R. Tierney

1231 T. P. Wright

1232 W. Beezhold

1233 G. A. Zawadzkas

$1234 \mathrm{~J}$. Chang

1235 J. M. Hof fman

1240 K. R. Prestwich

1240A K. A. Stanley

1241 J. R. Freeman

1244 R. A. Gerber

1245 D. E. Hasti

1248 M. T. Buttram

1250 T. H. Martin

1250A T. Holovka
D. L. Rost, 3442 date

M. M. Carroll, 3442 date

\section{1}

1252

1254

1254

1260

1261

1263

1264

1265

1270

1271

1272

1273

3160

3161

3161

3161

3163

3163

3442

3442
S. A. Goldstein Actg.

B. N. Turman

S. A. Goldstein

All Personnel

D. L. Cook

D. H. McDaniel

J. N. Olsen

P. A. Miller

M. M. Widner

R. B. Miller

M. L. Clauser

C. A. Ekdahl

M. K. Matzen

J. E. Mitchell

K. C. Frazier

W. R. Geer

N. S. Hey

L. S. Borgrink

R. H. Austin

D. L. Rost

M. M. Carroll 


\section{SAFE OPERATING PROCEDURE \\ FOR \\ ESCORTING VISITORS \\ AT \\ PBFA II, BLDG. 983}

\section{Introduction}

A. General

As PBFA II proceeds through the construction phase and into its operational phase, the importance of presenting the facility in a safe, professional manner will continue to be of prime concern to all involved. This SOP reviews the potential problems associated with escorting visitors through the 983 highbay complex and suggests methods for ensuring safety, reacting to non-standard situations, and minimizing interference with facility operations.

\section{B. Phases of the PBFA II project}

The development of the PBFA II accelerator into a mature facility has been divided into distinct phases, i.e. the assembly phase, the test phase and the operational phase. All stages of PBFA II development represent different environments in and around the accelerator. These phases should be recognized by any personnel conducting tours through the facility.

During the assembly phase, the area around the accelerator tank will closely resemble an industrial construction site, with extensive use of heavy equipment (e.g. fork lifts, overhead motive equipment, power tools, and welding equipment). This environment will require that the tour guide keep visitors away from areas that may not be safe (under overhead loads, near motive equipment, etc.).

During the test phase of the PBFA II accelerator, high voltage systems in and around the accelerator will be active (some for the first time) as well as fluid transfer equipment, various pneumatic control systems and other potentially dangerous equipment. During this phase of PBFA II activities, personnel responsible for the escorting of visitors should be knowledgeable as to the hazards that exist and which areas should be avoided. 
The operational phase of PBFA II will encompass all of the above conditions to varying degrees. The different conditions that will exist throughout the lifetime of PBFA II reaffirm the need for careful coordination between the tour group and facility administrators.

C. Types of visitor access

1. "Tours"

A tour shall be defined as any personnel access activity requiring one or more of the following:
a) any modification of the PBFA II sche- dule
b) any special preparation of the building 983 complex (extensive area cleanup, set up of displays etc.)
c) any significant investment of time by highbay personnel (as escorting an individual or group, or giving a pre- sentation)
d) any group of people too large to be safely escorted by a single 1200 tour guide (larger than 15-20 people)

NOTE: A tour that in any way affects the schedule of accelerator activities (in most cases all of the above) may affect the productivity of the facility and therefore MUST have proper authorization (see section $D$ below)

\section{2. "Visits"}

A visit shall be defined as any access involving a small group of people escorted by qualified personnel where no preparation of the machine or surrounding area is required.

Visits should be limited to persons having a professional connection with the Pulsed Power Programs at SNLA. Generally, family members and friends are not allowed in the facility.

NOTE: A visit as defined above does not take precedence over accelerator activities and therefore may be interrupted, postponed or cancelled by highbay activities. Though visits are not to 
interfere with the PBFA II schedule, proper authorization is still required (see section D below).

\section{Required Authorizations}

1. Tours - A tour must be planned in advance by notifying the 1260 Department office, supplying pertinent information for the 1200 Tour Information Sheet (see Appendix $A$ ), and obtaining the approval of D. L. Cook, or a delegated representative. AUTHORIZATION FOR A TOUR TO TAKE PRECEDENCE OVER HIGHBAY ACTIVITIES MUST APPEAR ON THE TOUR INFORMATION SHEET AND BE CONFIRMED BY THE 1260 DEPARTMENT MANAGER OR DELEGATE.

2. Visits - A visit must have prior approval by a Division Supervisor or above within 1220, 1230, $1240,1250,1260$, 1270, or the 1200 Director's office. After obtaining proper authorization, the escort shall be responsible for coordinating the visit with the Facility Manager or delegate.

NOTE: All escorts for tours or visits MUST be familiar with the PBFA II facility, its hazards, and the appropriate course of action in emergency situations. An escort must also be familiar with the provisions of this Safe Operating Procedure.

E. Indoctrination Required for Visitor Escorts

1. Escorts must be familiar with the general operation of PBFA II and the environment within the facility.

2. Escorts must be familiar with the responsibilities they accept when escorting visitors as outlined in this Safe Operating Procedure.

3. Escorts should explain to visitors the hazards they may encounter during the course of the tour.

4. Escorts must be prepared to escort tour groups out of the facility should emergency evacuation be required.

5. Escorts must maintain control of their groups at all times in order to ensure safety. 


\section{TOURS}

The initiator of any tour must assure that the ratio of 20 visitors per escort is not exceeded. As tours are pre-planned through the 1260 Department office, no prior notification of highbay personnel is required before entry into the facility

\section{VISITS}

Escorts of visits must check in with the Facility Managert prior to entry into the highbay to determine the status and planned activity for the facility.

* The name and phone number of the on-duty Facility Manager will be posted near the entrance to the Data Aquisition Room (RM 104). The Facility Manager may be reached by phone, PA announcement, or personal pager. 


\section{Hazards and Safety Considerations}

A. Flammable and Combustible Materials

Several areas in and around the 983 highbay involve the use of extremely flammable solvents or have limited fire fighting capabilities. This situation will change throughout the phases of accelerator development and operation such that an escort must be alert to locally posted signs throughout the highbay as well as specific areas designated in this SOP. Areas in which smoking will not be permitted at any time will be posted with signs as NO SMOKING ISLANDS (see Appendix B). These areas shall include:

1. PBFA II Control/Monitor Room (Rm 105)

2. PBFA II Data Acquisition Room (Rm 104)

3. The areas within the accelerator tank

4. The -10 foot, -12 foot, -25 foot levels of the highbay and the catwalks and mezzanine area above the accelerator tank

5. The Marx assembly/refurbishment area 1ocated in the southeast corner of the highbay

6. The entire phase $C$ addition of 983 10cated in the southeast corner of the building

7. Areas within the zero foot level as posted.

8. The utility tunnel at the -25 foot level of the mechanical room.

Other areas within the complex where smoking is not permitted shall be posted as such. Escorts should be alert to warning signs if tour groups are to be taken into other sections of the 983 complex not specifically covered by this sOP.

B. Motive Equipment and Mechanical Hazards

1. Heavy equipment (fork lifts, overhead cranes, scissors lifts, etc.) will be in use during all phases of accelerator activity. Escorts should ensure that visitors are clear of this equipment at all times. 
2. Potential mechanical hazards exist throughout the PBFA II complex. Escorts should ensure that tour groups remain within specified tour routes and that visitors are informed of the specific hazards that may be present.

C. Slips and Falls

The walkways in the PBFA II complex may become covered with small quantities of oil or water from the accelerator at any time. Visitors to the facility should be advised to watch their footing at all times and to utilize handrails whenever possible to prevent falls. Slipping is probably the most prevalent hazard associated with a visit to PBFA II.

D. Stairs, Ladders, Gratings and Catwalks

1. Tours through the 983 highbay will be restricted to specific routes to ensure visitor safety (see appendix B). In some cases these pathways will cross the metal gratings covering the trench system around the accelerator. Escorts should advise visitors of the problem of shoe heels becoming caught in these gratings and the danger of tripping on the irregular surface that may be present.

2. Visitors to 983 will be restricted to the stairways whenever movement from level to level is necessary. Escorts should be aware of the location of the stairways in 983 and ensure that the visitors utilize these paths rather than ladders or other less safe means to move from level to level.

3. Catwalks over PBFA II have a load rating of 150 pounds per square foot. This rating is sufficient to handle any normal distribution of people.

E. Electrical Hazards

Electrical power throughout building 983 is routed through safe commercial buss networks and should not present a hazard under normal circumstances. Escorts should be aware of potential safety problems and advise visitors accordingly $(\mathrm{e} . \mathrm{g}$. if this equipment is under repair).

Escorts should also direct visitors away from any accelerator equipment or other devices along the tour route that may present an electrical hazard. 
Visitors should be discouraged from any contact with accelerator components unless the tour guide understands the safety aspects involved and deems such contact necessary for the specific tour (an example of permitted contact would be the close examination of components in the display area; an example of prohibited contact would be any contact with components in a refurbishment area of the highbay).

Although warning signs are required, escorts should be on the lookout for unmarked electrical hazards throughout the highbay at all times.

F. Hard Hat Areas

The ENTIRE PBFA II highbay area is designated as a hard hat area. Visitors and escorts will be required to wear bump caps in order to gain entry to the highbay. Safety glasses will also be required in some areas of the facility. These areas will be posted as such. Anyone in the highbay without required safety equipment will be asked to leave the premises until such equipment is obtained. This equipment will be available at visitor entry points to the highbay (see Appendix B).

G. Warning Lights and Audible Alarms

Highbay activities that may present hazardous conditions to building occupants will be preceded by one or more warning signals. In most cases, activation of accelerator systems will be preceded by a public address announcement stating the operation to be performed and the response required from highbay occupants. Tour groups should be prepared to respond to such conditions. Escorts will be responsible for directing visitors to the proper location in case of an evacuation announcement (see Appendix B).

At all times escorts and visitors should be prepared to respond to directions from highbay personnel in case an emergency situation should occur. 
Escorts should also make visitors aware of the consequences of a PA announcement if it is not readily apparent (e.g. if the PA address warns of a subsystem test that may present a loud noise, escorts should inform visitors to cover their ears!).

H. Locked Doors

The 983 access control system utilizes automatic locking mechanisms in order to prevent entrance into the highbay during accelerator testing. Escorts should make sure that visitors do not attempt to open doors which are secured. The Access Control system locks facility doors and gates such that entry into dangerous areas is prevented but egress from these areas is not. Doorknobs on the "secured" side of facility gates remain operative such that escape is straightforward. All highbay doors have a red "emergency escape" button next to them that will unlock the door when activated. During standard operations, adequate time will be provided for all highbay occupants to exit through designated access routes (see Appendix B). 


\section{Action in Case of Emergency or Injury}

A. Evacuation in Case of Fire

Should the fire alarm sound in building 983, the building Fire Team will assist all personnel in evacuating to a safe location. Whenever a fire alarm sounds, escorts should be aware of exit routes from their location and direct visitors to the nearest safe exit from the building. At anytime during such an emergency, escorts and visitors should be prepared to take direction from Fire Team personnel. Fire Team members are responsible for redirecting evacuation routes if blocked by fire so their instructions must be adhered to.

Once outside the building, escorts should verify that all nembers of their groups are accounted for. Personnel evacuating from building 983 should proceed to the area north or west of the building staying clear of emergency vehicles (see Appendix B).

B. Injury or Emergency

Escorts should inform a Facility Administrator of the Pulsed Power Operations Division, 1254, and $\mathbf{S}$. A. Goldstein, 1254, as soon as possible after any injury which occurs during a tour or visit. If immediate assistance is required, the escort should seek help from any highbay personnel they can find. These people are familiar with the proper procedures and know where to find appropriate help.

In case immediate attention is required, the appropriate organizations should be informed of the problem, location and aid required:

a) Emergency aid other than fire (EXT. 144)

b.) Fire Station (EXT. 117)

c) Security (EXI. 4-4657)

d) Environmental Health (EXT. 4-2735)

e) Safety Department (EXT. 4-4152)

Fire and Emergency numbers appear on stickers posted on all telephones throughout the facility. 
Necessary steps should be taken to prevent any injury or emergency situation from worsening until help arrives. Many individuals in the facility are trained in First Aid and CPR. If needed these personnel will aid in an emergency situation. 


\title{
Appendix A
}

\section{Tour Information Sheet}

Date:

\begin{abstract}
$\star \star * * * * * * * *$ TOUR INFORMATION SHEET
$\star * \star * * * * * * *$

Tour Initiator:

Tour Guide:

Purpose of Tour:

Org. $\quad$ Ph. No.

Tour Date(s):
\end{abstract}

\section{VISITORS}

Name

Affiliation

Citizenship

\section{ITINERARY}

Tech Area $\quad$ Facility $\quad$ Time

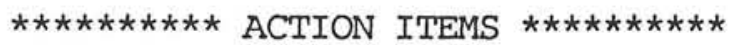

[ ] VIP Tour

[ ] TOUR TAKES PRECEDENCE OVER SHOT/SHOT PREPARATION

[ ] SHOT/SHOT PREPARATION TAKES PRECEDENCE OVER TOUR

[ ] Presence and/or assistance required by other 1200 personnel:

[ ] Presentation/Briefing required:

[ ] Specific Area Preparation:

[ ] Specific Material Displays:

[ ] General Area Cleanup (Breezeway, entrance to buildings)

[ ] Miscellaneous Instructions: Call Bob Johnston 4-3147 one hour prior to touring.

If you have questions, contact Terry 6-7806.

\section{APPROVED BY:}

$$
\text { D. L. Cook, } 1260
$$

Distribution:

1200 J. P. VanDevender

1230A Rosalie Tierney

1236 G. A. Zawadzkas

1240 Kip Stanley

1254 S. A. Goldstein
1254 R. Johnston

1254 J. M. Wilson

1254 G. D. Peterson

1260 D. L. Cook

1260 Terry Martinez 
Appendix B

- Entry Points, Tour Routes, and No Smoking areas

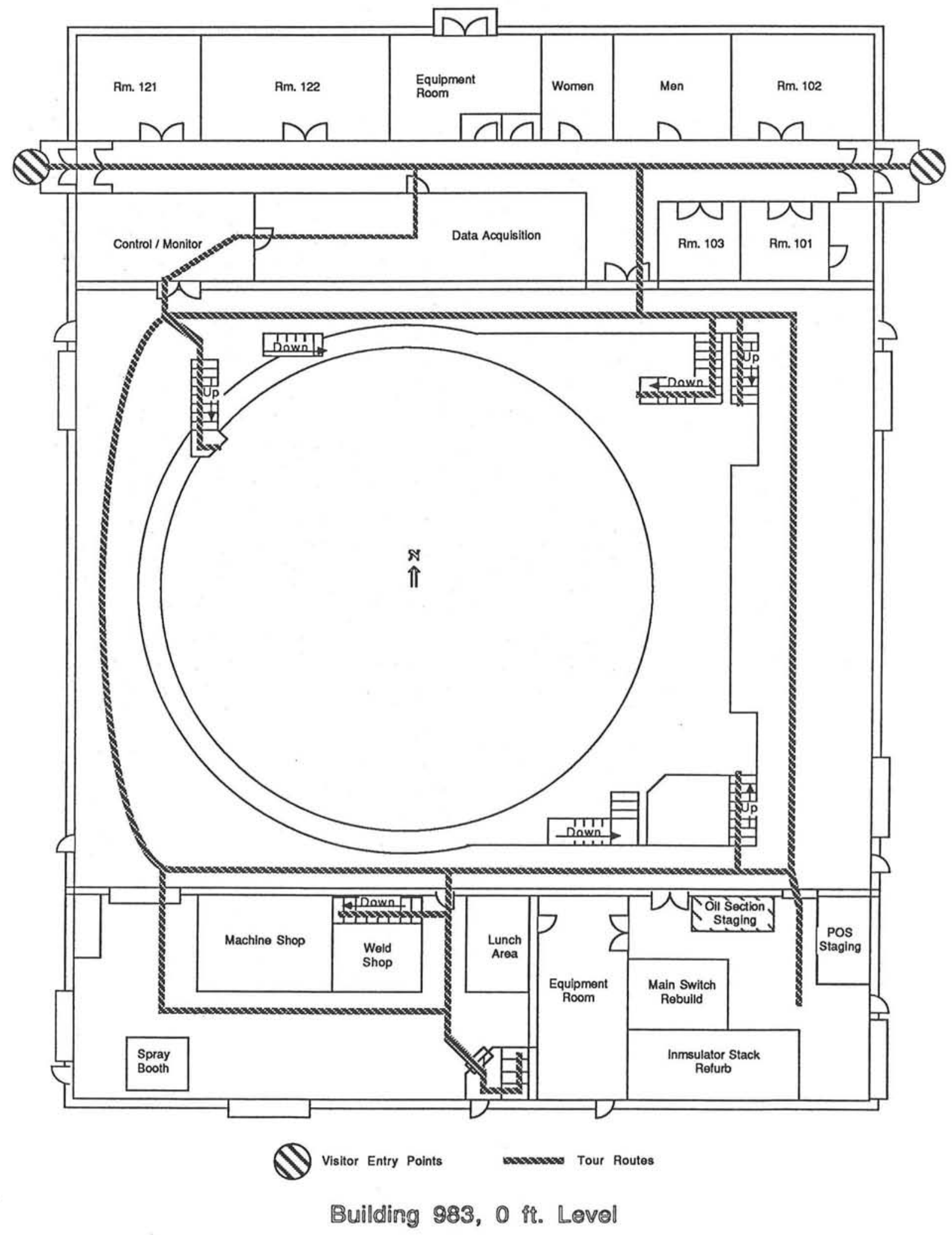




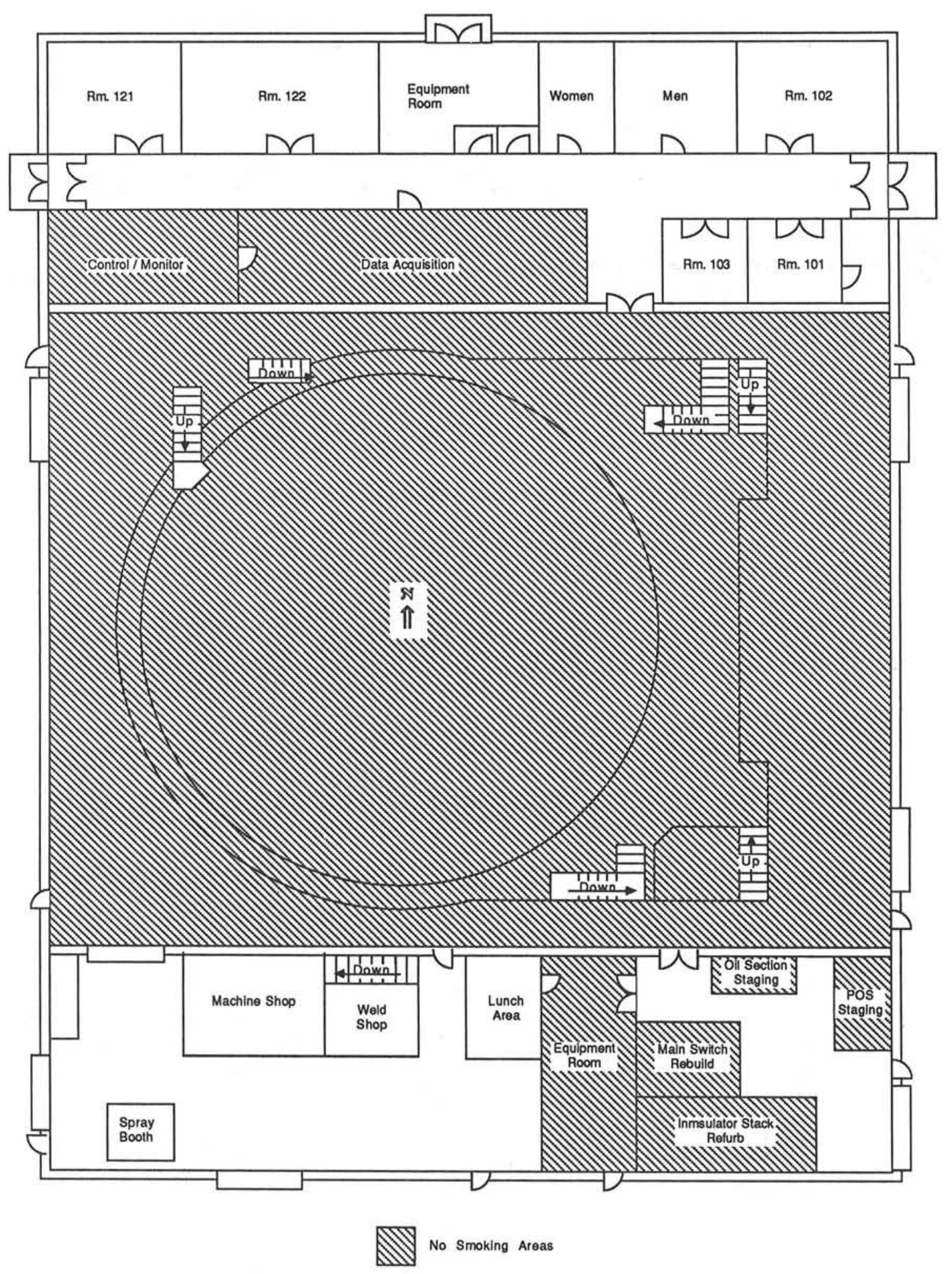

Building 983, 0 fr. Lovel 


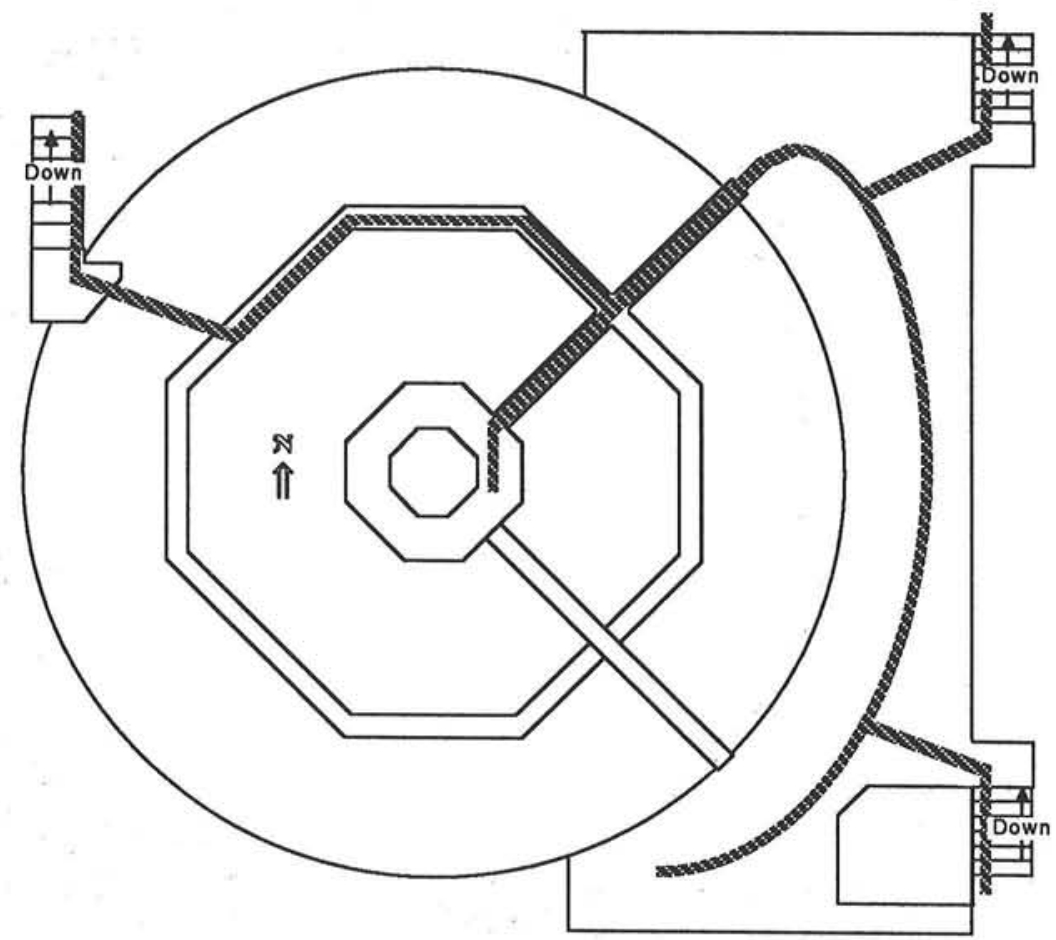

Sonesenes Tour Routes

Smoking is Prohibited on the entire $+10 \mathrm{ft}$. level of Building 983

Building $983,+10$ fit. Lovel 


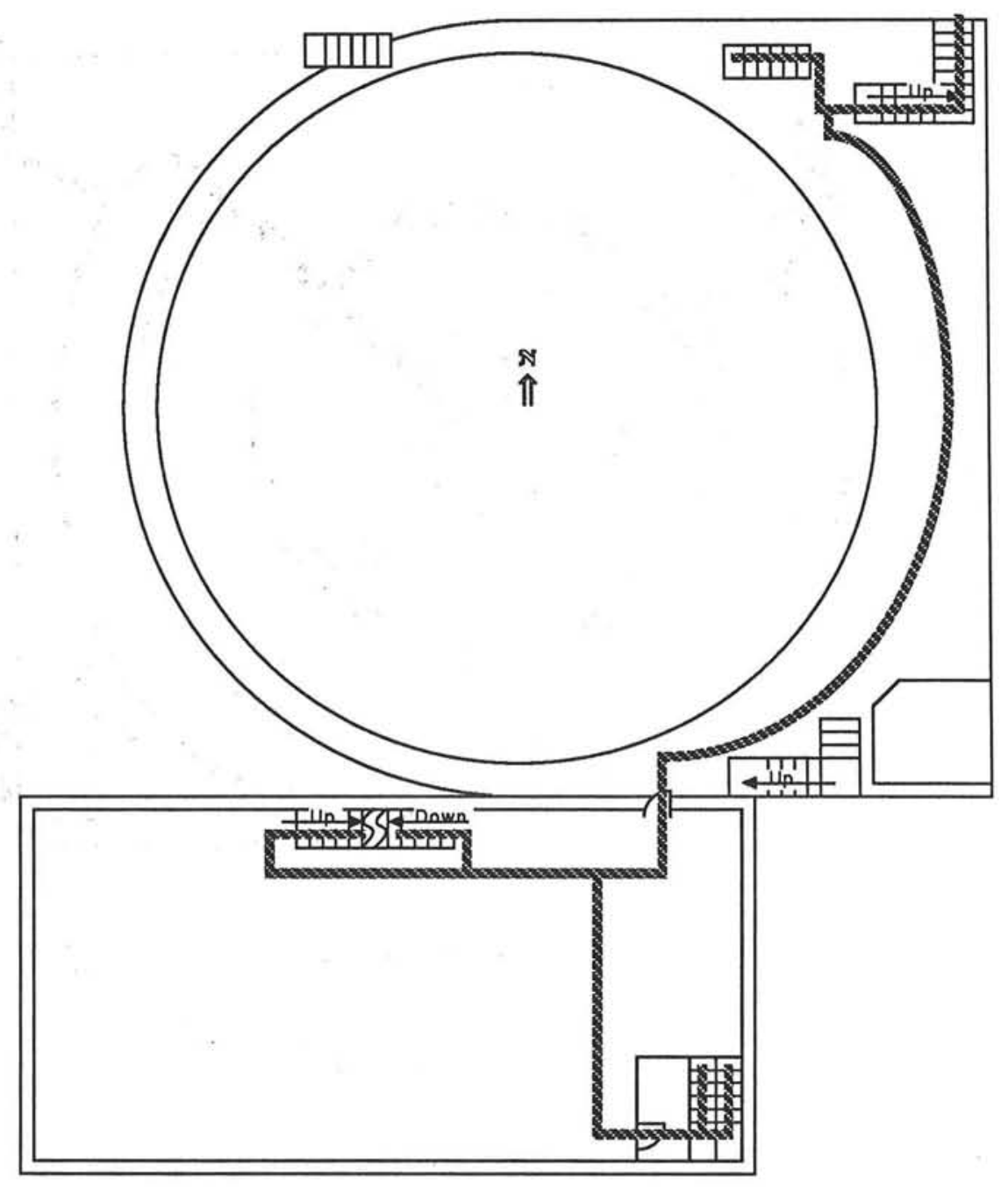

Nour Routes

Smoking is Prohibited on the entire $-10 \mathrm{ft}$. level of Bullding 983

Building 983, -10 ft. Level 


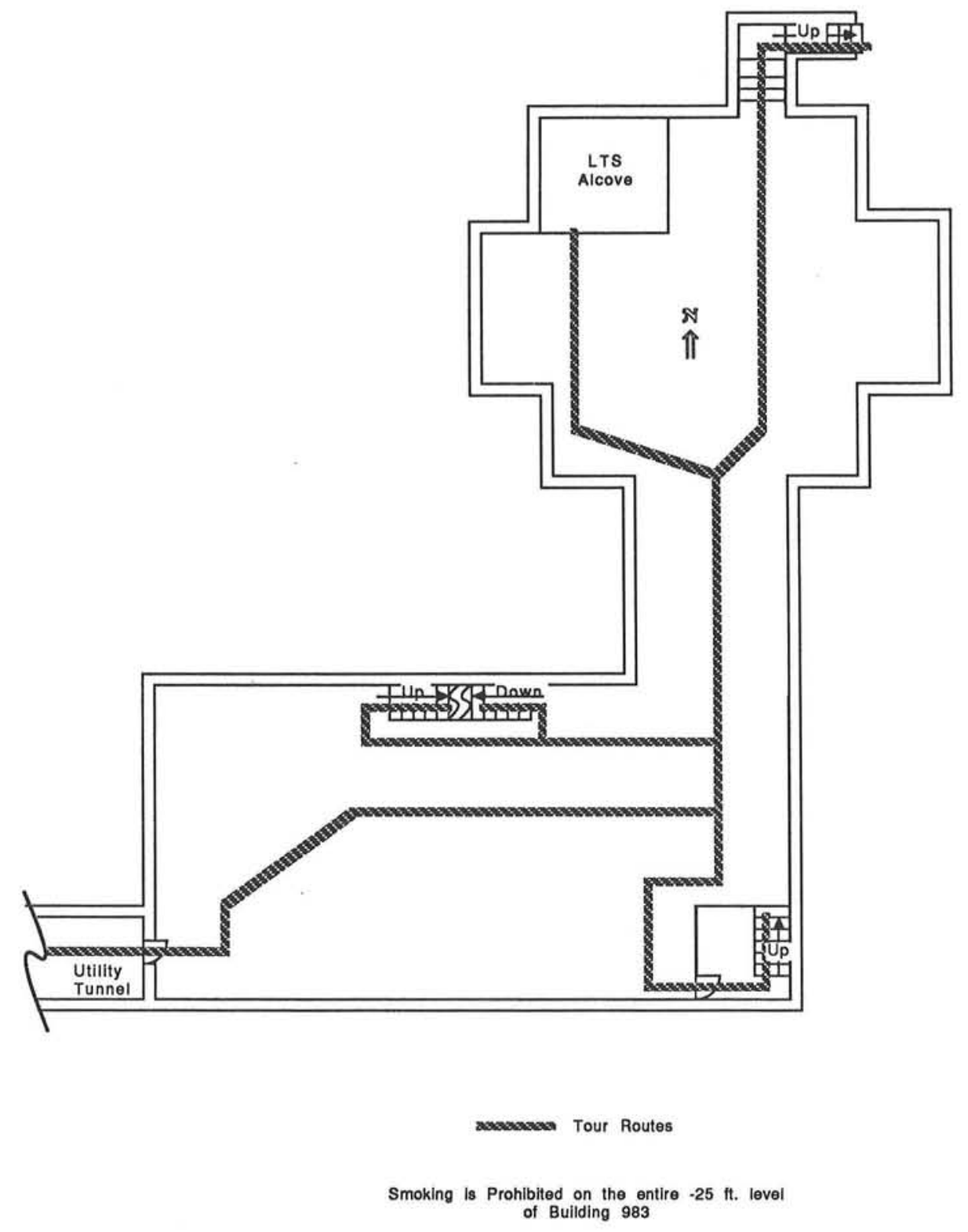

Building 983, -25 \%. Lov@l 


\section{SAFE OPERATING PROCEDURE \\ FOR THE \\ STAFF MACHINE SHOP \\ AT \\ PBFA II, BUILDING 983}

Appendix 2 


\section{Table of Contents}

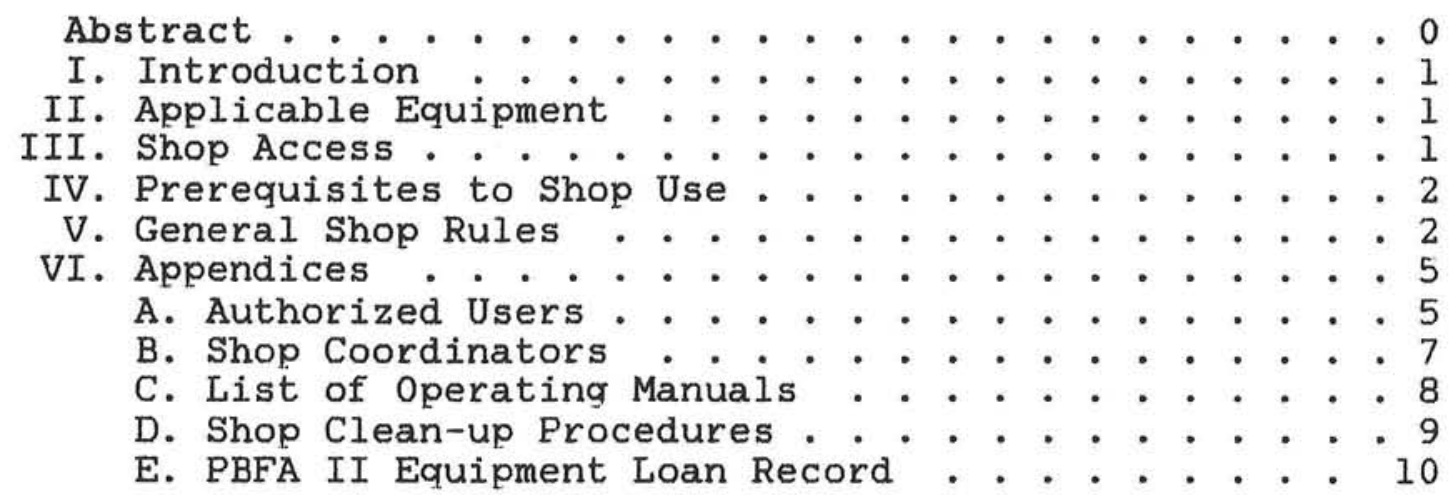




\title{
SAFE OPERATING PROCEDURE
}

FOR THE

STAFF MACHINE SHOP

AT

PBFA II. BUILDING 983

\begin{abstract}
This SOP outlines techniques for safelv using the equipment in the Staff Machine Shop in Building 983. Poor shop practices may result in personal iniuries and/or damage to equipment and material.
\end{abstract}

T. H. Martin, 1250 date

S. A. Goldstein, 1254 date
D. L. Rost. 3316

A. M. Fine, 3316 date

date

Distribution:

1233 G. A. Zawadzkas

1254 S. A. Goldstein

1254 G. L. Donovan (2)

1254 All Personnel

3316 D. L. Rost

3316 A. M. Fine 


\section{SAFE OPERATING PROCEDURE}

FOR THE

STAFF MACHINE SHOP. BLDG. 983

I. Introduction

The research nature of the PBFA II facility of ten requires that mechanical modifications be performed both to accelerator components and test hardware. In most cases these modifications delay progress at the facility and therefore must be accomplished in the shortest possible time. A staff machine shop has been set up in Building 983 to accommodate these cases where the skills of professional machinists are not required and time is critical. All personnel who use the the staff shop are responsible for its safe operation and qeneral cleanliness. Users and/or the shop coordinator are also responsible for determinina when work is inappropriate for staff personnel and a trained machinist is required.

II. Applicable Equipment

DoAll band saw model \#2013-20

LeBlond lathe model \#E07714-00

Bridgeport series II mill

DoAll drill press model \#DG-24

Dayton abrasive finishing machine model \#EB

Milwaukee bench arinder model \#41935G835

Miscellaneous hand and power tools

III. Shop Access

Use of the Building 983 staff machine shop shall be limited to personnel working on work-related projects within the complex. A list of authorized users will be maintained at the machine shop (see Appendix A). This list will be updated as required by the resident machine shop coordinator. Personnel outside the complex who require use of the shop must first check with the resident machine shop coordinator to determine shop availability. Priori- 
ties among the current jobs in the shop facility will be resolved by the shop coordinator or higher as appropriate ( see Appendix B).

\section{Prerequisites to Shop Use}

Before using the machine shop facility all persons MUST first:

1. Be familiar with the contents of this Safe Operating Procedure.

2. Be competent in the operation of the machinery they use in the shop.

3. Be familiar with the operating manuals of the machines they use in the shop (see Appendix C).

In addition to the above, personnel using the facilitv must follow the directions of the shop coordinator, particularly when the safety of persons or property is involved. This person is responsible for the safe operation and upkeep of the facility and has the authority to prevent persons from harmina themselves, others, or causing damage to equipment. Realizing that few shop users will be qualified machinists, the shop coordinator will also instruct whenever there is a question about a machining operation. Besides helping prevent accidents in the shop, the coordinator can also be very helpful in advising how to accomplish a task. Don't be bashful. If you are unsure of anything - ASK!

\section{General Shop Rules}

The following list is not all-inclusive but should be added to the store of common sense taken into the shop area.

1. SAFETY GLASSES ARE REOUIRED! This rule applies to everyone, all the time. Several pairs of safety glasses are available at the entrance to the shop area. Failure to comply with this rule may result in loss of shop privileges.

2. Face shields shall be worn over safety glasses when using the grinder. If you've ever seen a grinding wheel fail, you'll know why.

3. CLEAN UP YOUR MESS! Part of the privilege in using the machine shop is the responsibility you have in cleaning up your own mess. If a job is not finished at the end of the day, it may be $0 . K$. to just sweep the floor around the machine and finish the 
cleanup when the job is complete but you must get the approval of the shop coordinator (see Appendix D).

4. Personnel should not work alone in the shop unless absolutely necessary. Under no circumstances will anvone be allowed to work in the shop when no one else is in the building.

5. Put away all tools. They should be put back where they belong during your cleanup effort if not sooner! If you bring your own tools into the shop. take them with you when you leave or they will be your gift to the shop.

6. Borrowing some of the shop's special tools is allowed in most cases. You will be asked to complete an equipment loan record before taking any equipment from the shop area (see Appendix E).

7. Don't be afraid to ask questions if you have any doubts about how to use a machine or tool. Don't worry about appearing ionorant: we all are until we learn the first time. If you can't find the right person to ask, look harder! (see Appendix B)

8. Don't use the machines improperly. Consult the operating manuals and again don't be afraid to ask. That's why the coordinator is there!

9. Before starting a machine, know how to stop it!

10. Stay alert anytime you are in the machine shop. The major cause of shop accidents is machinist's hypnotism. This happens after long periods of performing the same operation. Personnel using the shop should be aware of this potential danger and take rest breaks at appropriate intervals.

11. Anytime you see someone else breaking the rules that you work so hard to follow. bring it to their attention. If they won't listen. find the shop coordinator. You may be doing them a very big favor!

12. Never wear loose clothing around any machine. Roll up your sleeves. If you have long hair wear appropriate headgear (no one wants to see the results of that accident).

13. Remove any rings, watches, bracelets or any other jewelry that may get caught in the machinery. 
14. Always stop a machine before inspecting your work or cleaning the machine.

15. Before starting a machine, make sure the spindle will clear the tool holder or other fixtures.

16. Keep your hands away from all moving parts (such an accident could remove your shop privileges at the wrist).

17. Don't operate a machine unless all of the safety guards are in place.

18. NEVER, repeat NEVER, leave a running machine unattended.

19. Whenever a tool is broken or damaged, make a note on the clip board by the shop coordinator's desk. That way he'll be able to replace it before you need to use it aqain!

20. The shop is a limited access area for work related machining activity. Casual visitors will not be permitted.

21. Personnel working in the shop must maintain a professional, safety conscious attitude. Anyone who cannot maintain such an attitude will not be permitted in the shop.

22. If you ever see any problems in the shop, please tell the shop coordinator.

23. All accidents or injuries within the machine shop must be reported to the shop coordinator or the facility administrator.

24. Although part of the reason for having a staff machine shop is quick turnaround time, make sure you take the time necessary to be safe. 
Appendix A

Building 983 Authorized Shop Users

Name

Org.

Bal1, Andrew

1254

Brovles. Theresa

1254

Chambers, Rod

1254

Cleary, Richard

1254

Clevenger. Bob

1254

Devlin. Gary

1254

Donovan, Guy

1254

Dow, Dan

1233

Drennan, Scott

1254

Figures, Jim

1252

Grelle, Nibby

1254

Henderson, Blake

1233

Herman. Mark

1252

Holman, G.T.

1254

Howard, Bill

1233

Ives, Harry

1251

Jobe, Dan

1254

Johnson, Mark

1254

Johnston, Bob

1254

King, Curt Jr. 1254

Lake, Pat

1254

Lundstrom, Joe

1254

McDonnel1, John

1254

McGovern, Harry

1254

Mikkelson, Jim

1254

Naro, Mark

1251

Nations, Dennis

1254

Nielsen, Dan

1254

Orth, Scott

1254

Osborn, Rick

1254 
Appendix A (cont.)

Building 983 Authorized Shop Users

$\begin{array}{ll}\text { Name } & \text { Org. } \\ & \\ \text { Penn, Jay } & 1252 \\ \text { Rollins, Bruce } & 1254 \\ \text { Ross, Bob } & 1233 \\ \text { Schaub, Mike } & 1254 \\ \text { Schmidlapp, Alan } & 1233 \\ \text { Seals, Bobby } & 1254 \\ \text { Simmons, Mike } & 1236 \\ \text { Smith. Ellanor } & 1254 \\ \text { Stewart, Joe } & 1254 \\ \text { Tanner, Wayne } & 1254 \\ \text { Torrison, Len } & 1236 \\ \text { Velasquez, Dan } & 1254 \\ \text { Wilson, Mike } & 1254 \\ \text { Woolston, Tom } & 1251 \\ \text { Ziska, Zeke } & 1254 \\ \text { JMorgan, Frank } & 1252\end{array}$




\section{Appendix B}

The resident shop coordinator for the Building 983 machine shop is Ray Palkovic. Division 1254. Mark is responsible for all facets of machine shop operation and maintenance.

If you have a problem relating to the shop that Mark can not help you with, or if he is unavailable, contact Bob Johnston, Division 1254. Bob will act as administrative coordinator for the shop facility.

Ray Palkovic Org. $1254 \quad 844-2953$

Bob Johnston Org. 1254 844-3147 (pager 142-193) 
Appendix C

Copies of the operating manuals for all equipment in the machine shop are available from the shop coordinator. These manuals should be consulted anvtime you have a question about machine operation.

Bridgeport Series II Milling Machine manual \#M-101

LeBlond Machine Tool manual \#3932

DoAll Drilling Machine manual

DoAll Contour Sawing Machine manual

Bench Grinder safety instructions

Abrasive Finishing Machine operating instructions 


\author{
Appendix D \\ Clean-up Procedures for the Building 983 Machine Shop
}

1. Put all tools back in their proper places. This includes tools. tool holders, hold down clamps, vises, and anything else you use in vour machining operation.

2. Clean all chips or shavings off the machine. Do not use compressed air for this step unless you are certain the flying chips will not cause injury to yourself or others. If compressed air is to be used, a face shield will be required and the safety nozzle used must be in its' original condition (i.e. no tape over vent holes).

3. Wipe off the machine, especially if you used any cutting oil or coolant.

4. Sweep and/or vacuum the entire area around each machine you have used.

5. When finished with a machining operation, be sure to remove your work and scraps from the shop area.

6. If you take over a dirty machine, you assume the responsibility for cleaning it!

7. Shop cleanliness and organization helps to limit safety hazards and prevent injuries. A clean shop also makes for a much better atmosphere in which to work. Your cooperation in maintaining a clean machine shop will be appreciated and REOUIRED! 


\section{Appendix E}

\begin{tabular}{|c|c|c|c|c|c|c|}
\hline $\begin{array}{l}\text { TOOL } \\
\text { (PBFA }\end{array}$ & EQUIPMENT LOAN RECORD & $\begin{array}{l}\text { MACHINE } \\
\text { WELD }\end{array}$ & & DAT & & \\
\hline $\begin{array}{l}\text { ITEM } \\
\text { NO. }\end{array}$ & TOOL OR EQUIPMENT DESCRIPTION & $\begin{array}{c}\text { SERIAL } \\
(O R \text { I.D.) } \\
\text { No. }\end{array}$ & $\begin{array}{l}\text { LOANED } \\
\text { TO }\end{array}$ & $\begin{array}{l}\text { DATE } \\
\text { OUT }\end{array}$ & $\begin{array}{l}\text { DATE } \\
\text { IN }\end{array}$ & $\begin{array}{l}\text { LOANED } \\
\text { BY: }\end{array}$ \\
\hline & & & & & & \\
\hline & & & & & & \\
\hline & & & & & & \\
\hline & & & & & & \\
\hline & & & & & & \\
\hline & & & & & . & \\
\hline & & & & & & \\
\hline
\end{tabular}

PBFA-II, AREA IV, BLDG. 983

PBFA II Equipment or Tool Loan Record 
SAFE OPERATING PROCEDURE

FOR

OPERATION, MAINTENANCE, AND REPAIR

OF THE TESTBED FACILITY AT

PBFA II, BUILDING 983

Appendix 3 
Table of Contents

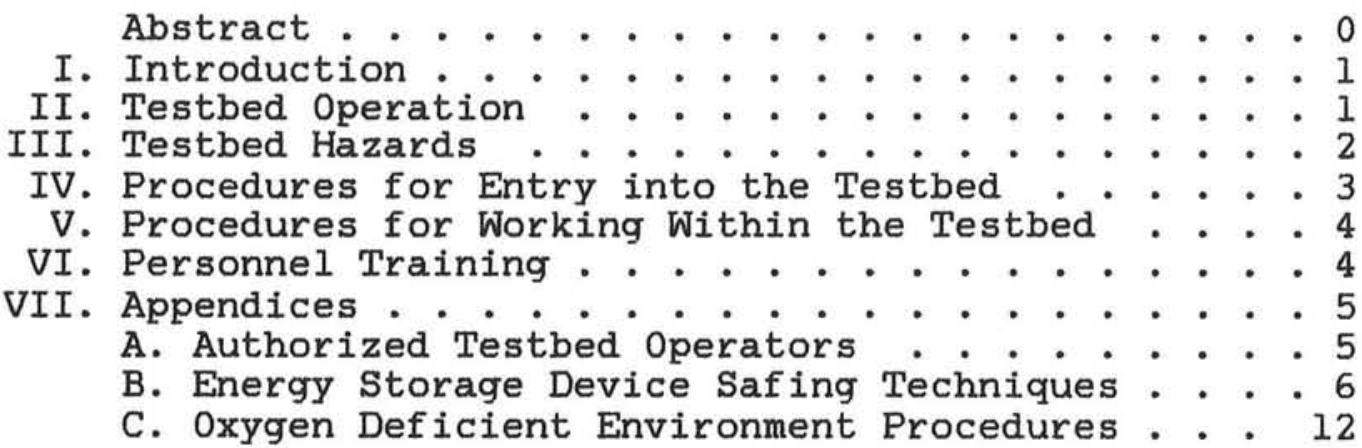


SAFE OPERATING PROCEDURE

FOR OPERATION, MAINTENANCE AND REPAIR

OF THE TESTBED FACILITY

$\mathrm{AT}$

PBFA II, BUILDING 983

\begin{abstract}
This document covers procedures for operation, maintenance and repair at the PBFA II testbed facility. Two major hazards are associated with these operations:

1. High voltage, resulting from either active or residual charge left on the Marx Trigger Generator (MTG) or Marx Generator.
\end{abstract}

2. Slips and falls resulting from residual oil on the floor or testbed components.

\begin{tabular}{ll}
\hline D. L. Cook, 1260 & date \\
\hline S. A. Goldstein, 1266 & date
\end{tabular}

D. L. Rost, 3316 date

S. A. Goldstein, 1266 date

A. M. Fine, 3316 date

Distribution:

1236 G. A. Zawadzkas

1260 D. L. Cook

1266 S. A. Goldstein

1266 G. L. Donovan (2)

1266 Division Members

3316 D. L. Rost

3316 A. M. Fine 
SAFE OPERATING PROCEDURE

FOR OPERATION, MAINTENANCE AND REPAIR

OF THE TESTBED FACILITY

AT

PBFA II, BUILDING 983

I. Introduction

The PBFA II Testbed Facility is located in the southeast corner of Building 983 with associated control console and data acquisition screenroom located on the highbay 0 foot level. The facility is designed to test $400 \mathrm{kiloJ} o u l e$ PBFA II Marx generators into representative machine loads. The testbed incorporates independant charging, triggering and safety/alarm systems all of which are controlled locally through the testbed control console.

II. Testbed Operation

The PBFA II Testbed Facility poses no radiation hazard and only localized high voltage hazards and therfore may be operated independantly from Building 983 main Control/Monitor and Safety systems. The hazards associated with testbed operation require personnel evacuation only from areas within the test tank, areas on the +10 foot level directly above the test tank, and areas surrounding high voltage supplies on the +10 foot level south of the tank. This requires that testbed operators be responsible for local access controls as well as other safety aspects of operation.

Only authorized personnel shall be allowed to operate the PBFA II Testbed Facility and shall be responsible for following guidelines set forth in this SOP and the testbed operating procedures (see Appendix A).

A. Procedures

1. High Voltage Keys

Immediately following test series at the PBFA II testbed, all high voltage systems shall be deenergized and high voltage system keys shall be removed from the console and returned to the acting PBFA II Shot Coordinator to be secured in the C/M 
lockbox. Keys shall be obtained from the Shot Coordinator prior to test sequences.

During test series where the testbed may remain idle between shots (i.e. operator leaves console area) high voltage keys shall be removed from the console and kept in the posession of the responsible operator.

2. Safety systems

Prior to testing, the operation of all testbed safety systems and interlocks shall be verified. This shall include all rotating beacons, audible alarms, and access control interlocks.

Inoperative safety system components shall be repaired prior to testing or suitable replacements shall be implemented (e.g. portable facility beacons may be used to replace inoperative testbed beacons).

III. Testbed Hazards

Operation of the PBFA II Testbed Facility requires that periodic repair be performed as well as routine maintenance operations. Entry into the testbed presents a number of potential hazards to personnel.

A. Residual electric charge may be present on any high voltage devices having energy storage capability. These devices include the main Marx capacitor bank, the Marx Trigger Generators (MTG) and their trigger and charge cables, the charging system filter capacitors, and various pulser units that may be present for calibration purposes. All potentially dangerous components must be made safe before personnel are allowed to work on or near these devices.

B. The potential for slips and falls in and around the testbed is augmented by residual transformer oil after the tank has been drained. Personnel entering the testbed should be aware of this hazard and wear appropriate, non-slip footwear.

C. The confined nature of the testbed together with the numerous components greatly increase the bump hazard within the tank. Personnel entering the testbed will be required to wear bump caps at all times.

D. Because of the confined nature of the testbed, heavy use of solvents (freon, hexanes, etc.) within the testbed can lead to overexposure and toxic effects. Personnel planning to use solvents for extended periods 
SOP - Testbed Maintenance and Repair bldq. 983 / page 3

of time or in significant quantities should notify the Facility Supervisor. Industrial Hygiene (Division $3311)$ will be requested to monitor exposures and recommend proper controls.

E. A large release of SF6 gas from the high voltage components can result in a local oxygen deficient atmosphere in the confined workspace of the testbed. Personnel entering the testbed should be aware of this potential hazard and if an oxygen deficient condition is suspected the environment should be tested for percent oxygen content.

F. The height at which personnel are sometimes required to work in the testbed would result in severe injury should a fall occur. Personnel working on the upper part of the testbed are required to wear safety belts and lanyards in order to limit the severity of a fall, should one occur.

IV. Procedures for Entry Into the Testbed

Before personnel entry into the PBFA II Testbed Facility for maintenance or repair activity, the following actions shall be performed:

A. An authorized testbed operator shall verify that the oil transfer system, high voltage charging system, and all high voltage trigger and/or calibration systems are properly "SAFED" and all high voltage keys are properly secured.

B. The shorting rods on the Marx generator shall be raised and locked in the up position.

C. The mandoor located on the -10 foot level shall be opened.

D. Personnel entering the oil section shall take percent oxygen measurements as required (see Appendix C).

E. Any personnel entering the testbed tank shall be observed by another person during repair and maintenance activity. Both members of the team shall be authorized by the Operations Division, 1266, as having been trained in component safing procedures within the PBFA II testbed (see Appendix A).

F. It shall be determined that at least one person in the immediate vicinity is trained in Cardiopulmonary Resuscitation (CPR). 
SOP - Testbed Maintenance and Repair bldg. 983 / page 4

V. Procedures for Working Within the Testbed

Maintenance and repair teams entering the PBFA II testbed shall comply with the following procedures:

A. Before personnel are permitted to touch any energy storage device within the testbed, the device shall be made safe using approved techniques. All other devices in the immediate vicinity of the work area shall also be safed before work begins (see Appendix B for safing procedures).

NOTE: consideration must be given to the dielectric recovery phenomenon of capacitors. This is a characteristic by which recently exercised capacitors can build up an electric charge in the absence of any power source. This is true even for capacitors that have been properly discharged after use. For this reason, each capacitor must be continuously shorted to be considered completely safe.

B. Any energy storage device worked on shall be held at ground potential using an approved grounding strap with secure attaching devices at each end.

C. Should work be performed within the testbed for extended periods of time, or if significant amounts of solvents are used during maintenance operations, a fan or blower shall be placed in front of the entry door to direct air out of the tank to provide additional ventilation.

D. Work platforms shall be utilized whenever available. Personnel shall take appropriate precautions when working at heights by wearing safety belts and lanyards (reference PBFA II Safety Equipment SOP).

E. Upon completion of oil section activity, personnel shall ensure that all tools, cleaning materials, shorting straps, and other equipment is removed from the tank.

VI. Personnel Training

PBFA II Operations, Division 1266, shall organize training sessions for testbed personnel with regard to:

A. Proper shorting techniques of high voltage equipment.

B. Cardiopulmonary rescusitation and First Aid. 


\section{Appendix A}

\section{Authorized PBFA II Testbed Operators}

Name

Baca, Phil

Jobe, Dan

Rice, Scott

Ziska, Gerold
Org.

Signature

1266

1266

1266

1266
Date

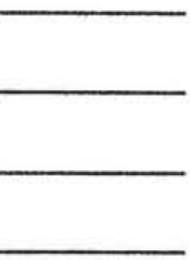




\section{Appendix B}

Energy Storage Device Shorting Techniques

A. Basics

1. Definitions

A. "SHORT" - Good electrical contact to both capacitor terminals. Good electrical contact refers to bare metal to bare metal contact through a low resistance path, as with a shorting stick.

B. "GROUND" - Electrically tie a component to ground potential.

C. "GROUND CONNECTION" - Bare metal contact point providing a low resistance path to ground potential.

D. "OPEN CIRCUIT" - Incomplete circuit resulting from poor connections or missing and/or failed components.

E. "SHORTING STRAP" - A strap made of low resistance material (e.g. wire braid) used to electrically tie component together and/or to ground potential.

2. Capacitor Safing Procedures.

A. Use facility shorting sticks with large hooks only.

B. Connect the grounding stick ground strap to a suitable ground connection.

C. Touch the hook end of the grounding stick to the capacitor case.

D. Maintain contact with the capacitor case and simultaneously touch the hook to the high voltage terminal of the capacitor.

E. While maintaining contact with the grounding stick, place a shorting strap from the capacitor case to the high voltage terminal. 


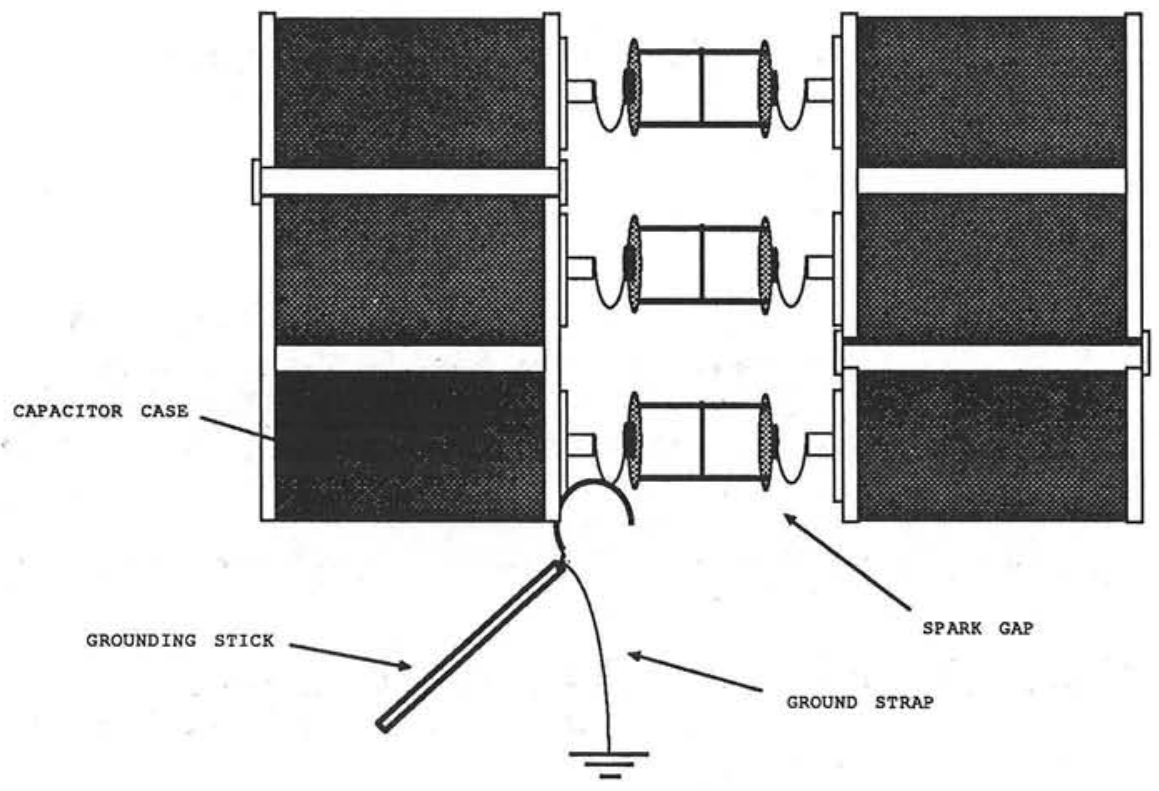

Figure 1.

3. Preliminary Safety Procedures.

Before beginning work on high voltage components within the PBFA II testbed, the following procedures must be adhered to:

A. Ensure that the high voltage keys are removed from the testbed console and either secured in the C/M lockbox or in the posession of the testbed operator.

B. Inspect the dump relay and charge buss to ensure that they are shorted to ground.

C. Raise all Marx shorting rods from the top of the Hframe.

NOTE: Although the shorting rods are the primary method for remote shorting assembled Marx generators, their operation should NEVER be relied upon as being a fail-safe mechinism. Marx capacitors must always be shorted with a shorting stick, as described above, in addition to the shorting rod system. 
Appendix B (cont.)

D. Before entering the testbed tank, inspect your equipment for any faulty materials or poor connections.

E. Remove watches, rings and other jewelry or metalic objects from your person.

F. Follow the two-man rule!

4. Basic Marx Fault Modes

Capacitors in a Marx generator are connected in parallel (see Figure 2).

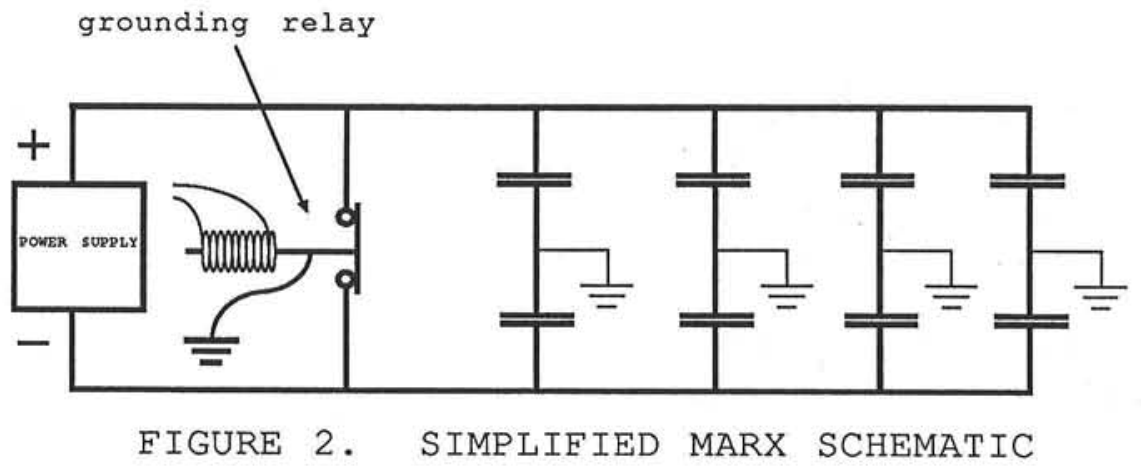

The grounding relay is normally closed, thus, the capacitors in the Marx are usually shorted and tied to ground potential. Figure 3 illustrates three common fault modes.

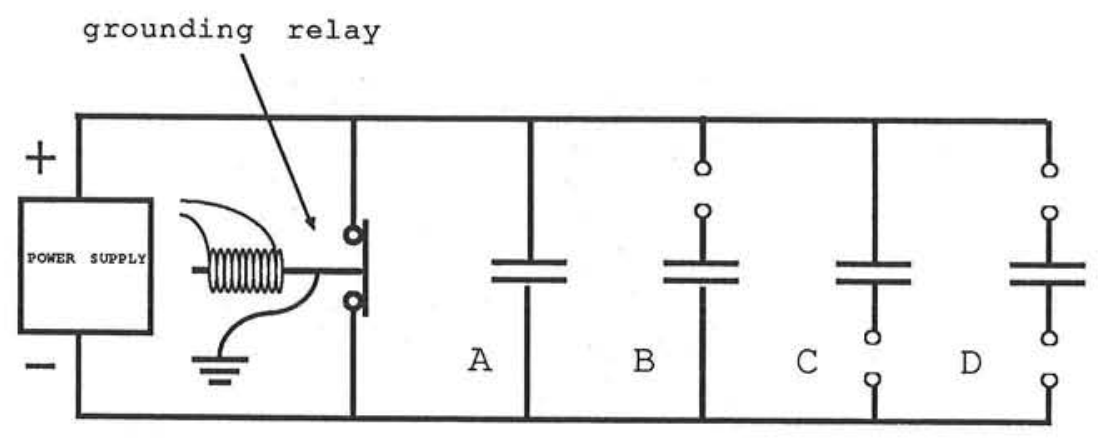

FIGURE 3. BASIC FAULT MODES 
Appendix B (cont.)

Capacitor \#2 has its high voltage terminal in an open circuit condition and its case is tied to ground. This condition is dangerous! Figures 4 \& 5 show two scenarios by which energy from this capacitor can result in injury or death.

Capacitor \#3 has its high voltage terminal grounded and its case in an open circuit condition. This condition is dangerous! Figure 6 shows how the energy potentially stored between the case and high voltage terminals can be transfered into an unsuspecting worker.

Capacitor \#4 has both its high voltage terminal and case in an open circuit condition. This condition is dangerous! Figure 7 illustrates the potential danger.

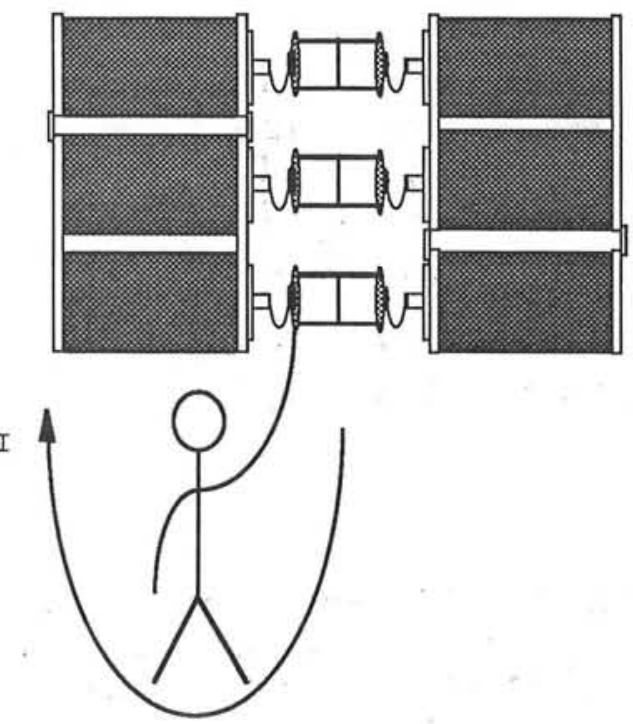

EIGURE 4. BODY IN DISCHARGE PATH

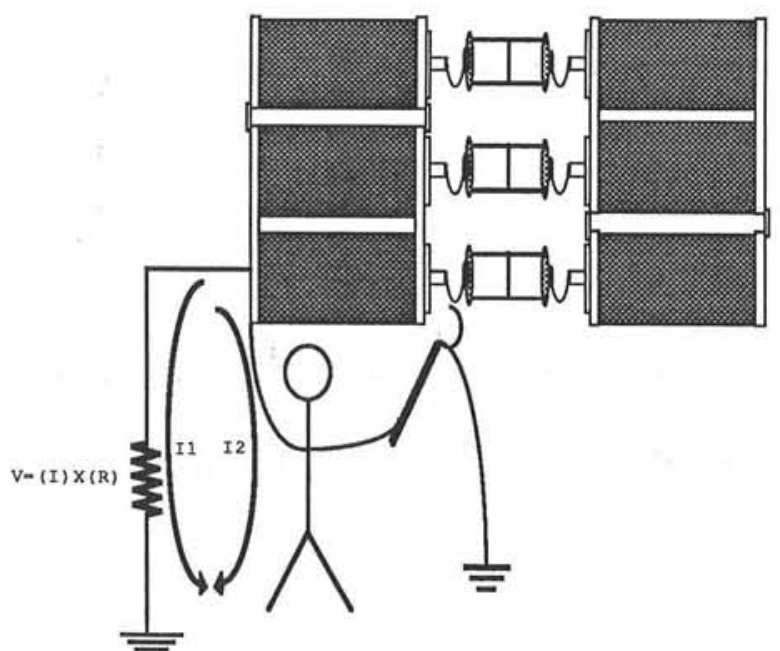

FTGIJRF, 5. RODY TN PARAT,T.F,T, WTTH DTSC.HARGF, PATH RF.STSTANCF, 
Appendix B (cont.)

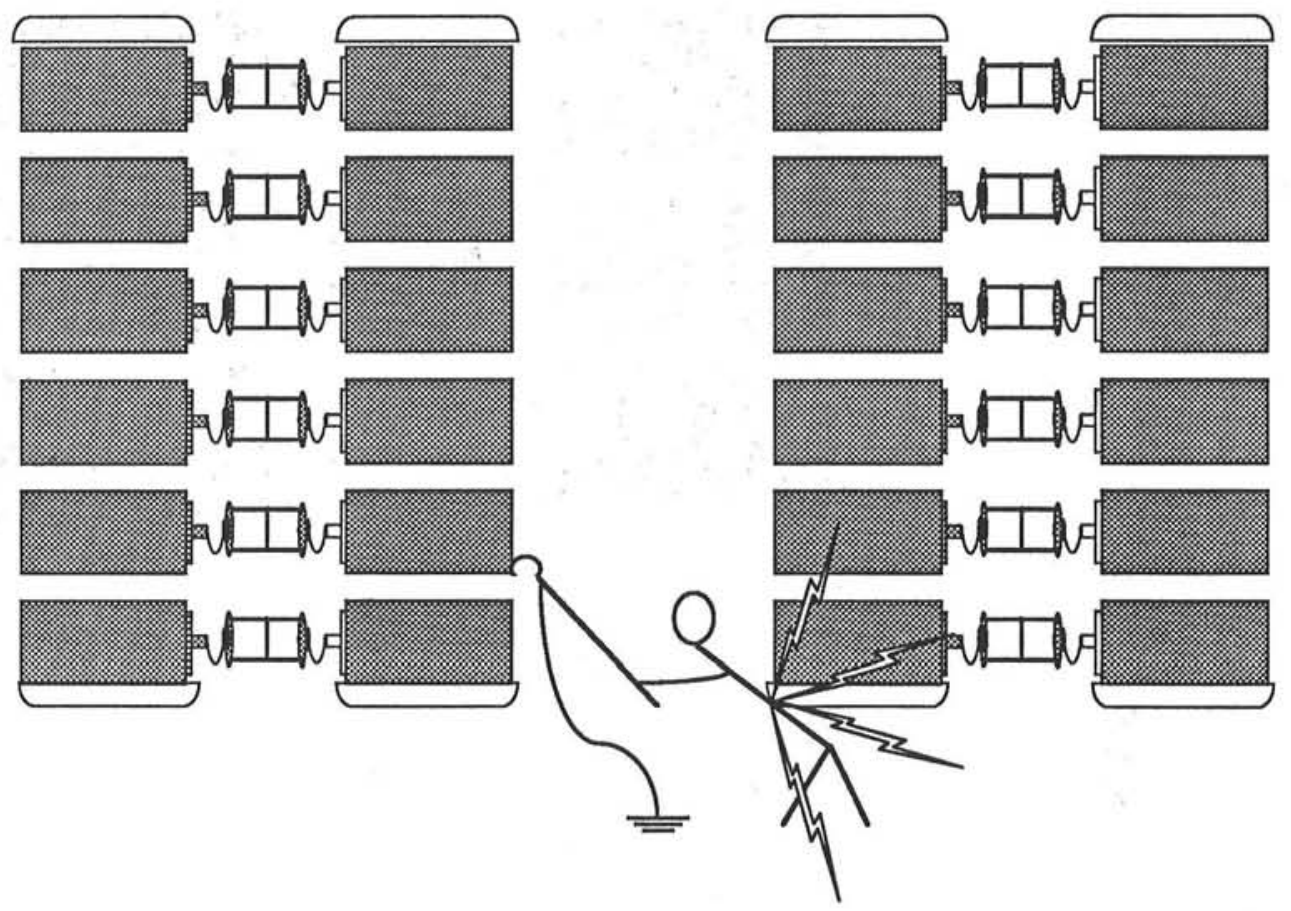

Figure 6 . 
Appendix B (cont.)

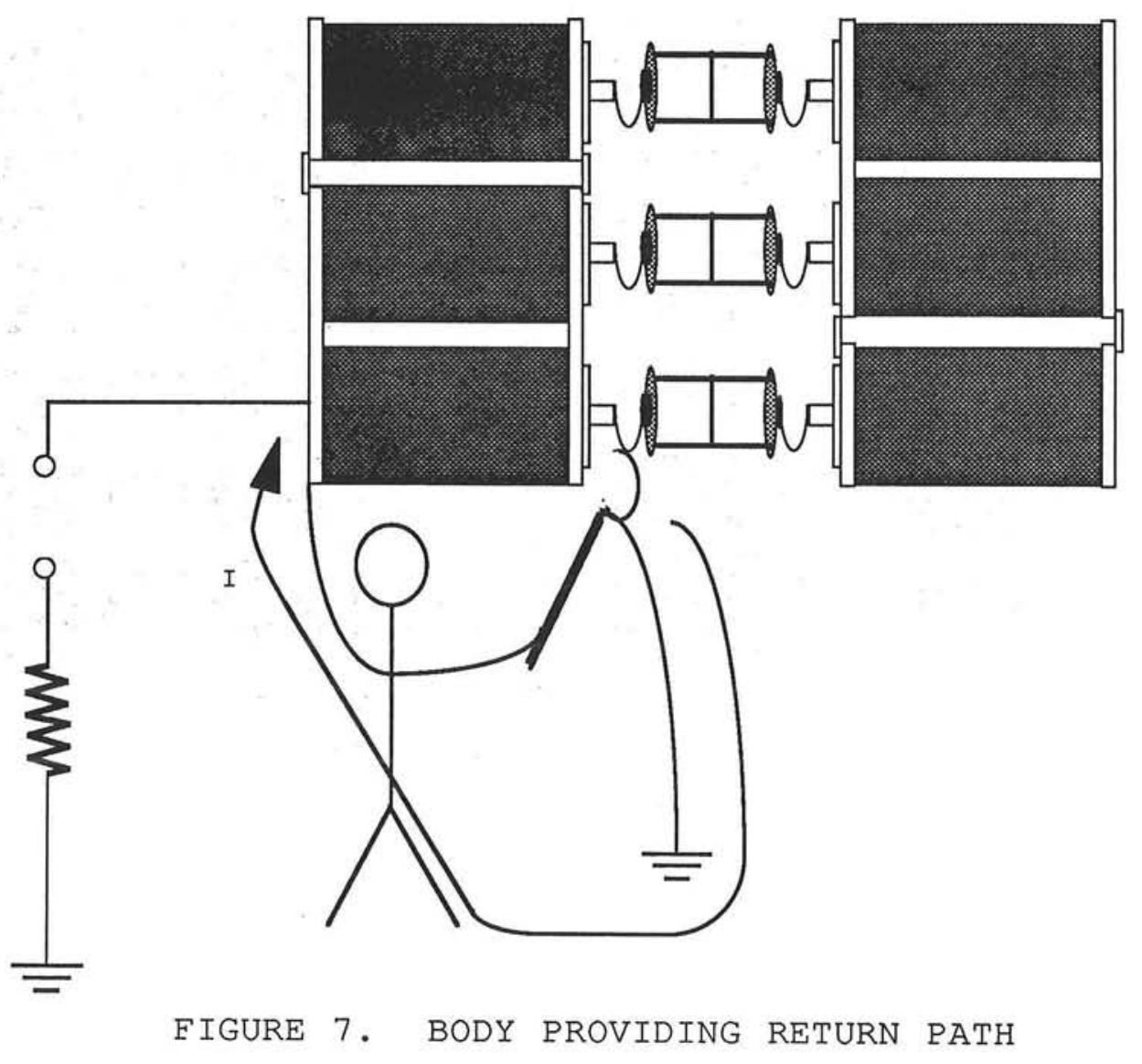


Appendix B (cont.)

5. General Testbed Safety

A. NEVER TOUCH ANY DEVICE UNTIL IT IS GROUNDED TO THE TANK. Ground devices with a grounding stick first, then attach a ground strap as described in section 1 .

B. Stay as far away from devices as possible when walking around the tank.

C. Make sure grounding sticks are secured to a suitable ground connection before attempting to ground any device.

\section{Safing A Marx Generator}

A. Attach grounding stick to a suitable ground connection.

B. Touch the head of the grounding stick to the cases of the outside capacitors (see Figure 8).

C. Attach the case of the bottom capacitor in row 1 to tank ground with a ground strap while maintaining contact with the stick.

D. Attach all capacitor cases in row 1 to ground potential maintaining grounding stick contact to the ungrounded case at all times.

E. Repeat this procedure for all capacitors in the generator until all cases are held at ground potential with shorting straps.

F. Touch the grounding stick head to the bottom capacitor, row 1, high voltage terminal while maintaining contact with the case (see Figure 9).

E. While maintaining contact, attach a ground strap from the case to the high voltage terminal.

F. Repeat this procedure for all capacitors, working from the bottom up, and then from the outside of the generator to the inside making sure to avoid touching any components which have not previously been safed. 
Appendix B (cont.)
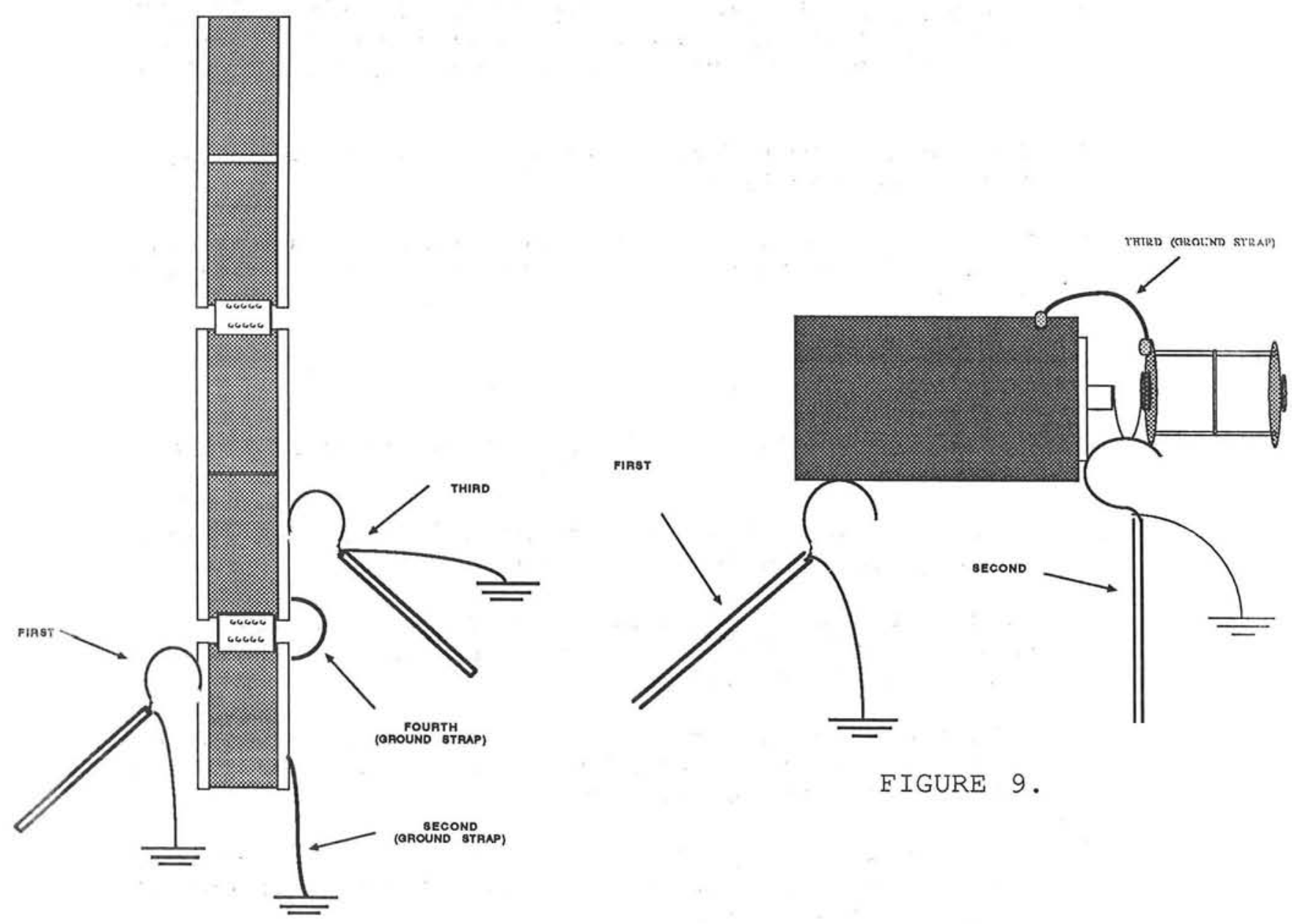

FIGURE 8 . 
Appendix C

Oxygen Deficient Environment Monitoring Procedures

A leak of SF6 gas used in testbed high voltage components can result in a local oxygen deficient environment within the testbed. If personnel entering the testbed suspect that this condition may exist, the tank should be tested before entry, or periodically during the work session if new leaks have been discovered.

Percent oxygen monitors are kept inside the PBFA II Control/Monitor room. Personnel requiring use of these instruments should report to Bob Johnston, ext. 4-3147, or personal pager \#142-193. Bob is the PBFA II Safety officer and is responsible for issuing these devices.

Percent oxygen measurements shall be made at more than one location around the top of the tank from the catwalk. A measurement shall also be taken at the testbed door before entry. Should these measurements show less then $19.5 \%$ oxygen, personnel should delay entry and remeasure every half hour until the oxygen level is at or above this level. 
SAFE OPERATING PROCEDURE

FOR

REACTING TO EMERGENCIES

AT

PBFA II, BUILDING 983

Appendix 4

$4-1-4-2$ 
Table of Contents

Abstract............... . . . . . 0

I. Introduction . . . . . . . . . . . . . . . . . . 1

A. Emergency Response Duties . . . . . . . . . . 1

1. List of Emergency Telephone Numbers . . . . I

II. Fire Control Procedures . . . . . . . . . . . . 2

A. Building Fire Team . . . . . . . . . . . . . . 2

B. Fire Team Personnel . . . . . . . . . . . . 2

C. Safetv Drills . . . . . . . . . . . . . . . 2

IIJ. Procedures for Personnel Injurv Reaponse. . . . . 2

A. Slips and Falls. . . . . . . . . . . . . . 2

B. Asphyxiation or Potential Drowning . . . . . . 2

C. Electrocution . . . . . . . . . . . . . . 3

D. Documentation .. . . . . . . . . . . . . . 3

IV. Emergency Preparedness . . . . . . . . . . . 3

V. Appendices . . . . . . . . . . . . . . . . . 4

A. Fire Team Responsibilities . . . . . . . . . 4

l. Buildina Fire Captain . . . . . . . . . . 4

a. F'ire Captain Checklist . . . . . . . 6

2. Zone Officer........ . . . . . . 7

a. Zone Officer Checklist . . . . . . . 9

3. Evacuation Squad . . . . . . . . . 10

4. Extinquisher Squad . . . . . . . . . . . 11

5. Annunciator Panel Monitor . . . . . . . 12

6. Building Perimeter Observer . . . . . . 13

7. Sprinkler Valve Guard . . . . . . . . . . 14

8. Radio Dispersers . . . . . . . . . . 15

B. Buildina 983 Fire Team . . . . . . . . . 16 
SAFE OPERATING PROCEDURE

FOR

REACTING TO EMERGENCIES

AT'

PBFA II, BUILDING 983

\begin{abstract}
This SOP outlines procedures for reacting to emergency situations within the PBFA II complex. Improper response to emergencies may result in area residents being subjected to hiqher than necessary risks and/or increased damaqe to equipment.
\end{abstract}

T. H. Martin, 1250 date

S. A. Goldstein, 1254 date

Distribution:

1236 G. A. Zawadzkas

1250 T. H. Martin

1254 S. A. Goldstein

1254 G. L. Donovan (2)

1254 All Personnel

3316 D. L. Rost

3316 A. M. Fine

3662 D. D. Knott

3662 V. L. Duke
D. L. Rost, 3316 date

A. M. Fine, 3316 date

D. D. Knott, 3662 date

V. L. Duke, 3662 date 
SAFE OPERATING PROCEDURE

FOR

REACTING TO EMERGENCIES, BLDG. 983

\section{Introduction}

Building 983 residents. working in a remote location from Tech Area I, must be prepared to react properly to emergency situations. Examples of potential emergency situations are:

1) Fire within the 983 complex

2) Severe personnel iniury

3) Activation of the Emeraency Preparedness System

Facility residents must be prepared to deal with such emergencies by performing several duties rapidly and efficiently :

A. Inform appropriate organizations (including 1200 manacement) of the emergency, location, and aid required:

1. Emergency Assistance (other than fire): Ext. 144

2. Fire Station: Ext. 117

3. Security: Ext. 4-4657

4. Safety: Ext. 4-4152

5. Environmental Health: Ext. 4-2735

6. Emergency Preparedness Sector Chief: (S.A.Goldstein) Ext. 4-3976 or paqer 142-192

7. Maintenance: Ext. 4-4571

B. Take necessary steps to prevent the situation from worsening until help arrives.

C. Inform other personnel of any action required to ensure their safety (e.g. evacuation).

D. When help arrives, be prepared to provide information on the emergency and any problems posed by unique features of the 983 facility.

E. Document events for future investigation and/or report. 
II. Fire Control Procedures for Building 983

A. In order to effectively respond to a fire emergency. residents of the 983 complex have been organized into a fire response team. The 983 fire team positions are listed below. Responsibilities and sugqested response of team members to a facility fire are listed in Appendix A.

1. Building Fire Captain

2. Fire Team Zone Officers

3. Extinquisher Squad

4. Evacuation Squad

5. Sprinkler Valve Guard

6. Annunciator Panel Monitor

7. Building Perimeter Observer

8. Radio Dispersers

B. Authorized fire team personnel - see Appendix B.

C. Safety drills and fire protection trainina will be conducted at least once a year under the supervision of the Operations Engineering Division, 3662. These training sessions will serve to refresh the skills of fire team members and building personnel in the use of dry chemical, carbon dioxide, and Halon extinguishers as well as the AFFF (aqueous film forming foam) firehose system.

\section{Procedures for Personnel Injury Response}

A. Slips and falls;

1. When injuries are severe enough to hamper subject's movement, do not attempt to move or treat. If no hazard of drowning exists, phone Medical immediately for advice (Ext. 4-2471) or the Ambulance Service (Ext. 144) if conditions warrant.

2. If hazard of drowning exists (e.q. a fall into the accelerator tank), provide subject with buoyancy device or secure with safety line before proceedina with step 1 .

B. Asphyxiation or potential drowning

Using SCUBA or Scott Air Pack breathing supply as appropriate, remove subject from detrimental environment utilizing safety lines to both the person in trouble and the rescuer. (NOTE: this should only be attempted if the safety of the rescuer can be assured). Instruct other members of the rescue team to phone the Ambulance Service, and administer CPR and/or First Aid. as applicable, as soon as possible. 


\section{Electrocution}

If circuit is live, power should be disconnected and circuit discharged. If this is not possible, remove subject from hazard using non-conductive device (e.g. a component safing rod) making sure not to endanger yourself or others on the rescue team. Instruct another member of the rescue team to phone Ambulance Service and administer CPR and/or First Aid, if needed, as soon as possible.

D. Documentation

It is the responsibility of employees and contract per sonnel to report ALL accidents, near accidents. injuries, and illness to their immediate supervisor as soon after the event as possible. For all injuries. form SF-2050P "Report of Occupational Occurrences, Injury/Illness" should be filled out immediately. This form should be taken (with one copy) to Medical by the injured person or his or her escort. Additional copies shall be distributed as follows:
a) A. M. Fine, 3316
b) J. P. VanDevender, 1200
c) T. H. Martin, 1250
d) S. A. Goldstein. 1254

For serious incidents of injury or major property damages. immediate notification of management to higher levels is required. In all cases, accurate recordina of the sequence of events is important.

\section{Emerqency Preparedness}

The Emergency Preparedness System is administered by the Security Plans and Training Division. 3436. The authorized Sector Chief for Area IV ( desianated Sector 50 ) is S. A. Goldstein, Pulsed Power Operations Supervisor, Ext. 4-3976. parer 142-192. The Sector Chief's responsibility is to inform Area IV residents of necessary action in case of a large scale emercency. The Emergency Preparedness Sector Chief should be notified immediately of any emergency requiring outside aid or building evacuation so that an appropriate area-wide response can be formulated. 
Appendix A

Building Fire Team Responsibilities:

Six Functions of Building Fire Team:

1. Evacuate Personnel

2. Locate Fire

3. Notify Fire Department

4. Use Hand Extinquishers and other Fire Control Aids

5. Assist and Advise Fire Department

6. Assure Sprinkler Valves are Open or Closed as Instructed

\section{Building Fire Captain}

A. Before the alarm:

1. Oraanize Building Fire Team and appoint members with approval of their supervision. Buildina Fire Team to consist of :
a) Alternate Fire Captain (as required)
b) Zone officers
c) Extinguisher Squad (each zone)
d) Evacuation Squad (each zone)
e) Sprinkler Valve Guards (as required)
f) Annunciator Panel Monitor
g) Building Perimeter Observer
h) Radio Dispersers

2. Maintain roster of Fire Team Members and Alternates and send up-to-date roster to Fire Protection Enqineerina, Division 3662.

3. Instruct Fire Team Members.

4. Anticipate problem areas such as:

a. Evacuation of disabled persons.

b. Unusual hazards that may be encountered.

c. Absent Zone Officers or Team members.

5. Become familiar with location and function of building alarm svstem (including remote alarms and sensors). extinquishers, sprinkler system, and evacuation system throughout the facility.

6. Assist Fire Protection Endineering in conducting practice drills. 
7. Request training from Fire Protection Engineering when deemed necessary.

B. When the alarm sounds:

1. Report to Building Command Post and ensure that Fire Department has been notified.

2. Make contact with Zone officers, Radio Dispersers, Annunciator Panel Monitor, Building Perimeter Observer, and Sprinkler Valve Guards. Assign alternates as necessary.

3. Receive reports from and give direction (when required) to Evacuation and Extinquisher squads through zone officers, and maintain contact by radio.

4. When Fire Department personnel arrive, assist by providing information about the fire and any hazards they may encounter within the facility.

5. Assist the Fire Department by obtaining advice and equipment as needed (with the assistance of Security and Fire Protection personnel).

6. When professional Firefighters arrive, the Building Fire Captain should turn control of activities over to the Fire Department personnel and withdraw the fire team from the building (or assist if instructed to do sol.

C. After the All Clear Sounds

1. Relieve Sprinkler Valve Guard(s) if necessary.

2. Gather reports from Zone Officers on any problems encountered during alarm period.

3. Report any unsatisfactory conditions to Fire Protection Engineering.

4. Acquire needed information to document the incident and report to appropriate management. 


\section{Fire Captain Checklist}

\section{After Fire Alarm Sounds:}

Fire Department notified.

Security notified to open electric gates to Area.

Radio dispersers present.

Annunciator Panel Monitor present.

- Sprinkler Valve Guard present.

Building Perimeter Observer present.

Zone Officers/Zone Teams present.

North lowbay/Screenrooms

___ Highbay/S.E. Addition

_ Pit/South lowbay/Mech. Room

Report Situation to Fire Department Officer.

After the All Clear Sounds:

Relieve Valve Guard (if necessary).

Gather reports from Zone Officers.

Document Incident, report to supervision.

Report unsatisfactory conditions to Fire

Prevention Engineering.

Comments : 


\section{Zone Officer}

A. Before the alarm:

1. Help Building Fire Captain organize Zone Team. Zone Team to consist of:

1) Alternate Zone Officer (as required)

2) Squad Leaders (as required)

3) Extinguisher Squad (each zone)

4) Evacuation Squad (each zone)

2. Maintain roster of Zone Team Members and Alternates and send up-to-date roster to Building Fire Captain.

3. Assist Building Fire Captain in instruction of Squad Leaders and Zone Team members.

4. Anticipate problem areas such as:

a. Evacuation of disabled persons.

b. Unusual hazards that may be encountered.

c. Absent Team Members.

5. Become familiar with location and function of alarms, extinguishers, and sprinkler system within your zone, and evacuation system throughout the facility.

6. Make sure all aisles and exits, extinguishers, firehoses, and sprinklers in your zone are free from obstructions.

7. Assist Building Fire Captain in conducting practice drills.

B. When the alarm sounds:

1. Report to Building Command Post to make contact with Building Fire Captain and receive radio.

2. Proceed with Zone Team to assigned area.

3. Receive reports from and qive direction to Evacuation and Extinguisher squads.

4. Keep Building Fire Captain appraised of the situation within your zone.

5. When professional Firefighters arrive, the Building Fire Captain should turn control of activities over to the Fire Department personnel. Zone Officers should be prepared to withdraw their teams from the building when instructed by Building Fire Captain or 
Appendix A (cont.)

Fire Department Personnel.

6 . Under no circumstances should the team members be placed in danger. If hazardous conditions exist, Zone officers should withdraw their teams and wait for professional firefighting personnel.

C. After the All Clear Sounds:

1. Gather reports from Zone Team members on any problems encountered during alarm period.

2. Report any unsatisfactory conditions to Building Fire Captain. 


\section{Zone Officer Checklist}

- Contact made with Building Fire Captain

- Evacuation Squad.

- Present (at least team of two)

Dispersed

- Extinguisher Squad.

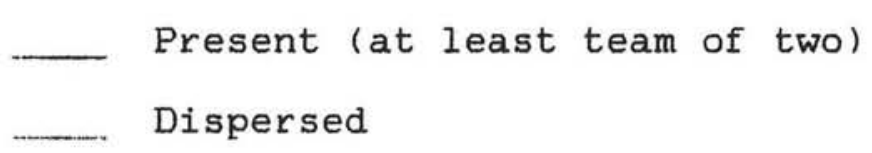

Report "FIRE" or "ZONE CLEAR" to Fire Captain.

After All Clear Sounds:

- Gather reports from Zone Team Members.

Report to Building Fire Captain.

Comments : 


\section{Evacuation Squad}

A. Before the Alarm sounds, each member sha1l:

1. Know the floor plan of the building.

2. Know the normal exit routes.

3. Know alternate exit means.

4. Keep main corridors and aisles clear and all exits in their zone free from obstructions.

5. Be aware of the location of handicapped persons requiring notification or assistance in case of emergency.

B. When the alarm sounds:

1. Report to predetermined location. Zone Teams should gather close to Building command post such that Fire Captain can assign alternates in absense of Zone officer.

2. After making contact with Zone officer or alternate, qo to assigned area and evacuate all personnel.

3. Direct personnel to follow normal exit routes in an orderly manner.

4. Render assistance to disabled persons as they may require.

5. If normal exit routes are blocked, direct personnel to alternate routes.

6. Announce alarms in rest rooms and other areas where they may not be heard.

7. Assist in search for fire and close all doors to limit spread of $\mathrm{f}$ ire and to help determine that all personnel have been evacuated.

8. Notify fire extinquisher squad and zone officer of location of fire.

9. Notify Zone officer when area is evacuated.

10. Withdraw from building upon orders from Zone officer or when conditions warrant.

C. After the "All Clear" Sounds:

1. Notify Fire Team Zone officer of any problems encountered during the alarm period. 


\section{Extinguisher Squad}

A. Before the Alarm sounds, each member shall:

1. Know the location of assigned extinquisher.

2 . Make sure the extinguishers' inspection and/or service records are up to date.

3. Learn the operation of the extinguisher and know what type of fires i.t can be used on.

B. When Alarm Sounds:

1. Report to predetermined location. Zone Teams should aather close to Building command post such that Fire Captain can assign alternates in absense of Zone Officer.

2. After making contact with Zone officer or alternate, get assigned extinguisher and go to designated station.

3. Be ready to respond to fire.

4. Assist in locating fire, when requested.

5. Disconnect electrical power to equipment involved in fire.

6. Carry extinguisher to fire and apply agent if extinguisher is of proper type.

7. Assist fire department when requested.

8. Withdraw from building upon orders from Zone officer or when conditions warrant.

C. After "All Clear" Sounds:

1. Notify Fire Team Zone Officer of any extinguishers which were discharced or found to be defective.

2. Notify Fire Team Zone Officer of any problems encountered during alarm period. 


\section{Annunciator Panel Monitor}

A. Before the Alarm:

1. Know the location of the annunciator panel which indicates the status of the building fire system (the annunciator panel for Building 983 is located at the extreme east end of the lowbay hallway, between the two sets of entry doors).

2. Become familiar with the building zones indicated on the panel and the operation of the panel itself. A Fire Protection Endineer can explain how to interpret the information displayed on the panel and how the panel will respond during a fire.

B. When the Alarm Sounds:

1. Report to the Building Command Post and check in with the Building Fire Captain.

2. After making Contact with the Fire Captain, proceed rapidly to the annunciator panel and observe and record the status of the panel. Return rapidly to the Command Post and report this status to the Building Fire Captain.

3. Be prepared to be reassiqned to alternate duty or return to the annunciator panel as directed by the Building Fire Captain.

C. After the "ALI CLEAR" Sounds:

1. Report on operation of panel to Building Fire Captain.

2. Report any problems during alarm period to Building Fire Captain. 


\section{Building Perimeter Observer}

A. Before the Alarm:

1. Become familiar with the layout of the 983 complex and surrounding structures and installations (including the oil tank farms).

2. Be aware of potential sources of fire around the complex and any obstructions to fire fighting equipment (construction equipment, etc.).

3. Become familiar with firehose locations within the complex that may be used to fight a fire external to the building.

B. When the Alarm Sounds:

1. Report to Building Command Post and check in with Building Fire Captain.

2. After checking with Fire Captain and being issued a radio, conduct a rapid search of building perimeter. This should include all construction areas and especially the oil tank farms.

3. Note the status of the areas and report to Building Fire Captain via radio (NOTE: if no radio was available for issue, return rapidly to Command Post to report status).

4. Should an external building fire be found, be prepared to deploy available fire fightina equipment AFTER REPORTING TO BUILDING FIRE CAPTAIN. If no fire is found, be prepared to be assiqned to alternate duty or continue perimeter search after reporting to Fire Captain.

C. After the "ALL CLEAR" Sounds:

1. Report to the Building Fire Captain any problems encountered during the alarm period. 


\section{Sprinkler Valve Guard}

A. Before the Alarm:

1. Know where the assigned valve is located.

2. Learn how it operates.

a. Opens counterclockwise.

b. Arrow on top indicates direction to open.

c. Window shows open or shut.

d. Handle is locked to valve post.

e. Lock has frangible shank, can easily be broken with rock or screwdriver.

B. When the Alarm Sounds:

1. Report to command post and make contact with Building Fire Captain.

2. Go to valve and stay with valve.

3. Look at window.

4. If valve is open, stay at valve until all clear is sounded.

5. If valve is shut;

a. If tag attached, do not open valve, but notify Building Fire Captain immediately for instructions.

b. If no tag is attached, remove break-of $f$ lock and open valve. Stay with valve and notify Building Fire Captain.

6. Sprinkler valve should be closed ONLY upon instruction of Professional Firemen. Under no circumstances should fire valve be closed by anyore other than Firemen or sprinkler crews.

C. After the All Clear Sounds:

1. If valve was not closed, you are relieved when all clear sounds.

2. If there was a fire and valve was closed by Firemen or sprinkler crew, standby to open valve if fire rekindles or until relieved by Building Fire Captain or Fire Department officer. 
Appendix A (cont.)

\section{Radio Dispersers}

A. Before the Alarm:

1. Know the location of the radios and portable carrier.

2. Make sure all radios are in good working condition.

B. When the Alarm Sounds:

1. Go To radio storage cabinet and place radios into portable carrier. Set all radios on channel 1 .

2. Proceed to emergency command post.

3. Provide radios to Building Fire Captain, Zone Officers, and as many evacuation squads as possible beginning with the Pit Evacuation Squad.

4. Remain to assist Building Fire Captain or evacuate building, as directed. 


\section{Appendix B}

BUIILIDING $9 \$ 3$ IFIIRE TTEAM

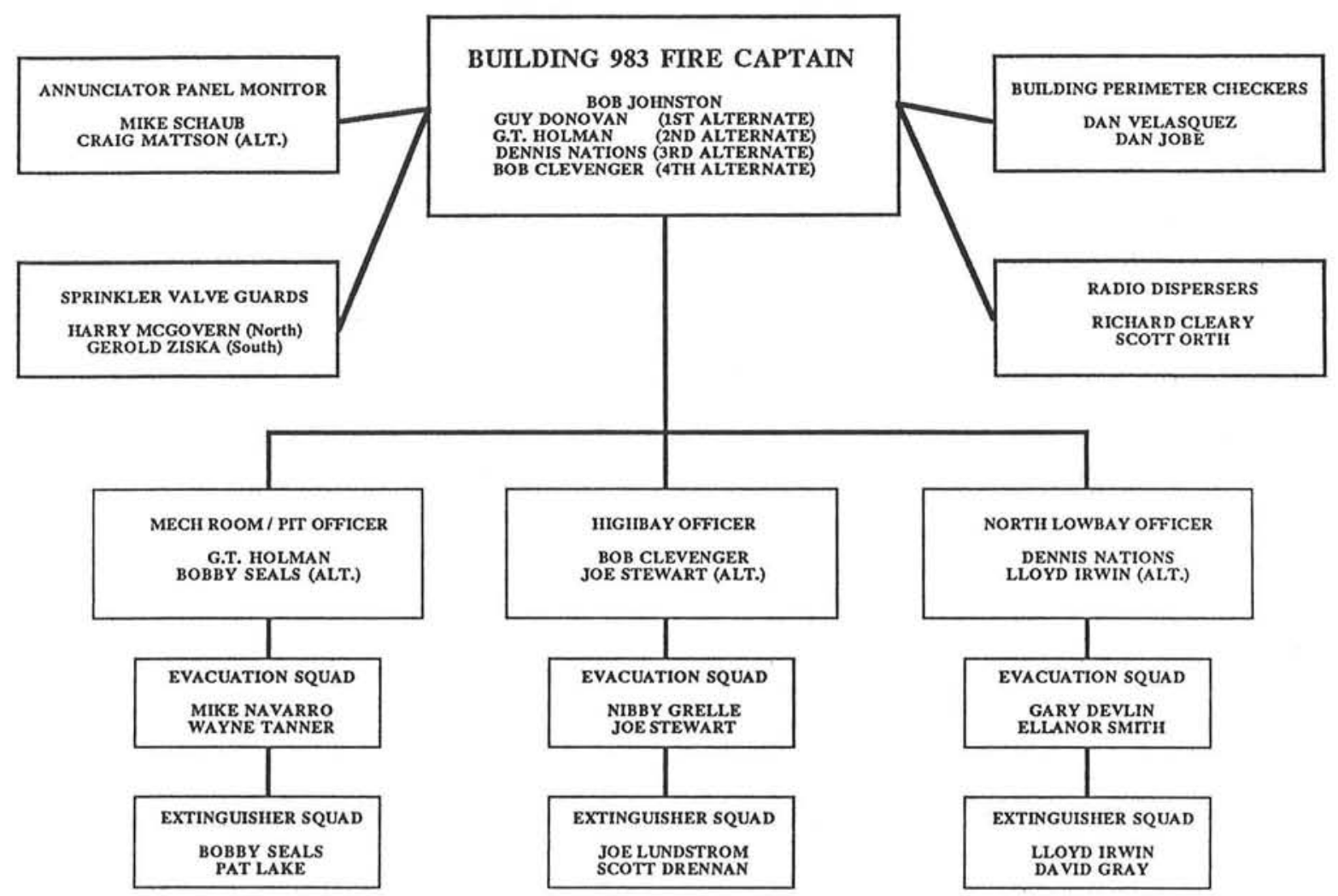

\begin{tabular}{|c|}
\hline ALTERNATE TEAM MEMBERS \\
ANDREW BALL \\
THEREA BROYLES \\
ROD CHAMBERS \\
GUY DONOVAN \\
RUSTY GREEN \\
JOIN HOGAN \\
MARK JOHNSON \\
CURT KING \\
CRAIG MATTSON \\
JERRY MILLS \\
JHN MCDONNELL \\
RICK OSBORN \\
PHIL PARKS \\
DON PETMECKY \\
BRUCE ROLLINS \\
\hline
\end{tabular}




\section{SAFE OPERATING PROCEDURE FOR \\ MOTIVE EQUIPMENT OPERATION}

AT

PBFA II, BUILDING 983

Appendix 5 


\section{SAFE OPERATING PROCEDIJRE \\ FOR}

MOTIVE EQUIPMENT OPERATION

AT

PBFA II, BIILDING 983

$5-3-5-4$ 
Table of Contents

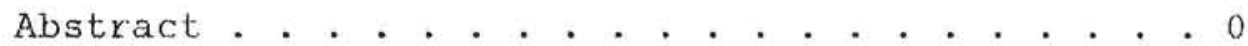

I. References . . . . . . . . . . . . . . . . 1

II. Introduction . . . . . . . . . . . . . . . . . . . 1

III. Applicable Equipment. . . . . . . . . . . . . . . I

IV. Hazards . . . . . . . . . . . . . . . . . . . 2

V. Handing Precautions . . . . . . . . . . . . . 2

VI. Motive Equipment Operational F'rocedures . . . . . 2

A. Cranes and Hoists . . . . . . . . . . . . . . 2

B. Material Handling Equipment. . . . . . . . . . 4

C. Fersonnel Motive Equipment . . . . . . . . . . 4

D. slifting Fixtures. . . . . . . . . . . . . . 4

VII. Specific Operational Procedures . . . . . . . . . 5

A. 10-ton Hiqhbay Bridae Crane. . . . . . . . . . 5

B. 10-ton Highbay Gantry Cranes . . . . . . . . . 5

C. 1/2-ton Highbay Jib Cranes . . . . . . . . . . 6

D. 1/2-ton Test Tank Rail Crane . . . . . . . . . 6

E. Facility Material Handling Equipment . . . . 6

VIII. Appendices . . . . . . . . . . . . . . . . . 7

A. Training Requirements and Procedures . . . . . 7

B. Operatina Manuals . . . . . . . . . . . . . . . 8

C. Material Handling Equipment Access . . . . . . 9

D. Rigoing Considerations . . . . . . . . . . .10

E. SAND81-1807, Revision A, Section 4.6.3 . . . .12

F. SLA-74-0206 (Hoisting Equipment Manual) . . . .15

G. Industrial Handling Trucks Operators Manual . .25

H. Authorized Operating Personnel. . . . . . . . .43 
SAFE OPERATING PROCEDURE

FOR

MOTIVE EQUIPMEN'T OPERATION

AT

PBF'A II, BUILDING 983

\begin{abstract}
This SOP outlines proper use of devices to move personnel and materials in and around Building 983. Improper techniques can result in personal injury and destruction of property.
\end{abstract}

T. H. Martin, 1250 date

S. A. Goldstein. 1254 date
D. L. Rost, 3316 date

A. M. Fine, 3316 date

Distribution:

1236 G. A. Zawadzkas

1254 S. A. Goldstein

1254 G. L. Donovan (2)

1254 R. K. Osborn

1254 Division Members

3316 D. L. Rost.

3316 A. M. Fine 
SAFE OPERATING PROCEDURE

FOR

MOTIVE EQUIPMENT OPERATION

$\mathrm{AT}$

PBFA II, BUILDING 983

\section{References}

All existing standards concerning motive equipment operation shall be complied with.

\section{Introduction}

During the evolution of the PBFA II facility from the assembly and test phase through the operational life, several types of motive equipment will be used in and around the Bldg. 983 complex. This SOP is designed to complement the above mentioned standards to ensure the safe operation of this equipment.

III. Applicable Equipment

\begin{tabular}{lrll}
\multicolumn{1}{c}{ Type } & Cap. & I.D.\# & Prop.\# \\
\hline highbay bridge crane & $20000 \#$ & & \\
highbay gantry crane & $20000 \#$ & & \\
highbay jib cranes & $1000 \#$ & & \\
test tank rail crane & $1000 \#$ & & \\
mechanical room bridge crane & $10000 \#$ & & \\
southeast lowbay bridge crane & $12000 \#$ & & \\
Caterpillar diesel forklift & $8000 \#$ & T86E & S282683 \\
Drexel swivel-mast forklift & $3000 \#$ & D31C & S299949 \\
Clark electric forklift & $3000 \#$ & & S308879 \\
Big Joe electric forklift & $2000 \#$ & BJ29A & S291023 \\
Sky Climber scissors lift & $750 \#$ & SM22 & S308958 \\
Sky Climber scissors lift & $750 \#$ & SM22 & S308599 \\
Big Joe manlift & $2000 \#$ & BJ & S271882 \\
Taylor-Dunn cart & -- & T18 & S266095 \\
center section hydraulic lift & $20000 \#$ & & \\
mechanical room hydraulic lift & $20000 \#$ & & \\
& & &
\end{tabular}


IV. Hazards

Improper operation of motive equipment presents hazards to the operator, the equipment, and any surrounding equipment or personnel. The equipment must be used only for its designed purpose, within its lifting capacity, and according to the manufacturers' operating procedures to avoid damage to material and/or personnel.

V. Handling Precautions

No personnel shall operate any Bldg. 983 motive equipment unless authorized by PBFA II Operations (see Appendix A). Proper operating procedures for all motive equipment shall be determined by reference to the manufacturers' operating manuals (see Appendix B) and in the case of forklifts, further defined by the Industrial Handing Trucks Operator's Manual (see Appendix G).

Motive equipment is divided into two categories of primary use: equipment moving and personnel moving. Operators should make sure the equipment they use is the proper type for the job.

VI. Motive Equipment Operational Procedures

The 983 complex contains many types of motive equipment designed for different uses. Personnel using this equipment should refer to the various operating manuals for specific guidelines. The following is a list of procedures relating to the general use of this equipment within the 983 facility.

A. Cranes and Hoists:

1. No lifting operation should be performed unless the lifting capacity of the crane or hoist is known to be greater than the load to be lifted.

2. Crane cables should be visually checked for kinks, frays, and secure mounting prior to use. The load hook should also be inspected for cracks or other signs of failure.

3. Before near-maximum lifting operations the crane brakes should be checked for proper operation. To do this, lift the load a few inches off the ground and turn the controls of $f$. If the brakes operate properly, the load will not slip closer to the 
floor. If the load does slip, do not use the crane. Contact a facility administrator. He/she will arrange for inspection and repair.

NOTE: near maximum loads are encountered each time a full Marx generator is lifted by the bridge or gantry crane. This brake test should be performed at least once each day such loads are hoisted.

4. Before lifting, cranes should be positioned directly over the loads center of gravity to prevent swinging.

5. Operators should ensure that their intended path is clear before moving the load.

6. Begin movement slowly to avoid swinging and keep the load as close to the ground as possible.

7. Maintain visual contact with the load at all times.

8. Remain aware of crane position relative to the stops. Never allow the crane to run into any of the stops (including the up stop!).

9. Loads should never be carried over personnel.

10. Be aware of other equipment in the vicinity. Avoid bumping into other cranes or facility structures.

11. Guide ropes should be used whenever possible to prevent loads from spinning.

12. Standard hand signals should be used when communication is required.

13. Never leave a load suspended from an unattended crane.

14. After use, cranes and remote control boxes or pendants should be returned to their assigned parking places (see section VII).

15. During accelerator activity, power should be disconnected from designated equipment (see section VII).

16. Cranes and hoists should be used for personnel movement only in conjunction with a facility bosun's chair or other device approved by the Safety Oraanization. Division 3316. No personnel shall ride the hook. 
SOP - Motive Equipment Operation Bldg. 983 / page 4

B. Material Handling Equipment:

Forklifts at the 983 complex are under the control of Division 1254 Operational Logistics Personnel (see Appendix C). General material handling should be coordinated through the Area IV material handler (pager \#142-206).

C. Personnel Motive Equipment:

1. Whenever personnel motive equipment is used, operators should be particularly aware of bump hazards and obstacles, especially in the pit area or other conf ined spaces.

2. While moving the equipment in any direction, operators should concentrate on operating the device and not the task at hand.

3. Extreme care should be taken when moving upright manlifts while they are extended. Operators should understand that this should be done for short distances only.

D. Lifting fixtures ;

An inventory system listing all the lifting fixtures and slings used in Building 983 will be maintained by PBFA II Operations. The facility inventory shall represent the formal link to the safety accountability of all lifting devices. All straps, chains and other lifting fixtures used in the 983 complex MUST be registered in the facility inventory prior to use (see Appendix D).

1. Before selecting any lifting device, make sure the load rating of the device is greater than the load to be lifted. Remember the safe load limit depends upon the way the load is rigged (see Appendix D).

2. Prior to each use, lifting straps should be visually inspected for cuts, frays, or wear that may affect load rating.

3. When rigging with flexible slings or chains, use the maximum sling to load angle possible (see Appendix D).

4. Lift loads smoothly and evenly to limit stresses on the lifting device.

5. Don't tie knots in lifting straps or tie them together. 
SOP - Motive Equipment Operation Bldg. 983 / page 5

6. Don't use nylon slings in environments above 180 degrees Fahrenheit.

7. Hitches, hooks, lifting eyes, and anything else used to secure the load to the motive equipment should be inspected for signs of wear and secure mounting prior to use.

VII. Specific Operational Procedures:

The following lists some specific cautions and procedures with regard to individual pieces of 983 motive equipment.

A. 10-ton Highbay Bridge Crane:

The parking place for the 983 bridge crane is the extreme east side of the highbay. The crane should be returned to this location with the pendant in the up position before any accelerator activity ( NOTE: don't rely on the limit switch when raising the pendant - visually check the height during this operation). After EACH use, the radio controller for the highbay bridge crane should be returned to it's storage location on the west highbay wall near the breaker box. Power to the crane should be disconnected at this breaker during accelerator activity.

Note: During operation of the highbay bridge crane, the "creep" speed switch must be engaged ONLY while the crane is at a complete stop. Engagement while in motion could cause serious damage. The creep speed should be used whenever accurate positioning is required. Under no circumstances should the control button be jogged to achieve slight movement! When moving the bridge (east-west travel) at high speed, the operator should first switch to slow speed before stopping. This prevents harsh brake grab which causes load swing and possible crane damage.

B. 10-ton Highbay Gantry Crare:

The parking spot for this crane is the southernmost position on the railway. The crane should be moved to this location and power disconnected during accelerator activity. The disconnect is located on the east highbay wall in panel D6 ( breaker \#38 - bottom left side). 
C. 1/2-ton Highbay Jib Cranes:

When not in use, the two jib cranes on the west side of the machine should be stored in the lowered position oriented such that they are as close to the catwalks as possible without interfering with catwalk traffic. The jib crane on the east side of the machine should be stored in the lowered position pointed east northeast. Fower should also be disconnected at the disconnect boxes on each crane when they are not in use.

The telescoping mast on the jib cranes MUST be extended or retracted under no load conditions ONLY. Up and down movement of the mast requires that the trolley be fully retracted (towards mast) in order to trip an interlock switch that controls the telescope drive power. Do not move the masts up and down unnecessarily, this may lead to frequent repair requirements.

Operators should be careful not to run the jib cranes into other motive equipment, facility structures, or the crane stops. Stops on the southwest and north cranes are set for 3500 of rotation. The northwest crane stops are set at 2800 to prevent hitting the north highbay wall.

During accelerator activity, all cranes should be moved to their designated parked positions (see above) with power disconnected and locked out.

D. 1/2-ton Test Tank Rail Crane:

The parking place for this crane is above the handrail between the 0 and -10 foot levels. The crane should be kept there when not in use. During accelerator activity, power should be disconnected at the disconnect box located above the crane controls.

E. Facility Material Handling Equipment:

Operators of material handing equipment will be responsible for returring equipment to its assigned storage area after use. These areas will be indicated on the equipment use log when signed out (see Appendix C). 
Appendix A

Training Requirements and Procedures

Safety Engineering, 3316 will provide motive equipment training and certification for facility personnel. Classes for this training will be arranged by the Pulsed Power Operations Division. 1254.

Persornel authorized to operate motive equipment at PBFA II under the provisions of this SOP are listed in Appendix $\mathrm{H}$.

Outside contractors who have been granted permission to use building 983 motive equipment must first be checked out in its operation. Before use of this equipment, contractors should check in with the onduty Facility Manager(1) to arrange the check-out procedure. if this has not already been done.

(1) The name and phone number of the on-duty Facility Manager will be posted near the entrance to the Data Acquisition Room (RM 104). The Facility Manager may be reached by phore. PA announcement, or personal pager. 


\section{Appendix B}

Operating manuals for Building 983 motive equipment are available from the 1254 Logistics personnel in Mol48. These manuals should be refered to for specific operational procedures.

Operating guidelines for forklifts are further defined by the attached Industrial Handling Trucks Operator's Manual (see Appendix G). 
Appendix C

The Division 1254 Operational Logistics person for PBFA II is Rick 0sborn (ph. 6-2692, pager 142-354). Rick maintains control of the keys to all Building 983 material handling equipment. Anyone requiring the use of this equipment should contact Rick and sign the equipment use log in M0148, room 1.

Movement of facility materials or equipment within the Building 983 highbay or the inflatable storage building may only be accomplished by Rick or other personnel designated by PBFA II Operations. General material handing needs should be coordinated through the Area IV material handler (pager 142206). 


\section{Appendix D}

\section{Rigging Considerations}

The safe lifting capacity for slings and other flexible lifting devices is dependent upon a number of factors. The "Rated Capacity" for such devices (the number that appears on the sling) corresponds to the minimum breaking strength divided by the desion safety factor:

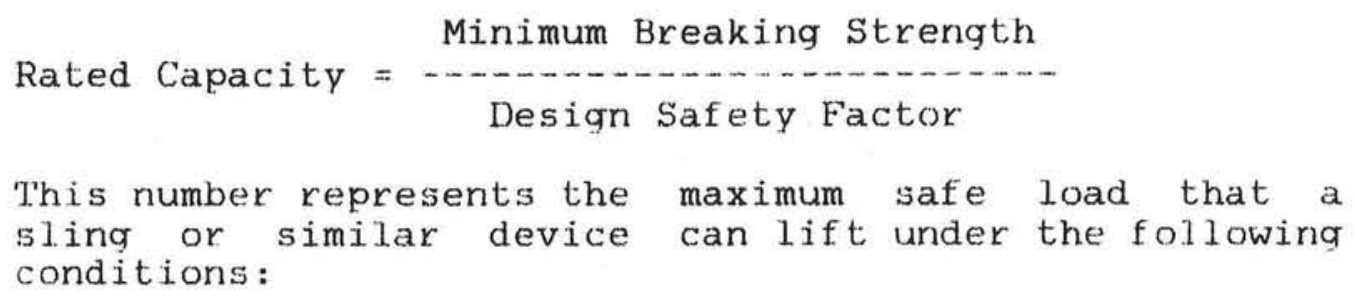

1. In a straight vertical pull

2. When the sling is new

3. Ideal sling conditions

4. Ideal test conditions

The term "Rated Capacity", therefore, does not represent the slings lifting capacity under all lifting conditions and at any time during its working life. When determining which sling to use in a certain situation, it is necessary to consider:

1. The increased loading of lifting at angles

2. The loss of sling strength through age, wear or damage

3. Added sling loading of acceleration, deceleration, and shock

4. Added stress applied to the sling from sharp corners on the load 
Appendix D (cont.)

To prevent possible problems, slings should be inspected before use for wear, damage, and current certification of load testing through the facility inventory system. Worn or damaged slings, or those without current certification should be brought to the attention of Bob Clevenger, Division 1254 (ph. 6-2691, pager 142-467). $\mathrm{Bob}$ is in charge of the lifting fixture inventory and will arrange for retesting or replacement of damaged slings.

In use, operators should begin movement of any load slowly to prevent unnecessary acceleration loads on fixtures. Operators should also protect slings from sharp corners with some type of softener.

Another consideration when choosing a lifting sling is the manner in which it is used. As mentioned above, the rated capacity of a sling is based upon a straight vertical lift. When a sling is used in the choke-hitch configuration, it safe load limit is reduced to twothirds of the single leg vertical rating. Similarly, when a sling is used in the basket-hitch position, its safe load limit decreases as the angle of the legs with horizontal decreases. The table below shows the relationship between load angles and the effect on load ratings.

\begin{tabular}{|c|c|c|c|}
\hline \multirow{3}{*}{$\begin{array}{l}\text { SLING-TO-LOAD ANGLE } \\
\text { (ANGLE: BETWEEN LEG } \\
\text { AND HORIZONTAL) }\end{array}$} & \multicolumn{3}{|c|}{ SLING CAPACITY (ONE LEG) } \\
\hline & LIFTING & VERTICAL & ACTUAL \\
\hline & EFFICIENCY & CAPACITY & CAPACITY \\
\hline 900 & $1 \ldots 100 \%$ & $1000 \#$ & $1000 \#$ \\
\hline 750 & I $96.6 \%$ & $1000 \#$ & $966 \#$ \\
\hline 600 & $186.6 \%$ & 1000\# & $866 \#$ \\
\hline 450 & $170.7 \%$ & 1000\# & 707\# \\
\hline 300 & $150.0 \%$ & 1000\# & $500 \#$ \\
\hline 150 & I $25.8 \%$ & $1000 \#$ & 258\# \\
\hline 50 & $18.7 \%$ & 1000\# & 87\# \\
\hline
\end{tabular}

EFFECT OF LOAD ANGLE ON LIF'TING EFFICIENCY

(PER LEG) 


\section{Appendix E}

Sandia National Laboratories Safety Manual

SAND81-1807, Revision A

Printed August 1984

section 4.6 


\subsection{Hoisting and Rigging Equipment}

This section contains the safety practices to be observed when using hoisting and rigging equipment. Information is also provided on maintenance, inspection, and storage of equipment to ensure safety and serviceability.

\subsubsection{Definitions}

Hoisting Equipment. Electrical or mechanical devices used for raising and lowering londs. Includes hand-and power-operated hoists, derricks, hydraulic lifts, forklifts, and cranes.

Rigging. Fquipment used with hoisting devices to suspend or balance loads. Rigging includes chains, cables, ropes, slings, eyelets, strongbacks, hooks, rings, clevises, plate grips, bails, shanks, and tongs.

lingineering Inspection. Semiannual inspections conducted by Plant Operations lingineering inspectors to ensure that hoisting equipment and rigking are in good condition and can be safely (1) erated in accordance with ANSI safety codes. Fach hoist is also load-tested biannually.

\subsubsection{Hoisting Equipment}

\subsubsection{Organization Responsiblities}

All purchase requisitions for hoisting or rigging equipment must be approved by Plant kngineering to ensure that it is of proper design for its intended use.

l'lant Engineering is also responsible for the engineering inspection of hoisting equipment and will establish the safe load limits for such items. Maintenance for hoisting equipment is performed by Plant Maintenance except for mechanically powered lifts. Mechanically powered lifts such as forklifts and truck cranes are maintained by the Transportation Division. At SNII, maintenance is performed by the Plant Maintenance Division.

The Sundia Laboratories Hoist Manual, the American National Standards Institute Safety Code for Cranes, Derricks, and Hoists, and the manufacturer's specifications will be used as minimum standards during maintenance and inspections. Additionally, the Manual for (Use, Inspection, and Maintenance of Iloisting E'quipment, SLA74-0206, should be used as required.

\subsubsection{Chain Replacement}

'The chnin with which a hoist is originally equipped shall not be replaced with uny other kind of chain except with the approval of the Plant Engineering Design Department. Unless otherwise specified, the new chain shall be purchased from the manufacturer of the hoist.

\subsubsection{H Equipment}

Specially designed handling items, designated as " $\mathrm{H}$ " equipment, used on the Sandia National Laboratories' premises are exempt from the inspection provisions in this subsection. However, all supervisors authorized to use this type of equipment are responsible for its proper design, use, maintenance, and inspection, in accordance with the prescribed operations manuals.

\subsubsection{Rigging Equipment}

\subsubsection{Organizational Responsibilities}

The supervisor of a division that uses rigging equipment is responsible for the following:

- Proper use, storage, and maintenance

- Visual inspections prior to use

- Control record system

- Scheduling load proof tests

- Ensuring that all SNL-fabricated rigging is load-proof tested prior to use.

Note: For a comprehensive review of rigging equipment, refer to Rigging Equipment Manual, Design, Fabrication, Inspection, Use, and Testing, SAND73-()564.

The Plant Maintenance and Operations Department is responsible for load testing all rigging items in accordance with procedures prescribed by Plant. Fingineering.

\subsubsection{Inspection/Load Proof-Testing of Rigging Equipment}

New rigging items, whether purchased or fabricated by Sandia National I,aboratories, shall be visually inspected and identified by the using organization before being used. Suggested markings are the organization number and control number, e.g., $\times x \times x-())$, $-(1) 2$, etc. The method of marking should be compatible with the rigging material. The control number for each item of rigging should be entered in the control record system of the using organization. Any size card, preferably $5 \times 7$ in., can be used as an inspection record card-one card for each identified piece of rigging.

The division supervisor must require the using personnel to visually inspect all rigging equipment, especially nylon webbing slings because of their susceptibility to damage, prior to each day's use, and, as a minimum, visually inspect all items of rigging twice each year. The biannual visual inspections must be entered in the control record system. 
lond proof-testing is required when visual inspections note excessive abrasion, wear, or reduced cross section of any type of rigging equipment. In ndilition, rigging equipment used in arens of frecpuent. steress or exposure to fumes, acids, or other chemicals must be lond-tested anmunlly. It is recommended that. all other rigging equipment be lond prowf-tested every four years. A load test record sheet (Figure A7 in Appendix A) may be used to record load test results. If this sheet is used, the lond test results should be recorded on the record curds, nnd the sheets retnined until the next lond lests are conducted.

To have load tests performed, the supervisor should initiate a work order through telecon, 4-4571; prepare a Load 'T'est Record Sheet; originate a Move Order Form, SA6941AD); and send the rigging items and the Load Test Record Sheet to Bldg. 887, Room $14: 3$ by calling the Dispatehers at $4-8048$.

Fach item of rigging that is load tested by the Plant Modification I)ivision will be marked with the date of test, in addition to recording the test results on the test record sheet.

\subsubsection{Designation of Safo Load Limits}

Supervisors of organizations engaged in the design of rigging items, whether purchased or fabricated by Sandia, are responsible for establishing safe load limits for each item. These limits are not to be exceeded by using organizations. As a guide for establishing the safety factor, the designing organization will consult the latest edition of the National Safety Council's Accident Preesention Manual for Industrial Operations, available from sisfety.

\subsubsection{Slings}

All slings must be marked with their maximum safe load limit (in pounds) for use in the single-leg vertical position. Fach leg of a multileg sling assembly shall be marked with its strnight-pull maximum safe load limit in pounds.

Use of single or multileg slings in a position other than vertical progressively decreases their designated safe-load limits as the angle between the sling leg(s) and the horizontal is decrensed. Safe-load limits are also decreased when slings are used in the choke or basket hitch positions. When a sling is used in the choke hitch position, its sale-load limit is reduced to two-thirds of the sling's maximum safe load single-leg vertical value. When a sling is used in the basket hitch position, its maximum sale-load limit decreases as the angles of the legs with the horizontal decreases.
If slings are used in other than the single-leg vertical position, approprinte standard loading tables should be comsulted so that the true, safe load limit. can be determined. When doubt exists as to the safe loading limits of any rigging sling, contact Safety Engineering. I, oading tables can be found in SI,A73()564.

The maximum safe lond limits and identification numbers of all wire rope and nylon slings shall be conspicuously marked on each sling. If a sling cannot be marked, the information will be stamped on a metal tag or plate securely fastened to the item.

The supervisor of the using organization shall ensure that every sling used by employees under his direction is visually inspected before each use and at least biannually. He will also ensure that all slings issued to his organization are load tested annually by Plant Maintenance and Operations Department.

Slings shall be stored in a manner which will ensure that they do not become kinked or exposed to liquids. It is recommended that they be hung in a storage locker.

When a defect is found on a sling during an inspection or load test, the sling will be removed from service, destroyed, or sent to Reclamation.

\subsubsection{Chains}

The maximum safe-load limit of a chain and its identification number shall be conspicuously marked by stamping the information on an idle link, or by stamping the information on a metal plate which is then securely attached to a link near the end of the chain or to an idle link. Stampings shall not be made or heat applied to links, hooks, or rings used for load carrying.

\subsubsection{Repair and Replacement}

When defects are found during the inspection of rigging items, the inspector shall notify the supervisor that the equipment is defective and should be removed from service.

Chains, cables, or flexible metal belts used for hoisting purposes shall not be repaired, and the use of replacement links is prohibited. 
Appendix F

Manual for Use, Inspection, and Maintenance of Hoisting Equipment

SLA-74-0206

Printed July 1974 
SLA - 74-0206

Unimited Release

Printed July 1974

MANUAL FOR USE, INSPECTION, AND MAINTENANCE OF HOISTING EQUIPMENT

Lee Stinnett Maintenance Staff Engineer

Plant Maintenance Department 9710

W. R. Mitcham and W. G. Mabry (Retired)

Control, Operations, and Material Services Division 9753

\section{ABSTRACT}

This manual provides guidance for operational use, mechanical and electrical inspection, and maintenance of hoisting equipment at Sandia Laboratories. Hoisting equipment includes cranes, bridges, trolleys, monorails, gantries, jibs, winches, and lifts. Responsibilities for inspection, servicing, testing, reviewing, and record keeping are assigned. 


\section{NOTICE}

The guidelines in this manual are minimal and in no way are they intended to replace manufacturers' manuals or Federa codes and regulations.

Each individual using, inspecting, or servicing hoisting equipment should familiarize himself with the definitions, general requirements, and inspection classifications and the testing, mantenance, and operational guidelines contained in Section 1910.179 of Subpart N - Materials Handling and Storage. Chapter XVII, Title 29, Code of Federal Regulations, Occupational Safety and Health Standards. Any conflicts between the referenced standards and this manual should be brought to the attention of the authors. 


\section{MANUAL FOR USE, INSPECTION, AND MAINTENANCE OF HOISTING EQUIPMENT}

\section{Definitions, Nomenclature, and General Instructions}

In general usage, the words "crane" and "hoist" usually mean the same thing. They are bott. defined as "apparatus or machines used to raise, lower, or move elevated loads." Lifts and winches can also fulfill the same purpose and therefore are included in this manual.

For the purpose of simplicity and continuity of terms in this program, the following definitions are applied.

CRANE - An all inclusive term which includes hoists, supporting structures, and auxiliary equipment. Cranes also include truck-type mobile units which have booms and winches.

HOIST - A basic lifting unit. For purposes of load testing, hoists are identified by a discrete and individual maintenance number.

BRIDGE - A wheeled, four-point, supported crane structure containing one or more trolleys and hoists. The bridge spans the distance between the supporting rails. The bridge travels directionally, forward and reverse, parallel to the rails which normally are supported by building members or columns.

TROLLEY - A wheeled accessory which supports a hoist and when it is part of a bridge crane travels on the bridge laterally to the directional movement of the bridge. When suspended from a monorail, the trolley travels along the monorail.

MONORAIL - A single structural member, usually an I-beam, which supports a trolley.

GANTRY - A crane structure consisting of two A-frame type members, connecting monorail, trolley, and hoist. A gantry usually is mobile.

- A crane structure consisting of a monorail, trolley, hoist, and vertıcal supporting member. It is braced or supported so that the monorail can rotate about the main supporting member.

WINCH - A device consisting of a power unit and rotating drum on which chain or wire rope is wound. The rotating action winds the chain or rope around the drum, pulling the load on the level or on inclined ramps. A winch is also used to raise loads vertically when used with a boom and pulley. 
- A devire, usuallv livdraulic, whirh rases and lowers loads in a pre defined vertical path. Commonly used in automotive shops or seryce centers. The lifting force also may be exerted by scissor-like mechanical jacks or screws.

Figure 1 shows the functions and interrelationships of hoisting equipment. Figure 2 illugtrates several typical types of hoisting equipment which are defined above.

\begin{tabular}{|c|c|c|c|c|c|c|}
\hline & HKIIST & WINLII & (MAN): & BRIDCL. & TROI.L.I:Y & MONKIRAIL \\
\hline Iefinitionn: & $\begin{array}{l}\text { Powired device } \\
\text { ued in rasise } \\
\text { and inver } \\
\text { hrav loads }\end{array}$ & $\begin{array}{l}\text { Powered devire } \\
\text { to indl or haul } \\
\text { heave inads }\end{array}$ & $\begin{array}{l}\text { Interehange- } \\
\text { oble with } \\
\text { noist }\end{array}$ & $\begin{array}{l}\text { Wneeled } \\
\text { sirurture } \\
\text { which iravels } \\
\text { abone station. } \\
\text { orr rails }\end{array}$ & $\begin{array}{l}\text { Wheeled device } \\
\text { whirh travels } \\
\text { :aterally to ine } \\
\text { direetion or } \\
\text { iravel of } \\
\text { bridure or on } \\
\text { and parallel } \\
\text { sith o monorail }\end{array}$ & $\begin{array}{l}\text { Single support } \\
\text { memoer }\end{array}$ \\
\hline $\begin{array}{l}\text { Funrion: } \\
\text { Primar. }\end{array}$ & 1.1ns luad & Pull. load & $1.1 \mathrm{fes} 1000$ & $\begin{array}{l}\text { Supporia irol. } \\
\text { lev } \\
\text { llolds inan }\end{array}$ & $\begin{array}{l}\text { Supporta noist - } \\
\text { Holas load }\end{array}$ & $\begin{array}{l}\text { Supports trol- } \\
\text { lev }\end{array}$ \\
\hline Seronuar: & lowers loat & Raises lisad & lowers load & Hoces rowlles & Abves ibist & Holdes loso \\
\hline Power & $\begin{array}{l}\text { i:Hertrir } \\
\text { livuraulir } \\
\text { Air } \\
\text { Ham (C hain) }\end{array}$ & $\begin{array}{l}\text { lifertirie } \\
\text { Air } \\
\text { latiers } \\
\text { bincine } \\
\text { lianu (C rank) }\end{array}$ & $\begin{array}{l}\text { I:Iertrir } \\
\text { Horawis } \\
\text { Air } \\
\text { Hana (C hain) } \\
\text { Pusil (Pull) }\end{array}$ & $\begin{array}{l}\text { l:lertrie } \\
\text { Manu (C nain) } \\
\text { Pusi. (1'ull) }\end{array}$ & $\begin{array}{l}\text { I. leririr } \\
\text { Hand (Cliain) } \\
\text { Puxn (Pull) }\end{array}$ & $\begin{array}{l}\text { Pusin Wio } \\
\text { Tyei }\end{array}$ \\
\hline Trues: & 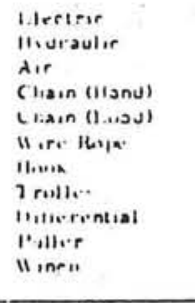 & 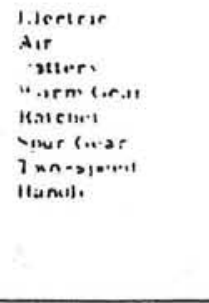 & 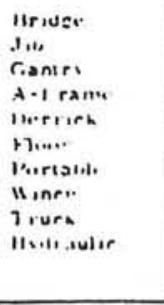 & $\begin{array}{l}\text { Mntorizeil } \\
\text { C.earive } \\
\text { inal. } \\
\text { lusi (Rull) }\end{array}$ & 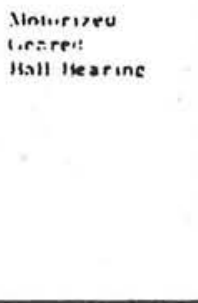 & $\begin{array}{l}\text { Stationar. } \\
\text { Troiles } \\
\text { Hotatine }\end{array}$ \\
\hline
\end{tabular}

Figure 1. Hoistung equipment reference matrix 

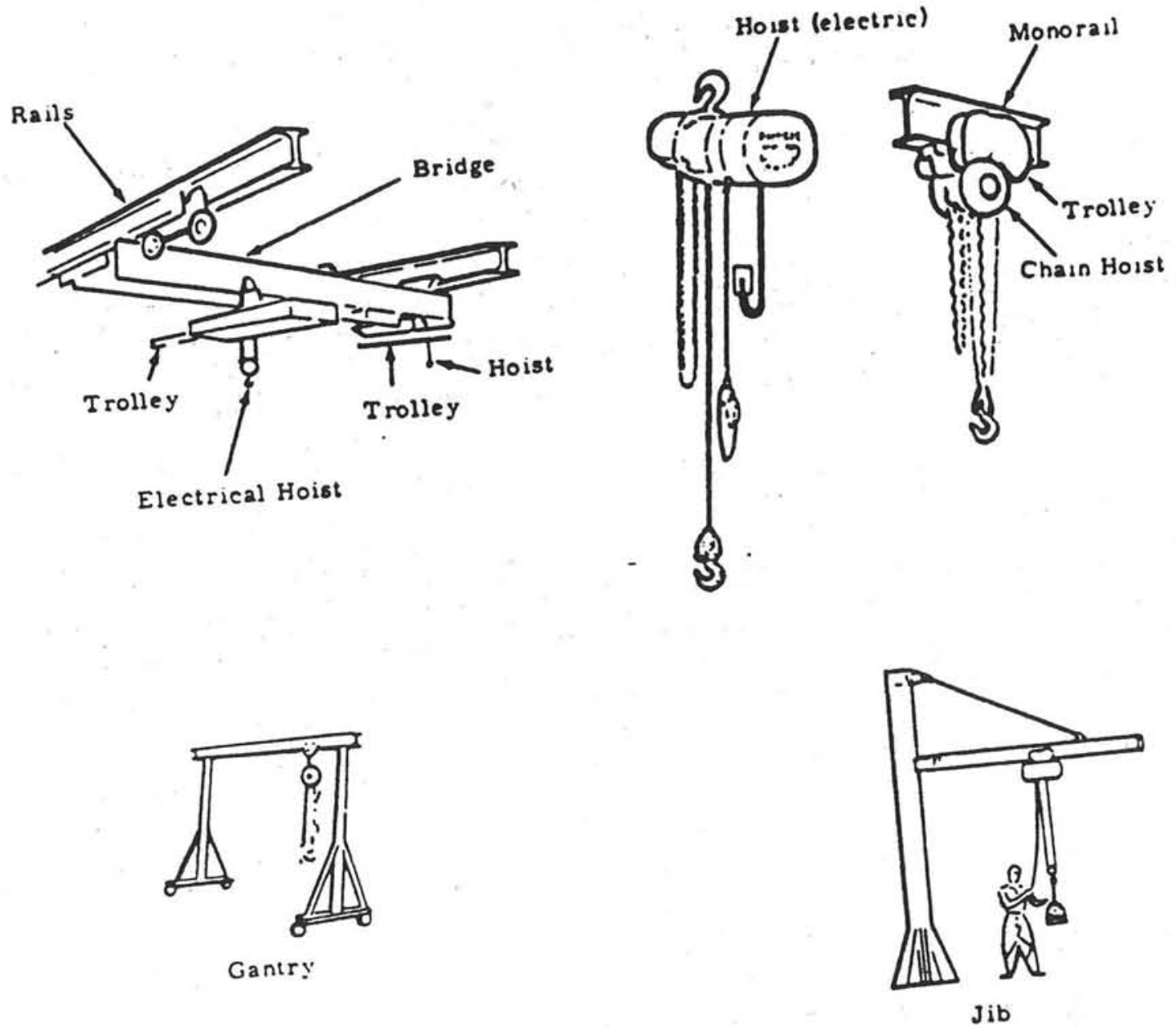

CRANES AND HOISTS

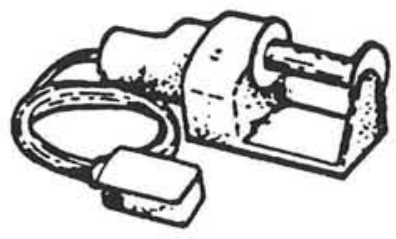

Electrical
WINCHES

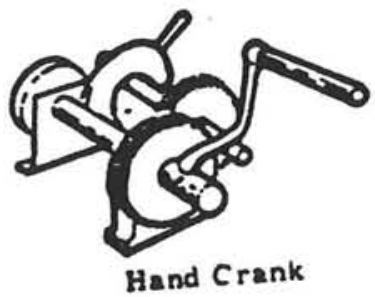

Figure 2. Typical hoisting equipment 
Procedures in this manual are presented in the following order: (1) use. (2) inspertion, and (3) maintenance service. The following guidelines should be observed in the sequence they are presented in order to provide control for the computersed preventuve masntenance program for hossting equipment. A control or masntenance number should be affixed (by deral) to each hoist, winch, or lif in a conspicuous and relatively identscal position on all units.

The number first applied to a hoist or a bridge will also be used to identify, for purposes of mainsenance, any associated motors, mechanical equipment, trolleys, etc. Each additional hosst on a bridge will have a maintenance number affixed to it. Each additional number will also be used to identify the associated trolley, motor, etc., which support the extra hoist on the bridge.

A maintenance number shall be affixed to each hoist, liff, or winch, portable or nonportable. whether the device is in use, stored in place, in formal storage, or out of service for any reason. The decal carrying the maintenance number is removed only when the piece of equipment is sent to reclamation.

Permanent maintenance numbers identify hossts for the following reasons:

1. To assist in control of equipment that is frequently relocated.

2. To make inventory of plant accountability items more efficient.

3. To provide a control number for the plant accountability items valued at less than $\$ 300$.

4. To provide andividual host load test histories.

5. To control preventive maintenance schedulıng.

A computer program ${ }^{*}$ is used to schedule maintenance serviring and operations engineerıng inspections as part of Sandia Laboratories Plant Maintenance Preventıve Maıntenance Program. Electrical and mechanical maintenance and load cherk functions are coded 08 . The engineering inspection function is coded 50. Figures 3 through 7 are examples of Preventive Maintenance scheduling cards.

The preventive maintenance program requires annual electrical and mechanical maintenance service and engineerıng inspections and hiennial load testıng. This schedule is in accordanre with the American National Safety Code for Cranes, Derricks, and Hoists.

Computer printouts provide inspection and maintenance service data and load test history. The load test work cards (Figure $i$ ) are retaıned for two vears to he used as verifıration of certıfication compliance.

*or details of the romputer program see Plant Mlauntenance l'reventive Alaintenance Program, SC-A1-i2-0041, A. D. Smailer, March 1972. 


\section{Use of Hossting Equipment}

The lailure of a hoist may cause not onl property loss and program delay but also serious Injury even though there is no mechanical failure. For these reasons it is of the utmost importance to review all aspects of hoist operation before the hoist is used.

Personnel using hoisting equipment should frequently refer to the following check lists.

\section{Check Before Operation}

1. Determine safe load limit of hoistung equipment. Do not exceed this limit.

2. Check controls daily for proper operation. Does the action of the hoist correspond to the intended signal for the button operated?

3. Check pendant control cable for damage. Look for cuts, kinking, or aigns of wear.

- 4. Visually check hoist cables for fraying, kinking, crushing, or any other sign of deterioration. Do the hoist cables twist between the block and the drum?

5. Look at the hoist drum. Are the cables properly aligned? Check for any stacking of the cable on the drum. Make sure the cables are aligned in the drum guides.

6. Lower the hook and visually inspect it for cracks, bending, or distortion. Check safety latch for proper operation."*

\section{Check During Hookup}

1. Check sling for signs of wear. Are cables free of kinks or other damage? Are clevises and load rings in good repair?

2. Position the hoist directly over the load. Side of end pull must be avoided. If hoist will not center over the load other lifting means must be used to center the load under the hosst.

3. After the hoist hook is placed in the lifting ring apply slight pressure to the hoist to be sure lifting ring is seated in the bottom of the hook and the hook is properly alignèd.

4. Whenever the hoist is lowered sufficiently to make the ropes slack, the operator should check before makıng another lift to be sure the wire rope is properly reeved on the drum.

5. Attach a sufficient number of guide ropes so that control of the load being moved may be maintaıned. A minımum of two guide ropes will be used at all tumes. Bulky items such as stabilizers, lobes, etc., will have a minimum of four guide ropes. In every rase a sufficient number of guide ropes will be used to prevent swinging of the load. Be sure that ropes are long enough for handlers to position themselves so that they are not under the load.

These check lists are from the AEC Health and Safety Information memorandum, 1ssue No. 301, November 5, 1970.

" If cracks, excessive throat opening, or twisted hooks are discovered, call the Operations Engineering Inspector. 
6. Check intended movement path. Is it clear of personnel? Are there areas where guide ropes or controls must pass around or over obstructions? Is the intended destunation site ready to receive the load?

\section{Check During Operation}

1. Be sure you have proper clearancc for movement.

2. Position yourself on the pendant side of the hoist. This will give you maximum clearance from the unit being liffed and will prevent entanglement of electrical and lifting cables.

3. Lift the load carefully to prevent cables, chains, and sling from being shockloaded. Sudden starts, stops, or reverses must be avoided.

4. Raise the load only high enough to clear obstructions.

5. Do not travel loads over workers. If they cannot stand aside, stop the load unt il the area can be vacated.

6. Do not permit the operator or guide rope handlers to become distracted. Overhead movement of equipment demands complete attention.

7. Be alert for any variations of the hoist operations (cables out of drum guides, cables twisting, brake slipping, hoist problems, or travel diffirulties, etc). If you experience any malfunction or suspect any damage during hoisting operations, lock and tag the hosst and place it out of service and report the proble : to cognizant supervision and the Maintenance Organization at once. This is ynur obligation to the next user of the hoist.

8. Do not leave load suspended in the aur. If a short delay in movement is experienced, lock the controls.

In addition, all safety devices should be checked for malfunctions, and air or hydraulic sys tems should be checked daly for deterioration or leakage.

Hoisting equipment may be operated by one person. However, many points must be taken into consideration when a jib crane, monorail, or bridge crane is operated by one person. A knowledgeable person must assist him by using the standard hand signals shown in Figure 8 .

Standby cranes and any crane which has been stored in place or otherwise not used for six months or more shall be inspected by the Operations Engineering Inspector before being used.

Reference to the publication Rigging Equipment Manual--Design, Fabrication, Inspection, Use, and Testing, SLA-73-0564, November 1973, will be useful when slings, cables, chains, strongbacks, etc., are used with hoisting equipment. 


\begin{tabular}{|c|c|c|}
\hline $\begin{array}{l}\text { HOIST With foresrm vertical, foretinger } \\
\text { Dointing uD. move nano in smill norizontal } \\
\text { cicle }\end{array}$ & $\begin{array}{l}\text { OOWER With arm extended oowmwzo. } \\
\text { lorefinger Dointing oown. move nond in } \\
\text { small horizontal arcles. }\end{array}$ & $\begin{array}{l}\text { USE MAIN HOIST TOD tist on neso. } \\
\text { inen Use IEgular Signais }\end{array}$ \\
\hline $\begin{array}{l}\text { USE AUXILIARY HOIST. TOD } \\
\text { elDow with one hano. Inen use } \\
\text { regular signals. }\end{array}$ & $\begin{array}{l}\text { TRAVEL. Arm extended forwerd, nand } \\
\text { ODen and singniliv raseed, moke Dushing } \\
\text { motion in direction of travel. }\end{array}$ & $\begin{array}{l}\text { DOG EVERYTHING. Clasp nands in } \\
\text { tront OT DOOY. }\end{array}$ \\
\hline 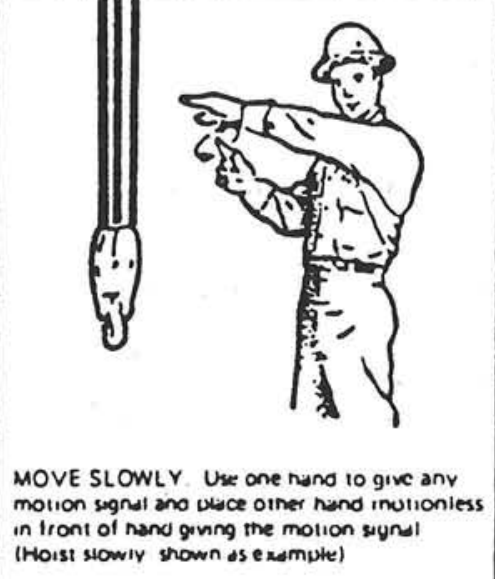 & $\begin{array}{l}\text { STOP. Arm exiended, paim somn. now } \\
\text { nosition inidiy. }\end{array}$ & $\begin{array}{l}\text { EMERGENCY STOP. Arm extended. } \\
\text { Daim dOWm. move nand rapidiy rignt and } \\
\text { lett. }\end{array}$ \\
\hline
\end{tabular}

Figure 8. Standard hand signals for controlling crane operations 
Appendix G

\author{
Operators Manual \\ for \\ Industrial Handling Trucks \\ by Frank Sayner, 3132
}

\begin{abstract}
ACKNOWLEDGMENT
The author would like to thank the Clark Equipment. Company and the Yale and Towne Manufacturing Company for permission to use their driver's manuals as references to this work.
\end{abstract}




\section{Chapter I}

\section{Responsibilities of the Fork Lift Driver}

You have been selected to operate a fork lift because of your special qualifications. As an operator, you have certain responsibilities which no one else can carry out for you. It is the purpose of this manual to inform you of these responsibilities and to help you in meeting them.

In many instances, the proper handling of Corporation property and materials will depend entirely upon your judgment and your handling of your machine. Therefore, it is important that you understand the Corporation policy and what the Corporation feels to be safe and efficient operating procedures and that you follow them.

\section{Responsibility for the Machine}

Although daily service checks are performed by specially trained men, you, as operator of the lift, must make an additional check before the forks are started and moved from the yard. A check-off list such as the one below should be used. This list should be memorized so that it may be used almost automatically each time you use your fork.

I. When approaching the fork, check underneath for leaks

2. Check the tires.

3. Climb into the driver's seat and set the controls in neutral.

4. Gas Fork Trucks

Start and warm up the engine before moving a gas fork truck. Check fuel and oil gauges with engine running. After the engine warms up, check the temperature gauge.

This simple check requires little of the operator's time and can result in considerable savings in repair costs and in manhours lost. The Maintenance Section of the Motor Pool Division has qualified men and proper tools and equipment to keep the machines on the job. but their work is simplified when the operators himself exercises common sense and reports troubles before the machine is moved. No operator is expected to drive a faulty machine. If during the day you notice anything wrong with your machine, report it to your supervisor at once. It will then be his decision whether or not to report it to the motor pool. 
The operator is responsible for knowing how to use his machine properly. By proper use, the machine is kept on the production line and you not only preserve the equipment and decrease the need for spare parts, but also save the time of skilled repairmen and avoid the overtime use of other equipment while the one you are supposed to use is being repaired. Finally, your skill as an operator is determined, in part, by the way a machine you use is cared for.

\section{Responsibility for Material Handled}

The responsibility for the material being handled is yours. When you pick up a load with your forks, you pick up the responsibility at the same time. If the load is improperly stacked or blocked, don't pick it up until it is right. For once you have accepted it, it's your problem; you have accepted the responsibility for delivering that load to its destination, undamaged and ready for use.

When damage occurs to material you are handling, report it immediately to your supervisor and to the receiver. At Sandia, much of the equipment you will handle is delicate and can be damaged by dropping or jarring. It is far better if the damaged article is tested here rather than having it shipped out to fail in the field. Only by making a report to your supervisor can you relieve yourself of the responsibility for the damage caused.

The operator is also responsible for the safe and efficient stacking of material, particularly in areas where space is at a premium. It should be stacked closely with the material that will be needed first in the most accessible location. If, at some later time, material must be moved to gain access to material behind it, always be sure that that the original stacking order is restored.

Stacking should be performed skillfully and with a minimum of maneuvering. Each maneuver and approach should be final and exact. Abrupt stops, speeding, "cowboying," and other unsafe practices result in damaged material and are a distinguishing mark of the immature and unsafe operator. In every instance, work and drive safely and your job will go easier.

Material should be stacked neatly so as to leave passageways between the stack which will permit storekeepers or packers to get to needed material. Unless authorized by your supervisor, no material should be stacked in pedestrian aisles, doorways, or roadways.

-Chains, ropes, security covers, and other handling equipment 
should be removed from the truck as soon as the need for them has passed. No improvised covers or windshields will be permitted on Corporation trucks. The working area must also be clean of boards, trash, and other obstacles before work is begun. While it is not entirely your responsibility to insure that working areas are clean, it is your responsibility to work efficiently in a safe area; therefai: you had better clean up the obstacles or notify the supervisor of the area concerned.

The speed at which you will be able to work will be determined by the type of loads you are handling, the condition of the roadway and area you are working in, and the volume of foot or vehicle traffic that is moving through the work area. Never move at a speed at which there is any danger of your losing control of your machine or the load it carries.

\section{Responsibility for Fire Prevention}

The operator must not block fire fighting equipment with his truck or his load even for a short time. Inflammable or combustible materials must not be carried inside a warehouse without permission.

\section{Responsibility for Security}

Although security is of prime importance to every employee at Sandia, it will be discussed only briefly because it is a subject in itself. All security regulations must be complied with. That is the basic rule. When in doubt, find out what the regulations are before you handle classified material. Your supervisor will be glad to answer any security questions for you. Generally, the operator is responsible for the visual security of his load, and he must arrange and keep the security cover in place. The operator is also responsible for placing the load in an authorized area. Most unauthorized and authorized storage areas are so marked.

\section{Responsibility for Safety}

As an operator, you are responsible for your own safety and the safety of others working about you. Approved operating practices are detailed in each section of this manual; it is your responsibility to see that they are followed. 


\section{Chapter II}

\section{THE FORK TRUCK}

\section{Its Care and Operation}

Your fork truck is your partner, your tool for doing your job. You supply the skill and brainwork, and your truck supplies the muscle. For this reason, its proper operating condition is of more than just passing importance to you. Each one of the operations you perform with it - starting, stopping, backing up, or maneuvering - must be efficiently performed if you are to perform your job in the manner you would like. An improperly operating machine makes it difficult to do a good piece of work, one that you can be proud of. Besides your natural pride in a job well done, the proper operation of your fork will make your job easier and quicker. It will also reduce deadline time and maintenance costs.

\section{Fork Lift and Tilt System}

The spread of the forks is adjusted manually to fit the width and the shape of the load. This adjustment is accomplished by pulling up the locking pin which holds each arm of the fork in place and by sliding the arm along the track to the desired position. The locking pin is then replaced. Both bars should be moved equal distance so that the load will be balanced in the center of the carriage. (Fig. 1).
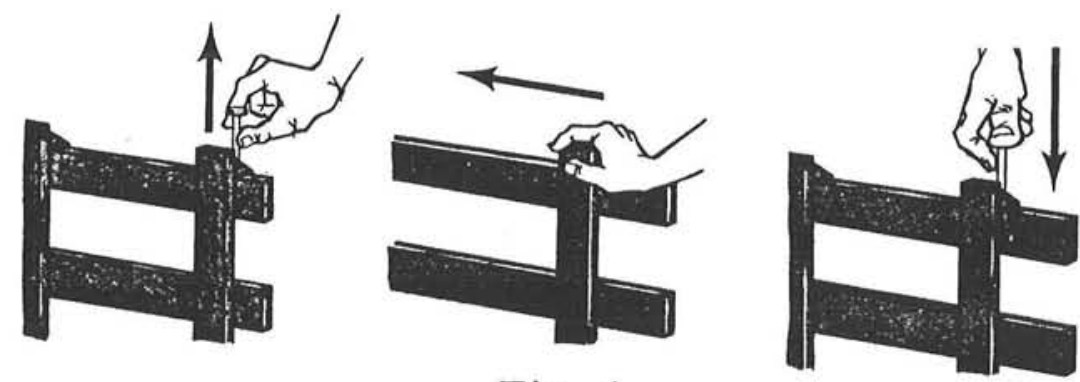

Fig. 1

On most machines, an engine-driven hydraulic pump supplies the power for the lifting and tilting mechanisms. The pump and its system is controlled by levers (see Figure 2). The load is raised or lowered as the lift lever is moved backward or forward. The tilt lever is moved backward or forward. 
Fluid Drive With Clutch

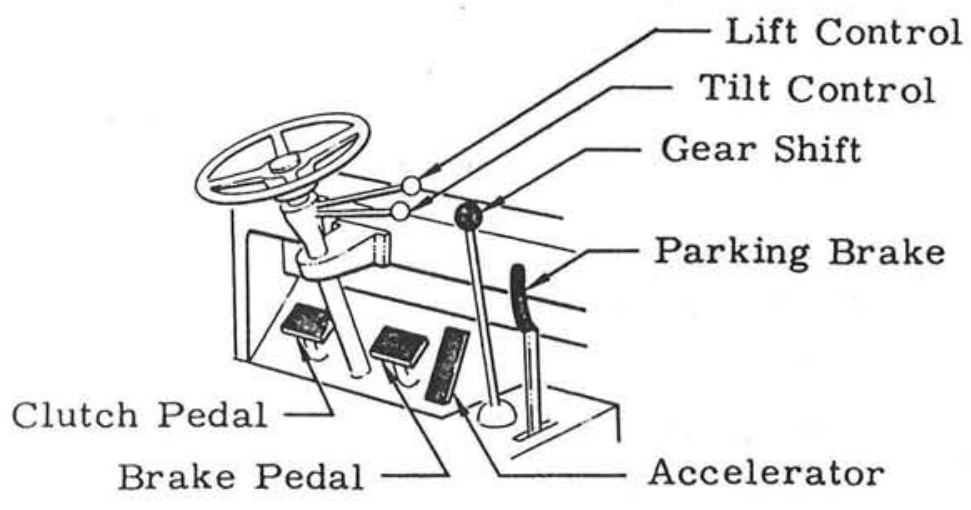

Fig. 2

\section{The Gasoline Fork Truck}

Transmission

Three types of transmissions are found on the trucks used at Sandia Corporation:

I. Conventional shift with clutch (soon to be discontinued)

2. Fluid drive with clutch. (Fig 2)

3. Torque converter (Fig. 3)

Torque Converter

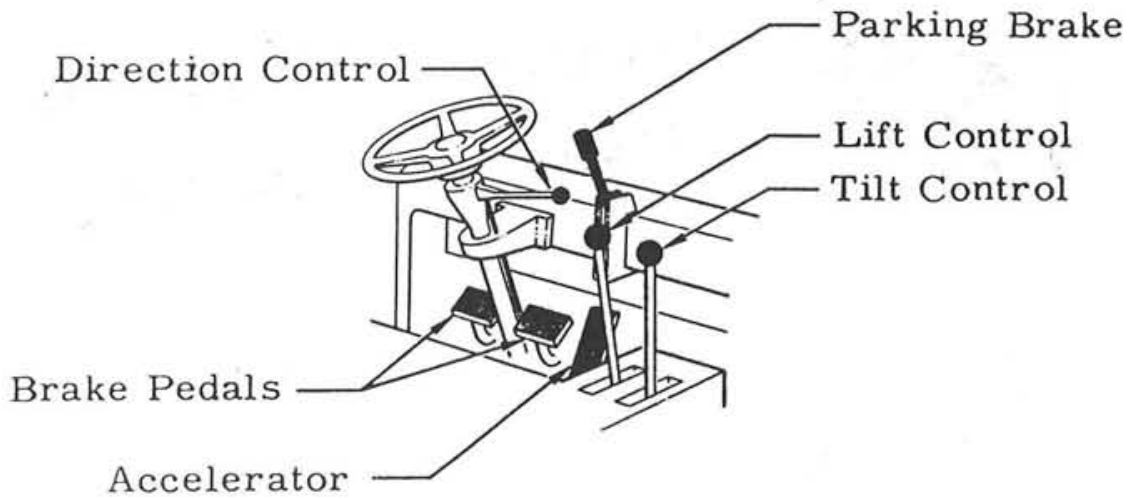

Fig. 3 
Since several different makes of fork trucks are used, and since each manufacturer often uses a different type of transmission for different sizes of fork lifts, no attempt will be made here to explain them. Your supervisor or lay-out operator will explain the various types of equipment that may be assigned to your organization.

\section{Speeds}

On fork trucks that have more than one speed range, the low gear range should be used for moving heavy or bulky loads, for moving up and down ramps, and for going through areas where maneuvering is difficult.

\section{The Electric Fork Truck}

The electric fork truck receives its power from a storage battery that not only supplies the electrical energy to drive the truck but also serves as ballast to offset the weight of the load being carried. Since much of the material to be moved is inside buildings, electric trucks are used in preference to gasoline trucks because the electric trucks operate more quietly and without dangerous and unpleasant exhaust fumes. Electric trucks are also capable of maneuvering in less space than that required for gasoline trucks.

Electric trucks have solid tires and should be operated only on paved surfaces.

\section{Starting}

I. The battery should be completely charged. Normally, it is recharged at the end of each work day. When the battery must be charged in the work area, personnel from the Motor Pool Division (4573) should be present to instruct the operators in the following charging procedures.

(a) connecting charger to battery

(b) setting timer on the charger for proper charge rate

(c) checking battery water level

(d) safety procedures

No one should attempt to recharge a fork lift battery without instructions.

2. On machines having ignition switches, the switch must be "on."

3. The operator must be on the seat before the truck can be placed in motion. A safety switch beneath the seat cuts 
off current to the motor when he seat is raised. The automatically-applied brake system should be checked at this time also; this system should be operating when the seat is in the raised position.

4. Controls, brake, and horn should be checked to ensure that they are operating satisfactorily.

\section{Driving}

When the direction control is in its neutral position, no current flows to the drive motor. To start the machine, this lever must be placed in the first point of power. On some machines, starting is accomplished by simply moving the control switch lever from its neutral position to either forward or reverse position. On other makes, the directional control lever must be moved to the desired position before the speed control lever can be moved to the first. butint of power.

When operating in the first point of power, the machine may be inched into position by depressing and releasing the foot brake, since applying the brake trips a switch that cuts the flow of current to the drive motor. When the brake is released, the current will again flow to the drive motor and the machine will move. In all other points of power, the controls must be returned to first point of power after applying the foot brake before the machine will move. This safety feature is built into electric trucks to prevent the accidents and damage that might occur if the machine were to suddenly start in second, third, or fourth point of power.

\section{Proper Use of Points of Power}

First point of power is used for starting and as described above. Second point of power will cause the machine to move faster but should be used with judgment; operation in either first or second point of power for long periods will cause the acceleration resistor to overheat and smoke. When this condition is observed, the machine must be stopped and allowed to cool before resuming operation. Otherwise the resistor will be damaged.

Third point of power moves the machine even faster and produces the most power to move heavier loads or to climb ramps. Third or fourth point of power is the recommended point for operating with a light load or in an unobstructed area.

Fourth point of power produces the greatest speed of the machine, but does not produce as much torque as does third point. For this reason, fourth point of power is used only in open aisle ways or on longer hauls. It should not be used for going up ramps. 


\section{Warnings}

1. Never change directions without coming to a complete stop. Such action places a great strain on the drive assembly and motor; it also burns the contact points, and wears the tires.

2. Never fail to make positive contact with the points of power when operating the accelerator, or the lift and tilt control levers. When a loose contact is made, the points arc and burn.

3. Never travel for long distances in low speed. Of course, there may be occasions when it is necessary, and in such cases it is permitted.

4. Never turn the steering wheel while the truck is stopped.

5. Never stall an electric fork truck and leave the controls in an operating position. Such action invariably results in a burned out drive motor.

\section{Handling the Fork Truck}

Some of the distinguishing features of a fork truck have been described. We are now ready to list and to discuss the approved practices that are followed in the everyday operation of a fork truck:

\section{Driving Forward or Backward}

1. Obey all vehicle and traffic regulations.

2. Before changing direction of motion, come to a complete stop.

3. Be careful to avoid overhead obstructions - sprinklers, overhead doors, etc.

4. Face in the direction of motion; never back up without looking first.

5. Drive in reverse when going down a ramp or other grade and carrying a load.

6. Drive in reverse when carrying a high or a bulky load that obstructs clear vision.

7. Sound the horn whenever approaching anyone from the rear.

8. Start high-capacity trucks in low range and shift up when conditions permit. 


\section{Turning}

Since fork trucks are steered by the rear wheels, the following must be observed:

1. Allow for the swing of the rear end when going forward.

2. Allow for the swing of the forks or of the load when going backwards.

3. Drive slowly while making turns.

\section{Parking}

The following sequence must be followed when parking or leaving a truck:

1. Lower the forks until they are flush with the floor. This operation should always be performed with the motor running so that full control is maintained over the machine.

2. Move the shift lever to neutral. This step is particularly important on electric machines.

3. Turn off the switch.

4. Set the parking brake.

\section{General Rules of the Road}

Expert drivers always abide by this list of rules:

I. Remain alert at all times for other vehicles, pedestrians, and obstacles.

2. Drive only at a speed which is safe for the area in which you are working.

3. Always face the direction of motion. Always drive in the direction which gives you the better vision.

4. Always remember that speed is not always a time-saver. Accuracy is far more important because it reduces the number of unnecessary movements for both the machine and the driver. Accuracy - helped along by care and caution - also reduces the amount of damage which you will inflict upon the material you handle. At Sandia, care and caution in handling material is far move desirable than speed. 


\section{Chapter III}

\section{MATERIAL HANDLING PROCEDURES}

Even though you may be a new employee, you have probably noticed that material handling here at Sandia is unlike material handling at other companies. Much more care is, of necessity, given to material because most of it is both expensive and delicate. Also, many devices which come through the loading docks at Sandia are essential to the weapons program of the country. These devices are expected to be reliable, and Sandia - or its contractors - makes them that way. But no matter how well a device is made, it seldom functions reliably after it has been dropped or struck by a fork.

Occasionally, an accident may happen. Whenever one does, however, the damaged package must be reopened, tested, and packaged again, even if there is no apparent damage. As you can see, a great deal of expense and time can be involved in the most minor of careless mistakes. Your supervisor may be interested in your getting the job done in the shortest possible time, but he never wants you to sacrifice careful handling to gain speed.

In most manufacturing plants, you might be expected to move large number of units in a hurry, and the large volume moved would compensate for any loss caused by the hurried handling. At Sandia, such is never the case; in spite of pressing time schedules, care and caution are the rule for handling material. And there is good reason for the rule: many of the items produced by Sandia are "one-of-akind," single components produced for testing and evaluation. More can't be ordered from some supply house; the one you are handling is all there is. For example, one component was fabricated, tested, packaged and delivered to the loading dock. This component cost a lot of money, but - more important - it was needed immediately at one of the testing sites. A fork lift driver who was in a hurry made a pass at the package and picked it up. He moved it a few feet and dropped it. The packaged component fell a distance of three feet. As a result, several engineers had to work overtime to test and repair the device. After repair and reassembly, it was repackaged, but a special plane had to be chartered to get the device to its destination on time. The additional expense incurred because of one man's haste was equal to that man's total salary for at least six months.

Not everything, of course, has to be handled as if it were a case of eggs. But, since no one can tell how delicate a package is from looking at it, each fork lift driver at Sandia is expected to handle all 
material efficiently and well; if he does that, he will create no problems. Operators often could avoid damaging sensitive equipment by asking the project engineer for special handling instructions.

Most of the loads handled here will be on skids or pallets because they are easier to move, but the driver is also expected to be able to handle a wide variety of loads. Some loads will be single boxes, drums, or crates that are easy to handle, but others will be loose boxes, reels, or miscellaneous items that require careful treatment to avoid spilling. Therefore, before any load is picked up. it should be checked to determine that it is properly loaded and ready to move.

To secure items such as testers and AN cans, it is recommended that web straps be used to bind the articles together. When strapped together, they can then be handled safely with little chance of one or more of the items slipping off of the skid. Although reinforced tape can be used on cartons, it should never be used on testers, AN cans, or cartons that are labeled or stenciled because the adhesive substance on the tape ruins the labels. Tall instrument racks and similar items should be bound to the mast of the fork truck with a strap or rope. Furniture pads should be used to avoid scratching delicate instrument cases.

Again, once you have picked up the load with the forks, the responsibility for its safe delivery is yours.

\section{Steps in Picking up a Load}

The proper method of picking up a load is as follows:

I. With forks adjusted for maximum spread under the load, approach the load squarely and at slow speed to avoid jarring or overturning the load.

2. Drive forward uritil the load rests against the mast. The forks must be long enough to reach at least three-fourths of the distance under the load.

3. Raise the forks until they are tight against the bottom of the load.

4. Tilt the forks back until the center of gravity of the load shifts towards the backrest. Degree of tilt will vary with the type of load - cans, package, machinery, etc.

5. Lift the load slowly up to four or six inches for travelling. (When tilting and lifting the load, make certain that there is adequate clearance on the side as well as above. Much damage can occur when the operator disregards this rule.) 
Placing the Load on a Truck

1. Drive up to the truck and stop before starting to raise the load.

2. Raise the load to the desired height.

3. Drive forward until the load is directly above the desired unloading position.

4. Tilt the mast forward until the load is level.

5. Lower the load until it rests on the bed of the truck; then back slowly away and position the forks four to six inches from the floor for travelling.

\section{General Rules for Travelling and Maneuvering}

Since a fork truck itself is a stout, rugged piece of equipment, all of the jar and shock of an operation with it is transmitted to the material it carries; the truck, therefore, must be operated smoothly and carefully to avoid damage. For this reason, always drive backwards when carrying a bulky load that obstructs your vision or when going down ramps. Often it is also desirable, and easier, to drive backwards when travelling long distances; this is particularly true of the 15,000 pound and higher capacity trucks in summertime operation. These trucks steer better and the engine cools more efficiently when the truck is driven backwards.

When required to drive onto a van truck to load or unload, make sure that the brakes on the van truck are set and that the wheels are blocked. The fork operator should also see that the bridge plate is firmly in place and that there is sufficient clearance above and to the side of the load.

\section{Stacking the Load}

The importance of where and how to stack a load must not be overlooked; usually, there will be no problem, but - when in doubt:

I. Get complete instructions before you begin. It will save you time and trouble by eliminating unnecessary rehandling.

2. Use storage space to best advantage by stacking evenly and neatly; this is especially important around the warehouses where working space is always at a premium.

3. Observe aisle markings. Do not leave cartons or boxes sticking out into the aisle. They are an invitation to an accident.

4. Find out beforehand whether you can stack more than one pallet high. 
5. Before starting to load a vehicle make a loading plan, which will give the best load distribution for the availabie space. When heavy material is placed on a flat-bed truck, the loads should be alternated between the two sides of the bed to maintain its balance. Two or more loads on one side will have the truck leaning so badly that loading the other side will become difficult and hazardous.

\section{Chapter IV}

\section{SAFETY}

Safety regulations, to be effective, must utilize a man's early training and redirect that training to the particular job at hanc. We have all been trained since childhood to avoid those things that could do us, or others around us, harm; it wasn't too long before we were taught not to play with matches, with guns, or with other dangerous instruments. And, as we grew up, we were also taught about those machines which could, through our ignorance or carelessness, result in injury to ourselves or to another person. In most of us, these safety regulations became a part of our nature, and, though we had accidents, few of these accidents had serious consequences because we were protected by our built-in "safety consciences."

All you are asked to do now is to extend that conscience to the job you do for the Corporation. And this is something no supervisor and no safety program can do. The rest of this chapter will be devoted to telling you, the driver, how best to avoid hurting yourself, or someone else, with your fork lift. But if you do not make these regulations a part of you so that you will practice them almost automatically, they will remain just so many pages of paper. If you do use them, you will find that they not only make your job safer - but easier. In each instance, the rules presented are not only safe but - in the long run - efficient. They will save you time and, perhaps, an injury to yourself or your buddy.

\section{Safety Regulations}

In each previous chapter, you were instructed in the approved operating practices for that particular phase of fork truck operation. The practices are "approved" because they were written down directly from the experiences of veteran drives. These drivers have proven time and time again that they were the best. For this reason, the procedures which they had derived by trial, error, and common sense were presented to you to help you to become the kind of driver 
the Corporation wants on its pay roll. The safety rules which follow were also derived from their experiences - and from accident reports. Every rule here could be illustrated with pictures of accidents caused by their violation; for whenever a man is working around a running machine, that man is in some danger. The fork lift you will operate is a big machine and a powerful one. Once get your hand caught in the drive chain of the lift, and the hand is gone. The machines just doesn't have the sense to shut itself off. You are supposed, however, to have sense enough not to get your hand in there in the first place. Some of the rules below may help you avoid "losing yourself in your job."

1. Be alert. Always look in all directions before moving a truck.

2. Operate the fork truck at a safe speed. No speed limit can be set for fork lifts because too many types of trucks and situations are involved, but a safe speed is always one in which you have perfect control over your machine and the load it carries. A wide open storage lot and the inside of a van truck present different situations and different speeds are required - but the above rule will always present a guide. When in doubt, go slow.

3. Avoid bumps and holes in the street or driveway. Hitting a hole can jar and sway the load dangerously.

4. Do not use a fork lift as an elevator for personnel unless an approved safety platform is used. The platform should be so constructed that it prevents the platform from falling off the forks; and it should have guard rails and a toe board. Lifting a person on either the bare forks or an empty pallet is never authorized.

5. Do not haul "hitchhikers." Fork truck operation is a one man job. Even on cab-equipped fork lifts never permit anyone to ride with you, even if he is going to work with you at a distant location. Always ask him to find other transportation.

6. Use the right equipment for the job. Select the fork that is equipped with forks long enough to extend at least $3 / 4$ ths of the way under the load, and use one that has plenty of reserve load capacity, especially when a high lift will be necessary. But try not to use a 7,000 pound capacity truck to lift a 50-pound crate.

7. Always balance the load at its center of gravity. To do this, it may be necessary to reposition or restack it. In any case, study and know the load before you pick it up. 
15

8. Use care when handling long lengths of metal stock, pipe, or lumber. When you are required to handle any material that will not go through the gates or doorways, have your supervisor show you how to swing the material through by approaching at an angle. Avoid going over the top of gates.

9. Keep clear of the edge or loading docks.

10. Always have a guide ahead of you when going forward with bulky loads through passageways or up grades. Some suggested hand signals which you and the guide can use are: (Fig: 4)

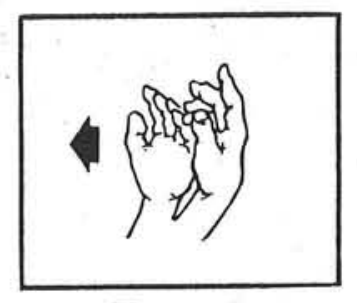

Travel

Forward

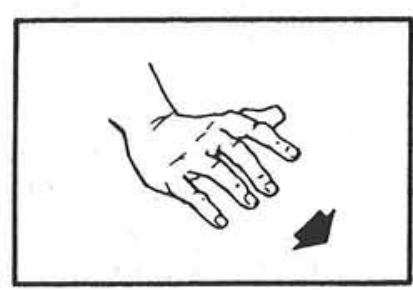

Tilt Down

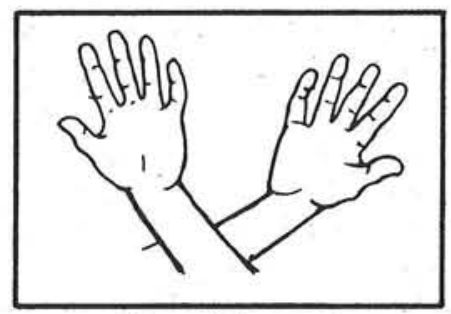

Stop Travel

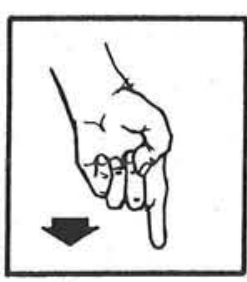

Lower

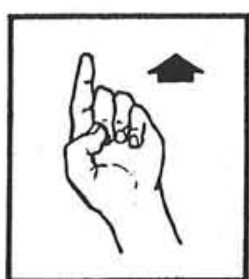

Raise

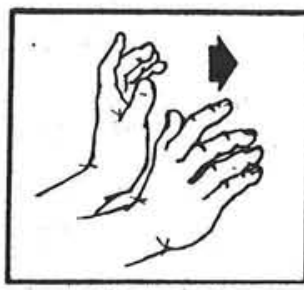

Travel

Backward

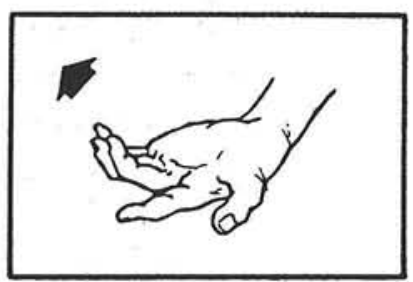

Tilt Up

Fig. 4

11. Drive "defensively." Drive as if everyone were intending an attack on you personally. In the Tech Area there are a lot 
of people and a lot of trucks. Some of the people are smart and alert. Some aren't. And you can't always tell which is which by just looking at them. They'll walk in front of you without looking. They'll stack material in aisles. They'll push or drive trucks right in your road. If all else fails, they'll ram you from the rear.

There is no "maybe" about these statements - one of them will happen and to you. Statistics prove this. The only way you can keep those stupid acts on another person's part from turning into your accidents is to drive always as if the other people around you could be counted on to do the wrong thing at the wrong time. And they will. So be ready to stop or to turn out of their way. Keep your machine under control at all times.

\section{Conclusion}

The rules discussed above do not give you an answer for every situation you will face. No set of rules could do that, but if you will apply these rules and the principles of common sense, good judgment, and good driving to them, they will prevent you from getting into what may be a serious accident.

If, in spite of all you can do, an accident happens, it is your responsibility, as a driver, to carry out the following procedures:

1. Notify the Medical Department. The Corporation ambulance can reach any part of the Tech Area in two minutes; and since the Medical Department is better qualified than you are at first aid, it is not recommended that you try to render first aid. If a man should be profusely bleeding, of course, try to stop the bleeding; artificial respiration also should be administered when necessary - but after the ambulance has been called by you or someone else. ,

2. Notify your Supervisor. You should always be the first one to tell your supervisor when you have damaged material or been in an accident. No matter how slight the damage or minor the accident, notify him. He will then notify the Safety Engineering Department. Should the accident occur in an area away from supervision, you should call a Safety Engineer if the accident is serious.

3. Remain at the Scene of the Accident. In case there should be an investigation resulting from the accident, nothing should be moved. 
Authorized Operating Personnel

\begin{tabular}{lll} 
Name & Org. Date \\
Broyles, Theresa & 1254 \\
Cleary, Richard & 1254 \\
Clevenger, Bob & 1254 \\
Devlin, Gary & 1254 \\
Donovan, Guy & 1254 \\
Drennan, Scott & 1254 \\
Hogan, John & 1254 \\
Holman, G.T. & 1254 \\
Jobe, Dan & 1254 \\
Johnson, Mark & 1254 \\
Johnston. Bob & 1254 \\
King, Curtis Jr. & 1254 \\
Lundstrom, Joe & 1254 \\
McDonnel1, John & 1254 \\
McGovern, Harry & 1254 \\
Naro, Mark & 1251 \\
Nations, Dennis & 1254 \\
\hline
\end{tabular}


Appendix H (cont.)

Authorized Operating Personnel

$\begin{array}{lll}\text { Name } & \text { Org. } & \text { Signature } \\ \text { Osborn, Rick } & 1254 & \\ \text { Palkovic, Ray } & 1254 & \\ \text { Petmecky, Don } & 1254 & \\ \text { Schaub, Mike } & 1254 & \\ \text { Seals, Bobby } & 1254 & \\ \text { Tanner, Wayne } & 1254 \\ \text { Velasquez, Dan } & 1254 \\ \text { Ziska, Gerold } & 1254\end{array}$


SAFE OPERATING PROCEDURE

FOR

USE OF FLAMMABLE LIQUIDS

AT

PBFA II, BUILDING 983

Appendix 6 


\section{Table of Contents}

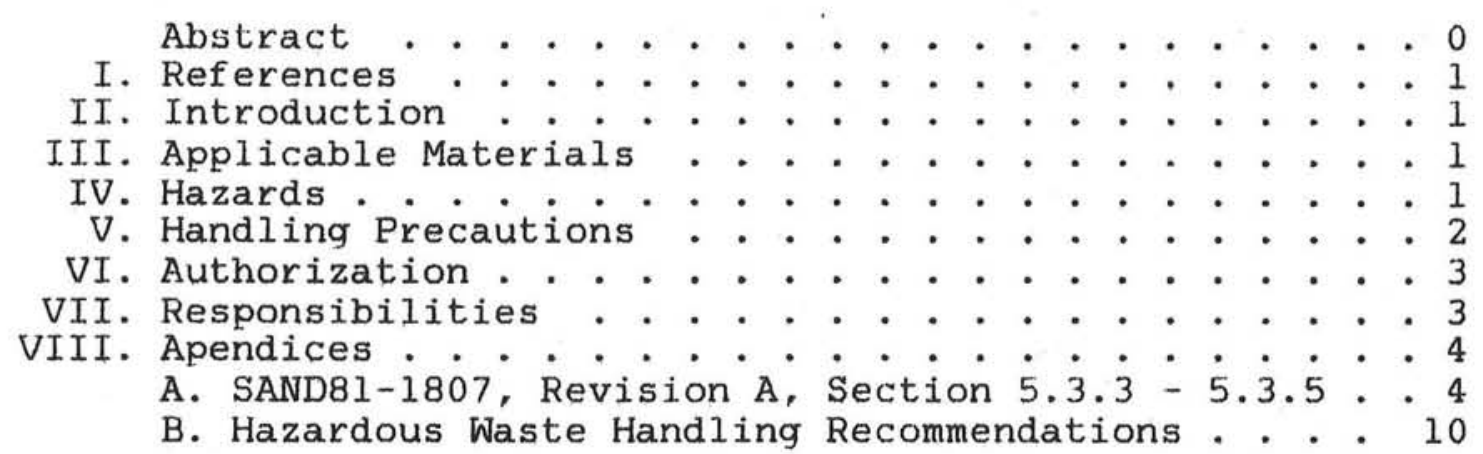


SAFE OPERATING PROCEDURE

FOR

THE USE OF FLAMMABLE LIQUIDS

AT

PBFA II, BUILDING 983

\begin{abstract}
This SOP outlines proper procedures for use and disposal of flammable liquids in and around Building 983. Improper handling of these materials can result in fires that could cause injury and destruction of property.
\end{abstract}

T. H. Martin, 1250 date

S. A. Goldstein, 1254 date

D. R. Parker, 3311 date

J. M. Phelan, 3311 date

D. L. Rost, 3316 date

A. M. Fine, 3316 date

Distribution:

1233 G. A. Zawadzkas

1254 S. A. Goldstein

1254 G. L. Donovan (2)

1254 Division Members

3311 D. R. Parker

3311 J. M. Phelan

3316 D. L. Rost

3316 A. M. Fine

3662 D. D. Knott

3662 V. L. Duke

D. D. Knott, 3662 date

V. L. Duke, 3662 date


SAFE OPERATING PROCEDURE

FOR

THE USE OF FLAMMABLE LIQUIDS

AT

PBFA II, BUILDING 983

\section{References}

All rules and standards in effect for specific areas within Bldg. 983 shall be complied with in addition to the guidelines in this Safe Operating Procedure.

\section{Introduction}

Flammable liquids are used throughout Building 983 as solvents and cleaners, This Safe operating procedure is designed to ensure the safe handling, storage, use, and disposal of these fluids.

\section{Applicable Materials}

Flammable liquids used in Bldg. 983 include:

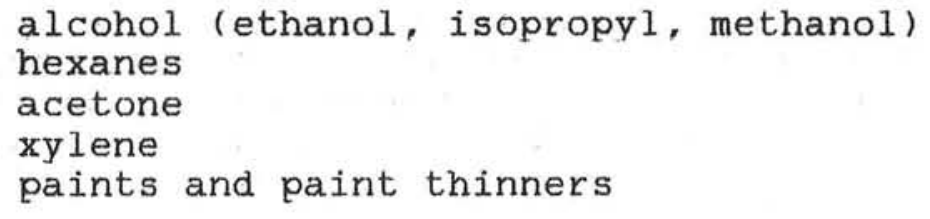

IV. Hazards

A. Accidental combustion is the primary hazard in the use of flammable liquids. Because of the volatile nature of these liquids, combustion is possible even with lowenergy ignition sources. When these fluids are heated, atomized, or wicked (as into a rag), the combustion hazard increases.

B. Toxicity is another possible hazard for users of these liquids. Contact with flammable liquids may cause irritation to the skin, and inhalation of vapors can be hazardous. 
SOP - Use of Flammable Liquids Blda. 983 / page 2

C. Improper handling or disposal of these materials can increase the severity of the above hazards and may pollute the environment.

V. Handing Precautions

A. Flammable liquids within Bldg. 983 must be stored in approved facility flammables cabinets in approved containers (see Appendix A).

B. Flammable liquids to be used at worksites within Bldg. 983 shall be withdrawn from facility flammables cabinets in plastic squeeze bottles or other unbreakable containers with tops. Quantities taken to worksites shall be limited to the minimum amount required for the job. The liquids listed above are all class $1 \mathrm{~B}$ flammables. Quantities of fluids in this class should be further limited to 1 quart per non-breakable container removed from storage. For other flammable liquids, refer to Appendix A.

C. All containers, including those used at worksites within the facility, shall be labeled as to the type of liquid it contains.

D. Flammable storage cabinets and worksites where flammable liquids are being used shall be designated NO SMOKING areas. Personnel using flammable liquids shall be responsible for posting such areas.

E. Proper ventilation is required before use of any flammable liquids. Respirators may be required for specific areas (i.e. confined work spaces) or for certain materials. Respirators will be provided, and their use monitored by Industrial Hygiene Division, 3311.

F. Rags used with flammable liquids shall be disposed of in approved fireproof containers as soon as possible after use.

G. Flammable liquid waste shall not be poured in facility drains or sewers except as approved in the sanitary system disposal guidelines developed by the Environmental Protection and Hazardous Waste Management Division, 3314 (see Appendix B). Flammable liquid waste shall be packaged in approved containers and disposed of by filling out a Chemical Waste Disposal form. Division 3314 will arrange for pick-up of the waste.

H. Flammable liquid spills shall be cleaned up immediately. Rags or absorbent material used shall be disposed of properly as in "F" above. 


\section{SOP - Use of Flammable Liquids Bldq. 983 / page 3}

VI. Authorization

Industrial Hygiene, Division 3311 approves the initial use of solvents within sections of the accelerator. Once approved, procedures may be used until they are changed or solvent quantities are increased. Division 3311 will assist Division 1254 in establishing procedures for use of solvents in specific accelerator areas by measuring personnel exposure and providing ventilation requirements and/or respirators where needed.

VII. Responsibilities

PBFA II Operations, Division 1254, will be responsible for authorizing access to flammable liquids within Bldg. 983. PBFA II Operations will designate authorized facility flammables cabinets and ensure proper storage procedures are followed. 


\section{Appendix A}

Sandia National Laboratories Safety Manual

SAND81-1807, Revision A

Printed August 1984

section $5.3 .3-5.3 .5$ 


\subsubsection{Flammable Liquicis}

\subsubsection{Classification}

liquids are classified as flammable or combusti. he acoording to Mash point and boiling point as defined in Table 5.1. Flammable liquids vaporize at relatively low temperatures, and usually obtain sufficient heat at room temperature to be easily ignited. Combustible liquids usually require additional heat hefore ignition can occur.

Examples of flammable and combustible liquids are included in the following listings:

\section{Flammable liquids}

Class IA: Benzol, diethyl ether, aerosol paints. JP.4 fuel. gasoline. methyl sulphide, and napthas

Class 113: Acetone, amyl acetate, ethyl alcohol, methyl ethyl ketone. isopropyl alcohol, toluene, tet rahydrofu. ran. lacquers, and carbon disulphide

Class IC: N-propyl alcohol, n-dibutyl ether, and xilene

\section{Combustible Liquids}

Class 11: Fuel uiis Nos, 1, 2, 3, 4, and 5, mineral spirits, turpentine. Il'ti fuel, enamels, glacial acetic acid, and furmaldehyde

Class 111 A: Aniline, butyl cellosolve, fuel oil No. 6. cycluhexanol. kerosene, and dimethylaniline

Class 1113: Mlineral vil. triethanolamine, propylene glvoul. plvierine

\subsubsection{Bulk Storage}

Bulk supplies of flammable liquids are stored in the Hazardous Materials storehouse operated by General Stores. Paints, lacquers, and solvents are kept in a specially protected building operated by General Stores.

\subsubsection{Operational Storage}

Supplies of flammable liquids in operating areas are ordinarily limited to the amount consumed in an average day's operations. Quantities of nonstock. special-purpose items are held to a minimum consistent with rate of use and speed of procurement. Fuel oil and gasoline may be stored in operational areas in limited quantities, if necessary, in containers approved by the fire marshal.

\subsubsection{Containers for Flammable Liquids}

\subsubsection{Size of Containers}

Table 5-2 serves as a guide in the selection of container sizes based upon the flammable properties of the liquid and the container construction. When flammable liquids are purchased for laboratory use, the commercially available size nearest to that shown in Table $5-2$ is usually obtained.

\subsubsection{Manufacturers' Containers}

The use of original manufacturers' containers is encouraged unless the size of the container is in extreme violation of Table 5-2. For example, ligroin and pentane are purchased in 2-kg quantities in glass bottle containers instead of in pint bottles. As long as the $2 \cdot \mathrm{kg}$ container remains untouched in Chemical Stores, no unacceptable fire hazard exists. However, when the container is handled, the possibility of drop. ping it increases in proportion to handling and dis. pensing. To minimize the hazard, a pint quantity should be withdrawn into a pint-size working contain. er, and the large container should be returned to a safo location where it will not be distruhed.

\subsubsection{Glass Bottles}

The size of glass bottles is shown in Table 5.2 . Se. preceding paragraph for use of working quantitics.

\subsubsection{Polyethylene Containers}

Because of the static spark generation hayard when pouring Class I flammable liquids, the maxi. mum size of polyethylene containers is $1 \mathrm{pt}$.

\subsubsection{Safety Cans}

Safety cans for flammable liquids are required for use where glass bottles could easily break. Fxamples are machine shops, paint and special-product coating and spraying areas, plastics shop, maintenance shorm. etc. Flammable liquids that corrode terneplate: ator that must be free of contamination should be kept in stainless steel safety cans. One gallon of a flammatsle. liquid spilled and vaporized in a room can form a:. explosive mixture with the air which, if ignited. coulc? cause extensive property damage and human injury w? death. One-gallon stainless steel safety cans are avait able from General Stores. 


\begin{tabular}{cccc}
\hline \hline $\begin{array}{c}\text { Table 5-1 } \\
\text { Liquid }\end{array}$ & Clammable and Combustible Liquid Classification \\
\hline Flammable & IA & Flash Point $\left({ }^{\circ} \mathrm{F}\right)$ & Boiling Point $\left({ }^{\circ} \mathrm{F}\right)$ \\
& IB & Below 73 & Below 100 \\
& IC & 73 to 100 & 100 or higher \\
Combustible & II & 100 to 140 & \\
& IIIA & 140 to 200 & \\
& IIIB & Above 200 & \\
\hline
\end{tabular}

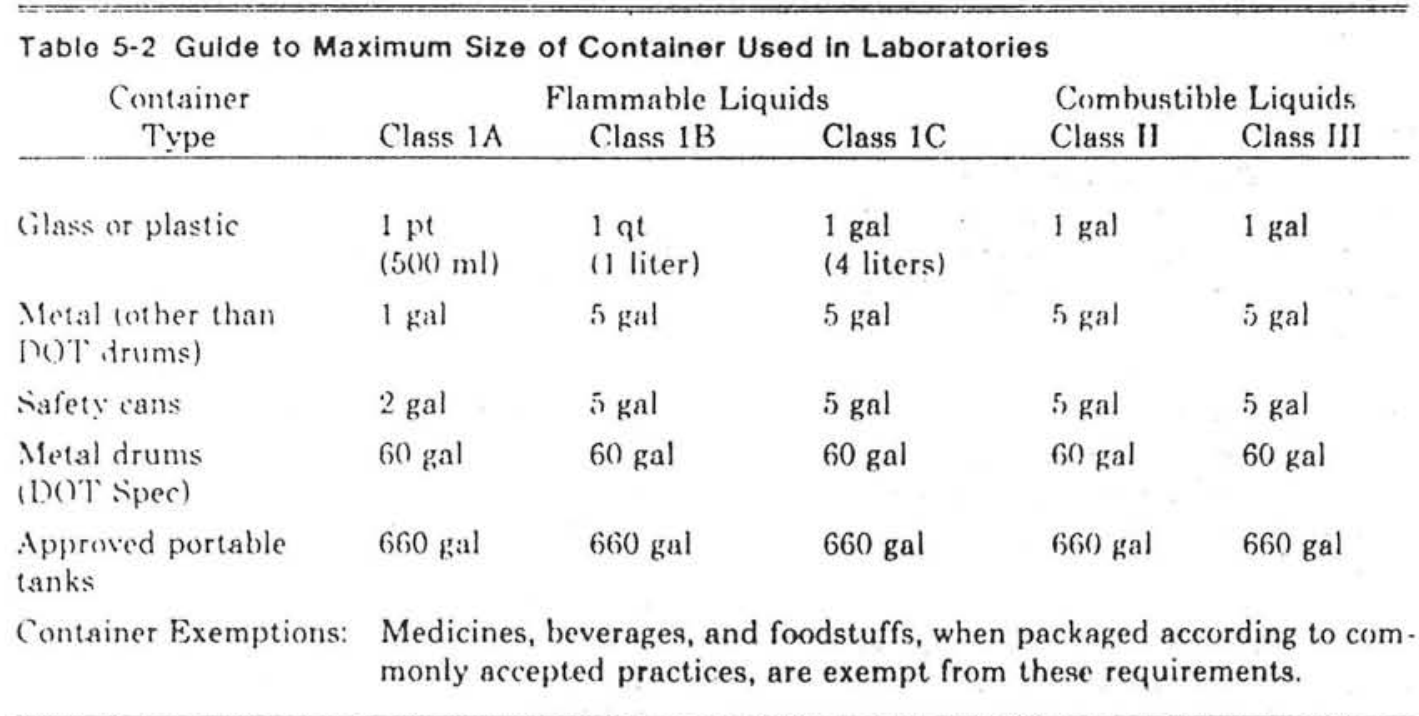




\subsubsection{Dip Tanks}

Tanks used for dipping and cleaning with flamma. ble liquids are equipped with covers held open with fusible links. Larger wheeled tanks are limited to 50 -gal capacity and must be approved by the fire protection engineers. Portable dip tanks, plunger cans, drip cans, dispensing cans, etc., are available from General Stores and manufacturers (Table 5-3).

\subsubsection{Metal Contalners of Coating Materlals}

Pails up to a 5-gal capacity containing flammable noncorrosive liquids or congealing products such as paints, lacquers, enamels, and adhesives may be brought into operating areas. The covers of these containers should be kept securely in place except when dispensing the product into smaller open containers used for actual application.

\subsubsection{Stationary Drums}

Drums or tanks used for storage and for the dispensing of flammable liquids shall be grounded and bonded to the receiving container.

\subsubsection{Waste Containers for Llquids}

Flammable liquid waste containers approved by the Industrial Hygiene Division and the fire protec. tion engineers shall be provided for use inside build. ings. Flammable liquid waste shall not be poured into drains or sewers except as approved by the Industrial Hygiene Division. Flammable liquids, whether soluble or not, shall not be disposed of in drains which empty. into septic tanks, specifically in Areas II, III. and V and $\mathrm{CTF}$.

\subsubsection{Containers for Waste Rags}

Supplies of loose, clean rags, or waste are stored in covered metal cans. Oily or soiled waste and rags are placed in Underwriters' Laboratories-approved metal self-closing cans. See Table 5-3 for descriptions of cans available from General Stores. Cans for oily rags are emptied daily into designated outside storage containers (usually metal garbage cans painted green) by the operating organizations. The contents of the'se containers are picked up by the Support Service. Section for disposal.

\section{Table 5-3 Stock Safety Containers}

$\begin{array}{ccc}\text { Item } & \text { Capacity } & \text { Stock No. } \\ \text { Can, short spout, no fill cap, terneplate } & 1 \mathrm{gal} & 653414 \\ \text { Can, short spout, no fill cap, stainless steel, } & 1 \mathrm{gal} & 653436\end{array}$

Type 316 , oval shape, 4.75 in. wide $x 7.5$ in. deep $\times 13.0 \mathrm{in}$. high, no fill cap. Designed to use less shelf space. Stainless steel reduces contamination.

Can, 5/8-in.-dia flexible hose in spout, has separate fill cap, terneplate.

Can, 1 -in.-dia flexible hose in spout, has separate fill cap, terneplate.

Safety can with bottom, self-closing faucet, fill cap on $\omega \mathrm{p}$, terneplate. Must be placed on workbench for dispensing.

Plunger can has a 5 -in.-dia dasher and fire baffle. Pushing dasher down pumps a fixed amount of solvent up into dasher. Ideal for wetting cloths, Protectoseal 237-C, terneplate.

Oily waste can is equipped with foot pedal. operated, hinged cover.

$6 \mathrm{gal} \quad 63 i+15$

Degreaser dip tanks are equipped with lids which will close automatically in case of fires.

Small size: $5-3 / 4 \times 5-3 / 4 \times 3-1 / 4$ in. high Medium size: $8-1 / 2 \times 8-1 / 2 \times 4-1 / 4 \mathrm{in}$. high Large size: $13 \times 13 \times 13 \mathrm{in}$. high

$\begin{array}{ll}3 \mathrm{pt} & 653427 \\ 1 \mathrm{gal} & 653428 \\ 5 \mathrm{gal} & 653430\end{array}$

$\begin{array}{ll}3 \mathrm{gal} & 653416 \\ 5 \mathrm{gal} & 653417 \\ 5 \mathrm{gal} & 6534335 \\ 1 \mathrm{gt} & 6534375\end{array}$




\subsubsection{Marking Containers}

Contents of all containers should be suitably identified, and flammability characteristics should be marked. Portable dip tanks, plunger-type cans, safety cans, and drip cans are painted red or yellow by the manufacturer. White paint is used for labeling. Stainless steel cans are not painted but are labeled with decals. plastic tape, or adhesive labels. Where space is limited, include as much of the following information as possible (listed in order of importance).

\section{FLAMMABLE OR DANGER KFFP LIGHTS AND FIRES AWAY \\ Name of material \\ Stock number of material \\ Organization number}

Stationary drums containing flammable liquids need not be painted red. A sign shall be fastened to the tank, or to the wall above the tank, bearing the following. or substantially equivalent, legend in conspicuous lettering:

\section{DANGER \\ FLAMMABLE LIQ('II)S NO SMOKING}

Flammable liquid disposal cans and commercial steel drums used outdoors for flammable waste shall be painted red and labeled with lettering as specified in the preceding paragraph.

()ily waste cans shall bear the words OIl, WASTFCAN - EMIP'TY EVERY DAY, or equivalent.

\subsubsection{Cleaning, Maintenance, and Inspection of Containers}

Comtainers for flammable materials shall be kept clean. Containers shall be thoroughly cleaned before they are used for another purpose.

Fire protection personnel make periodic inspec. tions of all containers and storage areas. Questions regarding the painting, labeling, or maintenance of safety containers should be referred to fire protection personnel.

\subsubsection{Dispensing and Transporting Flammable Liquids}

Flammable liquids shall be dispensed outdoors or in approved fume hoods, or in rooms equipped with ventilation and explosion-proof equipment approved by the fire protection engineers. No open flames, hot surfaces, smoking, or spark-producing devices are per. mitted nearby. When dispensing, a bonding wire should be connected hetween the dispensing and re. coing metal containers to prevent a static spark.
Flammable materials shall be transported furm one area to another in approved safety containers, in suppliers' original metal containers, or in glass con. tainers within heavy rubber buckets.

\subsubsection{Disposal}

For disposal of flammable liquids, contact Finvi. ronmental Health Department (Section 6.2.8).

\subsubsection{Accidental Spills}

An accidental spill of any flammable or combusti. ble liquid into any sewer stream, arroyo, or ont., the floor should be reported immediately to (Jperi tions Engineering Division and to Industrial Hygir.n. Division.

\subsubsection{Approved Safety Containers in General Stores}

Table 5-3 lists approved safety containers asai. able from General Stores. Special-purpose safety cam may be purchased from the manufacturers.

\subsubsection{Spray Finishing Using Flammable Liquids}

\subsubsection{General}

Spray finishing with lacquer, stress coat. wil his.. varnish, enamel. oil base, or shellac is a very hazart.... operation. In accordance with basic fire preventin! principles, all spraying operations should be p..: formed in a separate area room or spray bexith :.: noncombustible construction, with flocor drainage. ar: equate ventilation, automatic sprinkler protections. and explosion-proof electrical equipment. Siraying operations shall be conducted only in areas designed by Plant Engineering and approved by the fire pro. tection engineers and Industrial Hygiene Division. Occasional use of an aerosol can requires reasunabl. precautions.

\subsubsection{Spray Booths and Chemical Exhaust Hoods}

Paint spray booths and exhaust systems ar. in stalled to remove flammable vapors. Laboratory $*$. haust hoods shall be designed so that any spill in ih. hood will not flow out onto the floor and the velerit: of exhaust is sufficient to remove all vapors. 
Appendix B

Laboratory Hazardous Waste Handling Recommendations August 20, 1984 Edition 


\section{Int드odu도토므므:}

Many of the chemicals used or synthesized in laboratories are legally considered hazardous wastes by governmental agencies. Most waste laboratory chemicals which may not be legally defined as hazardous wastes are nonetheless considered hazardous wastes by Sandia, due either to known toxicity of or the lack of toxicity information for the chemicals. All hazardous wastes are subject to detailed regulations governing their handling and disposal. Sandia fully supports compliance with all applicable environmental regulations including those governing hazardous waste.

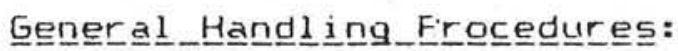

1. All chemical disposal must be coordinated through Division 3314. The only exception is the disposal of small amounts of water-soluble, low-toxicity chemicals in accordance with Appendix

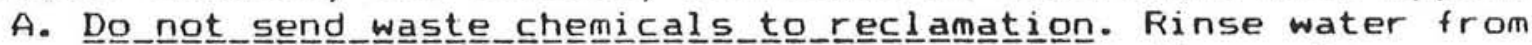
washirig of lat ware is not considered chemical disposal.

2. Complete a "Chemical Waste Disposal Request" form and list all chemicals for disposal. Send the form to Division 3314 . Do not list radioactive wastes on the form. Call 4-4966 for forms or

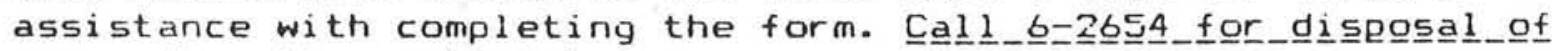

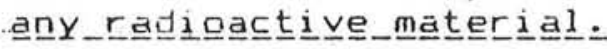

3. Division 3314 wili review the chemicals on the form and classify the chemicals as either hazardous or nonhazardous waste. 3314 will arrange the pick-up of hazardous waste. For nonhazardous waste, 3314 will notify the waste generator of proper alternate disposal methods.

4. Hazardous waste must be safely packaged for pick-up. Froper packaging includes compatible container material, secure 1 ids or caps, content 1 abels and nonleaking containers. Hazardous waste which is not properly packaged will not be accepted for pick-up. Empty containers are available through General Stores and are listed in the Chemicals Stock Catalog. Call 4-4966 if assistance is needed in selecting proper packaging materials and methods.

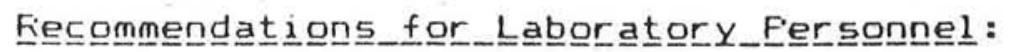

1. Include planning for chemical waste disposal as part of the considerations for Fin activities. This is particularly true for activities which will generate wastes in quantities greater than approximately 5 gallons or generate any new or unusual wastes. 
If you are designing a new activity which will generate chemical wastes, notify 3314 of the expected waste so proper handling and disposal methods can be arranged. Early notification, preferably three months prior to the generation of the waste, would be of large benefit to the waste management program.

2. Keep chemical purchases to a level of realistic use. Sandia disposes of a significant quantity of unused chemicals which were overordered. Not only do the chemicals cost money, the disposal of the unused portions is also costly.

3. Fequest the disposal of unneeded chemicals as soon as the chemicals are no longer needed. The disposal of chemicals which are $1 \%, 20$ and even 30 years old represents a major hazard to Sandia personnel since the chemicals may have formed unstable or unknown reaction products during their long storage. This is particularly true for water-reactive, pyrophoric and

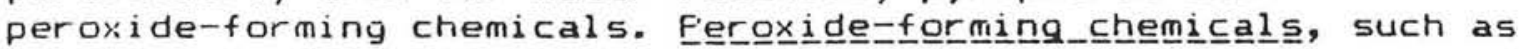
ethers, should be disposed of within six months of their synthesis or first opening of a container.

4. Hazardous waste regulations require proper identification of wastes. Chemical waste generators must be specific when listing chemicals on the disposal request form. Each waste should be listed separately and correctly identified. If a waste composition is unknown, an effort should be made to identify it based upon use or generating process. If the material cannot be identified, then the known characteristics $(\mathrm{pH}$, reactivity, flammability, etc.) of the material should be listed.

5. Where possible, segregate different chemical wastes into separate containers. Hazardous wastes are segregated for storage and disposal according to their chemical characteristics. If chemical wastes are mixed in the same container, characterization of the waste becomes a difficult task. Never mix incompatible wastes into the same container.

6. Hazardous wastes are, by definition, hazardous chemicals and should be handled with the same precautions as handling unused hazardous chemicals. Contact Division 3311 for assistance in the proper handling of hazardous chemicals.

The Environmental Frotection and Hazardous Waste Management Division has the lead responsibility for the proper handling of hazardous wastes. However, the large diversity of waste chemicals generated by Sandia requires that all personnel generating hazardous wastes be cognizant of and implement proper handling methods. By working together, we can assure that the management of Sandia's chemical wastes will both be in compliance with regulations and, more importantly, protect our environment. 
The following lists comprise compounds that are suitable for disposal dowri the drain with excess water in quantities up to about $100 \mathrm{~g}$ at a time. However, compounds with disagreeable odors should not be sent down drains. Division 3314 should be contacted $(4-4966)$ to arrange for disposal of compounds not found on either list, in amounts greater than $100 \mathrm{~g}$ or that have disagreeable odors. Compounds on both lists are water soluble to at least $3 \%$ and present low toxicity hazard. Those on the organic list are readily biodegradable. Chemicals not on the lists should not be sent down the drain.

I. ORGANIC CHEMICALS

Alcohols

Alkanols with less than 5 carbon atoms t-Amyl alcohol

Alkanediols with less than 8 carbon atoms

Glycerol

Sugars and sugar alcohols

Alkoxyalkanols with less than 7 carbon atoms

$\mathrm{n}-\mathrm{C}_{4} \mathrm{H}_{9} \mathrm{OCH}_{2} \mathrm{CH}_{2} \mathrm{OCH}_{2} \mathrm{CH}_{2} \mathrm{OH}$

2-Chloroethanol

Aldehydes

Aliphatic aldehydes with less titan 5 carbon atoms

Amides

$\mathrm{RCONH}_{2}$ and RCONHR with less than 5 carbon atoms

$\mathrm{RCONR}_{2}$ with less than 11 carbon atoms

Amines

Aliphatic amines with less than 7 carbon atoms

Aliphatic diamines with less than 7 carbon atoms

Benzylamine

Pyridine

Carboxylic Acids

Alkanoic acids with less than 6 carbon atoms

Alkanedioic acids with less than 6 carbon atoms

Hydroxyalkanoic acids with less than 6 carbon atoms

Aminoalkanoic acids with less than 7 carbon atoms

Ammonium, sodium, and potassium salts of the above acid classes with. less than 21 carbon atoms

Chloroalkanedioic acids with less than 4 carbon atoms 
$\underline{\text { Ketones }}$

Ketones with less than 6 carbon atoms

\section{Esters}

Esters with less than 5 carbon atoms

Isopropyl acetate

\section{Ethers}

\section{Tetrahydrofuran \\ Dioxolane \\ Dioxane}

Nitriles

Acetonitrile

Propionitrile

Sulfonic Acids

Sodium or potassium salts of most are acceptable

II. INORGANIC CHEMICALS

This list comprises water-soluble compounds of low-toxic-hazard cations and low-toxic-hazard anions. Compounds of any of these ions that are strongly acidic or basic $(2 \geq \mathrm{pH} \geq 12)$ should either be neutralized to a $\mathrm{pH}$ between 2 and 12 or mixed with sufficient water as they are sent down the drain so they are diluted to a pH between 2 and 12 .

$\begin{array}{ll}\text { Cations } & \frac{\text { Anions }}{\mathrm{Al}^{3+}} \\ \mathrm{Ca}^{2+} & \mathrm{BO}_{3}^{3-}, \mathrm{B}_{4} \mathrm{O}_{7}^{2-} \\ \mathrm{Cu}^{2+} & \mathrm{Br}^{-2}{ }^{2-} \\ \mathrm{Fe}^{2+}, 3+ & \mathrm{CO}_{3}^{2-} \\ \mathrm{H}^{+} & \mathrm{Cl}^{-} \\ \mathrm{K}^{+} & \mathrm{HSO}_{3}^{-} \\ \mathrm{Li}^{+} & \mathrm{OCN}^{-} \\ \mathrm{Mg}^{2+} & \mathrm{OH}^{-} \\ \mathrm{Na}^{+} & \mathrm{I}^{-} \\ \mathrm{NH}_{4} & \mathrm{NO}_{3}^{-} \\ \mathrm{Sn}^{2+} & \mathrm{PO}_{4}{ }^{2} \\ \mathrm{Sr}^{2+} & \mathrm{SO}_{4}^{2-} \\ \mathrm{Ti}^{3+}, 4+ & \mathrm{SCN}^{-} \\ \mathrm{Zn}^{2+} & \\ \mathrm{Zr}^{2+} & \end{array}$

Reference: Prudent Practices for Disposal of Chemicals from Laboratories, National Research Council, National Academy Press, Washington, D.C., 1983. 
SAFE OPERATING PROCEDURE FOR

USE OF SAFETY EQUIPMENT

AT

PBFA II, BUILDING 983

Appendix 7 
Table of Contents

Abstract ................... 0

I. Introduction ................. I

II. Applicable Equipment . . . . . . . . . . . . . . l

III, Procedures ................. . . 1

IV. Inspection and Maintenance . . . . . . . . . . 3

VI. Appendices . . . . . . . . . . . . . . 5

A. SAND81-1807, Revision A, Section 4.2.4.8...5

B. Scott Air Pack Authorized Users . . . . . . 6 
SAFE OPERATING PROCEDURE

FOR THE

USE OF SAFETY EQUIPMENT

AT

PBFA II, BUILDING 983

\begin{abstract}
This SOP outlines proper procedures for use of safety equipment within Building 983. Failure to use this equipment properly will cause personnel to be exposed to unnecessary risk and may result in falls or other personal injury.
\end{abstract}

T. H. Martin, 1250 date

S. A. Goldstein, 1254 date
D. L. Rost, 3442

A. M. Fine, 3442 date

date

Distribution:

1236 G. A. Zawadzkas

1254 S. A. Goldstein

1254 G. L. Donovan (2)

1254 Division Members

3442 D. L. Rost

3442 A. M. Fine 
SAFE OPERATING PROCEDURE

FOR THE

USE OF SAFETY EQUIPMENT

AT

PBFA II, BUILDING 983

\section{Introduction}

Safety equipment within Building 983 is provided to aid personnel in completing their job assignments safely or to assist in the rescue of injured personnel.

Manufacturers instructions for the use and care of specific safety equipment within 983 shall be complied with in addition to the guidelines in this Safe operating Procedure.

II. Applicable Equipment

Safety equipment provided in Bldg. 983 includes:

$\begin{array}{ll}\text { Safety belts } & \text { Scott Air Packs } \\ \text { Lanyards } & \text { Life Preservers } \\ \text { Bosun's chairs } & \text { Rescue Hooks } \\ \text { Stretchers } & \text { Fire blankets }\end{array}$

\section{Procedures}

A. Safety belts: safety belts are used to fasten personnel to an anchor point (as with a lanyard) in order to lessen the severity of falls, should they occur. Safety belts are also used to rescue personnel who are unconscious or injured in confined spaces by providing an attachment point for rescuers.

Safety belts shall be worn by personnel who must work above floor level where falls may occur, or in confined spaces where rescue would be difficult. These include areas within the accelerator and test tank, and confined spaces such as fluid storage tanks.

B. Lanyards: lanyards are tie lines used to secure personnel to anchor points via safety belts or har- 
nesses. Lanyards may incorporate shock absorbing devices in order to prevent injuries from the sudden stop afforded by a standard tie line.

Lanyards should be used whenever work must be done above floor level where personnel are otherwise not protected from falls, as with catwalks or work platforms. Lanyards should be attached to a secure anchor point that is above shoulder level (this limits the distance of a fall).

C. Bosun's chairs: bosun's chairs are facility devices that are used when personnel must ride a crane hook. These should be used when normal access is not possible and the use of a crane is necessary.

Bosun's chairs should be used when personnel must work above floor level within the accelerator tank or other areas where work platforms are not available. Personnel using Bosun's chairs should keep the safety chain fastened at all times and utilize a safety belt and lanyard attached to the crane hook, in case of a fall from the chair.

D. Stretchers: rescue stretchers are used to move injured personnel who are unable to move under their own power. These stretchers may be carried by other personnel or attached to facility motive equipment (i.e. the bridge or jib cranes) by using the supplied sling.

Two stretchers are provided within the PBFA II Facility. One is located on the south side of the +10 foot level of the highbay. The other is located in the north end of basement $(-25$ foot level) on the east wall.

E. Scott Air Packs: these devices are full-face, self contained breathing apparatus that are to be used ONLY when personnel MUST enter oxygen deficient or other hazardous environments for rescue of injured personnel or to secure hazardous systems.

Scott Air Packs are mounted in pairs at various locations within the facility. The "buddy system" shall be utilized whenever it is necessary for personnel to don air-packs. Industrial Hygiene, Division 3311, will make periodic inspections and perform required maintenance to the air packs as needed. Division 3311 will also train personnel in the use of this equipment on a yearly basis. Scott Air Packs shall only be used as directed by Industrial Hygiene during training (see Appendix B for a list of authorized users within Bldg. 983). 
F. Life preservers: these devices are used to aid in the rescue of personnel on the surface of the water. A person who is floundering on the surface should be thrown a life preserver until rescue can be accomplished.

Six life preservers will be located around the top of the PBFA II tank. These will be mounted on the handrail between the oil and water sections of the accelerator.

G. Rescue hooks: these devices are used to aid personnel that have fallen into the oil or water sections of the accelerator. Rescuers using these devices should attempt to give victims support until they can reach a place where they may be removed from the tank. Rescue hooks are not made to lift people from the tank and this could also endanger the rescuer.

Two rescue hooks will be located around the top of the accelerator. These hooks are mounted on the oil side of the handrail between the oil and water sections of the accelerator.

H. Fire blankets: fire blankets are used to extinguish flames on personnel whose clothing has caught fire or to cover injured personnel during movement.

Fire blankets are kept in red cabinets located next to rescue stretchers on the +10 foot and -25 foot levels. In addition, two fire blankets are located on each facility stretcher.

IV. Inspection and Maintenance

A. Safety belts, lanyards, and other safety equipment shall be inspected for damage before or after each use as appropriate. Damaged safety equipment should be brought to the attention of the Bldg. 983 Facility Supervisor(1). In addition, safety equipment shall not be modified in any way without the specific approval of the appropriate safety organization.

(1) The name and phone number of the on-duty Facility Manager will be posted near the entrance to the Data Acquisition Room (RM 104). The Facility Manager may be reached by phone, PA announcement, or personal pager. 
B. Safety belts and lanyards MUST NOT be load tested.

C. Do not tie knots in lanyards or other safety lines. This will decrease the load rating of these devices.

D. Personnel should make sure there is no danger of contact with accelerator circuitry or facility power sources before using metal safety lines. Where this hazard exists, as in or above the accelerator tank, personnel should use only non-conductive safety lines. 
Appendix A

Sandia National Laboratories Safety Manual

SAND81-1807, Revision A

Printed August 1984

section 4.2 .4 .8

"Lifelines and safety belts are required for employees working without scaffolds on high overhead jobs, on high rigging, or on steeply pitched roofs. These items are also required by all employees exposed to falls, such as window washers, riggers, or painters at work on poles or steel frame constructions more than $15 \mathrm{ft}$ above solid ground, floor, or platform. All safety belts must be made of welltanned leather, nylon, linen, or cotton webbing equipped with harness and lanyard suitable for the job. All belts, D-rings, harnesses, and lanyards shall have a minimum tensile strength of $5000 \mathrm{lb}$ and shall comply with ANSI code A.10.14, Class 1. 


\section{Appendix B}

\section{Personnel Authorized For Scott Air Pack Use}

Name

Chambers, Rod

Clevenger, Robert

Drennan, Scott

Holman, G.T.

Jobe, Dan

Johnson, Mark

Johnston, Robert

Lundstrom, Joe

Navarro, Mike

Schaub, Mike

Seals, Bobby

Stewart, Joe

Tanner, Wayne

Velasquez, Dan

Ziska, Gerold
Org.

Signature

Date

1254

1254

1254

1254

1254

1254

1254

1254

1254

1254

1254

1254

1254

1254

1254 


\section{SAFE OPERATING PROCEDURE FOR PERSONNEL ACCESS \\ AT \\ PBFA II, BUILDING 983}

Appendix 8 
Table of Contents

Abstract .. . . . . . . . . . . . . . 0

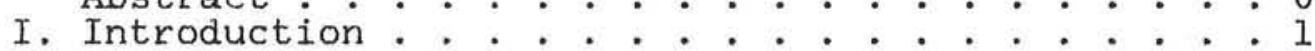

II. System Description . . . . . . . . . . . . . . . . I

III. Operating Mode Descriptions . . . . . . . . . . . 2

A. Full Access. . . . . . . . . . . . . . . . 2

B. Laser Trigger Alert. . . . . . . . . . . . 2

C. High Voltage Alert . . . . . . . . . . . . 2

D. Full Alert . . . . . . . . . . . . . . . 2

E. High Voltage On/Off. . . . . . . . . . . 3

IV. Facility Evacuation Criteria.. . . . . . . . . 3

A. Laser Test Alert Status . . . . . . . . . 3

B. High Voltage Alert Status . . . . . . . . . 3

C. Full Alert Status. . . . . . . . . . . . 3

V. Emergency Access. . . . . . . . . . . . . . . . 4

VI. Roof Access . . . . . . . . . . . . . . . . . . 4

VII. System Testing . . . . . . . . . . . . . . . . . . 4

VIII. Appendices . . . . . . . . . . . . . . . . 5

A. Access Control Evacuation Procedures . . . . 5

1. High Voltage Test Alert . . . . . . . . 5

2. Laser Test Alert. . . . . . . . . . . 6

3. Full Alert. . . . . . . . . . . . 8

a. Limited Full Alert . . . . . . . . 8

b. Unlimited Full Alert . . . . . . . . 10

B. Facility Warning Beacon Identification . . 12 
SAFE OPERATING PROCEDURE

FOR

PERSONNEL ACCESS

TO

PBFA II, BUILDING 983

\begin{abstract}
This SOP describes the Access Control System and access procedures at PBFA II, Building 983. This system is used to limit personnel access to areas of the 983 complex during accelerator testing or other potentially dangerous activity. The hazards involved with improper access controls include personnel exposure to intense electromagnetic fields, ionizing radiation, high energy laser radiation, high level accoustical noise, and hazards associated with high voltage equipment.
\end{abstract}

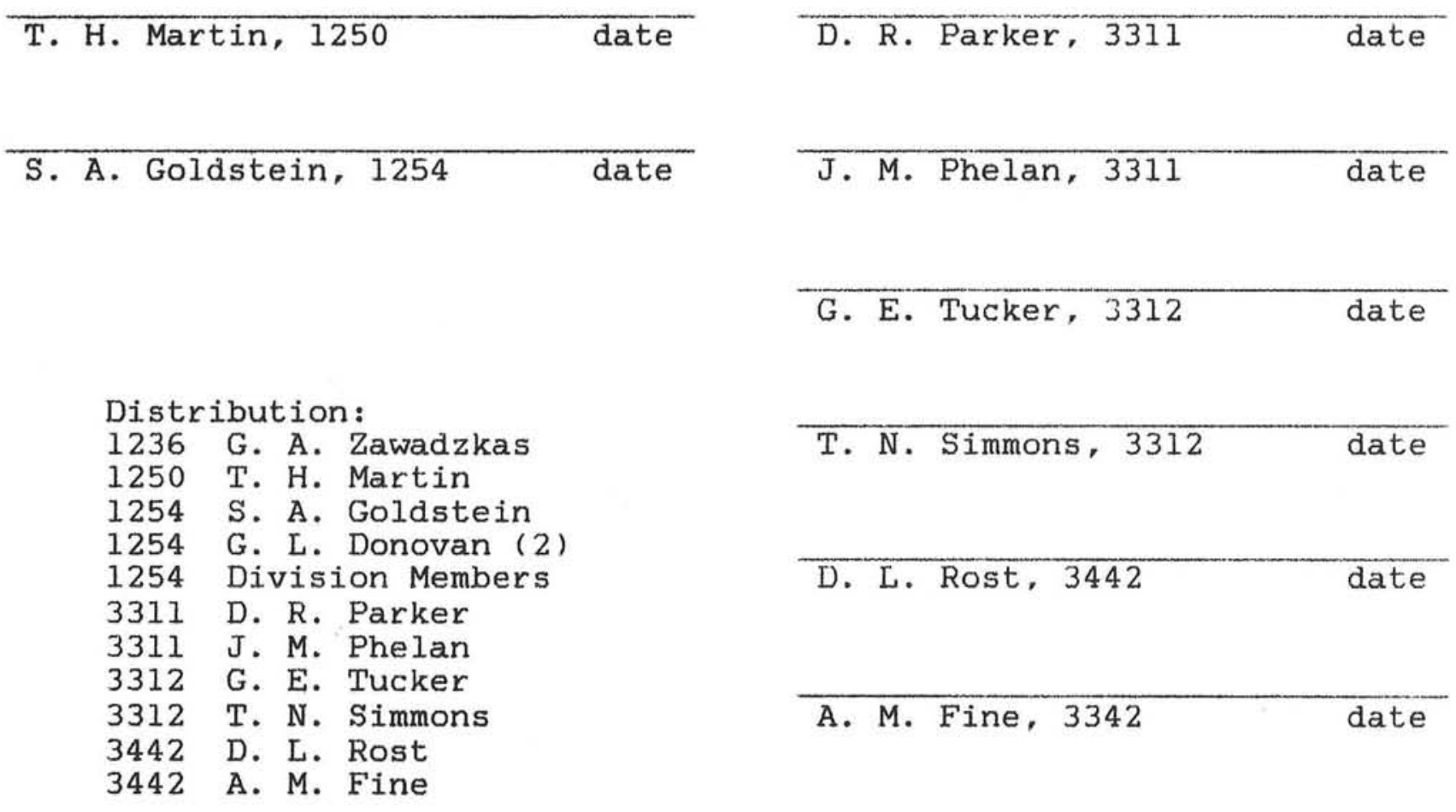


SAFE OPERATING PROCEDURE

FOR

PERSONNEL ACCESS

T0

PBFA II, BUILDING 983

\section{Introduction}

The Building 983 Access Control System (ACS) has been designed to limit personnel access to various areas of the facility during potentially hazardous activity. The access restriction imposed on the facility ranges from evacuation of a local area within the highbay to complete evacuation, throughout the facility, of all but essential personnel.

The system protects personnel from the high level EMP and various forms of radiation produced during accelerator shots and local hazards present during maintenance and troubleshooting tests involving accelerator subsystems.

\section{System Description}

The PBFA II ACS consists of a series of lockable doors and gates, access stations with status indicators, rotating beacons, audible alarms, the Facility Safety Computer (FSC), an operator interface, and the facility public address system (PA). When a test requiring the ACS is announced over the PA, the appropriate status indicators will change from "SAFE" to "CAUTION". Status indicators will remain in this state until evacuation personnel enable individual access stations throughout the facility. When a station is enabled, the status indicators assigned to that station are changed from "CAUTION" to "DANGER" by the FSC. This indicates that the area has been evacuated of personnel up to that point, and the locking doors and gates associated with that station are now secured.

The ACS incorporates emergency exit buttons located on the inside (secured side) of each lockable door. This allows exit from a secured area, through the lockable doors, in case a person is missed during evacuation or should an emergency force the evacuation team to retreat from the area being evacuated. 
SOP - Personnel Access to Bldg. 983 / page 2

System status is monitored on the Main Access Control Display (MACD) on the Operator's Console in the Control Monitor Room. The MACD will display ACS status and inform the machine operators of any access breach. Should a system fault occur, as a mechanical or wiring problem, a "FAULT" message is sent to the operators console and the system is put on hold pending an operator response. The operator then has the option to restart the procedure at the access station at fault, abort the test alert, or in unusual circumstances to override the fault. The latter option requires a special password from the Facility Manager who is responsible for ensuring alternate safety measures are taken before issuing the override command.

\section{Operating Mode Descriptions}

The facility ACS operates in five distinct modes: (see Appendix A for specific procedures)

A. FULL ACCESS status indicates that no access alert has been initiated. During FULL ACCESS all doors and gates are unlocked, status indicators are set to "SAFE", and the entire area under the control of ACS is safe for personnel access (NOTE: this does not include locally posted areas that are controlled for other than test related activities).

B. LASER TEST ALERT status indicates that a test of the Laser Trigger System has been initiated. Before beginning a test that propagates Laser radiation outside established beampaths, the ACS requires evacuation of the $-25 \mathrm{ft}$. level of the facility.

C. HIGH VOLTAGE ALERT status indicates that a limited test of a machine subsystem has been initiated. This test alert condition exists when hazardous areas exist within the highbay, but a FULL ALERT condition is not required. Examples of this condition would be a test of the Marx Generator trigger system, or a test of the Marx Generator Charging System.

D. FULL ALERT status indicates a test requiring complete evacuation of either A) the entire highbay and $-25 \mathrm{ft}$ mechanical room, or B) the entire facility including lowbay areas. The former represents standard evacuation for large scale tests that involve stored energy of more than 3.5 Megajoules within the accelerator. The latter represents a test condition in which high level radiation is expected to be produced from the machine Center Section. All tests that impose hazard on hiqhbay personnel, other than those covered by other ACS evacuation procedures, require FULL ALERT evacuation. 
E. HIGH VOLTAGE ON/OFF denotes a manual mode in which the ACS control is not activated BUT the high voltage breakers can be activated by the machine operator. A special operator password is required to enter this mode. The operator initiating this access action is responsible for the evacuation and safety of facility personnel who might be at risk.

IV. Facility Evacuation Criteria

The criteria for evacuation of personnel from specific areas of the PBFA II facility have been based upon past experience with other pulsed power accelerators. The following guidlelines are suggested by this experience and current knowledge of the hazards that exist.

A. Laser Test Alert Status is required when a Laser test is conducted that propagates energy outside established Laser Trigger System (LTS) beampaths at intensity levels which could be hazardous to personnel.

B. High Voltage Alert Status is required for tests that present localized hazards but DO NOT impose undue risk to highbay personnel. In this mode, the ACS restricts access to the $-25,-10$, or +10 foot levels of the facility only, allowing work activity to continue in other areas of the highbay.

C. Full Alert status is required for:

1. All activity in which more than six (6) accelerator modules transfer energy into the Pulse Forming Section of the accelerator.

2. All activities in which more than 3.5 Megajoules of energy are stored within the accelerator.

3. All activities which deviate from established operating procedures that may impose unique or unknown hazards to facility personnel.

4. All activities, regardless of accelerator status, which place the safety of facility personnel at risk, that cannot be adequately covered with other ACS alert modes. 
V. Emergency Access

Access into a controlled area of the Building 983 highbay during a lockout, except where such access is part of a planned test procedure, shall be restricted to emergency situations only. An emergency is defined as a life threatening situation or a condition that may lead to destruction of property.

Keys allowing personnel to breach secured doors and gates will be controlled by the Facility Manager(1), This person shall be responsible for authorizing personnel to enter during such emergency situations AND shall ensure the safety of these personnel.

VI. Roof Access

The on-duty Facility Manager is the only person authorized to allow access to the roof of the PBFA II facility. Keys to the roof access ladders will be controlled by the Facility Manager. Access procedures require verification that roof access is secure and that keys are in the Managers control before any accelerator activity that propagates energy through the Pulse Forming Section can take place.

VII. System Testing

Performance of the Access Control system shall be tested for mechanical or other failures on a weekly basis. This testing shall verify proper operation of all door and gate locks to ensure system integrity. Should any part of the system not operate properly, either during a system test or actual lock-out, the problem must be repaired before the system is utilized. Should repair not be possible in the appropriate time frame, a fail-safe manual lock-out may be implemented temporarily (i.e. a chain and facility padlock). Should a fail-safe alternative not be possible, activities requiring access control shall be suspended until repairs can be made.

(1) The name and phone number of the on-duty Facility Manager will be posted near the entrance to the Data Aquisition Room (RM 104). The Facility Manager may be reached by phone, $\mathrm{PA}$ announcement, or personal pager. 
Appendix A

\section{Access Control Evacuation Procedures}

1. High Voltage Test Alert:

During a High Voltage Test Alert evacuation of the -10, 25 , or +10 foot levels of the highbay is required. The Facility Manager, thru consultation with Division 1254 Supervision, shall determine potential risks to facility personnel and implement appropriate access controls prior to the test. The following describes the procedures required for evacuation of all of the areas that could be involved in a High Voltage Test Alert. This evacuation requires two personnel whose routes are as follows:

Evacuator 1: Proceeds from the double doors on the north side of the highbay, with evacuator 2 , down the northeast stairway to the -10 foot level, closing the gate at the top of the stairs as they pass. At this point the evacuators split and \#1 waits at the bottom of the northeast 0 to -10 foot stairs while \#2 sweeps the -10 foot level. This prevents missing any personnel on this level. After making visual contact with \#2 after the sweep of the -10 , \#l proceeds down the north stairway leading to the -25 foot level. He/she secures the stairway gate at the -20 foot level, activates the Access Control Station ( $\mathrm{AC} 02)$, and proceeds to the -25 foot level evacuating personnel towards the stairs at the north side of the -25 foot mechanical room. \#l should be sure to check the LTS alcove, Vaccuum alcove, and other possible places where persons may not readily be seen. \#l then proceeds to the southeast stairwell and verbally announces to clear the area into the stairway. He/she then secures the doox and activates $\mathrm{ACO}_{3}$ (this locks the stairwell door and the door to the utility tunnels on the west side of the pit). Evacuator \#1 then proceeds up the north mech room stairs to the -12 foot level closing the gate at the top of the stairs. After closing this gate, evacuator \#l should proceed to the trench access gate located in the northwest corner of the -12 foot level. and ensure that the gate is shut and padlocked (NOTE: access to this gate is controlled by the facility manager, if unlocked he/she should be consulted before 
evacuation proceeds). Evacuator \#l again proceeds to the southeast stairwell and verbally announces to clear the area into the stairwell. The evacuator then secures AC04 located next to this door, this secures the stairwell door and locks the gate at the top of the -25 to -12 foot stairs. Evacuator \#l now proceeds to the 0 foot level via the mechanical room stairs and repeats the evacuation announcement into the southeast 0 foot stairwell. After securing the Access Control Station at the southeast 0 foot stairwell ( $A C 11$ ), evacuator \#1 then proceeds through the highbay to the starting point at the double doors.

Evacuator 2: After seperating from evacuator \#1, proceeds around the north side of the accelerator tank evacuating any personnel up the stairway on the northwest side of the -10 foot level. \#2 then closes the gate and activates $\mathrm{ACl} 4$ at the top of these stairs and proceeds around the west side of the tank on the -10 foot level to the doorway between the 10 foot level and the -12 foot mechanical room. \#2 ensures that this door is closed and then proceeds to make visual contact with \#l who is waiting at the bottom of the northeast 0 to -10 foot stairs. At this point \#2 waits for \#l to go down the -10 to -25 foot stairs and activate $\mathrm{ACO} 2$ which secures the -12 foot to -10 foot doorway. \#2 now checks this door to ensure that it is locked and completes the sweep of the -10 foot level. Evacuator \#2 then proceeds up the stairway at the south end of the -10 foot level and activates AC06 at the top of these stairs. \#2 now evacuates the +10 foot level of the highbay by proceeding up the stairway on the southeast side of the highbay closing the gate behind him, making a sweep of the mezzanine to the west 0 to +10 foot stairway, securing the gate at the top of these stairs, and returning to the top of the southeast stairs to activate AC07. Evacuator \#2 then proceeds to the 0 foot level via the stairs on the northeast side of the highbay. At this point evacuator \#2 activates AC08 at the bottom of these stairs and returns to the double door starting point.

2. Laser Test Alert:

During a Laser Test Alert, evacuation of the -25 foot level is required. The south elevator must also be moved to the -12 foot level to prevent reflections of Laser 
radiation into unsecured areas. This evacuation procedure requires one evacuator:

The Evacuator, before proceeding, should ensure that the south mechanical room lift has been moved to the -12 foot level. Once the lift is in place, the evacuation procedure begins from the double door entryway to the highbay, down the stairs in the northeast corner of the highbay, to the access gate located on the north stairway between the -10 and -25 foot levels of the highbay. He/she secures this gate and activates the control station $\mathrm{ACO} 2$ and proceeds to the -25 foot level, evacuating people towards the stairs at the north side of the -25 foot mechanical room. The evacuator should make sure to check the LTS alcove, vaccuum alcove, and other areas where personnel may be hidden from view. The evacuator then proceeds to the southeast stairway and verbally announces into the stairwell "clear the area". $\mathrm{He} / \mathrm{she}$ then secures the door and activates AC03 (this locks the stairwell door and the door to the utility tunnels on the west side of the pit). At this point, the evacuator should disconnect power to the south elevator to ensure that it remains at the -12 foot level. The service disconnect for the south elevator is located on the east wall of the -25 foot level behind the green control units. The evacuator then proceeds up the north mech room stairs to the -12 foot level closing the gate at the top of the stairs. After shuting this gate, evacuator \#l should proceed to the trench access gate located in the northwest corner of the -12 foot level and ensure that the gate is shut and padlocked (NOTE: access to this gate is controlled by the facility manager, if unlocked he/she should be consulted before evacuation proceeds). At this point the evacuator again proceeds to the southeast stairwell and verbally announces to clear the area into the stairwell. The evacuator then secures AC04 10cated next to this door, this Control Station secures the southeast stairway door and the gate at the top of the -25 to -12 foot stairs. He/she then proceeds to the 0 foot level via the mechanical room stairs and repeats the evacuation announcement into the southeast stairwell. After securing the Access Control Station next to the southeast 0 foot stairwell door (ACll), the evacuator then proceeds through the highbay to the starting point at the double doors. 
3. Full Alert:

Facility Full Alerts indicate that a large scale test of the facility has been initiated and evacuation of either

A) the entire highbay $(0,+10,-10$, and -25 foot levels) and -25 foot mechanical room.

OR

B) the entire facility, including lowbays, of all but essential personnel.

The former represents a standard large scale test of the accelerator during which personnel in all areas of the facility are not considered at risk. The latter alert condition represents accelerator activity in which expected radiation levelis warrant evacuation of personnel not essential to the test. Either evacuation procedure requires a team of two evacuators:

A) Limited Full Alert:

Evacuator 1: Proceeds from the double doors on the north side of the highbay, with evacuator 2 , down the northeast stairway to the -10 foot level, closing the gate at the 0 foot level as they pass. At this point the evacuators split and \#I waits at the bottom of the northeast 0 to -10 foot stairs while \#2 sweeps the -10 foot level. This prevents missing any personnel on this level. After making visual contact with \#2 after the sweep of the -10 , \#1 proceeds down the north stairway leading to the -25 foot level. He/she secures the stairway gate at the -20 foot level, activates the Access Control Station $(\mathrm{ACO} 2)$, and proceeds to the -25 foot level evacuating people towards the stairs at the north side of the -25 foot mechanical room. Evacuator \#l should be sure to check the LTS alcove, the vaccuum alcove, and any other places where personnel could be concealed. \#1 then proceeds to the southeast -25 foot stairwell door and verbally announces to clear the area into the stairway. He/she then secures the door and activates $\mathrm{ACO}_{3}$ (this locks the stairwell door and the door to the utility tunnels on the west side of the pit). Evacuator \#1 then proceeds up the north mech room stairs to the -12 foot level closing the gate at the top of the stairs. After closing this gate, evacuator \#1 should proceed to the trench access gate located in the northwest corner of the -12 foot level and ensure that the gate is shut and padlocked (NOTE: access to this gate is controlled by the facility manager, if unlocked he/she should be consulted before evacuation proceeds). At this point evacuator 
\#1 again proceeds to the southeast stairwell and verbally announces to clear the area into the stairwell. The evacuator then secures AC04 located next to this door, this Control station secures the southeast stairway door and the gate at the top of the -25 to -12 foot stairs. $\mathrm{He} / \mathrm{she}$ then proceeds to the 0 foot level via the mechanical room stairs and repeats the evacuation announcement into the southeast stairwell. After securing the Access Control Station next to the southeast 0 foot stairwell door (ACl1), evacuator \#1 then proceeds to the doorway between the 0 foot mechanical room and the highbay and activates AC05, located on the highbay side of this door. \#l waits here until establishing visual contact with \#2 after completion of his/her -10 foot level sweep. He/she then proceeds to the west side of the highbay, ensures the mechanical room to highbay roll up door is closed, continues the sweep of the west 0 foot level verifying that no personnel are in the trench system, activates the control station in the northwest corner of the highbay, and proceeds east back to the starting point at the double doors.

Evacuator 2: After seperating from evacuator \#1, proceeds around the north side of the accelerator tank evacuating any personnel up the stairway on the northwest side of the -10 foot level. He/she then closes the gate and activates $\mathrm{ACl} 4$ at the top of these stairs and proceeds counterclockwise on the -10 foot level around the tank to the doorway between the -10 foot level and the -12 foot mechanical room. \#2 ensures that this door is closed and then proceeds to make visual contact with \#l who is waiting at the bottom of the northeast 0 to -10 foot stairs. At this point \#2 waits for \#l to go down the -10 to -25 foot stairs and activate $\mathrm{ACO} 2$ which secures the -12 foot to -10 foot doorway. \#2 now checks this door to ensure that it is locked and completes the sweep of the -10 foot level. Evacuator \#2 then proceeds up the stairway at the south end of the -10 foot level and activates AC06 at the top of these stairs. \#2 now evacuates the +10 foot level of the highbay by proceeding up the stairway on the southeast side of the highbay closing the gate behind him, making a sweep of the mezzanine to the west 0 to +10 foot stairway, securing the gate at the top of these stairs, and returning to the top of the southeast stairs to activate AC07. Evacuator \#2 then proceeds to the 0 foot level via the stairs on the northeast side of the highbay. 
At this point evacuator \#2 activates AC08 at the bottom of these stairs and returns to the south side of the highbay until visual contact is made with \#l who will be coming through the 0 foot mech room to highbay door. After contact is made, \#2 sweeps the east side of the highbay ensuring that all manway and rollup doors are secured, activates $\mathrm{ACl} 2$ on the east wall, returns to the double door starting point, then exits highbay with evacuator \#l and activates ACOl inside the double doors.

B) Unlimited Full Alert:

Procedures for an unlimited facility test
evacuation are the same as a limited test
evacuation with the following additions:

1. Evacuator \#l, after securing the southeast stairway at the 0 foot level, evacuates the 0 foot mechanical room and enters the highbay through the mechanical room to highbay roll up door. He/she makes contact with \#2 who then activates AC05 outside the highbay/mechanical room door where evacuator \#2 has been waiting after securing the +10 foot level. \#l then returns into the 0 level mech room, shuts the rollup door, and sweeps the 0 foot mech room, moving from west to east, and then continues east through the south equipment room, into the southeast mediumbay, and back into the highbay through the east highbay to mediumbay rollup door. \#l then closes this door, makes contact with \#2, and they proceed to evacuate the 0 foot level towards the double doors as with the Limited Full Alert.

2. Evacuator \#2, as mentioned above, waits at the 0 foot level highbay to mechanical room door until evacuator \#l makes contact at the west highbay to mech room rollup door. After activating $\mathrm{AC} 05$ upon contact with evacuator \#1, evacuator \#2 again waits while \#1 evacuates the south mech room, equipment room and mediumbay. After \#l makes visual contact at the east mediumbay to highbay rollup door, both evacuators proceed to evacuate the 0 foot level towards the double doors as with the Limited Full Alert. 
3. Once both evacuators have reached the double door area, one member of the team sweeps the north lowbay while the other stands watch at the intersection of the main hallway and the highbay entrance. After evacuating the lowbay area, one evacuator should remain in the hallway to make sure no personnel reenter through the lowbay doors, at this time the other evacuator will activate ACOl located next to the double doors. This station secures the north lowbay entry doors. Both evacuators then return to the $\mathrm{C} / \mathrm{M}$ room to activate the final station. 
The Building 983 warning beacons, together with audible alarms, provide an indication of hazardous conditions throughout the facility. There are six different types of warning beacons:

1. Red beacons with alarms located on the roof of Building 983. These beacons are activated during a Full Alert when Marx generator charging commences and remain active until after the shot. These beacons indicate a hazardous condition may exist on the roof of the facility.

2. Red beacons without alarms located on the exterior of the building. These beacons are activated at the time a Full Alert is announced and remain active until after the test is completed.

3. Red beacons without alarms located on the interior walls of the highbay and -25 foot level. These beacons are activated at the beginning of a High Voltage Test Alert or a Full Alert and remain active until after the shot.

4. Yellow beacons with sirens located on the highbay ceiling. These beacons are activated whenever the Marx charging system high voltage is enabled to the PBFA II tank.

5. Yellow beacons without alarms located on the walls of the -25 foot level. These beacons are activated whenever the Laser Trigger system high voltage is active.

6. Yellow beacons located on the Marx Generator Test Bed. These beacons are activated whenever high voltage to the Test Tank is enabled. 
SAFE OPERATING PROCEDURE

FOR MAINTENANCE AND REPAIR

IN THE OIL SECTION

OF

PBFA II, BUILDING 983

Appendix 9

$9-1 \div 9-2$ 
Table of Contents

Abstract . . . . . . . . . . . . . . . 0

I. Introduction . . . . . . . . . . . . . . . . 1

II. Prodcedures for Entry into the 0il Section... . 2

III. Procedures for Working Within the Oil Section . . 2

IV. Personnel Training . . . . . . . . . . . . . . 3

V. Appendices . . . . . . . . . . . . . . . . . 4

A. Oxygen Deficient Environment Procedures . . . 4

B. Energy Storage Device Safing Techniques . . . 5 
SAFE OPERATING PROCEDURE

FOR MAINTENANCE AND REPAIR

IN THE OIL SECTION

OF

PBFA II, BUILDING 983

\begin{abstract}
This SOP describes procedures for performing maintenance and repair operations in the oil section of PBFA II, Building 983. Three major hazards are associated with entry into the oil section of PBFA II:
\end{abstract}

1. Hazards associated with high voltage equipment

2. Slips and falls resulting from residual oil in the tank.

3. Bump hazards due to the confined nature of the work space and numerous components

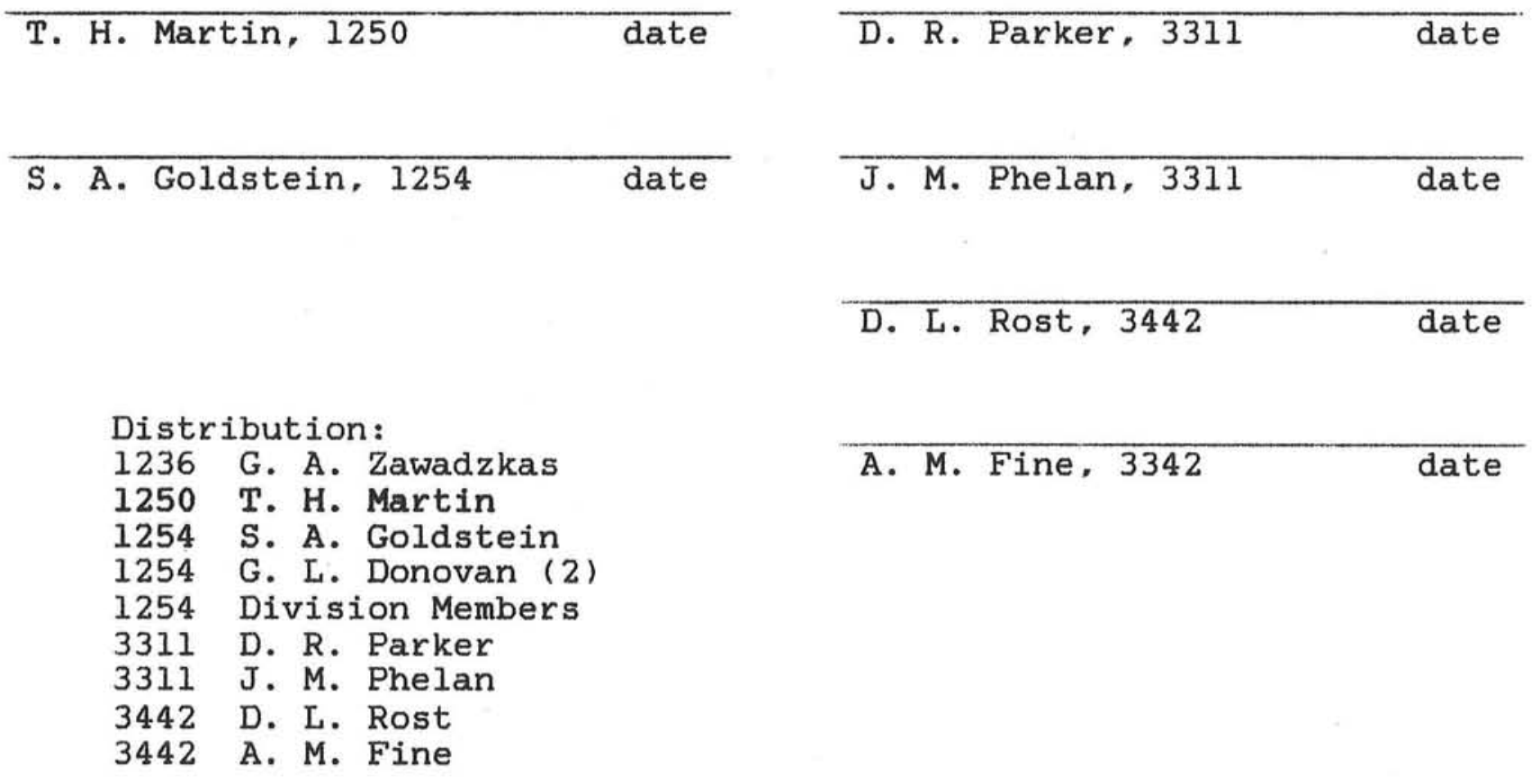


SAFE OPERATING PROCEDURE

FOR MAINTENANCE AND REPAIR

IN THE OIL SECTION

OF

PBFA II, BUILDING 983

\section{Introduction}

Operation of the PBFA II Energy Storage Section requires that periodic repair be performed as well as routine maintenance operations. Entry into the oil section presents a number of potential hazards to personnel.

A. Residual electric charge may be present on any high voltage devices having energy storage capability. These devices include the main Marx capacitor banks, the Marx Trigger Generators (MTG) and their trigger and charge cables, the charging system filter capacitors, and various pulser units that may be present for calibration purposes. All potentially dangerous components must be made safe before personnel are allowed to work on or near these devices.

B. The potential for slips and falls in and around the oil section is augmented by residual transformer oil after the tank is drained. Personnel entering the oil section should be aware of this hazard and wear appropriate footwear.

C. The confined nature of the oil section together with the numerous components greatly increase the bump hazard within the tank. Personnel entering the oil section will be required to wear bump caps at all times.

D. Becuse of the confined nature of the oil section, heavy use of solvents (freon, hexanes, etc.) within the oil section can lead to overexposure and toxic effects. Personnel planning to use solvents for extended periods of time or in significant quantities should notify the Facility Manager. Industrial Hygiene (Division 3311) will be requested to monitor exposures and recommend proper controls.

E. A large release of SF6 gas from the high voltage components can result in a local oxygen deficient atmosphere 
SOP - Oil Section Maintenance at PBFA II / page 2

E. A large release of SF6 gas from the high voltage components can result in a local oxygen deficient atmosphere in the confined workspace of the oil section. Personnel entering the oil section should be aware of this potential hazard and if an oxygen deficient condition is suspected the environment should be tested for percent oxygen content.

F. The height at which personnel are sometimes required to work in the oil section would result in severe injury should a fall occur. Personnel working on the upper part of the oil section are required to wear safety belts and lanyards in order to limit the severity of a fall.

\section{Procedures for Entry Into the 0il section}

Before personnel entry into the PBFA II oil section for maintenance or repair activity, the Facility Manager shall be notified and the following actions performed:

A. The oil transfer system, high voltage charging system, and all high voltage trigger and/or calibration systems shall be placed in a "SAFE" state and the keys to enable these systems shall be secured in the $\mathrm{C} / \mathrm{M}$ lock box.

B. The southeast oil section mandoor located on the -10 foot level shall be opened.

C. Personnel entering the oil section shall take percent oxygen measurements as required (see Appendix A).

D. The two-man rule shall be followed whenever personnel enter the oil section. Both members of the team shall be authorized by the Operations Division, 1254, as having been trained in component safing procedures within the PBFA II oil section.

E. It shall be determined that personnel ( other than those entering the oil section, are present in the highbay and that at least one person in the immediate vicinity is trained in Cardiopulmonary Resuscitation (CPR).

\section{Procedures for Working Within the Oil Section}

Maintenance and repair teams entering the PBFA II oil section shall comply with the following procedures:

A. Before personnel are permitted to touch any energy storage device within the oil section, the device shall 
be made safe using approved techniques. All other devices in the immediate vicinity of the work area shall also be safed before work begins (see Appendix B for safing procedures).

NOTE: consideration must be given to the dielectric recovery phenomenon of capacitors. This is a characteristic by which recently exercised capacitors can build up an electric charge in the absence of any power source. This is true even for capacitors that have been properly discharged after use. For this reason, each capacitor must be continuously shorted to be considered completely safe.

B. Any energy storage device worked on shall be held at ground potential using an approved grounding strap with secure attaching devices at each end.

C. Should work be performed within the oil section for extended periods of time, or if significant amounts of solvents are used during maintenance operations, a fan or blower shall be placed in front of the entry door to direct air out of the tank to provide additional ventilation.

D. Work platforms shall be utilized whenever available. Personnel shall take appropriate precautions when working at heights by wearing safety belts and lanyards (reference PBFA II Safety Equipment SOP).

E. Upon completion of oil section activity, personnel shall ensure that all tools, cleaning materials, shorting straps, and other equipment is removed from the tank.

\section{Personnel Training}

PBFA II Operations, Division 1254, shall organize training sessions for facility personnel with regard to:

A. Proper shorting techniques of high voltage equipment.

B. Cardiopulmonary rescusitation and First Aid. 
Appendix A

Oxygen Deficient Environment Monitoring Procedures

A leak of SF6 gas used in the high voltage components can result in a local oxygen deficient environment within the oil section. If personnel entering the oil section suspect that this condition may exist, the tank should be tested before entry, or periodically during the work session if new leaks have been discovered.

Percent oxygen monitors are kept inside the PBFA II Control/Monitor room. Personnel requiring use of these instruments should report to Dennis Nations, ext. 6-2690, or personal pager \#142-501. Dennis is the C/M Manager and is responsible for issuing these devices.

Percent oxygen measurements shall be made at three locations around the top of the oil tank from the catwalk. A measurement shall also be taken at the oil section door before entry. Should these measurements show less then $19.5 \%$ oxygen, personnel should delay entry and remeasure every half hour until the oxygen level is at or above this level. 
Appendix B

Energy Storaqe Device Shorting Techniques

A. Basics

1. Definitions

A. "SHORT" - Good electrical contact to both capacitor terminals. Good electrical contact refers to bare metal to bare metal contact through a low resistance path, as with a shorting stick.

B. "GROUND" - Electrically tie a component to around potential.

C. "GROUND CONNECTION" - Bare metal contact point providing a low resistance path to ground potential.

D. "OPEN CIRCUIT" - Incomplete circuit resulting from poor connections or missing and/or failed components.

E. "SHORTING STRAP" - A strap made of low resistance material (e.q. wire braid) used to electrically tie component together and/or to ground potential.

2. Capacitor Safing Procedures.

A. Use facility shorting sticks with large hooks only.

B. Connect the grounding stick ground strap to a suitable ground connection.

C. Touch the hook end of the grounding stick to the capacitor case.

D. Maintain contact with the capacitor case and simultaneously touch the hook to the high voltage terminal of the capacitor.

E. While maintaining contact with the grounding stick, place a shorting strap from the capacitor case to the high voltage terminal. 


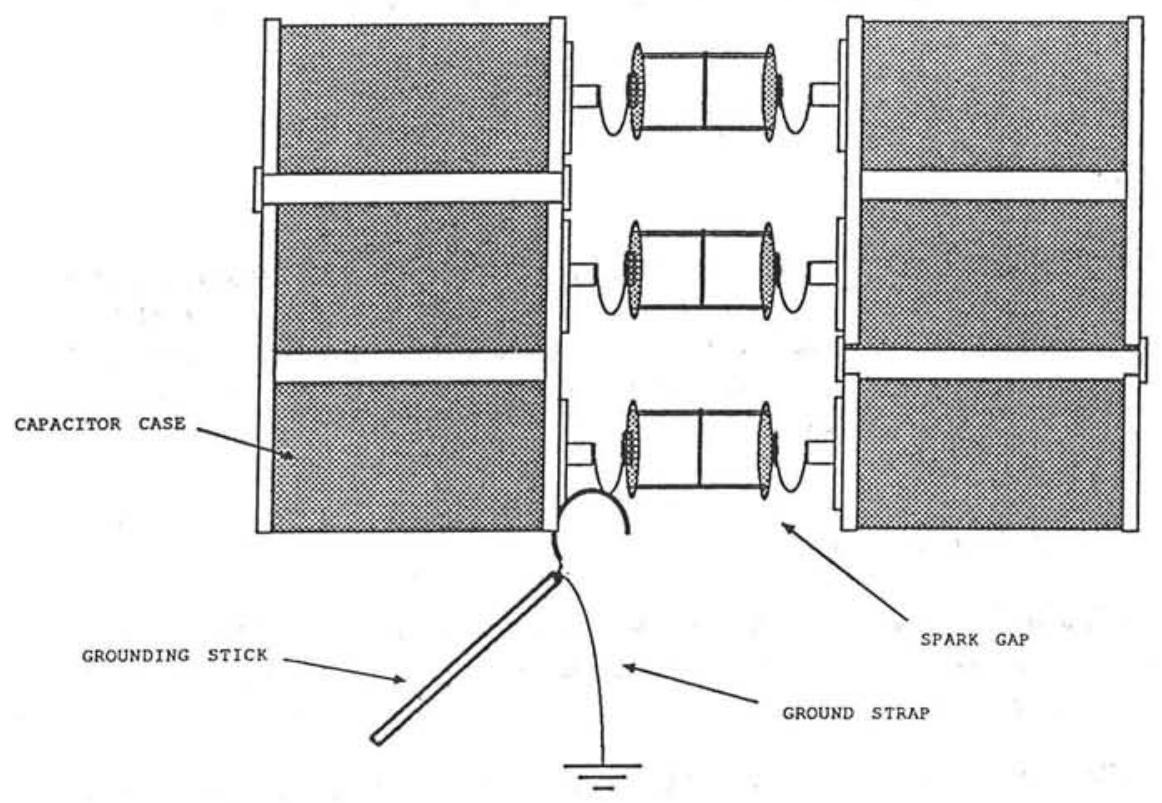

Eigure 1.

3. Preliminary Safety Procedures.

Before beginning work on high voltage components within the PBFA II oil section, the following procedures must be adhered to:

A. Ensure that the keys to the High Voltage breaker and High Voltage chassis are located in the $\mathrm{C} / \mathrm{M}$ lock box and lockout the box with the ESS padlock.

B. Inspect the dump relays and charge buss to ensure that they are shorted to ground.

C. Raise all Marx shorting rods from the top of the $\mathrm{H}$ frames.

NOTE: Although the shorting rods are the primary method for remote shorting assembled Marx generators, their operation should NEVER be relied upon as being a fail-safe mechinism. Marx capacitors must always be shorted with a shorting stick, as described above, in addition to the shorting rod system. 
Appendix B (cont.)

D. Before entering the oil section, inspect your equipment for any faulty materials or poor connections.

E. Remove watches, rings and other jewelry or metalic objects from your person.

F. Follow the two-man rule!

4. Basic Marx Fault Modes

Capacitors in a Marx generator are connected in parallel (see Figure 2).

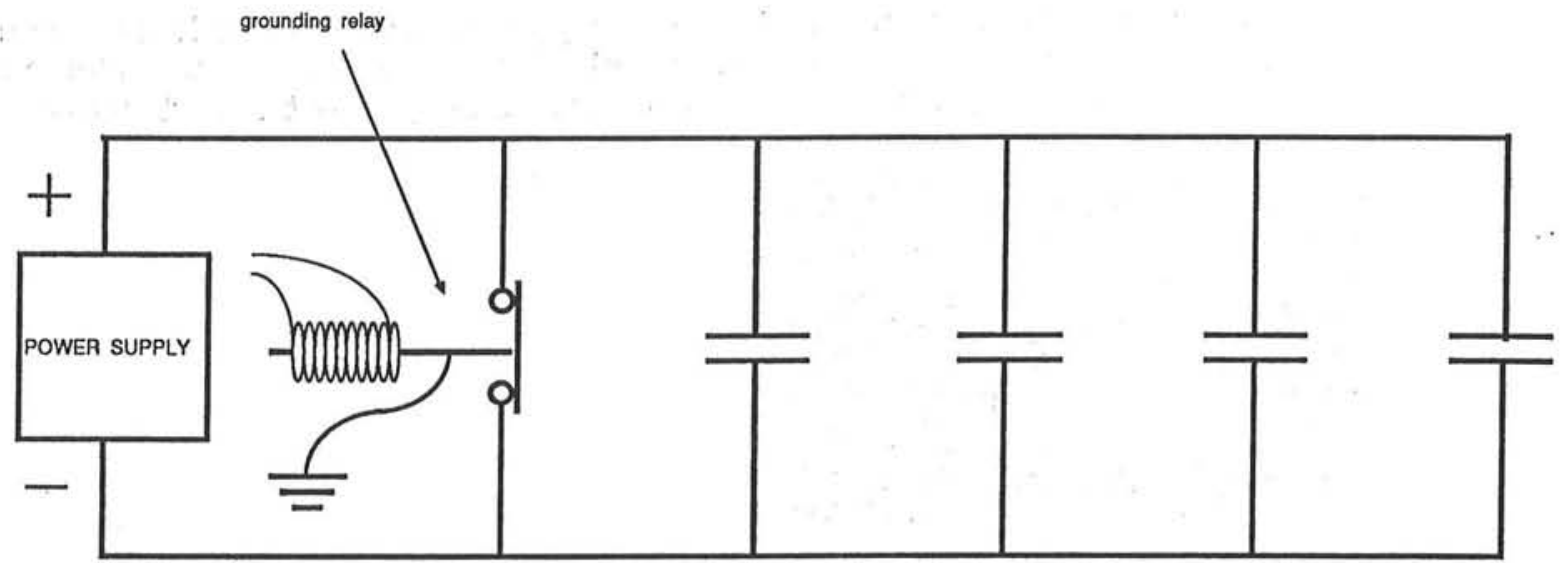

Figure 2. Simplified Marx Schematic

The grounding relay is normally closed, thus, the capacitors in the Marx are usually shorted and tied to ground potential. Figure 3 illustrates three common fault modes.

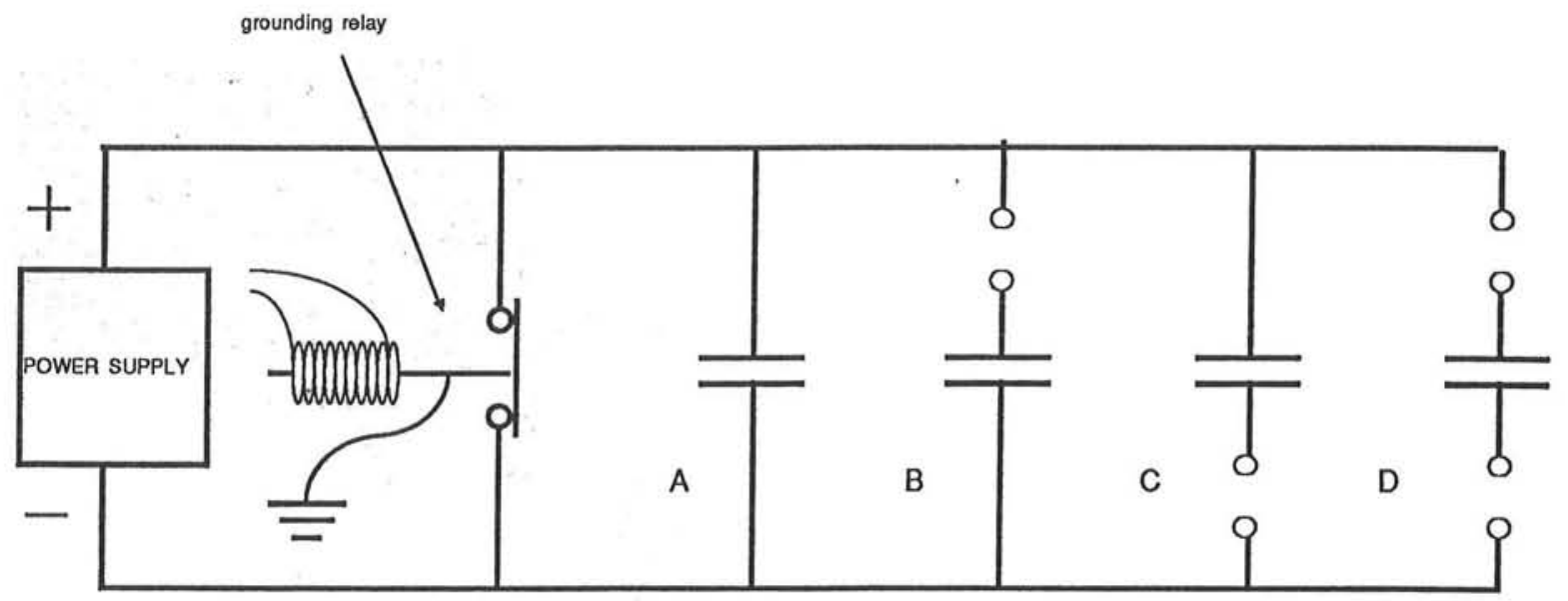

Figuro 3. Basic Fauli Modes 
Appendix B (cont.)

Capacitor \#2 has its high voltage terminal in an open circuit condition and its case is tied to ground. This condition is dangerous! Figures $4 \& 5$ show two scenarios by which energy from this capacitor can result in injury or death.

Capacitor \#3 has its high voltage terminal grounded and its case in an open circuit condition. This condition is dangerous! Figure 6 shows how the energy potentially stored between the case and high voltage terminals can be transfered into an unsuspecting worker.

Capacitor \#4 has both its high voltage terminal and case in an open circuit condition. This condition is dangerous! Figure 7 illustrates the potential danger.

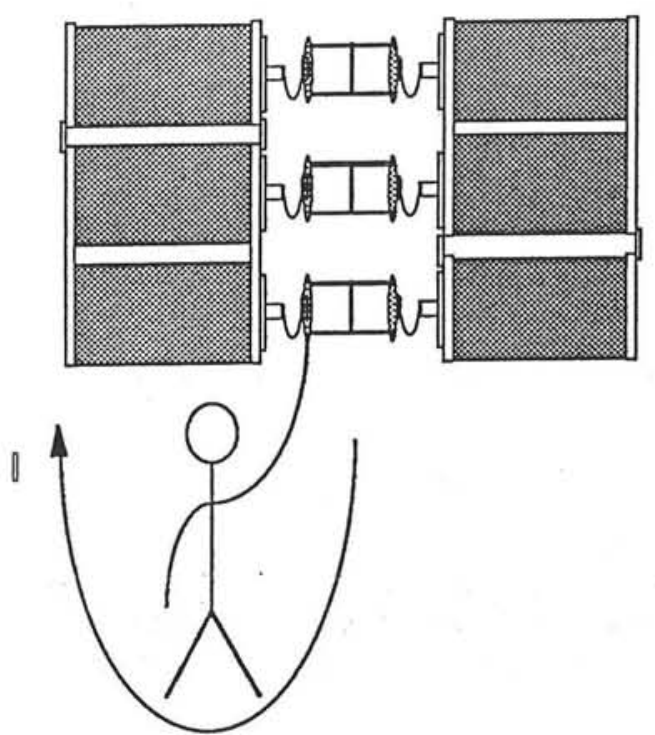

Figuro 4. Body In Dischargo Path

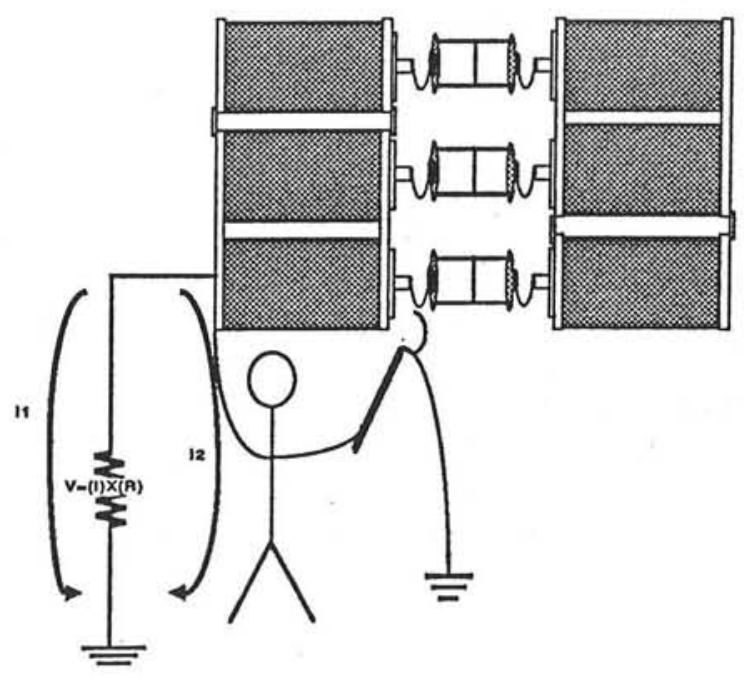

Figuro 5. Body In Parallel With Dischargo Path Resistanco 
Appendix B (cont.)

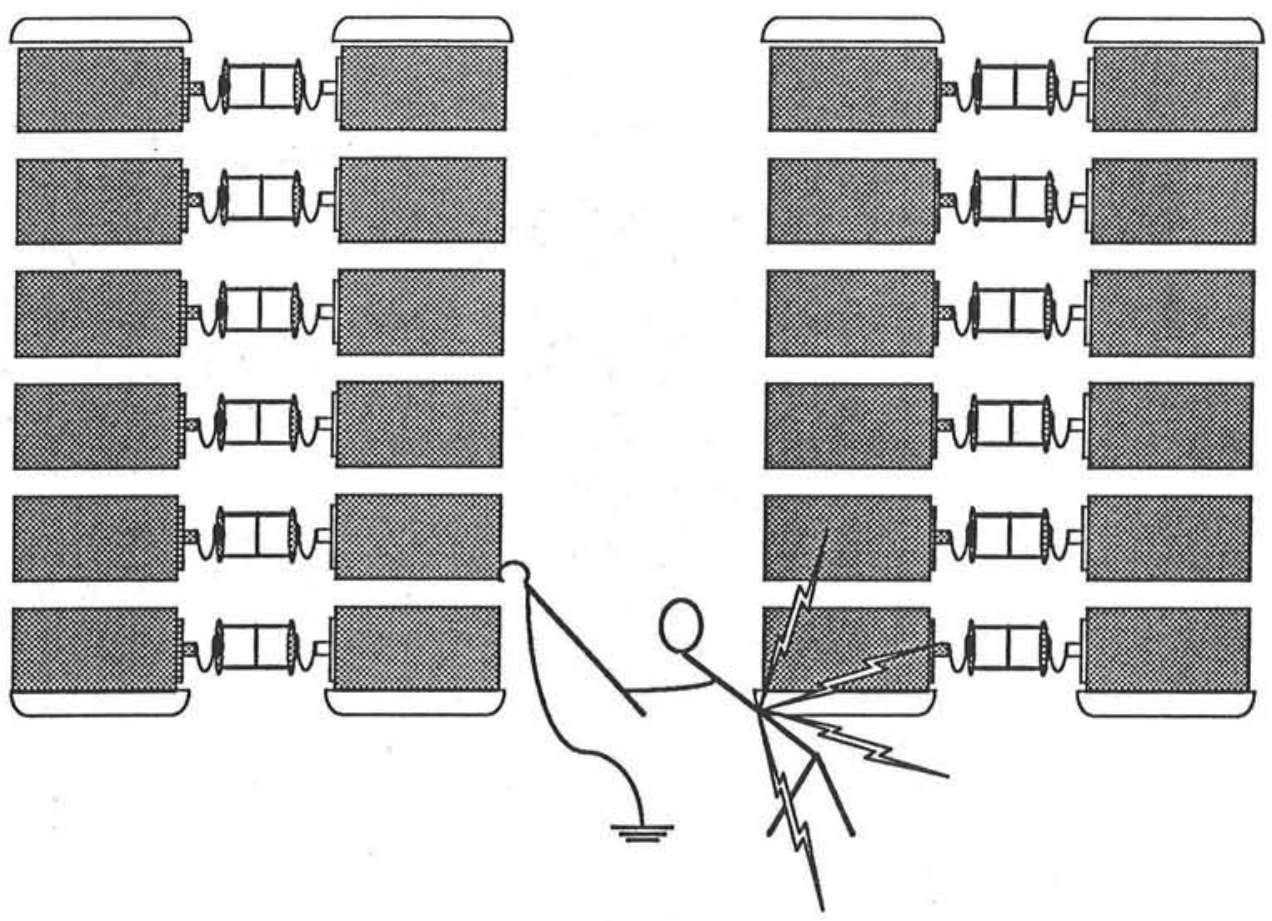

Figure 6. 
Appendix B (cont.)

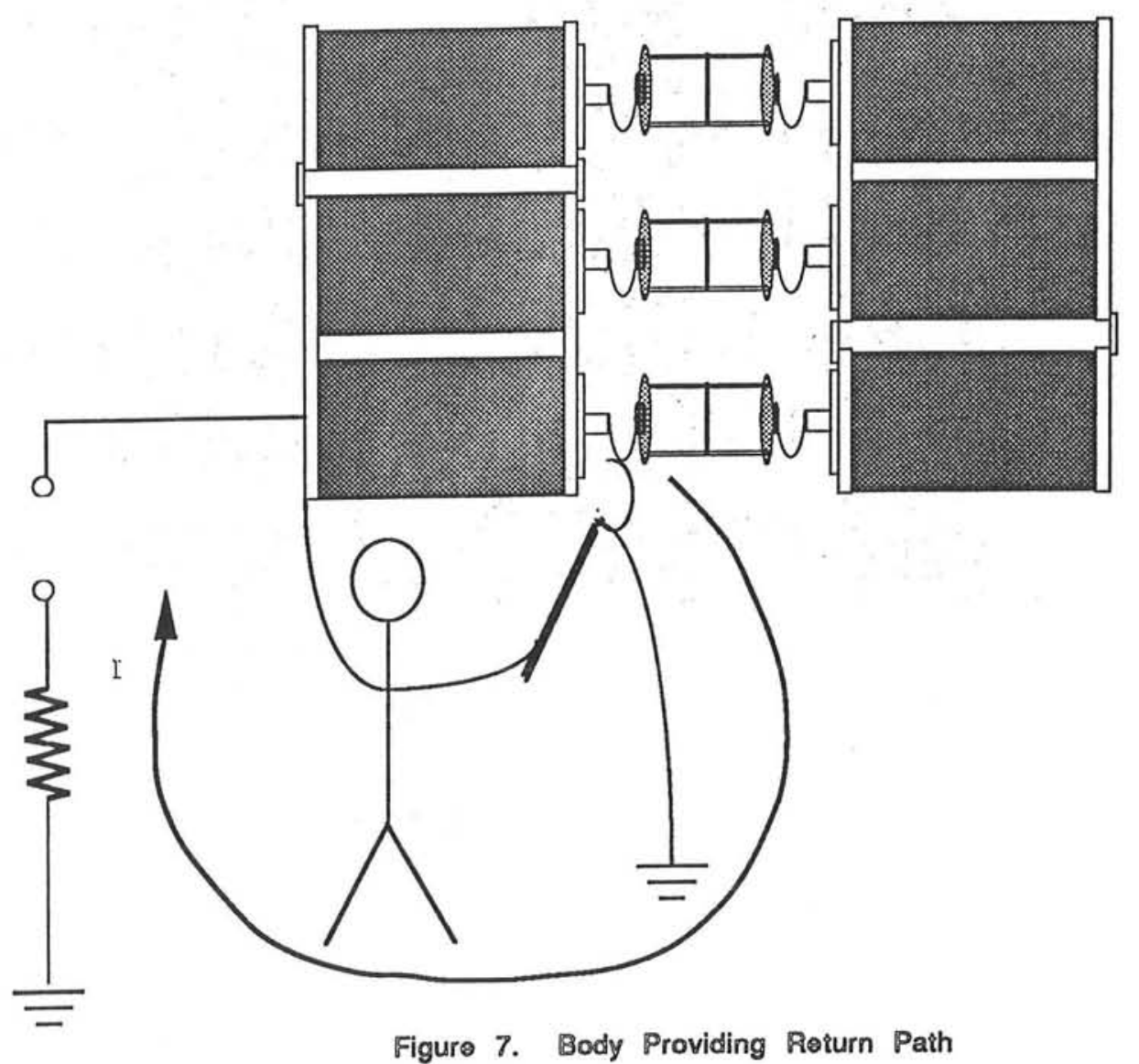


Appendix B (cont.)

5. General 0il Section Safety

A. NEVER TOUCH ANY DEVICE UNTIL IT IS GROUNDED TO THE TANK. Ground devices with a grounding stick first, then attach a ground strap as described in section 1 .

B. Stay as far away from devices as possible when walking around the tank.

C. Make sure grounding sticks are secured to a suitable ground connection before attempting to ground any device.

6. Safing A Marx Generator

A. Attach grounding stick to a suitable ground connection.

B. Touch the head of the grounding stick to the cases of the outside capacitors (see Figure 8).

C. Attach the case of the bottom capacitor in row 1 to tank ground with a ground strap while maintaining contact with the stick.

D. Attach all capacitor cases in row 1 to ground potential maintaining grounding stick contact to the ungrounded case at all times.

E. Repeat this procedure for all capacitors in the generator until all cases are held at ground potential with shorting straps.

F. Touch the grounding stick head to the bottom capacitor, row 1 , high voltage terminal while maintaining contact with the case (see Figure 9).

E. While maintaining contact, attach a ground strap from the case to the high voltage terminal.

F. Repeat this procedure for all capacitors, working from the bottom up, and then from the outside of the generator to the inside making sure to avoid touching any components which have not previously been safed. 
Appendix B (cont.)
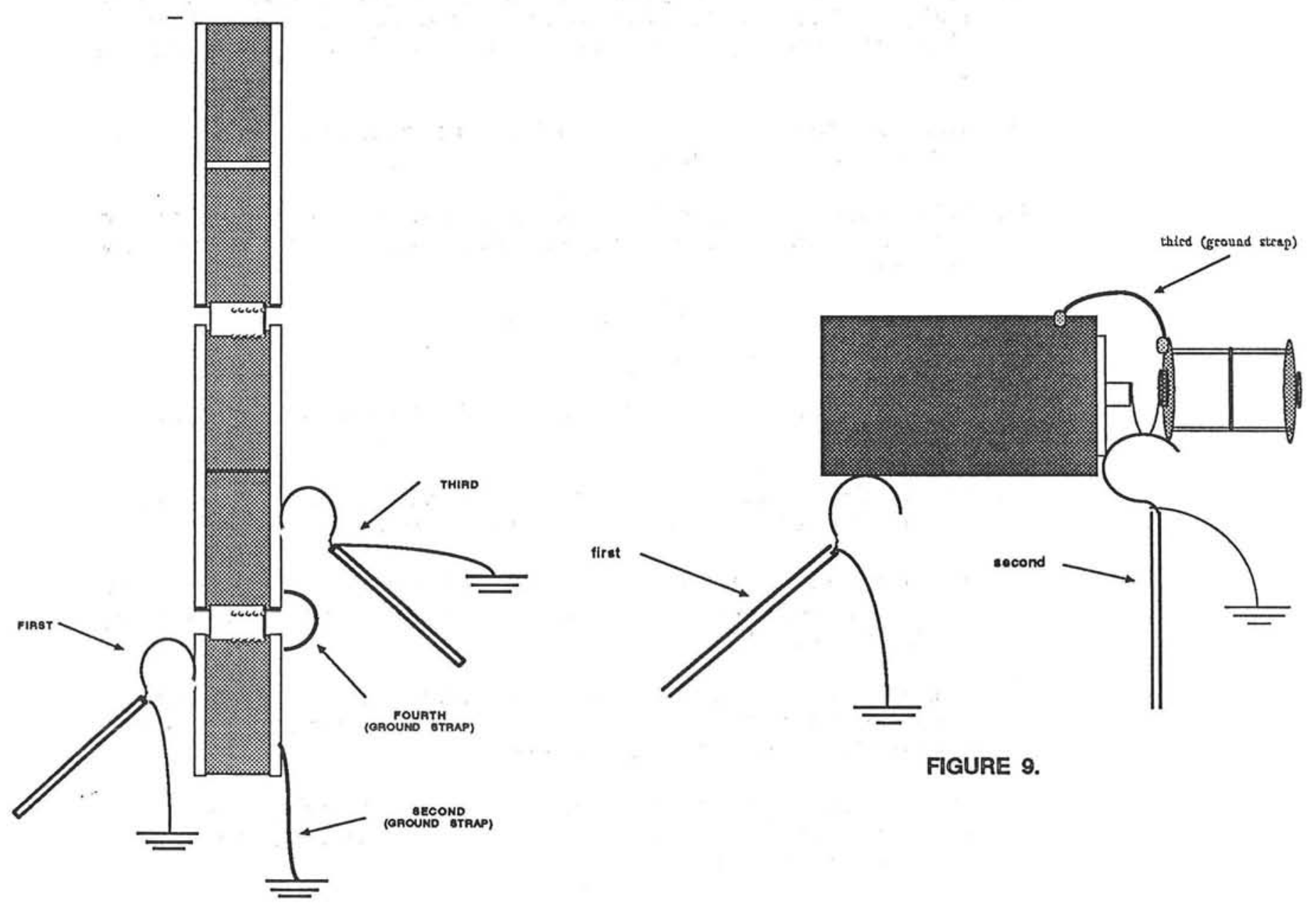

Figure 8. 
SAFE OPERATING PROCEDURE

FOR

FLUID SYSTEMS OPERATION

AT

PBFA II, BUILDING 983

Appendix 10

$10-1-10-2$ 
Table of Contents

Abstract . . . . . . . . . . . . . . . 0

I. References ..................... . . 1

II. Introduction . . . . . . . . . . . . . . . . . 1

III. System Hazards . . . . . . . . . . . . . . . . 1

A. Transformer 0il Processing System . . . . . . 1

B. Technical Water Processing System . . . . . . 2

IV. Appendices . . . . . . . . . . . . . . . . . . . 4

A. Authorized Fluid System Operators . . . . . . . 4

B. Fluid System Emergency Response Procedures. . 5 
SAFE OPERATING PROCEDURE

FOR

FLUID SYSTEMS OPERATION

AT

PBFA II, BUILDING 983

\begin{abstract}
This SOP describes the hazards involved with work in and around the PBFA II fluid systems. Improper safety practices can result in personal injury, destruction of property, and disruption of facility activities.
\end{abstract}

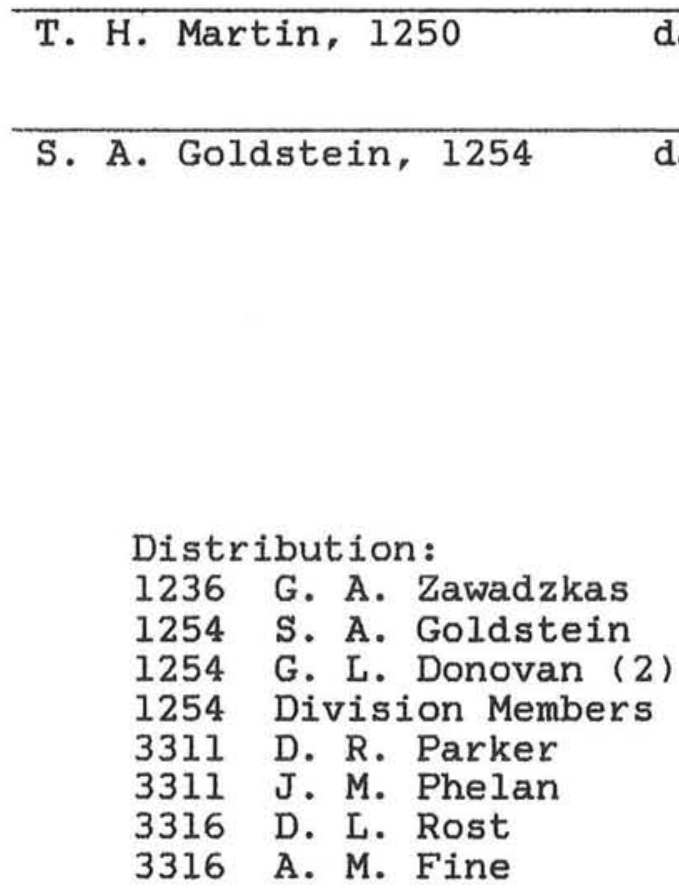

D. L. Rost, 3316 date

A. M. Fine, 3316 date

D. R. Parker, 3311 date

J. M. Phelan, 3311 date

Distribution:

1236 G. A. Zawadzkas

1254 S. A. Goldstein

1254 G. L. Donovan (2)

3311 D. R. Parker

3311 J. M. Phelan

3316 A. M. Fine 
SAFE OPERATING PROCEDURE

FOR

FLUID SYSTEMS OPERATION

AT

PBFA II, BUILDING 983

\section{References}

Reference materials for the PBFA II Fluid systems are kept by the Fluid system Manager, Bob Clevenger Div. 1254. Personnel requiring access to these documents should contact Bob at ext. 6-2691, or pager / 142-467. These documents cover specific operational procedures and in depth system descriptions. This Safe Operating Procedure will cover the hazards presented by these systems and procedures required of facility personnel.

\section{Introduction}

The PBFA II Fluid system is comprised of two separate systems :

1. Transformer Oil Processing System (TOPS)

2. Technical Water Processing System (TWPS)

These systems are designed to transfer and purify the 600,000 gallons of $0 i l$ and 500,000 gallons of deionized water required for the operation of PBFA II.

Operation of either of the Building 983 Fluid Systems is restricted to Fluid System personnel specifically authorized by PBFA II Operations, Division 1254 (Currently authorized personnel are listed in Appendix A). All facility residents should be aware of the hazards that may be encountered when working near fluid system equipment.

III. System Hazards

A. Transformer Oil Processing System:

Two major hazards are associated with working in and around the TOPS: 
1. Slips and falls may occur if residual oil is present around the work site or if spillage has occured. Personnel should be aware of this hazard, wear appropriate footwear, and put up barricades to warn other facility personnel who may pass by.

2. Injury may occur if personnel are working on or near remotely accuated devices during system operation. Personnel who must work on or near TOPS components must first contact the PBFA II Facility Manager (1) to ensure the appropriate subsystems are locked out.

B. Technical Water Processing System

A number of potential hazards may be associated with work in and around the TWPS:

1. Exposure to hazardous substances:

The operation of the PBFA II TWPS requires the use of three different hazardous substances:
a. Sulphuric Acid solution
b. Sodium Hydroxide solution
c. Chlorine Gas

During normal operation of the TWPS, these substances present no hazard to facility personnel; however, should an accident or failure of TWPS safety systems occur, immediate action is required of all facility personnel and visitors. Refer to Appendix B for emergency procedures.

2. Exposure to high noise levels during system operation. Personnel who must work near the TWPS during operation should wear appropriate hearing protection as recommended by the Industrial Hygiene Division, 3311 .

3. Slips and falls may occur if residual water is present or spillage has occured around the work site. Personnel should be aware of this hazard and put up barricades to warn other facility personnel who may pass by.

(1) The name and phone number of the on-duty Facility Manager will be posted near the entrance to the Data Acquisition Room (RM 104). The Facility Manager may be reached by phone, PA announcement, or personal pager. 
SOP - Fluid Systems Operation Bldq. 983 / page 3

4. A bump hazard exists within much of the TWPS due to the large number of overhead components. Personnel working in and around the TWPS are required to wear bump caps to prevent injury.

5. A shock hazard may exist when floors around TWPS components are wet. Work on electrical equipment shall not be attempted when water is present. If large amounts of water are present around electrical equipment, as from a significant spill, power should be disconnected until cleanup can be accomplished.

6. Exposure to ultraviolet light is possible within the system during maintenance operations. Personnel performing maintenance on the U.V. bacteria killers should wear appropriate face shields when equipment is operating. 
Appendix A

Authorized Fluid System Operators

Personnel authorized to operate the PBFA II Fluid Systems must be familiar with the hazards present during operation, emergency response procedures and the contents of this Safe Operating Procedure.

Transformer 0il Processing System Operators:

Name

Bob Clevenger

Scott Drennan

Nibby Grelle

Joe Lundstrom

Joe Stewart
Org.

Signature

1254

1254

1254

1254

1254
Date

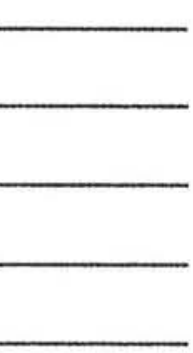

Technical Water Processing System Operators:

$\begin{array}{llll}\text { Name } & \text { Org. } & \text { Signature } & \text { Date } \\ \text { Bob Clevenger } & 1254 & \\ \text { Scott Drennan } & 1254 & \\ \text { Nibby Grelle } & 1254 & \\ \text { Joe Lundstrom } & 1254 & \\ \text { Joe Stewart } & 1254 & \end{array}$


Appendix B

Fluid System Emergency Response Procedures

Operation of the PBFA II Technical Water system requires the use of hazardous substances for process and purification operations. The TWPS incorporates safety systems and sensors to prevent inadvertant release of these substances; however, should an accident occur immediate response is required to prevent injury to building residents. The hazarous substances and required accident responses are:

A. Sulphuric Acid - a solution of this acid is used to regenerate water deionizer beds after depletion. The acid is stored in bulk in a tank on the southwest corner of Building 983. This storage tank contains a $97 \%$ solution of Sulphuric Acid that is diluted in use to a $6 \%$ solution.

Should a spill of this acid occur, the following actions are required:

1. Activate building evacuation system. All personnel should be moved to the north side of the asphalt perimeter around Building 983.

2. Shut off main acid supply line at storage tank to prevent further spillage.

3. Wash off any personnel with water who have had contact with acid and notify Medical personnel of such exposure when they arrive.

4. Call base Emergency number, extension 144, and announce an acid spill at Building 983, Area IV.

5. Fire Department personnel are in charge of this and all other chemical spill sites. Facility personnel must not attempt to enter the building until Fire Department personnel are on the scene, and then only when requested by the officer in charge.

6. Notify the Environmental Health Division and appropriate 1200 management personnel of the situation as soon as possible. The persons to notify in case of an acid spill are:

a. Environmental Health, Org. 3311 , Jim Phelan, phone \#4-7065 
b. Sector 50 Emergency Preparedness Chief, S. A. Goldstein, Org. 1254, phone \#4-3976, personal pager \#142-192

B. Sodium Hydroxide - a solution of this caustic base is required to regenerate water deionizer beds as with the acid described above. This material is stored in bulk in a tank on the southwest corner of Building 983, next to the acid bulk storage. This storage tank contains a $50 \%$ solution of Sodium Hydroxide that is diluted to a $6 \%$ solution before use.

Should a spill of this chemical occur, the following actions are required:

1. Activate building evacuation alarm. All personnel should be moved to the north side of the asphalt perimeter around Building 983 .

2. Shut off main caustic supply line at storage tank to prevent further spillage.

3. Wash off any personnel with water who have had contact with the caustic solution and notify Medical personnel of such exposure when they arrive.

4. Call base Emergency number, extension 144, and announce a caustic chemical spill at Building 983, Area IV.

5. Fire Department personnel are in charge of this and all other chemical spill sites. Facility personnel must not attempt to enter the building after evacuation until Fire Department personnel are on the scene, and then only when requested by the officer in charge.

6. Notify the Environmental Health Division and appropriate 1200 management personnel of the situation as soon as possible. The persons to notify in case of a caustic spill are:

a. Environmental Health, Org. 3311, Jim Phelan, phone \#4-7065

b. Sector 50 Emergency Preparedness Chief, S. A. Goldstein, Org. 1254, phone \#4-3976, personal pager \#142-192 
C. Chlorine Gas - this chemical is used to kill bacteria within the TWPS. Chlorine is confined to a small room within the Building 983 south mechanical room.

Should a leak of this chemical occur, the following actions are required:

1. Activate building evacuation system. All personnel should be moved to the north side of the asphalt perimeter around Building 983.

2. Call base Emergency number, extension 144, and announce a chlorine leak at Building 983, Area IV.

3. Help evacuate any personnel who have had contact with the chemical that require aid, and notify Medical personnel of such exposure when they arrive.

4. Fire Department personnel are in charge of this and all other hazardous spill sites. Facility personnel must not attempt to enter the building after evacuation until Fire Department personnel are on the scene, and then only when requested by the officer in charge.

5. Notify the Environmental Health Division and appropriate 1200 management personnel of the situation as soon as possible. The persons to notify in case of a caustic spill are:

a. Environmental Health, Org. 3311, Jim Phelan, phone \#4-7065

b. Sector 50 Emergency Preparedness Chief, S. A. Goldstein, Org. 1254, phone \#4-3976, personal pager \#142-192 


\section{SAFE OPERATING PROCEDURE \\ FOR MAINTENANCE AND REPAIR \\ IN THE WATER SECTION \\ OF \\ PBFA II, BUILDING 983}

Appendix 11 


\section{Table of Contents}

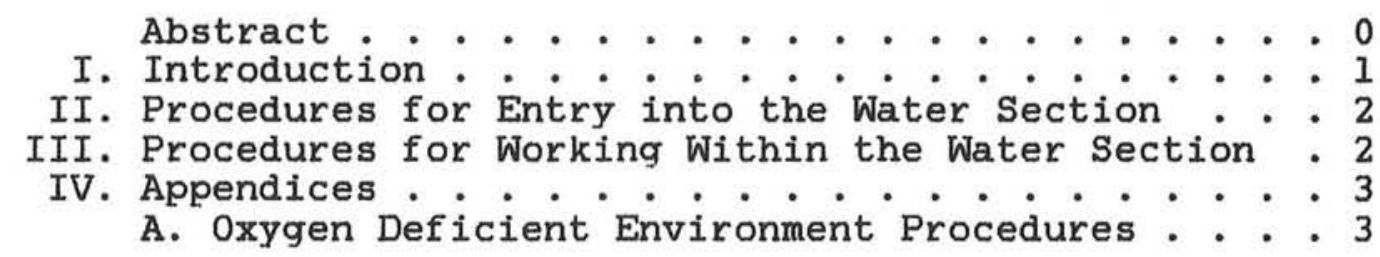




\title{
SAFE OPERATING PROCEDURE \\ FOR MAINTENANCE AND REPAIR \\ IN THE WATER SECTION
}

OF

PBFA II, BUILDING 983

\begin{abstract}
This SOP describes procedures for performing maintenance and repair operations in the water section of PBFA II, Building 983, when water is out of the machine ( reference PBFA II SOP for Underwater Diving for underwater operations). Three major hazards are associated with entry into the water section of PBFA II:
\end{abstract}

1. An oxygen deficient environment may occur in the tank from an SF6 gas leak.

2. Slips and falls resulting from residual water in the tank.

3. Bump hazards due to the confined nature of the work space and numerous components.

T. H. Martin, 1250 date

S. A. Goldstein, 1254 date
D. R. Parker, 3311 date

J. M. Phelan, 3311 date

Distribution:

D. L. Rost, 3316 date

1236 G. A. Zawadzkas

1250 T. H. Martin

1254 S. A. Goldstein

1254 G. L. Donovan (2)

A. M. Fine, 3316 date

1254 Division Members

3311 D. R. Parker

3311 J. M. Phelan

3316 D. L. Rost

3316 A. M. Fine 
SAFE OPERATING PROCEDURE

FOR MAINTENANCE AND REPAIR

IN THE WATER SECTION

OF

PBFA II, BUILDING 983

\section{Introduction}

Operation of the PBFA II Pulse Forming section requires that periodic repair be performed as well as routine maintenance operations. Entry into the water section presents a number of potential hazards to personnel.

A. The potential for slips and falls in and around the water section is enhanced by residual water left after the tank has been drained. Personnel entering the water section should be aware of this hazard and wear appropriate footwear.

B. The confined nature of the water section together with the high component density greatly increases the bump hazard within the tank. Objects dropped by personnel working overhead also adds to the potential for head injuries. Personnel entering the water section will be required to wear bump caps.

C. Because of the confined nature of the water section, heavy use of solvents ( freon, hexanes, etc. ) within the water section can lead to overexposure and toxic effects. Personnel planning to use solvents for extended periods of time or in significant quantities should notify the Facility Manager. Industrial Hygiene, Division 3311, will be requested to monitor exposures and recommend proper controls.

D. A large release of SF6 gas from the Rimfire gas switches or their supply system can result in a local oxygen deficient atmosphere within the confined workspace of the water section. Personnel entering the water section should be aware of this potential hazard and if an oxygen deficient condition is suspected the environment should be tested for percent oxygen content. 
SOP - Water Section Maintenance at PBFA II / page 2

E. The height at which personnel are sometimes required to work in the water section would result in severe injury should a fall occur. Personnel working on the upper part of the water section without benefit of suitable work platforms are required to wear safety belts and lanyards in order to limit the severity of a fall.

\section{Procedures for Entry Into the Water Section}

Before personnel enter the PBFA II water section for maintenance or repair activity, the following actions shall be performed:

A. The water transfer system and any high voltage calibration systems shall be placed in a "SAFE" state and the keys to enable these systems shall be secured in the C/M lock box.

B. Gas pressure within the Rimfire main switches shall be lowered to 20 psig or less.

C. Personnel entering the water section shall take percent oxygen measurements as required (see Appendix A).

D. Should maintenance operations affect the integrity of the $K r F$ Laser Trigger system beampaths, maintenance personnel shall inform the LTS operator and ensure that laser radiation is not propagated into that area of the water section.

E. The two-man rule shall be followed whenever personnel enter the water section. Both members of the team shall be authorized by the Operations Division, 1254.

III. Procedures for Working Within the Water Section

Maintenance and repair teams entering the PBFA II water section shall comply with the following procedures:

A. Should work be performed within the water section for extended periods of time, or if significant amounts of solvents are used during maintenance operations, a fan or blower shall be placed on top of the catwalk to direct air into the tank to provide ventilation.

D. Work platforms shall be utilized whenever available. Personnel shall take appropriate precautions when working at heights by wearing safety belts and lanyards (reference PBFA II Safety Equipment SOP).

E. Upon completion of water section activity, personnel shall remove all tools, cleaning materials, and other equipment from the tank. 
Appendix A

Oxygen Deficient Environment Monitoring Procedures

A leak of SF6 gas used in the Rimfire main switches can result in a local oxygen deficient environment. If personnel entering the water section suspect that this condition may exist, the tank should be tested before entry, or periodically during the work session if new leaks have been discovered.

Percent oxygen monitors are kept inside the PBFA II Control/Monitor room. Personnel requiring use of these instruments should report to Gary Devlin, ext. 6-4376 or 6-7709. Gary is the C/M Coordinator and is responsible for issuing these devices.

Percent oxygen measurements shall be made at three locations around the top of the water tank from the catwalk. A measurement shall also be taken at the water tank floor upon entry. Should any of these measurements show less then 19.5\% oxygen, personnel should delay entry and remeasure every half hour until the oxygen level is acceptable. 


\section{SAFE OPERATING PROCEDURE}

FOR THE

GAS SWITCH PRESSURE TEST VESSEL

AT

PBFA II, BUILDING 983

Appendix 12 
Table of Contents

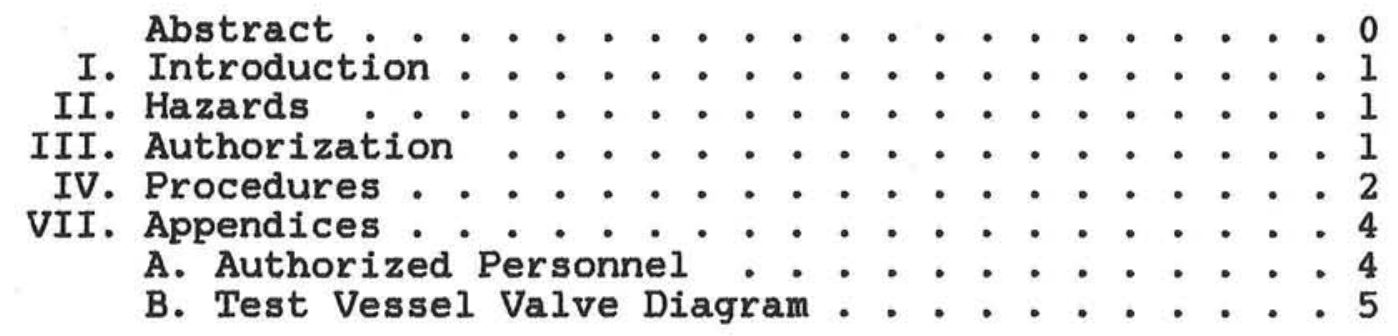


SAFE OPERATING PROCEDURE

FOR THE

GAS SWITCH PRESSURE TEST VESSEL

AT

PBFA II, BUILDING 983

\begin{abstract}
This document outlines safe operating procedures for the Rimfire Gas Switch pressure test vessel at PBFA II, Building 983. Improper use of this device could result in personal injury.
\end{abstract}

T. H. Martin, 1250 date

S. A. Goldstein, 1254 date
D. L. Rost, 3442 date

A. M. Fine, 3442 date

Distribution:

1236 G. A. Zawadzkas

1251 E. J. Constantineau

1254 S. A. Goldstein

1254 G. L. Donovan (2)

1254 Division Members

3442 D. L. Rost

3442 A. M. Fine 
SAFE OPERATING PROCEDURE

FOR THE

GAS SWITCH PRESSURE TEST VESSEL

AT

PBFA II, BUILDING 983

\section{Introduction}

Before being put into operation, PBFA II Rimfire gas switches are pressurized to ensure structural integrity and to determine if they have any gas leaks. Pressure testing is conducted underwater to a) limit the severity of an explosion should a switch fail, and b) provide visual indication of gas leaks.

\section{Hazards}

A. Rimfire gas switches have a volume of approximately 3.5 cubic feet and may be pressurized to as much as 150 psig. Should a switch fail during this test, an explosion of significant proportions could result. This test vessel has been provided to contain the energy released should an explosion occur.

B. A light fixture has been incorporated into the test vessel to aid in inspection during pressure testing. Should a switch fail during a test, water may splash onto the test vessels electrical circuitry. To prevent injury from this potential shock hazard, a ground fault interrupter has been provided.

\section{Authorization}

Only personnel authorized by the Pulsed Power Operations Division, 1254, shall be permitted to operate this device. Before being authorized these personnel shall:

A. Familiarize himself/herself with the test vessel gas handiing system including the valve configurations, safety relief valves, and pressure gauges.

B. Be instructed as to the proper operation of the test vessel with regard to pneumatic door opener operation as well as pressure test procedures. 
C. Be familiar with and understand the contents of this Safe Operating Procedure.

(see Appendix A for currently authorized personnel)

IV. Procedures

A. Make sure all the valves on the distribution system are closed and the supply regulator is set at 0 psi.

B. Ensure that the tank is filled to approximately 23 inches with water before beginning the test procedure.

C. Open the gas bottle supply valve and set the pressure regulator on the gas supply cylinder to 100 psig.

D. Open the tank lid by moving the "RED" knob on the door actuator towards the rear of the tank. This valve should be operated slowly to prevent rapid movement of the vessel lid. NOTE: whenever lid is in the raised position the mechanical brace on the side of the tank should be secured. This will prevent the lid from falling should a failure of the pneumatic system occur.

E. Install the pressure test end cover onto the gas switch using all bolts and pressurize the switch to 5 to 10 psig by cracking valve 1 and 4 .

(see Appendix B for valve diagram)

F. Lower the switch into the tank with the gas switch lifting fixture and either the portable hoist or a crane.

G. After the switch is properly placed on the tank rollers, close the lid by slowly moving the "RED" knob towards the front of the tank.

H. Secure the lid with the two latches on the front edge of the lid.

I. Crack open valves 1 and 4 until the pressure in the switch reaches 55 psia ( 43 psig SNLA), as shown on tank pressure gauge, then close valve 1. NOTE: under no circumstances should the lid be unsecured while the switch is pressurized above 5 to 10 psig. If a problem arises that requires access into the test vessel, the system must first be depressurized to the 5 to 10 psi level. 
J. Observe the switch every 15 minutes or so for one hour to determine if switch leaks.

$K$. At the end of one hour, open valve 2 until switch pressure is lowered to 5 to $10 \mathrm{psig.}$

L. Unsecure lid and remove switch from tank.

M. Vent remaining pressure from switch and remove pressure test end plate.

N. Close valve on gas bottle and back off pressure regulator to 0 psi.

0 . Vent supply line by opening valves 1 and 2 .

P. Close all valves. 
Appendix A

List of Authorized Users

Name

Chambers, Rod

Donovan, Guy

Drennan, Scott

Johnson, Mark

King, Curtis, Jr.

Lundstrom, Joe

McGovern, Harry

Mikkalsen, Jim

Nielsen, Dan

Schaub, Mike

Ziska, Gerold
Org.

Signature

Date

1254

1254

1254

1254

1254

1254

1254

1254

1254

1254

1254
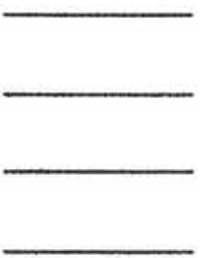
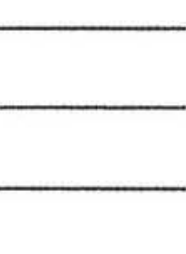


\section{Appendix B}

Test Vessel Valve Diagram

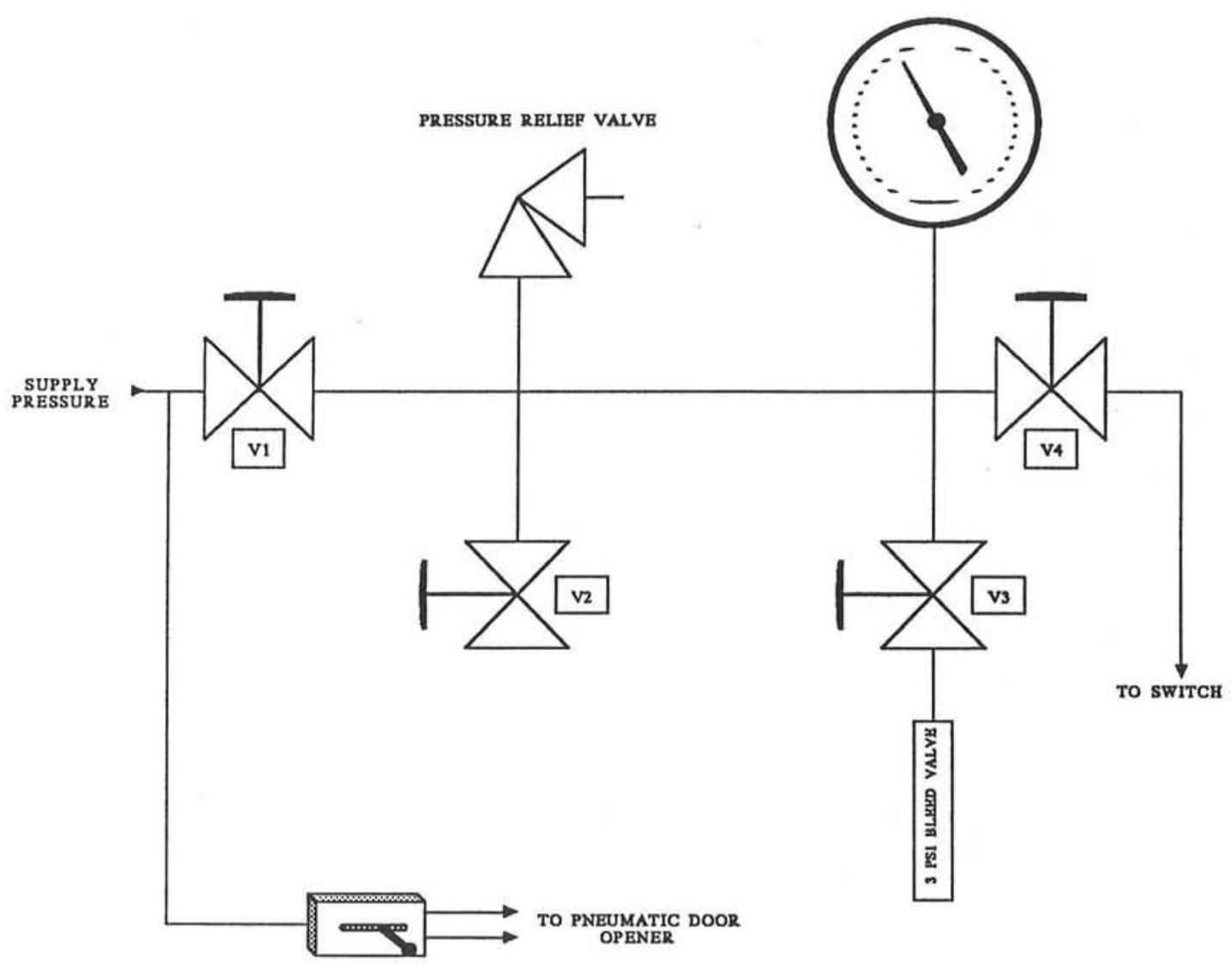

Test Vessel Valve Diagram 


\section{SAFE OPERATING PROCEDURE FOR \\ IONIZING RADIATION HAZARDS}

AT

PBFA II, BUILDING 983

Appendix 13 


\section{Table of Contents}

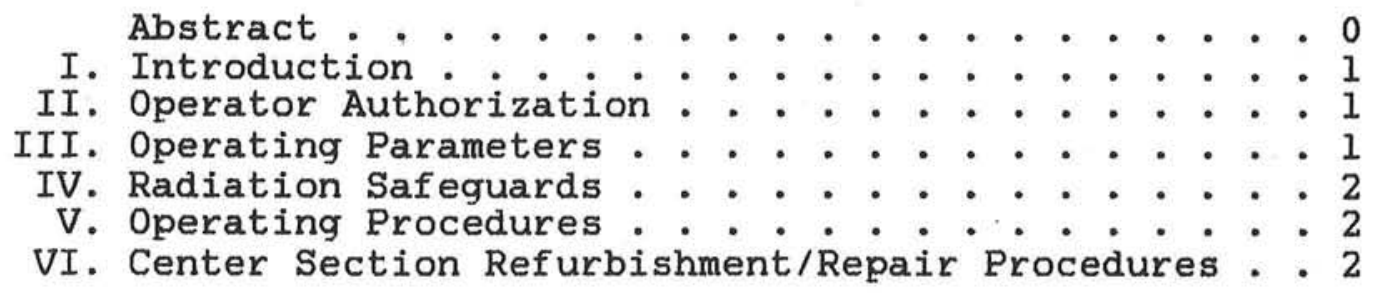




\title{
SAFE OPERATING PROCEDURE
}

FOR

IONIZING RADIATION HAZARDS

AT

PBFA II, BUILDING 983

\begin{abstract}
This SOP outlines procedures for minimizing hazards from ionizing radiation at PBFA II, Building 983. Failure to follow proper procedures can result in personnel exposure to high levels of radiation.
\end{abstract}

T. H. Martin, 1250 date

S. A. Goldstein, 1254

date
D. R. Parker, 3311 date

J. M. Phelan, 3311 date

G. E. Tucker, 3312 date

\begin{tabular}{ll}
\hline T. N. Simmons, 3312 & date \\
\hline D. L. Rost, 3316 & date \\
\hline A. M. Fine, 3316 & date
\end{tabular}

1236 G. A. Zawadzkas

1250 T. H. Martin

1254 S. A. Goldstein

1254 G. L. Donovan (2)

1254 Division Members

3311 D. R. Parker

3311 J. M. Phelan

3312 G. E. Tucker

3312 T. N. Simmons

3316 D. L. Rost

3316 A. M. Fine 
SAFE OPERATING PROCEDURE

FOR

IONIZING RADIATION HAZARDS

AT

PBFA II, BUILDING 983

\section{Introduction}

PBFA II is a pulsed ion accelerator used for inertial confinement fusion research at SNLA Area IV, Building 983. Operation of PBFA II is the responsibility of Pulsed Power Operations, Division 1254. Facility personnel are required to follow this Safe operating procedure (SNL Safety Manual Sec. 6.6).

\section{Operator Authorization}

PBFA II will be operated only by qualified, trained personnel who have been authorized by the supervisor, Division 1254. Operators must be knowledgable of all hazards involved with operation of the accelerator. A list of designated operators and their accelerator safety training shall be maintained by the Supervisor, Division 1254 .

III. Operating Parameters

PBFA II has the following maximum parameters at the Plasma Opening Switch region of the accelerator: 30MV, $4 \mathrm{MJ}$. These parameters shall not be increased without prior concurrence of Health Physics, Division 3312.

IV. Radiation Safequards

(Refer to SNL Safety Manual for additional guidance)

A. Efforts will be made to keep occupational radiation exposure to a minimum.

B. All personnel involved in the operation of PBFA II shall wear personal dosimeter badges when in Building 983. 
SOP - Ionizing Radiation Bldq. 983 / page 2

C. PBFA II will begin operations with $15 \mathrm{MV}$ at the diode region and will increase to $30 \mathrm{MV}$ during Phase II operations. Little or no radioactivity will be present at the beginning of operation. During Phase II, components of the vaccuum insulator stack may become activated and radioactive gases may be produced above and below the machine center section. Area IV Health Physicists will monitor for radioactivity and provide written instructions appropriate for the current radiation environment. These instructions shall be posted along with the SOP and carry the same force as the SOP. When Phase II operation is fully established, these instructions shall be made a permanent part of the Safe Operating Procedure.

D. Any test or experiment involving unusual conditions (abnormal accelerator voltage, accelerator current, or shot rate, or the use of toxic, radioactive, or explosive materials) shall be coordinated and approved by PBFA II Operations, Org. 1254, Industrial Hygiene, Org. 3311, Health Physics, 0rg. 3312, and Safety Division, Org. 3316.

\section{Operating Procedures}

Procedures specified in the PBFA II Personell Access SOP \#28000 8511, regarding facility access controls and system testing shall be adhered to. In addition, all facility safety beacons, audible alarms, and T.V. cameras shall be tested monthly to ensure proper operation. Results of these tests shall be logged in the PBFA II C/M log.

VI. Center Section Refurbishment/Repair Procedures

\section{A. General}

The PBFA II Center Section is now likely to be radioactive following a near full-power, 36 module, downline shot. For this reason the following policy shall be adhered to.

\section{B. Specific Policy and Procedures}

1. A member of Health Physics, Div. 3312, is required at all near full-power, 36 module downline shots until such a time as the radiation environment is well characterized and non-changing.

2. No one may enter the top radiation shield tank nor the bottom lift area until Health Physics has measured the radioactive gas concentration and gamma exposure and determined reentry requirements. 
SOP - Ionizing Radiation Bldg. $983 /$ paqe 3

3. For a period of 24 hours following a 36 module, near full-power downline shot persons working regularly above and below PBFA II must wear personnel dosimeters.

4. Following a near-full power downline shot, any burn marks on center section components must be surveyed by Health Physics personnel who will provide handling, refurb, and disposal instructions, prior to any refurbishment processing.

5. All radioactive components must be properly labeled. Health Physics will provide appropriate labels. Any components reading $2 \times 10-3 \mathrm{R} /$ hour or greater must be placed in an appropriately labelled radiation area or stored in a shieled enclosure.

6. Radioactive material will be bagged, labelled and given to Health Physics for disposal.

7. The following guidelines shall be used for cutting, grinding or welding any radioactive components.

Contact GM

( $\mathrm{mR} / \mathrm{hr}$ reading) Requirements

$0.1 \quad$ No action

0.1 to 0.5

Continuous Health Physics

coverage not required. Can be done in TA-IV but use of TA-I toxic shop is desirable. Place plastic or paper under work area to contain contamination. Respirators and anticontamination garments desirable but not required. $\mathrm{HP}^{\prime} \mathrm{s}$ will monitor area after operation.

0.5 to 5.0

Health Physics will cover operation if done in TA-IV. Operation will be done in TA-I toxic shop if possible. Floor shall be covered and a hotline established. Anticontamination garments and respirators shall be required. Persons, equipment and the work area will be monitored after the operation. 


\section{SOP - Ionizing Radiation Bldg. $983 /$ page 4}

$$
\begin{aligned}
& 5.0 \text { to } 100.0 \\
& >100.0 \mathrm{mR} / \mathrm{hr}
\end{aligned}
$$

Will not be done in TA-IV unless need is critical. Health Physics will support the operation and issue instructions.

Must be done in a hot shop. TA-I toxic shop may not accept the job. Work may have to be sent to Los Alamos. 


\section{SAFE OPERATING PROCEDURE \\ FOR \\ UNDERWATER DIVING \\ AT \\ PBFA II, BUILDING 983}

Appendix 14 


\section{Table of Contents}

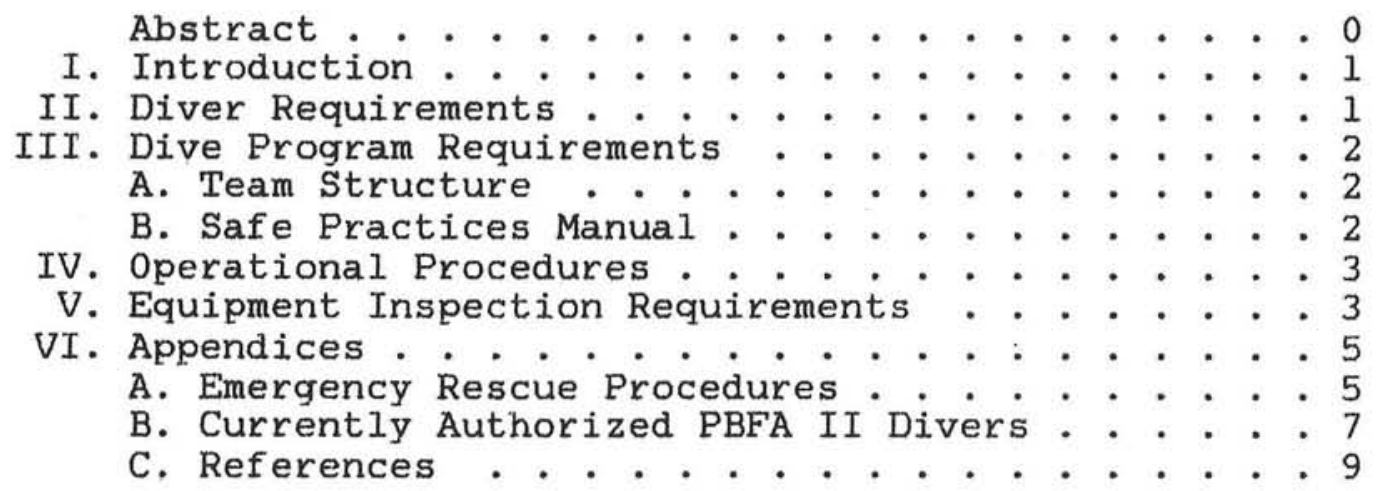




\title{
SAFE OPERATING PROCEDURE
}

FOR

UNDERWATER DIVING

AT

PBFA II, BUILDING 983

\begin{abstract}
This SOP outlines procedures for underwater diving operations at PBFA II. Building 983. The hazards involved include personal injury and drowning.
\end{abstract}

T. H. Martin. 1250 date

S. A. Goldstein, 1254 date

Distribution:

1236 G. A. Zawadzkas

1250 T. H. Martin

1254 S. A. Goldstein

1254 G. L. Donovan (2)

1254 Division Members

3311 D. R. Parker

3311 J. M. Phelan

3442 D. L. Rost

3442 A. M. Fine
D. R. Parker, 3311 date

J. M. Phelan, 3311 date

D. L. Rost, 3442 date

A. M. Fine, 3342 date 
SAFE OPERATING PROCEDURE

FOR

UNDERWATER DIVING

AT

PBFA II, BUILDING 983

\section{Introduction}

The Pulse Forming Section of PBFA II utilizes approximately 660.000 gallons of deionized water as its dielectric medium. Operation of this accelerator section and the Technical Water Processing system requires daily maintenance, inspection, and repair operations that can, and in some cases must, be performed underwater. Underwater diving techniques provide a means to accomplish many of these tasks in a safe and efficient manner. Both SCUBA and surface supplied air (hookah) operations are employed at Building 983. While hazards exist, diving conditions in PBFA II are very well controlled compared to typical open-water environments. The limited depth of dives within PBFA II do not require the use of dive tables. however, diving records shall be kept.

\section{Diver Requirements}

Before being authorized to perform underwater diving activities at PBFA II, all divers must have:

A. A certification in SCUBA diving by a nationally accredited school (N.A.U.I., P.A.D.I., N.A.S.D.S.)

B. Abovewater experience in the tasks to be performed underwater.

In addition to the above all team divers should have:

A. A medical examination prior to becoming active team members.

B. A current certification in both First Aid and CPR. 
SOP - Underwater Diving Bldg. $983 /$ page 2

\section{Dive Program Requirements}

A. Team Structure

Diving operations at PBFA II shall be organized in a team structure in which team members have specific duties and responsibilities. The dive team shall include:

1. Dive Coordinator who will be in charge of all aspects of the diving operation. These responsibilities shall include:

a. Ensuring the safe condition of the dive site.

b. Conducting a pre-dive briefing to include:

1. Tasks to be performed

2. Individual team member responsibilities

3. Unusual hazards or environmental conditions

4. Changes to established procedures.

c. Maintaining required documentation to include:

1. Name of Dive Coordinator

2. Name of Team Members and responsibilities

3. Date of dive operation

4. Start and finish time of dive operation

5. Tasks to be performed

6 . Unusual circumstances or problems.

d. Termination of any dive operation in which conditions threaten the health or safety of team members.

2. Surface Observers who shall be responsible for monitoring team divers during dive operations. Observers shall keep in constant visual contact with divers and not perform any tasks other than tending of air or safety lines, or relaying equipment to divers. There shall be at least one surface observer designated for every three divers.

3. Team Divers who shall perform underwater tasks. Divers shall understand the tasks to be performed and procedures to be utilized before the dive operation commences. A divers participation in a diving activity may be terminated at any time at the diver's discretion.

B. A Safe Practices Manual shall be maintained by the Facility Diving Supervisor. This manual is to be kept with the specified Dive Coordinator during pre-dive briefing and at the dive site during dive operations. The Safe Practices Manual shall include: 
SOP - Underwater Diving Bldg. $983 /$ page 3

1. The OSHA Standard on diving.

2. Sandia's policy on implementing the Standard.

3. Safety Procedures \& checklists for diving operations.

4. Assignments and responsibilities of dive team members.

5. Equipment procedures and checklists.

6. Emergency procedures for equipment failures and medical illness/injury.

7. A list of emergency resource phone numbers.

IV. Operational Procedures

Before each dive operation, the Dive Coordinator or his delegate shall ensure that:

A. The facility dive air system is operating properly including proper switching between compressors and pressure and flow regulation.

B. A first aid kit is readily available at the dive site in case of personal injury.

D. A full "pony bottle" of dive air is located near the surface observers position. This bottle shall be used for rescue purposes only.

E. The possibility of external hazards has been minimized by performing the following actions:

1. The dive site shall be policed to ensure no hazards exist from electrical equipment or from accessories falling into the tank.

2. "Diver Down" flags shall be prominently posted on the top of the accelerator tank and in the Control/Monitor room.

3. The Dive Coordinator shall ensure, through the facility Shot Coordinator, that all keys neccessary to energize accelerator high voltage systems are secured.

4. The Dive Coordinator shall ensure, through the facility Shot Coordinator, that gas pressure in the water section Main Switches has been lowered to 20 psig.

\section{Equipment Inspection Procedures}

Before each dive session, the Dive Coordinator shall ensure that the following inspections are performed:

A. Divers shall inspect diving accessories for proper operation or damage. This should include masks. weight belts, wetsuits and booties, fins if used, 
SOP - Underwater Diving Bldg. $983 /$ page 4

and any other accessories such as flashlights.

B. Divers shall inspect air delivery systems for proper operation. This should include regulator/hose assembly if surface supplied air is being utilized, or tank/regulator/backpack system if dive tanks are utilized.

At least Every six months, the Dive Coordinator shall ensure that the following inspections are conducted:

A. The output of the facility dive air system shall be tested for air purity. The air supplied by this system shall not contain:

1. Carbon monoxide greater than $20 \mathrm{ppm}$

2. Carbon dioxide greater than $1000 \mathrm{ppm}$

3. Oil mist greater than $5 \mathrm{mg} /$ cubic meter

4. A noxious or pronounced odor.

At least once every year, the following inspections shall be performed:

A. Surface supplied air hoses shall be tested to 1.5 times their working pressure.

B. Dive regulators shall be inspected and adjusted (if necessary) by a qualified individual or dive shop.

C. Dive tanks shall be visually inspected by a qualified individual or dive shop.

Every five years, dive tanks shall be hydrostatically tested by a qualified test facility. 
Appendix A

Emergency Rescue

In the event of a dive accident or other situation in which a dive team member requires rescue, the following procedures should be followed to limit the severity of the accident.

1. Diver Conscious

A. The diver in distress should signal either the surface observer or another team diver for assistance.

B. Diver should attempt to relax and gain self control.

C. If necessary, buoyancy should be established by dropping weight belt and grasping an accelerator component to keep head above water. If this is not possible, the diver should be provided with a floatation device (six ring type life preservers are located on the railing around the top of the PBFA II water section). Assistance to the diver may also be provided using the long-handled personnel safety hook mounted on the railing on the the northeast section of the tank.

D. Assistance should be summoned and First Aid administered as required.

1. Diver Unconscious

A. Surface observer should immediately summon help from other team divers or other available personnel.

B. Once other personnel have been summoned to help, ambulance service should be phoned (144) and informed of a possible drowning. 
C. Diver should be brought to the surface and moved to the nearest stairway leading out of the water section.

D. If breathing has stopped, artificial repiration should be administered by qualified personnel. If heartbeat has stopped, CPR is required. Diver should be moved to the catwalk above the water section to provide proper support. CPR should be started and maintained by qualified personnel until releived by Emergency Medical Team members. 
Appendix B

Currentlv Authorized PBFA II Divers

$\begin{array}{lll}\text { Name } & \text { Org. Dignature } \\ \text { Broyles, Theresa } & 1254 \\ \text { Cleary, Richard } & 1254 \\ \text { Clevenger, Bob } & 1254 \\ \text { Devlin, Gary } & 1254 \\ \text { Donovan, Guy } & 1254 \\ \text { Drennan, Scott } & 1254 \\ \text { Goldstein, Steve } & 1254 \\ \text { Gray, David } & 1254 \\ \text { Hodan, John } & 1254 \\ \text { Jobe, Dan } & 1254 \\ \text { Johnson, Mark } & 1254 \\ \text { Johnston, Bob } & 1254 \\ \text { Junod, Marcus } & 1254 \\ \text { Lundstrom, Joe } & 1254 \\ \text { Mattson, Craig } & 1254\end{array}$


Currently Authorized PBFA II Divers (cont.)

Name

McDonnell, John

McGovern, Harry

Nations, Dennis

Nielsen, Dan

Orth, scott

Osborn, Rick

Seals, Bobby

Stewart, Joe org.

Signature

Date

1254

1254

1254

1254

1254

1254

1254

1254
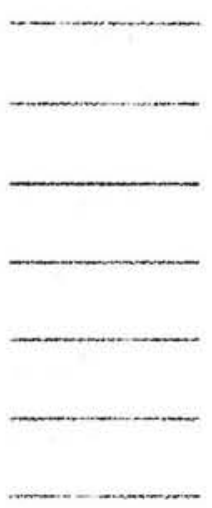
Appendix C

References

Memo, J.M.Phelan to G.L.Donovan, 7/23/85, Input to PBFA II Underwater Diving SOP

(w/attachment) 


\section{Sandia National Laboratories}

date: July 23,1985

Albuquerque, New Mexico 87185

to: G. L. Donovan, 1254

from: J. M. Phelan, 3311

subject: Input Into PBFA II Underwater Diving SOP

Your request for input into the diving SOP was made months ago, but not forgotten. The previous PBFA I SOP for diving was fairly complete, but could use the following upgrades:

1. Define the assignments and responsibilities of the dive team members.

2. Provide a written recording of each dive that includes the following:

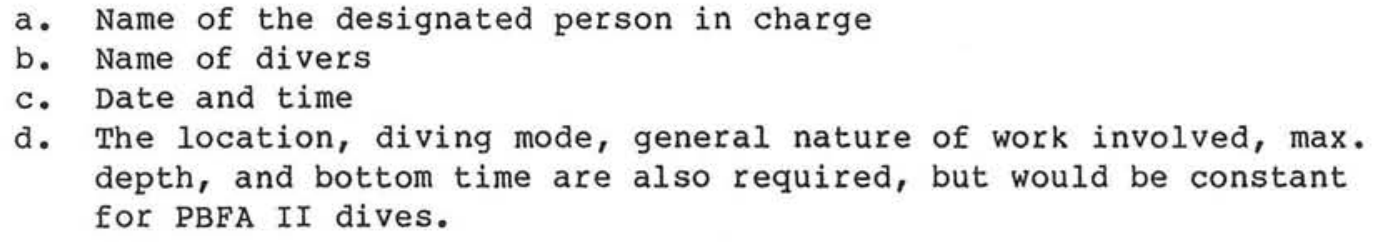

3. Require the use of diver-carried reserve breathing gas supply.

4. Document equipment maintenance, repair, modification, etc.

5. Specify that 1254 request 3311 to sample and analyze for breathing air purity every 6 months.

Also attached is a copy of the latest version of the OSHA Statutes for commercial diving operations and my excerpts of those sections that are applicable to PBFA II.

JMP : $3311:$ mg

Copy to:

3442 A. M. Fine

3311 J. M. Phelan

3310 File 
A. 1910.401 SCOPE

Sandia's diving operations do not conform to the requirements that allow an exclusion from this standard.

B. PROGRAM REQUIREMENTS FOR PULSED PÖWER OPERATIONS NEEDED TO SATISFY OSHA REQUIREMENTS

1. Personnel

a. Each dive team member shall have the experience or training to work in a safe manner to include:

1. Use of tools \& equipment

2. Techniques of diving

3. Diving operations \& emergency procedures

b. There shall be one person at the dive location to be in charge of all aspects of the diving operation that may affect health \& safety.

2. Medical Requirements

a. No medical requirements are required.

3. Safe Practices Manual

a. Shall include:

1. The OSHA Standard on diving

2. Sandia's policies for implementing the standard

3. Safety procedures \& checklists for diving operations

4. Assignments \& responsibilities of dive team members

5. Equipment procedures \& checklists

6. Emergency procedures for equipment failure and medical illness/injury.

4. Pre-dive Procedures

a. A readily available list of phone numbers of emergency resource personnel is required. 
b. A first aid kit must be readily available.

c. Planning and assessment of the dive shall include the safety and health aspects of the following:

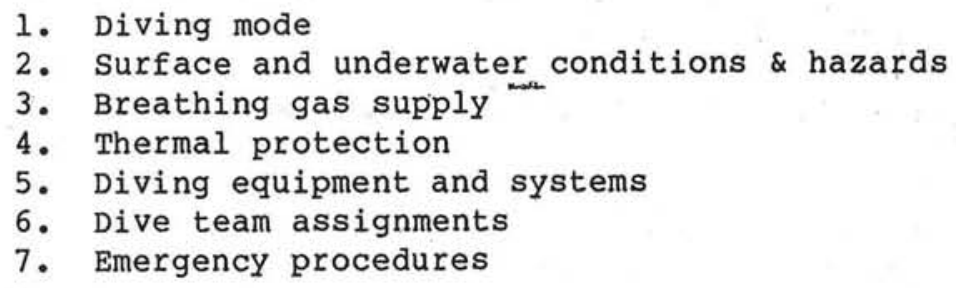

d. Employees briefing must include:

1. The tasks to be undertaken

2. Safety procedures for the diving mode

3. Any unusual hazards or environmental conditions

4. Any modifications to operating procedures due to a specific operation

e. Inspection of the following equipment must be made prior to each dive:

1. Breathing gas supply system

2. Regulators

3. Thermal protection

5. Procedures During Dive

a. A means for entry and exit of the water shall extend below the water surface.

b. Communications shall be maintained between the diver and dive team member.

c. The dive may be terminated at any time by the discretion of the diver.

6. Post-dive procedures

a. The following information shall be recorded and maintained for each diving operation:

1. Names of divers and the designated person-in-charge

2. Date, time \& location

3. Diving modes used

4. General nature of work involved

5. Approximate underwater \& surface conditions

6. Maximum depth and bottom time. 
7. Surface-supplied Air Diving

a. Each diver shall be continuously tended while in the water.

b. A diver-carried reserve breathing gas supply shall be provided whenever the diver is prevented from ascending directly to the surface.

8. Equipment

a. Each equipment modification, repair, test, calibration, or maintenance shall be recorded with the date, nature of work and name of person doing the work.

b. Air compressor systems are required to have a volume tank with a check valve on the inlet side, pressure gauge, a relief valve, and a drain valve.

c. Air compressor intakes shall be located away from areas containing exhaust or other contaminants.

d. Respirable air supplied to the diver shall not contain:

1. Carbon monoxide greater than $20 \mathrm{ppm}$

2. Carbon Dioxide greater than $1000 \mathrm{ppm}$

3. Oil mist greater than $5 \mathrm{mg} / \mathrm{m}^{3}$

4. A noxious or pronounced odor

e. The output of the air compressor shall be tested for air purity every six months.

f. Breathing gas supply hoses shall have:

1. A working pressure equal to the working pressure of the total system.

2. Have a rated burst pressure at least equal to 4 times the working pressure.

3. Be tested annually to 1.5 times their working pressure.

9. Recordkeeping

a. The records and documents required by this standard and the time period that they should be retained are as follows:

1. Safe Practices Manual - current document only

2. Recording of dive - 1 year

3. Equipment inspections and testing records - current entry or tag 


\title{
OCCUPATIONAL SAFETY AND HEALTH STANDARDS SUBPART T - COMMERCIAL DIVING OPERATIONS
}

\author{
(Code of Federal Regulations, Title 29, Chapter XVII, Part 1910, issued at 42 FR \\ 37649, July 22, 1977; amended at 45 FR 35212, May 23, 1980; corrected by 45 FR \\ 41634, June 20, 1980; amended by 47 FR 53365, November 26, 1982; 49 FR 881, \\ January 6,1984 )
}

Title 29-Labor

\section{CHAPTER XVII-OCCUPATIONAL SAFETY AND HEALTH ADMINISTRATION, DE- PARTMENT OF LABOR}

PART 1910-OCCUPATIONAL SAFETY AND HEALTH STANDARDS

Subpart T-Commercial Diving Operations GENERAL

1910.401 Scope and application.

1910.402 Definltions.

PERSONNEL REQUIREMENTS

1910.410 Quallifications of dive team 1910.411 Medical requirements.

General Operations Procedures

1910.420 Safe practice manual.

1910.421 Pre-dive procedures.

1910.422 Procedures during dive.

1910.423 Post-dive procedures.

SPECIFIC OPERATIONS PROCEdURES

1910.424 SCUBA dIving.

1910.425 Surface-supplied air diving.

1910.426 Mixed-gas diving.

1910.427 Liveboating.

EQUIPMENT PROCEDURES AND REQUIREMENTS

1910.430 Equipment.

\section{RECORDKEEPINC}

1910.440 Recordkeeping requirements. 1910.441 Effective date.

\section{APpENDIX}

Appendix A: Examples of Conditions Which May Restrict or Limit Exposure to Hyperbaric Conditions.

AUTHORITY: Sec. 6, 8, 84 Stat. $1593,1596$. 1599 (29 U.S.C. 655, 657): Secretary of Labor's Order 8-76 (41 FR 25059): 29 CFR Part 1911; sec. 41,44 Stat. (33 U.S.C. 941): sec. 107. 83 Stat. 96 (40 U.S.C. 333 )

Subpart T-Commercial Diving Operations General

$\S 1910.401$ Scope and application.

(a) Scope. (1) This subpart (standard) applies to every place of employ ment within the waters of the United States, or within any State, the District of Columbia, the Commonwealth of Puerto Rico, the Virgin Islands. American Samoa. Guam. the Trust Territory of the Pacific Islands. Wake Island, Jchnston Island, the Canal Zone, or within the Outer Continental Shelf lands as defined in the Outer Continental Sheli Lands Act (67 Stat. 462. 43 U.S.C. 1331). where diving and related support operations are performed.

(2) This standard applies to diving and related support operations conducted in connection with all types of work and employments, including general industry, construction, ship repairing, shipbuilding, shipbreaking and longshoring. However, this standard does not apply to any diving operation:

(i) Performed solely for instructional purposes, using open-circuit. compressed-air SCUBA and conducted within the no-decompression limits;

(ii) Performed solely for search, rescue, or related public safety purposes by or under the control of a governmental agency; or

(iii) Governed by 45 CFR Part 46 (Protection of Human Subjects, U.S. Department of Health, Education, and Welfare) or equivalent rules or regulations established by another federal agency, which regulate research, development, or related purposes involving human subjects.

(iv) Defined as scientific diving and which is under the direction and control of a diving program containing at least the following elements:

(A) Diving safety manual which includes at a minimum: procedures covering all diving operations specific to the program; procedures for emergency care, including recompression and evacuation; and criteria for diver training and certification.

(B) Diving control (safety) board, with the majority of its members being active divers, which shall at a minimum have the authority to: Approve and monitor diving projects; review and revise the diving safety manual; assure compliance with the manual; certify the depths to which a diver has been trained; take disciplinary action for unsafe practices: and, assure adherence to the buddy system (a diver is accompanied by and is in continuous contact with another diver in the water) for SCUBA diving. [Section 1910.401 (a)(2)(iv) added by 47 FR 53365, November 26, 1982] (b) Application in emergencies. An employer may deviate from the requirements of this standard to the extent necessary to prevent or minimize a situation which is likely to cause death, serious physical harm, or major environmenta damage, provided that the employer:

(1) Notifies the Area Director, Occupational Safety and Health Administration within 48 hours of the onset of the emergency situation indicating the nature of the emergency and extent of the deviation from the prescribed regulations; and

(2) Upon request from the Area $\mathrm{Di}$ rector, submits such information in writing.

(c) Employer obligation. The employer shall be responsible for compliance with:

(1) All provisions of this standard of general applicability; and

(2) All requirements pertaining to specific diving modes to the extent diving operations in such modes are conducted.

\section{§ 1910.402 Definitions.}

As used in this standard, the listed terms are defined as follows:

"Acfm": Actual cubic feet per minute.

"ASME Code or equivalent": ASME (American Society of Mechanical Eng1neers) Boiler and Pressure Vessel Code, Section VIII, or an equivalent code which the employer can demonstrate to be equally effective.

"ATA": Atmosphere absolute.

"Bell": An enclosed compartment. pressurized (closed bell) or unpressurized (open bell), which allows the diver to be transported to and from the underwater work area and which may be used as a temporary refuge during diving operations.

"Bottom time": The total elapsed time measured in minutes from the time when the diver leaves the surface in descent to the time that the diver begins ascent.

"Bursting pressure": The pressure at which a pressure containment device would fail structurally.

"Cylinder": A pressure vessel for the storage of gases.

"Decompression chamber": A pressure vessel for human occupancy such as a surface decompression chamber, 
closed bell, or deep diving system used to decompress divers and to treat decompression sickness.

"Decompression sickness": A condition with a variety of symptoms which may result from gas or bubbles in the tissues of divers after pressure reduction.

"Decompression table": A proflle or set of profiles of depth-time relationships for ascent rates and breathing mixtures to be followed after a specific depth-time exposure or exposures.

"Dive location": A surface or vessel from which a diving operation is conducted.

"Dive-location reserve breathing gas": A supply system of air or mixed-gas (as appropriate) at the dive location which is independent of the primary supply system and sufficient to support divers during the planned decompression

"Dive team": Divers and support employees involved in a diving operation, including the designated person-incharge.

"Diver": An employee working in water using underwater apparatus which supplies compressed breathing gas at the ambient pressure.

"Diver-carried reserve breathing gas": A diver-carrled supply of air or mixed gas (as appropriate) sufficient under standard operating conditions to allow the diver to reach the surface, or anothe source of breathing gas, or to be reached by a standby diver.

"Diving mode": A type of diving requiring specific equipment, procedures and techniques (SCUBA, surface-supplied air, or mixed gas).

"Fsw": Feet of seawater (or equivalent static pressure head).

"Heavy gear": Diver-worn deep-sea dress including helmet, breastplate, dry suit, and weighted shoes.

"Hyperbaric t conditions": Pressure conditions in excess of surface pressure.

"Inwater stage": A suspended underwater platform which supports a diver in the water.

"Liveboating": The practice of supporting a surfaced-supplied air or mixed gas diver from a vessel which is underway.

"Mixed-gas diving": A diving mode in which the diver is supplied in the water with a breathing gas other than air.

"No-decompression limits": The depth-time limits of the "no-decompression limits and repetitive dive group designation table for no-decompression air dives". U.S. Navy Diving Manual or equivalent limits which the employer can demonstrate to be equally effective.

"Psi(g)": Pounds per square inch (gauge)

"Scientific diving" means diving performed solely as a neceśsary part of a scientific, research, or educational activity by employees whose sole purpose for diving is to perform scientific research tasks. Scientific diving does not include performing any tasks usually associated with commercial diving such as: placing or removing heavy objects underwater; inspection of pipelines and similar objects; construction; demolition; cutting or welding; or the use of explosives.

[Added by 47 FR 53357, November 26, 1982]

"SCUBA diving": A diving mode independent of surface supply in which the diver uses open circuit self-contained underwater breathing-apparatus.

"Standby diver": A diver at the dive location available to assist a diver in the water.

"Surface-supplied air diving": A diving mode in which the diver in the water is supplied from the dive location with compressed air for breathing.

"Treatment table": A depth-time and breathing gas profile designed to treat decompression sickness.

"Umbilical": The composite hose bundle between a dive location and a diver or bell, or between a diver and a bell which supplies the diver or bell with ireathing gas, communications; power. or heat as appropriate to the diving mode or conditions, and includes a safety line between the diver and the dive location.

"Volume tank": A pressure vessel connected to the outlet of a compressor and used as an air reservoir.

"Working pressure": The maximum pressure to which a pressure containment device may be exposed unde standard operating conditions.

PERSONNEL REQUIREMENTS

\$ 1910.410 Qualifications of dive team. member shall have the experience or standard and the employer's policies for training necessary to perform assigned implementing the requirements of this tasks in a safe and healthful manner. standard.

(2) Each dive team member shall have experience or training in the following:

(i) The use of tools, equipment and systems relevant to assigned tasks:

(ii) Techniques of the assigned diving mode; and

(iii) Diving operations and emergency procedures.

(3) All dive team members shall be trained in cardiopulmonary resuscitation and first aid (American Red Cross standard course or equivalent).

(4) Dive team members who are exposed to or control the exposure of others to hyperbaric conditions shall be trained in diving-related physics and physiology.

(b) Assignments. (1) Each dive team member shall be assigned tasks in accordance with the employee's experience or training except that limited additional tasks may be assigned to an employee undergoing training provided that these tasks are performed under the direct supervision of an experienced dive team member.

(2) The employer shall not require a dive team member to be exposed to hyperbaric conditions against the employee's will, except when necessary to complete decompression or treatment procedures.

(3) The employer shall not permit a dive team member to dive or be otherwise exposed to hyperbaric conditions for the duration of any temporary physical impairment or condition which is known to the employer and is likely to affect adversely the safety or health of a dive team member.

(c) Designated person-in-charge. (1) The employer or an employee designated by the employer shall be at the dive location in charge of all aspects of the diving operation affecting the safety and dive team members.

(2) The designated person-in-charge shall have experience and training in \$ 1910.411 Medical requirements.

IEditor's note: This section of the diving standard was invalidated by the U.S. Court of Appeals for the Fifth Circuit July 16 (see 7

[Sec. 1910.411 deleted by 49 FR 881 , January 6 ,

General Operations Procedures

\$1910.420 Safe practices manual.

(a) General. The employer shall de(a) and maintain a safe practices manual which shall be made avallable at the dive location to each dive team nember.

(2) For each diving mode engaged in the safe practices manual shall include:

(i) Safety procedures and checklists for diving operations

(ii) Assignments and responsibilities of the dive team members:

(iii) Equipment procedures and check-

(iv) Emergency procedures for fire equipment failure, adverse environmental conditions, and medical illness and injury.

$\S 1910.421$ Pre-dive procedures.

(a) Gencral. The employer shall comply with the following requirements prior to each diving operation. unless otherwise specified.

(b) Emeryency aid. A list shall be kept at the dive location of the telephone or call numbers of the following:

11) An operational decompression chamber if not at the dive locations:

12. Accessible hospilats:

3. Aratiable jhysicia:is. 
(4) Available means of transportation; and

(5) The nearest U.S. Coast Guard Rescue Coordination Center.

(c) First aid supplics. (1) A first aid kit appropriate for the diving operation and approved by a physician shall be available at the dive location.

(2) When used in a decompression chamber or bell, the first aid kit shall be suitable for use under hyperbaric conditions.

(3) In addition to any other first aid supplies, an American Red Cross standard first aid handbook or equivalent, and a bag-type manual resuscitator with transparent mask and tubing shall be available at the dive location.

(d) Planning and assessment. Planning of a diving operation shall include an assessment of the safety and health aspects of the following:

(1) Diving mode:

(2) Surface and underwater conditions and hazards

(3) Breathing gas supply (including reserves) ;

(4) Thermal protection;

(5) Diving equipment and systems:

(6) Dive team assignments and physi cal fitness of dive team members (including any impairment known to the employer) :

(7) Repetitive dive designation or residual inert gas status of dive team members:

(8) Decompression and treatment procedures (including altitude corrections): and

(9) Emergency procedures.

(e) Hazardous activities. To minimize hazards to the dive team, diving operations shall be coordinated with other activities in the vicinity which are likely to interfore with the diving operation.

(f) Employce briefing. (1) Dive team members shall be briefed on:

(i.) The tasks to be undertaken;

(ii) Safety procedures for the diving mode:

(iii) Any unusual hazards or environmerilal conditions likely to affect the safety of the diving operation; and

(iv) Any modifications to operating procedures necessitated by the specific diving operation.

(2) Prior to making individual dive team member assignments, the employer shall inquire into the dive team member's current state of physical fitness, and indicate to the dive team member the procedure for reporting physical problems or adverse physiological effects during and after the dive.

(g) Equipment inspection. The breathing gas supply system including reserve breathing gas supplies, masks, helmets. thermal protection. and bell handling mechanism (when appropriate) shall be inspected prior to each dive.

(h) Warning signal. When diving from surfaces other than vessels in areas capa- ble of supporting marine traffic, a rigid replica of the international code flag "A" at least onc meter in height shall be displayed at the dive location in a manner which allows all-round visibility. and shull be illuminated during night diving operations.

\section{§ 1910.422 Procedures during dive.}

(a) General. The employer shall comply with the following requirements which are applicable to each diving operation unless otherwise specfied.

(b) Wuter ertry and exit. (1) A means capable of supporting the diver shall be provided for entering and exiting the water.

(2). The means provided for exiting the water shall extend below the water surface.

(3) A means shall be provided to assist an injured diver from the water or into a bell.

(c) Communications. (1) An operational two-way voice communication system shall be used between:

(i) Each surface-supplied air or mixed-gas diver and a dive team member at the dive location or bell (when provided or required) ; and

(ii) The bell and the dive location.

(2) An operational, two-way communication system: shall be available at the dive location to obtain emergency assistance.

(d) Decompression tables. Decompression, repetitive, and no-decompression tables (as appropriate) shall be at the dive location.

(e) Dive profiles. A depth-time profile including when appropriate any breathing gas changes, shall be maintained for each diver during the dive including decompression.

(f) Hand-held power tools and equipment. (1) Hand-held electrical tools and equipment shall be de-energized before being placed into or retrieved from the water.

(2) Hand-held power tools shall not bc supplied with power from the dive location until requested by the diver.

(s) Welding and burning. (1) A current supply switch to interrupt the cur rent flow to the welding or burning electrode shall be:

(i) Tended by a dive team member in voice communication with the dive performing the welding or burning; and

(ii) Kept in the open position except when the diver is welding or burning.

(2) The welding machine frame shall be grounded.

(3) Welding and burning cables, electrode holders, and connections shall be capable of carrying the maximum current required by the work, and shall be properly insulated.

14) Insulated gloves shall be provided to divers performing welding and burning operations.
(5) Prior to welding or burning on closed compartments, structures or pipes, which contain a flammable vapor or in which a flammable vapor may be generated by the work, they sholl be vented flooded, or purged with a mixture of gases which will not support combustion.

(h) Explosives. (1) Employers shall transport, store, and use explosives in accordance with this section and the applicable provisions of $\$ 1910.109$ and 81926.912 of Title 29 of the Code of Federal Regulations.

(2) Electrical continuity of explosive circuits shall not be tested until the diver is out of the water.

(3) Explosives shall not be detonated while the diver is in the water.

(1) Termination of dive. The working interval of a dive shall be terminated when:

(1) A diver requests termination;

(2) A diver fails to respond correctly o communications or signals from a dive team member;

(3) Communications are lost and can not be quickly re-established between the diver and a dive team member at the dive location, and between the designated person-in-charge and the person controlling the vessel in liveboating operations; or

(4) A diver begins to use diver-carried reserve breathing gas or the dive-location reserve breathing gas

$\S 1910.423$ Post-dive procedures.

(a) General. The employer shall comply with the following requirements which are applicable after each diving operation, unless otherwise specifled.

(b) Precautions. (1) After the completion of any dive, the employer shall:

(i) Check the physical condition of the diver

(ii) Instruct the diver to report any physical problems or adverse physiological effects including symptoms of decompression sickness;

(iii) Advise the diver of the location of a decompression chamber which is ready for use; and

(iv) Alert the diver to the potential hazards of flying after diving.

(2) For any dive outside the no-decompression limits, deeper than $100 \mathrm{fsw}$ or using mixed gas as a breathing mixture, the employer shall instruct the diver to remain awake and in the vicinity of the decompression chamber which is at the dive location for at least one hour after the dive (including decompression or treatment as appropriate).

(c) Recompression capability. (1) A decompression chamber capable of recompressing the diver at the surface to a minimum of 165 fsw (6 ATA) shall be avallable at the dive location for:

(i) Surface-supplied air diving to depths deeper than 100 sw and shallower than 220 fsw 
(ii) Mixed gas diving shallower than 300 Isw; or

(iii) Diving outside the no-decompression limits shallower than 300 fsw,

(2) A decompression chamber capable or recompressing the diver at the surface to the maximum depth of the dive shall be avallable at the dive location for dives deeper than $300 \mathrm{fsw}$. be:

(3) The decompression chamber shall

(i) Dual-lock;

(ii) Multiplace; and

(iii) Located within 5 minutes of the dive location.

(4) The decompression chamber shall be equipped with:

(1) A pressure gauge for each pressurized compartment designed for human occupancy

(ii) A built-in-breathing-system with a minimum of one mask per occupant:

(iii) A two-way voice communication system between occupants and a dive team member at the dive location:

(iv) A viewport; and

(v) Illumination capability to light the interior.

(5) Treatment tables, treatment gas appropriate to the diving mode, and sufficient gas to conduct treatment shall be available at the dive location.

(The second Section 1910.423(c)(4) renumbered as (c)(5) by 45 FR 41634 , June 20,1980

(6) A dive team member shall be available at the dive location during and for at least one hour after the dive to operate the decompression chamber (when required or provided).

[Section $1910.423(c)(5)$ renumbered as $(c)(6)$ by

46 FR 41634, June 20, 1980]

(d) Record of dive. (1) The following information shall be recorded and maintained for each diving operation:

(1) Names of dive team members in-

cluding designated person-in-charge;

(ii) Date, time, and location

(iii) Diving modes used;

(iv) General nature of work performed;

(v) Approximate underwater and surface conditions (visibility, water temperature and current); and

(vi) Maximum depth and bottom time for each diver.

(2) For each dive outside the no-decompression limits, deeper than $100 \mathrm{fsw}$ or using mixed gas, the following additional information shall be recorded and maintained: (i) Depth-time and breathing gas proflles

(ii) Decompression table designation (including modification); and

(iii) Elapsed time sínce last pressure exposure if less than 24 hours or repetitive dive designation for each diver.

(3) For each dive in which decompression sickness is suspected or symptom are evident, the following additional information shall be recorded and maintained:

(i) Description of decompression sickness symptoms (including depth and time of onset); and

(ii) Description and results of treatment.

(e) Decompression procedure assess ment. The employer shall:

(1) Investigate and evaluate each in cident of decompression sickness based on the recorded information, consideration of the past performance of decompression table used, and individual susceptibility;

(2) Take appropriate corrective action to reduce the probability of recurrence of decompression sickness; and

(3) Prepare a written evaluation of the decompression procedure assessment, in cluding any corrective action taken within 45 days of the incident of decompression sickness.

Specific Operations Procenures

\section{§ 1910.424 SCUBA diving.}

(a) General. Employers engaged in SCUBA diving shall comply with the following requirements, unless otherwise specified.

(b) Limits. SCUBA diving shall not be conducted:

(1) At depths deeper than 130 fsw:

(2) At depths deeper than $100 \mathrm{fsw}$ or outside the no-decompression limits unless a decompression chamber is ready for use:

(3) Against currents exceeding one (1) knot unless line-tended; or

(4) In enclosed or physically confining spaces unless line-tended.

(c) Procedures.

(1) A standby diver shall be available while a diver is in the water.

(2) A diver shall be line-tended from the surface, or accompanied by another diver in the water in continuous visual contact during the diving operation.

(3) A diver shall be stationed at the underwater point of entry when diving is conducted in enclosed or physically confining spaces.

(4) A diver-carried reserve breathing gas supply shall be provided for each diver consisting of :

(i) A manual reserve ( $J$ valve); or

(ii) An independent reserve cylinder with a separate regulator or connected to the underwater breathing apparatus.

(5) The valve of the reserve breathing gas supply shall be in the closed position prior to the dive.

§ 1910.425 Surface-supplied air diving.

(a) General. Employers engaged in surface-supplied air diving shall comply with the following requirements, unless otherwise specified.

(b) Limits. (1) Surface-supplied air diving shall not be conducted at depths deeper than 190 fsw, except that dives with bottom times of 30 minutes or less may be conducted to depths of $220 \mathrm{fsw}$.

(2) A decompression chamber shall be ready for use at the dive location for any dive outside the no-decompression limits or deeper than 100 fsw.

(3) A bell shall be used for dives with an inwater decompression time greater than 120 minutes, except when heavy gear is worn or diving is conducted in physically confining spaces.

(c) Procedures. (1) Each diver shall be continuously tended while in the water.

(2) A diver shall be stationed at the underwater point of entry when diving is conducted in enclosed or physically confining spaces.

(3) Each diving operation shall have a primary breathing gas supply suffcient to support divers for the duration of the planned dive including decompression.

(4) For dives deeper than $100 \mathrm{fsw}$ or outside the no-decompression limits:

(i) A separate dive team member shall tend each diver in the water:

(ii) A standby diver shall be available while a diver is in the water 
(iii) A diver-carried reserve breathing gas supply shall be provided for each diver except when heavy gear is worn; and

(iv) A dive-location reserve breathing gas supply shall be provided.

(5) For heavy-gear diving deeper than 100 fsw or outside the no-decompression limits:

(i) An extra breathing gas hose capable of supplying breathing gas to the diver in the water shall be available to the standby diver.

(ii) An inwater stage shall be provided to divers in the water.

(6) Except when heavy gear is worn or where physical space does not permit, a diver-carried reserve breathing gas supply shall be provided whenever the diver is prevented by the configuration of the dive area from ascending directly to the surface.

\section{\$ 1910.426 Mixed-gas diving.}

(a) General. Employers engaged in mixed-gas diving shall comply with the following requirements, unless otherwise specified.

(b) Limits. Mixed-gas diving shall be conducted only when:

(1) A decompression chamber is ready for use at the dive location; and

(i) A bell is used at depths greater than $220 \mathrm{fsw}$ or when the dive involves inwater decompression time of greater than 120 minutes, except when heavy gear is worn or when diving in physically confining spaces; or

(ii) A closed bell is used at depths greater than $300 \mathrm{fsw}$, except when diving is conducted in physically confining spaces.

(c) Procedures. (1) A separate dive team member shall tend each diver in the water.

(2) A standby diver shall be available while a diver is in the water.

(3) A diver shall be stationed at the underwater point of entry when diving is conducted in enclosed or physically confining spaces.

(4) Each diving operation shall have a primary breathing gas supply sufficient to support divers for the duration of the planned dive including decompression.

(5) Each diving operation shall have a dive-location reserve breathing gas supply.

(6) When heavy gear is worn:

(i) An extra breathing gas hose capable of supplying breathing gas to the diver in the water shall be available to the standby diver; and

(ii) An inwater stage shall be provided to divers in the water.

(7) An inwater stage shall be provided for divers without access to a bell for dives deeper than $100 \mathrm{fsw}$ or outside the no-decompression limits.

(8) When a closed bell is used, one dive team member in the bell shall be available and tend the diver in the water.

(9) Except when heavy gear is worn or where physical space does not permit. a diver-carried reserve breathing gas supply shall be provided for each diver: (i) Diving deeper than 100 fsw or outside the no-decompression limits; or

(ii) Prevented by the configuration of the dive area from directly ascending to the surface.

\section{$\S 1910.427$ Liveboating.}

(a) General. Employers engaged in diving operations involving liveboating shall comply with the following requirements.

(b) Limits. Diving operations involving liveboating shall not be conducted:

(1) With an inwater decompression time of greater than 120 minutes:

(2) Using surface-supplied air at depths deeper than $190 \mathrm{fsw}$, except that dives with bottom times of 30 minutes or less may be conducted to depths of 220 fsw:

(3) Using mixed gas at depths greater than 220 fsw:

(4) In rough seas which significantly impede diver mobility or work function:

(5) In other than daylight hours

(d) Procedures. (1) The propeller of the vessel shall be stopped before the diver enters or exits the water.

(2) A device shall be used which minimizes the possibility of entanglement of the diver's hose in the propeller of the vessel.

(3) Two-way voice communication between the designated person-in-charge and the person controlling the vessel shall be available while the diver is in the water.

(4) A standby diver shall be available while a diver is in the water.

(5) A diver-carried reserve breathing gas supply shall be carried by each diver engaged in liveboating operations.

EQUIPMENT PROCEDURES AND REQUTREMENTS

\section{$\S 1910.430$ Equipment.}

(a) General. (1) All employers shall comply with the following requirements, unless otherwise specified.

(2) Each equipment modification, repair. test, calibration or maintenance service shall be recorded by means of a tagging or logging system, and include the date and nature of work performed. and the name or initials of the person performing the work.

(b) Air compressor systems. (1) Compressors used to supply air to the diver shall be equipped with a volume tank with a check valve on the inlet side, a pressure gauge, a relief valve, and a drain valve.

(2) Air compressor intakes shall be located away from areas containing exhaust or other contaminants:

(3) Respirable air supplied to a diver shall not contain:

(i) A level of carbon monoxide (CO) greater than $20 \mathrm{ppm}$ :

(1i) A level of carbon dioxide (CO.) greater than $1,000 \mathrm{ppm}$ :

(iii) A level of oil mist greater than 5 milligrams per cubic meter: or

(iv) A noxious or pronounced odor

14) The output of air compressor sys temis shall be wested for air purity every six months by means of samples taken at the connection to the distribution system, except that non-oil lubricated compressors need not be tested for oil mist.

(c) Breathing gas supply hoses. (1) Breathing gas supply hoses shall:

(i) Have a working pressure at least equal to the working pressure of the total breathing gas system:

(ii) Have a rated bursting pressure at least equal to 4 times the working pressure:

(iii) Be tested at least annually to 1.5 times their working pressure; and

(iv) Have their open ends taped, capped or plugged when not in use.

(2) Breathing gas supply hose connectors shall:

(i) Be made of corrosion-resistant materials:

(ii) Have a working pressure at least equal to the working pressure of the hose to which they are attached; and

(iii) Be resistant to accidental disengagement.

(3) Umbilicals shall:

(i) Be marked in 10- $\mathrm{ft}$. increments to 100 feet beginning at the diver's end, and in $50 \mathrm{ft}$. increments thereafter:

(ii) $\mathrm{Be}$ made of kink-resistant materials: and

(iii) Have a working pressure greater than the pressure equivalent to the maximum depth of the dive (relative to the supply source) plus 100 psi.

(d) Buoyancy control. (1) Helmets or masks connected directly to the dry suit or other buoyancy-changing equipment shall be equipped with an exhaust valve.

(2) A dry suit or other buoyancychanging equipment not directly connected to the helmet or mask shall be equipped with an exhaust valve.

(3) When used for SCUBA diving, a buoyancy compensator shall have an inflation source separate from the breathing gas supply.

(4) An inflatable flotation device capable of maintaining the diver at the surface in a face-up position, having a manually activated inflation source independent of the breathing supply, an oral inflation device, and an exhaust valve shall be used for SCUBA diving.

(e) Compressed gas cylinders. Compressed gas cylinders shall:

(1) $\mathrm{Be}$ designed. constructed and maintained in accordance with the applicable provisions of 29 CFR $\$ 1910.166$ 171:

(2) Be stored in a ventilated area and protected from excessive heat;

(3) Be secured from falling; and

(4) Have shut-off valves recessed into the cylinder or protected by a cap, except when in use or manifolded, or when used for SCUBA diving.

(f) Decompression chambers. (1) Each decompression chamber manufactured after the effective date of this standard, shall be built and maintained in accordance with the ASME Code or equivalent.

(2) Each decompression chamber manufactured prior to the effective date of this standard shall be maintained in conformity with the code requirement. to which it was buitt, or equivaient. 
(3.) Each decompression chamber shall be equipped with:

(i) Means to maintain the atmosphere below a level of $25 \%$ oxygen by volume:

(ii) Mufflers on intake and exhaust lines, which shall be regularly inspected and maintained;

(iii) Suction guards on exhaust line openings: and

(iv) A means for extinguishing fire and shall be maintained to minimize sources of ignition and combustible material.

(g) Gauges and timekeeping devices. (1) Gauges indicating diver depth which can be read at the dive location shall be used for all dives except SCUBA.

(2) Each depth gauge shall be deadweight tested or calibrated against a master reference gauge every six months and when there is a discrepancy greater than two percent $(2 \%)$ of full scale between any two equivalent gauges.

(3) A cylinder pressure gauge capable of being monitored by the diver during the dive shall be worn by each SCUBA diver.

(4) A timekeeping device shall be available at each dive location.

(h) Masks and helmets. (1) Surfacesupplied air and mixed-gas masks and helmets shall have:

(i) A non-return valve at the attachment point between helmet or mask and hose which shall close readily and positively; and

(ii) An exhaust valve.

(2) Surface-supplied air masks and helmets shall have a minimum ventilation rate capability of $4.5 \mathrm{acfm}$ at any depth at which they are operated or the capability of maintaining the diver's inspired carbon dioxide partial pressure below 0.02 ATA when the diver is producing carbon dioxide at the rate of 1.6 standard liters per minute.

(i) Oxygen safety. (1) Equipment used with oxygen or mixtures containing over forty percent $(40 \%)$ by volume oxygen shall be designed for oxygen service.

(2) Components (except umbilicals) exposed to oxygen or mixtures containing over forty percent $(40 \%)$ by volume oxygen shall be cleaned of flammable materials before use.

(3) Oxygen systems over $125 \mathrm{psig}$ and compressed air systems over 500 psig shall have slow-opening shut-off valves.

Weights and hurnesses. (1) Except dive, or until completion of decompreswhen heavy gear is worn, divers shall sion procedure assessment where there be equipped with a weight belt or assem- has been an incident of decompression bly capable of quick release. sickness:

(2) Except when heavy gear is worn or (iv) Recording of dive ( $\$ 1910.423)$ in SCUBA diving, each diver shall wear 1 year, except 5 years where there has a safety harness with:

(i) A positive buckling device; been an incident of decompression sick-

(ii) An attachment point for the umbilical to prevent strain on the mask or helmet: and ness:

(iii) A lifting point to distribute the body.

\subsection{Recordkeeping require- ments.} pational injuries and illnesses in accord1904

(2) The employer shall record the ocilness which requires any-related injury or to be hospitalized for 24 hours or more specifying the circumstances of the incident

(b) Availability of records. (1) Upon the request of the Assistant Secretary of tor Occupational Safety and tute for Occupational Safety and Health. Department of Health, Education and Welfare or their designees, the employer opying any record or document required

(2) Records and documents required by this standard shall be provided upon request and the Assistant Secretary in accordance with 29 CFR 1910.20(a)-(e) and (g)-(i) time profiles (s1910.422), recordings of dives (s1910.423), decompression procedur assessment evaluations (s1910.423), and records of hospitalizations ( $\$$ 1910.440) shall be provided in the same manner as exposure or medical records. Equipment in spections and testing records which pertain to employees (s1910.430) shall also be provided upon request to empl

Section 1910.440(b)(2) amended at 21,1980

(3) Records and documents required by this standard shall be retained by the mployer for the following period:

(i) Dive team member medical records ears:

(ii) Safe practices manual $1 \$ 1910$.

(v) Decompression procedure assess rient evaluations (\$1910.423) -5 years: (vi) Equipment inspections and test- ing records $(\$ 1910.430)$-current entry or tag, or until equipment is withdrawn from service:

(vii) Records of hospitalizations (\$ 1910.440$)-5$ years.

(4) After the expiration of the retention period of any record required to be kept for five (5) years, the employer shall forward such records to the National Institute for Occupational Safety and Health, Department of Health and Human Services. The employer shall also comply with any additional requirements set forth at 29 CFR $1910.20(\mathrm{~h})$.

[Section 1910.440(b)(4) amended at 45 FR 35212 . May 23, 1980, effective August 21, 1980]

(5) In the event the employer ceases to do business:

(i) The successor employer shall receive and retain all dive and employee medical records required by this standard; or

(ii) If there is no successor employer. dive and employee medical records shall be forwarded to the National Institute for Occupational Safety and Health, Department of Health, Education, and Welfare.

\section{§ 1910.441 Effective date.}

This standard shall be effective on October 20, 1977, except that for provisions where decompression chambers or bells are required and such equipment is not yet available, employers shall comply as soon as possible thereafter but in no case later than 6 months after the effective date of the standard.

$$
\text { APPENDIX A }
$$

EXAMTES OF CONLITIONS WHICH MAY RESTRICT OP. LIMTT EXPOSURE TO HYPERBARIC CONDITIONS

The following disorders may restrict or limit occupational exposure to hyperbaric conditions depending on severity, presence of residual effects, response to therapy, number of occurrences, diving mode, or degree and duration of isolation.

History of seizure disorder other than earig febrile conqulsions.

Malignancies (active) unless treated and without recurrence for 5 yrs.

Chronic inability to equalize sinus and/or middle ear pressure.

Cystic or cavitary disease of the lungs.

Impaired organ function caused by alcohol or drug use.

Conditions requiring continuous medication for control (e.g. anthistamines. steroids, barbiturates, moodaltering drugs. or insulin)

Meniere's disease.

Hemoglobinopathies

Obstructive or restrictive lung disease.

Vestibular end organ destruction.

Pneumothorax

Cardlac abnormalitles (e.g., pathologtcal heart block, valvular disease, intraventricular conduction defects other than isolated right bundle branch block, angina pectoris, arhythmia, coronary artery disease)

Juxta-articular osteonecrosis. 


\section{SAFE OPERATING PROCEDURE \\ FOR \\ LASER TRIGGER SYSTEM OPERATION \\ AT \\ PBFA II, BUILDING 983}

Appendix 15 


\section{Table of Contents}

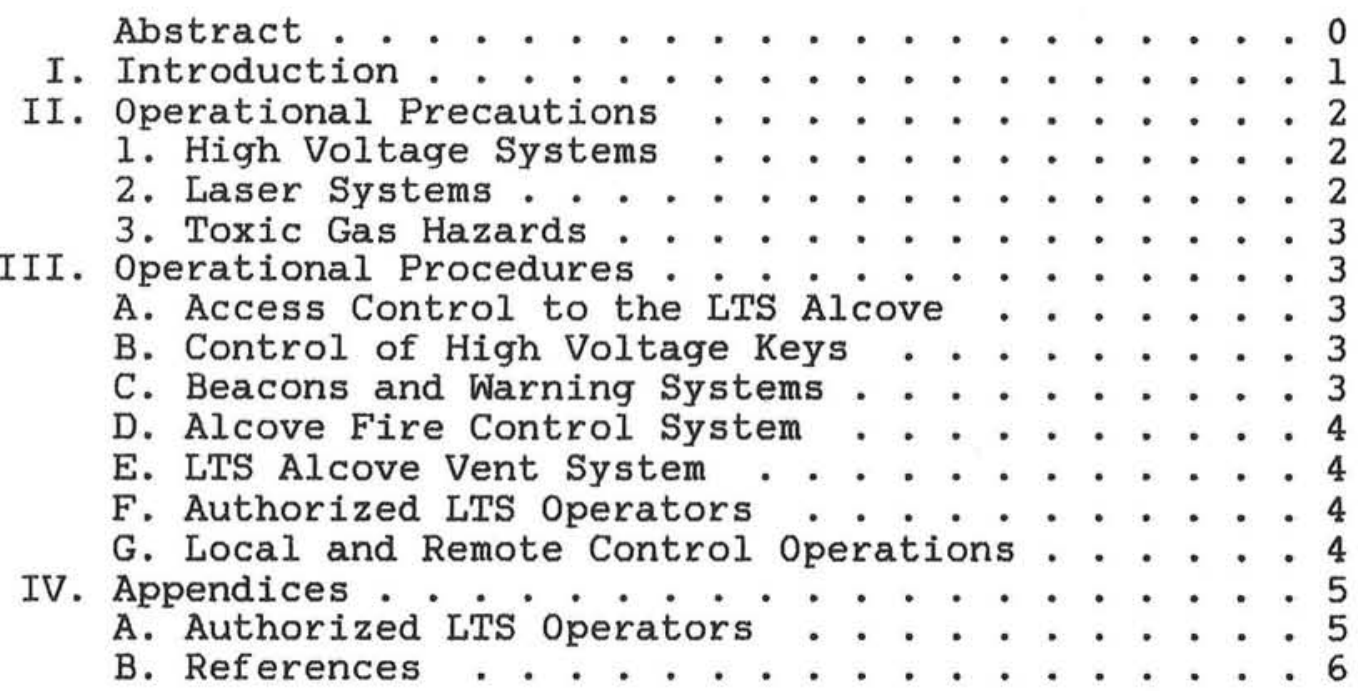


SAFE OPERATING PROCEDURE

FOR

LASER TRIGGER SYSTEM OPERATION

AT

PBFA II, BUILDING 983

\begin{abstract}
This SOP describes procedures for operation of the Laser Trigger system at PBFA II, Building 983. Three major hazards are associated with LTS operation:
\end{abstract}

1. Hazards associated with operation of high voltage equipment.

2. Hazards associated with exposure to Laser radiation.

3. Hazards associated with the handing of toxic gas.

Failure to operate this system properly could result personal injury and destruction of property.

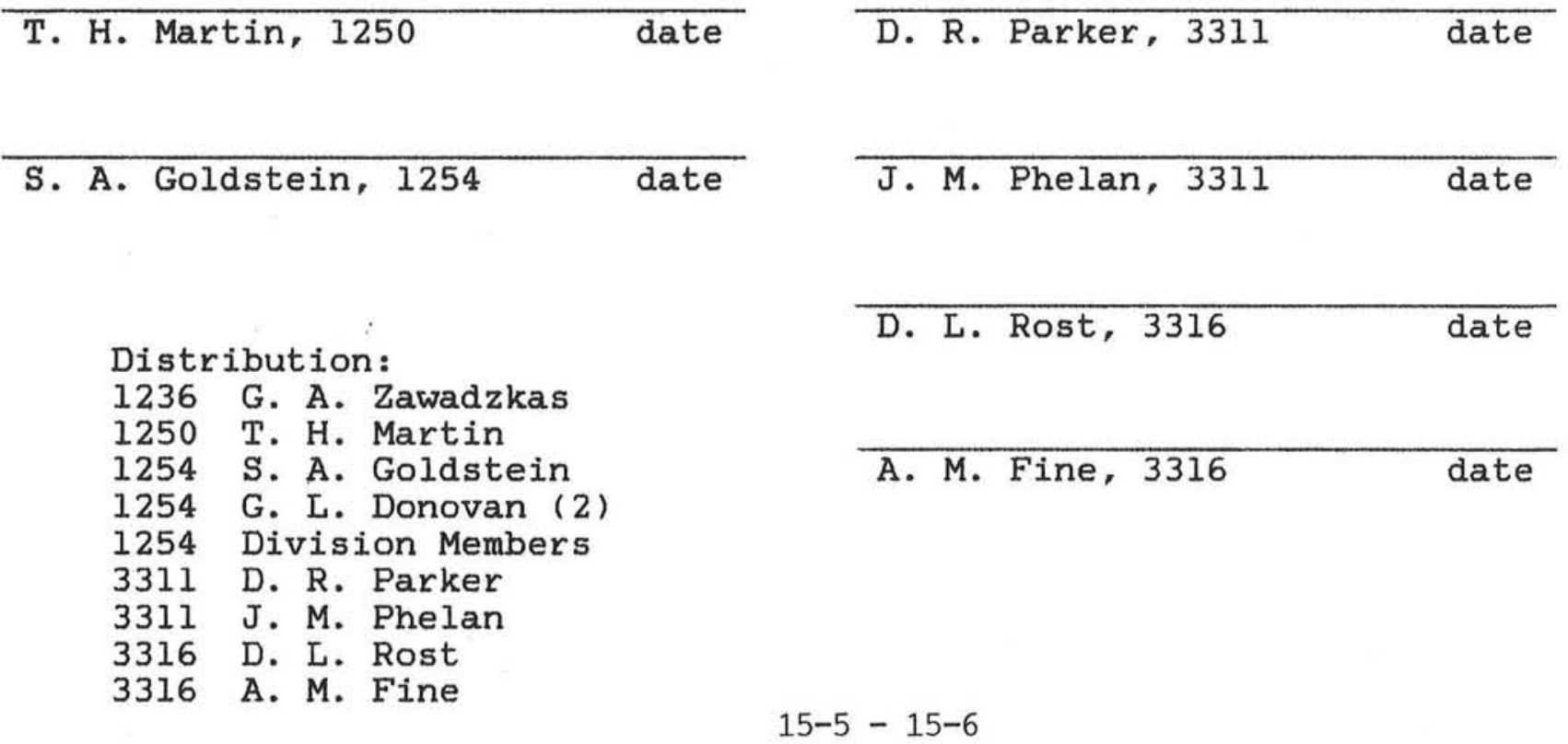


SAFE OPERATING PROCEDURE

FOR

LASER TRIGGER SYSTEM OPERATION

AT

PBFA II, BUILDING 983

\section{Introduction}

The PBFA II Laser Trigger System (LTS) consists of a pulsed 4 Joule Krypton-Flouride Laser and associated support and optical equipment. The Laser operates at a wavelength of 249 nanometers with a 20 nanosecond pulsewidth. The system is located at the -25 foot level of PBFA II in the LTS Alcove with enclosed optical paths extending through the -25 foot level into the PBFA II Pulse Forming Section. During operation, a single beam of laser light is propagated from the LTS Alcove into an enclosed distribution system that splits the beam into 36 seperate beamlets that are directed to the Rimfire gas switches.

Three main hazards are associated with operation of the PBFA II LTS:

A. High voltage equipment associated with the Lasers pulsed power systems. These include: a Marx generator for laser cavity preionization, laser master oscillator and its charging supply, pulse charging network for the laser power oscillator and its charging supply, and the main triggering pulser and its charging supply.

B. Personnel exposure to laser radiation: Three seperate lasers are used within the LTS alcove during normal operation. The 4 Joule $K r F$ laser mentioned above represents a Class IIIB laser hazard. In addition, a 5 millwatt helium-neon laser and a 50 milliwatt helium-neon laser are used for system alignment operations. The HeNe laser alignment system represents a Class IIIB laser Hazard.

The hazards involved with operation of these lasers require that specific precautions be taken to ensure the safety of operators and other building personnel. 
SOP - Laser Trigger System Operation at PBFA II / page 2

C. Operation of the PBFA II LTS requires the use of small amounts of toxic gas ( $5 \%$ concentration of Flourine). This gas mixture is located inside the LTS alcove within a dedicated gas barricade that is kept at negative pressure with respect to the alcove. This is accomplished through a venting system which discharges on the roof of Building 983. Should a failure of the gas handling system occur, this system will vent the resulting gas leak into the atmosphere outside the building.

II. Operational Precautions

Before personnel operate or perform maintenance activities to LTS systems, the following actions shall be performed:

1. High Voltage Systems:

Before operating any high voltage systems, LTS operator personnel shall verify that all safety devices are intact and that personnel are clear of the unit. Safety devices shall include all hardware normally in place to limit contact with high voltage systems (e.g. access panels shall be replaced, high voltage cable terminations shall be verified, safety interlocks shall be active, etc.).

Before performing any maintenance activity on high voltage systems, personnel must verify that all high voltage systems have been properly safed and that power has been disconnected. During maintenance operations all energy storage devices associated with the maintenance shall be shorted with appropriate grounding sticks and held to ground potential with grounding straps until the maintenance procedure is completed.

2. Laser Systems:

Personnel within the Laser Area (area surrounded by protective curtains) shall be required to wear protective eyewear whenever the $K r F$ laser is being operated. In addition, when alignment lasers are propagated outside of known beampaths, personnel shall be required to wear eyewear designed to limit HeNe laser light to acceptable levels. When laser light of potentially hazardous levels is propagated outside the LTS alcove to any area outside of established beampaths, controls shall be implemented to limit access of personnel to the propagation path (see section III). Personnel involved in such testing shall be required to wear appropriate eye protection. 
SOP - Laser Trigger System Operation at PBFA II / page 3

\section{Toxic Gas Hazards}

When changing out Flourine bottles or performing any work on Flourine transport lines or related equipment, personnel shall wear proper protective clothing including gloves, apron, long sleeve clothing and face shield. Flourine bottles shall be transported with plugs installed on suitable bottle handling carts with retainer chains secured.

III. Operational Procedures

A. Access Control to the LTS Alcove

Personnel access to the LTS Alcove is controlled by a door interlock that is activated during any operation involving high voltage or laser radiation. This interlock interupts power to potentially hazardous systems should an access breach occur.

During operation of the LTS the door safety interlock shall be active and personnel shall not attempt to bypass this interlock at any time. Operation of this interlock shall be verified each day that tests are to take place before hazardous systems are activated.

B. Control of High Voltage Keys

Operation of the LTS high voltage systems requires activation of the LTS H. V. breaker located within the alcove. Operation of this breaker is controlled by a key switch on the breaker enclosure. This key shall be kept in the C/M lock box under the control of the facility Shot Coordinator before and after each test requiring local operation. The LTS Operator responsible for the test shall aquire the key from the Shot Coordinator prior to testing and return it immediately following the test.

C. Beacons and Warning Systems

Whenever the LTS high voltage breaker is closed (i.e. supply voltage is available to the LTS), yellow beacons throughout the -25 foot level of Building 983 are activated. Signs posted on these beacons indicate that the laser is active. Operation of these beacons shall be verified prior to testing each day LTS operation is to occur. Results of this verification shall be noted in the LTS log book. Any beacons not operating properly shall be promptly repaired. 
SOP - Laser Trigger System Operation at PBFA II / page 4

D. Alcove Fire Control System

The LTS Alcove contains a dedicated fire prevention system consisting of a Halon discharge system and associated sensors. Facility personnel shall not modify or override any of the LTS fire control systems without prior consultation and approval by the Operations Engineering Division, 7862.

E. LTS Alcove Vent System

The LTS alcove incorporates a continuous venting system to vent any leaks of hazardous gases outside of Building 983. This system maintains a constant suction on the Flourine delivery cabinet, master oscillator enclosure, and the power oscillator enclosure in case of leaks from these systems. In the event of a major failure (e.g. a gasline rupture or breakage of a laser cavity optic) a switch has been provided to allow venting of the entire alcove through this system. The switch is located next to the alcove door on the inside wall. Should a major failure occur, LTS personnel shall immediately evacuate the alcove engaging this switch as they pass.

F. Authorized LTS Operators

Before being authorized to operate the PBFA II Laser Trigger system, personnel shall become familiar with the operation of LTS subsystems, procedures for safing these devices, and the hazards associated. Potential operators shall also become familiar with the contents of this SOP and spend sufficient time under observation to prove competence before being authorized. In addition, LTS operators shall complete the Laser Safety Course administrated by the Industrial Hygiene Division, 3311, or an approved facsimile. Personnel currently authorized as LTS Operators are listed in Appendix A.

G. Local and Remote Control Operations

Before any operation of the LTS that may produce laser radiation, the operator in charge of the LTS must perform the following actions:

1. Ensure that the protective curtain surrounding the laser area is in tact.

2. Ensure that all personnel within the laser are wearing protective eyewear and are aware of the testing to be performed. 


\section{SOP - Laser Trigger System Operation at PBFA II / page 5}

3. Ensure that laser beams will propagate within established beampaths through alignment check with low power HeNe alignment laser.

4. Ensure that beampaths are clear of obstructions.

Before any test that propagates laser radiation outside of the LTS alcove, the LTS operator shall:

1. Verify the integrity of beampath enclosures along the length of the propagation path.

2. Ensure that no facility personnel are working in areas that may place them at risk during the test.

3. Implement any required access control procedures through the facility Shot Coordinator before testing begins.

When testing requires propagation of laser radiation into the Pulse Forming Section the LTS operator shall verify, through the Shot Coordinator, that either the Rimfire switches are in place, or personnel working within the PFS are not at risk. During tests of this type, when Rimfire switches are not in place, a person shall be posted within the PFS to limit access of personnel to areas where laser radiation is being propagated. 
Appendix A

Authorized LTS Operators

Name

Chambers, Rod

Donovan, Guy

Johnson, Mark

Schaub, Mike
Org.

Signature

Date
1254

1254

1254

1254

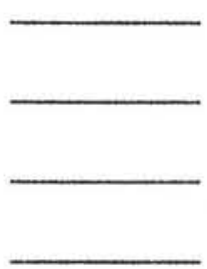


Appendix B

References

Memo, J.M.Phelan to G.L.Donovan, 12/10/85, Control Measures for LTS Flourine Gas Hazards.

Memo, J.M.Phelan to G.L.Donovan, 7/15/86, Control Measures for the LTS KrF Beam Hazards.

Report, SNLA Industrial Hygiene Services, 1/28/86, PBF'A II He-Ne Laser Hazard Analysis. 
date: December 10, 1985

to: G. L. Donovan, 1254

from: J. M. Phelan, 3311

subject: Control Measures for LTS Fluorine Gas Hazards

The present control measures for the fluorine gas used in the LTS include the following:

1. The minimum practical quantity and percentage of fluorine is used in the alcove ( 1 bottle of $5 \%$ F2 in neon).

2. The fluorine is stored in a exhausted gas cabinet while in the alcove.

3. The likely points of fluorine release on the laser body have or will have local exhaust ventilation.

4. The used lasing gas is passed through a charcoal scrubber prior to release into the laser exhaust ventilation pipe.

5. A pressure differential switch is used to monitor and report to $\mathrm{C} / \mathrm{M}$ the condition of the laser exhaust ventilation system.

6. A fluorine gas sensor is located in the alcove and triggers an alarm to $C / M$ in the presence of greater than $1 \mathrm{ppm}$ fluorine.

The flourine gas sensor has been installed in the alcove but has not been put on line. My evaluation of this unit in this application has shown that it may be more of an operational burden than being an adequate control measure to protect employee health. There are several factors that have led me to this conclusion. First, the unit functions as an oxidant monitor and was factory calibrated for ozone. The unit will work for fluorine, however a complicated calibration system for fluorine needs to be purchased in order for the unit to provide accurate values and provide a method to test the unit. Second, previous users of this type of unit have said that it is a high maintenance item requiring, at least, monthly service and calibration. I do not feel that this type of unit can be adequately maintained and calibrated to provide a reliable system to identify hazardous situations within the laser alcove. Other monitors are available on the market, but will have similar maintenance, calibration, and operational problems.

Third, the enginneering, operator training, and unique properties of the fluorine gas can provide sufficient control without a detection 
system. The engineering of the fluorine gas system has reduced the liklihood of releasing hazardous levels of fluorine by proper choice of materials of construction and exhaust ventilation. A leak from the source gas bottle or laser body will be collected and exhausted out of the laser alcove. The gas supply line is the only non-exhausted fluorine component and could be inadvertanly broken leaking fluorine gas into the alcove. However, the operators knowledge and experience with fluorine gas is a very important control measure. Proper handling and operational procedures (i.e. gas bottle changes or laser maintenance) can prevent exposures in all situations except equipment failure senarios. Even in this situation, the monitor could not alarm as fast as the irritating properties of the gas would cause a reaction in people.

Fluorine gas is a very irritating to the lungs and eyes, but it has no systemic effect from short term exposures. These unique properties will serve to limit personnel exposures and not endanger employee health from some insidious systemic toxic effects. Table I provides a summary of hazard information regarding the biological effects of short term exposures to fluorine gas.

The only likely use of a monitor would be to sense the release of fluorine gas into the alcove after a shot. The first person entering the alcove would not know if a fluorine gas hazard existed inside. Assuming that the proper procedures have been followed prior to a shot (the fluorine bottle valve and mixing can valves have been turned off), only a limited volume of gas from the supply line could be released into the alcove. The room concentration (using only that volume of the room separated by the laser curtain and including the laser table) due to the release of fluorine gas from the gas cabinet supply line can be estimated (see appendix for calculations):

\section{Assumptions}

No capture of the released fluorine by the exhaust system Complete mixing of the released gas in the room volume

gas cabinet supply line failure room concentration - 22 ppm

If the covers for the master and power oscillator were not present and those volumes of fluorine gas escaped, the following concentrations can be estimated (see appendix for calculations):

$$
\begin{aligned}
& \text { power oscillator failure room concentration - } 2 \mathrm{ppm} \\
& \text { master oscillator failure room concentration - } 0.2 \mathrm{ppm}
\end{aligned}
$$

These numbers are just estimates with local concentrations varying higher or lower by possibly an order of magnitude. Although these levels would definitely be noticeable, the hazard to personnel for a short period of time would be low. If during re-entry, the odor of fluorine is detected, the alcove should be remain evacuated until the ventilation system can reduce the concentration in the room.

My recommendation is to remove the fluorine monitor and rely on the engineering and operator experience rather than relying on a control measure that may not be able to provide the protection that it was 
G. L. Donovan, 1254

installed to provide.

JMP : 3311

Copy to:

1254 S. A. Goldstein

3311 D. R. Parker

3310 File 
TABLE I

Biological Effects of Very Short Exposures to Fluorine Gas

\section{Concentration}

$<1 \mathrm{ppm}, 0.14 \mathrm{ppm}$

0.10 to $10 \mathrm{ppm}$

15 to $30 \mathrm{ppm}$

30 to $100 \mathrm{ppm}$

ज़ > $100 \mathrm{ppm}$

$\stackrel{1}{\bullet} 100$ to $250 \mathrm{ppm}$
$>250 \mathrm{ppm}$
$1 \%(10,000 \mathrm{ppm})$
$>1 \%(10,000 \mathrm{ppm})$

\section{Biological Effects}

odor threshold (sharp, penetrating, sour, halogen like)

level of concentration can not be fixed from the smell

discomfort in the nasal passages after only 2 or 3 breaths

very irritating to the breathing passages and eyes

fluorine warms the skin and makes the body hair feel sticky

exposure for a few minutes will cause minor skin irritation, itching, and subsequent sunburn effect.

multiple breaths probably impossible to inhale

lethal to experimental animals after a 5 minute exposure

direct blast from pressurized 1 ines to the skin will cause second degree chemical/thermal burns 


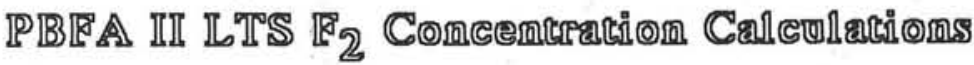

\section{SOMPe Volmm - Gra Ifine}

$12 \mathrm{ft}$. of $0.25^{\prime \prime}$ o.d. $/ 0.18^{\prime \prime}$ i.d. stainless steel tubing of $5 \% \mathrm{~F}_{2}$ in Neon at 20 psig:

$$
V_{g 1}=\left(0.03 \mathrm{ft}^{3}\right)(\{20 \mathrm{psig}+12\} \div 12)=0.08 \mathrm{ft}^{3} \text { of } \mathrm{F}_{2}
$$

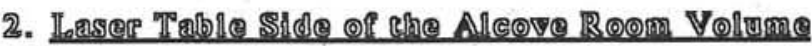

$$
V_{r}=(22 \mathrm{ft})(22 \mathrm{ft})(12 \mathrm{ft})-(8 \mathrm{ft})(22 \mathrm{ft})(12 \mathrm{ft})=3696 \mathrm{ft}^{3}
$$

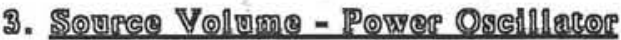

40 torr of $5 \% \mathrm{~F}_{2}$ in a total pressure of 3400 torr volume of 50 liters $\left(1.77 \mathrm{ft}^{3}\right)$

$\mathrm{F}_{2}$ concentration $=(40$ torr $\div 3400$ torr $) \times .05=6 \times 10^{-4} \% \mathrm{~F}_{2} @ 3400$ torr

$$
\begin{aligned}
\mathrm{V}_{\mathrm{po}}=\left(1.77 \mathrm{ft}^{3}\right)(\{3400 \text { torr }+630 \text { torr }\} & \div\{630 \text { torr }\})\left(6 \times 10^{-4} \mathrm{FF}_{2}\right) \\
& =0.01 \mathrm{ft}^{3} \text { of } \mathrm{F}_{2}
\end{aligned}
$$

\section{Souree Volmme - Master Oscillaror}

75 torr of $5 \% \mathrm{~F}_{2}$ in a total pressure of 1400 torr volume of 2 liters $\left(0.07 \mathrm{ft}^{3}\right)$

$\mathrm{F}_{2}$ concentration $=(75$ torr $\div 1400$ torr $) \times .05=3 \times 10^{-3} \% \mathrm{~F}_{2} @ 1400$ torr

$V_{m o}=\left(0.07 \mathrm{ft}^{3}\right)(\{1400$ torr +630$\} \div 630)\left(3 \times 10^{-3} \% \mathrm{~F}_{2}\right)=6 \times 10^{-4} \mathrm{ft}^{3}$

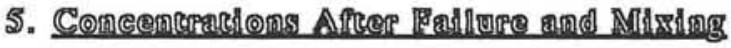

Concentration $(\mathrm{ppm})=($ Source Volume $\div$ Room Volume $) \times 10^{6}$

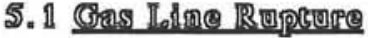

$$
\left(0.08 \mathrm{ft}^{3} \div 3696 \mathrm{ft}^{3}\right) \times 10^{6}=22 \mathrm{ppm}
$$

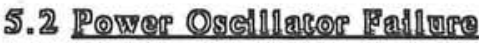

$$
\left(0.01 \mathrm{ft}^{3} \div 3696 \mathrm{ft}^{3}\right) \times 10^{6}=2 \mathrm{ppm}
$$

\subsection{Mascer Oschildrer Tantme}

$$
\left(6 \times 10^{-4} \mathrm{ft}^{3} \div 3696 \mathrm{ft}^{3}\right) \times 10^{6}=0.2 \mathrm{ppm}
$$


Sandia National Laboratories Albuquerque, New Mexico 87185

Date: July 15,1986

To: G. L. Donovan, 1254

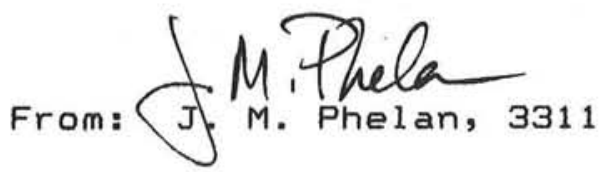

Subject: Control Measures for the LTS KrF Beam Hazards

This memo defines the hazards of the LTS KrF beam, the ANSI hazard classification, and the control measures required to meet Sandia laser safety criteria.

\section{$\underline{\text { KrF Beam Hazards }}$}

The LTS KrF lasers operate at $248 \mathrm{~nm}$ which is located in the ultraviolet range. Primary hazards to the eye from excessive acute exposures would be photokeratitis. This is a radiant energy induced damage to the outer epidermal cell layer of the cornea. Corneal hazing, exfoliation, photophobia and redness/tearing characterize the effects of photokeratitis. Chronic high level exposure may result in cataracts. The skin can also be affected with a reaction similar to sunburn.

In all cases, the biologic effect is based on the intensity of the beam when it hits the eye or skin. The following table shows the PBFA II LTS laser operating parameters:

laser $m f q$

Hel ionetics oscillator

power

master max enerqy

$\begin{array}{lll}6 & \mathrm{~J} & * \\ 4 & \mathrm{~J} & -1\end{array}$

beam size

$3 \times 4.5 \mathrm{~cm}$

$1 \times 0.5 \mathrm{~cm}$ irradiance

$445 \mathrm{~mJ} / \mathrm{cm} 2$ $300 \mathrm{~mJ} / \mathrm{cm} 2$ $100 \mathrm{~mJ} / \mathrm{cm} 2$

* design

- actual

\section{Laser Classification}

All lasers at Sandia are classified for potential hazard using the ANSI Z136.1 standard. The LTS KrF laser is considered Class IIIb since it can emit accessible radiation above the Maximum. Permissible Exposure (MPE) criterion limit, but less than $10 \mathrm{~J} / \mathrm{cm} 2$. The MPE is defined as a threshold value, with an intrinsic safety factor, above which the probability of biological damage is high. Any KrF laser with an output irradiance of greater than $10 \mathrm{~J} / \mathrm{cm} 2$ is considered Class IV.

The MPE for direct intrabeam exposure to the eye for a KrF laser (248 nm) beam for a duration of $1 \mathrm{~ns}$ to 30000 sec is 3 $\mathrm{mJ} / \mathrm{cm} 2$. The MPE for the $5 \mathrm{kin}$ is also $3 \mathrm{~mJ} / \mathrm{cm} 2$. All exposures to beams of greater intensity than $3 \mathrm{~mJ} / \mathrm{cm} 2$ have the capability to produce biologic damage. These exposures must be the result 
of an intrabeam or specular (mirror like) reflection. Ultraviolet lasers are not capable of producing a hazardous diffuse (non-mirror like) reflection.

\section{Control Measures}

Sandia uses ANSI 2136.1 requirements for the control of laser hazards. The 1986 revision of the standard incorporates a new concept (Nominal Hazard Zone) and allows for greater discretion in the application of control measures. These will be included in this discussion. The LTS KrF laser is considered a Class II l laser system with limited open beam paths.

Class II I lasers with limited open beam paths are required to have controls appropriate to the magnitude and extent of accessible radiation. The degree of protection required is based on the possibility of overexposure to laser radiation. Factors that are used in the assessment of adequate control measures are: beam intensities, frequency of personnel access and visitors, frequency of beam path alterations, and the probability of misaligned optics.

Class IIIb require the following controls for indoor laser operations:

* have warning signs posted

* be operated by qualified and authorized personnel

* be under the supervision of someone knowlegeable in laser safety

* have the Nominal Hazard Zones ( $\mathrm{NHZ}$ ) defined to establish laser controlled areas

* apply engineering and administative controls to prevent exposures above the MPE for operators and visitors

The first three items can be complied with without much misunderstanding. The NHZ defines the space within which the probability of exceeding the MPE is high. Within this zone, engineering and/or administative controls are required. Beams that escape the NHZ are below the MPE by definition and no controls are required. The definition of the NHZ considers all direct, reflected or scattered laser beam paths, normal operations and maintenance, and the probable failure of any type of engineering or administrative control measure (i.e. leaving an enclosure open, having a misaligned mirror and propogating a beam outside of the enclosure).

For Class II Ib laser systems the engineering and administrative controls are left vague, specifying only that access by visitors should be $1 \mathrm{imited}$ and require approval. The purpose of these control measures are to reduce the possibility of exposure to hazardous levels of laser radiation. Actual requirements are left to the discretion of the laser safety officer (div. 3311 ). 
Class IV lasers require all of the above controls as well as one of three methods for access control within the NHZ. The first is a non-defeatable entry way control. Second is a defeatable entry way control, where access is allowed only to authorized, trained individuals (keyed access). Third, a completely administative procedure could be used (curtains and signs). Any of these methods may be used, however, the control measures must be sufficient to provide adequate protection for laser operators and/or visitors.

\section{RECOMMENDATIONS}

The LTS laser system can be divided into two distinct NHZ's by the discrete locations, enclosures and beam intensities inherent in the design of the system. Each NHZ requires a separate evaluation of engineering and/or administrative control measures to comply with the intent of the ANSI standard. The laser screen room defines one specific $\mathrm{NHZ}$. The beam path down to the splitting tables (vertical and horizontal) are generally enclosed. This separates the down range optic table enclosures and switches and defines another $\mathrm{NHZ}$. The following table defines the beam intensities that could be found within these two $\mathrm{NHZ}^{\prime} 5$.

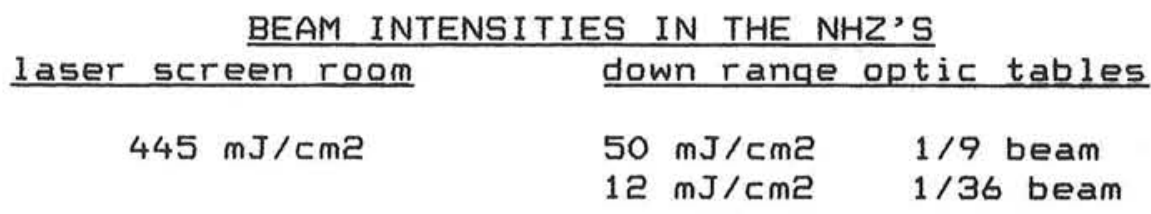

The laser screen room is within a NHZ with high beam intensities and is characterized by frequent access by LTS and non-LTS personnel. An optimal control measure would be to enclose the beam path area completely or partially to significantly reduce the $\mathrm{NHZ}$. The $\mathrm{NHZ}$ would then be located within a much smaller area of the screen room. A plexiglass parapet surrounding the laser table would significantly reduce the NHZ, allow adjustment of items on the laser table, and reduce the need for additional access control requirements. With the parapet, the blue laser curtain would not be required. Even the present interlock on the door would be supplemental since the laser operator would have visual control over the $\mathrm{NHZ}$ above the laser table. Without the enclosure, the curtain and or the door interlock would be required to prevent unexpected entry into a $\mathrm{NHZ}$.

The down range optic tables can be described as areas requiring infrequent access, usually by the laser operations crew, and are enclosed by material transparent to the KrF beam. The control measures for this area require only that the table enclosure be closed when firing (visual inspection) and posted with appropriate signs indicating the danger. These table enclosures need not be locked. 
JMP : 3311

Copy to:

$1254 \mathrm{~S}$. A. Goldstein

1254 R. R. Johnston

1254 C. M. Schaub

3311 D. R. Parker

$3310 \mathrm{File}$ 
INDUSTRIAL HYGIENE SERVICES INVESTIGATION REPORT

PERSON

CONTACTED: G. L. DOnOVan

ORG. : 1254

BLDG/ROOM: $983 /-25$

PROBLEM: PBFA II He-Ne Laser Hazard Analys is

PROBLEM CODE : $\boldsymbol{\beta} \cdot \boldsymbol{\alpha}$

REPORT DATE: $1 / 28 / 86$ INVESTIGATOR(S): Phelan

\section{INVESTIGATION :}

An evaluation of the optical hazard from the use of the helium neon laser for the LTS alignment system was performed. The object of the evaluation was to determine the locations of beam intensities great enough to cause eye damage. The distribution of the beam through the PBFA II accelerator warrants this evaluation in order to specify appropriate control measures at locations where the beam can cause eye damage.

\section{Specifications}

Spectra Physics model 125A, S No. 202268

Wavelength $633 \mathrm{~nm}$

Maximum Power $50 \mathrm{~mW}$

Beam Divergence 800 uRadians

Beam Diameter $0.18 \mathrm{~cm}$

\section{Classification}

The ANSI 2136.1-1980 Standard is used to classify the laser according to the ability of the primary laser beam to cause biological damage. Since the LTS system splits the beam into numerous beams, the hazard classification will change based on the power density at any chosen location. This laser has been classified as a medium-power (class IIIb) system with direct intrabeam viewing hazards. Diffuse reflection hazards are not present.

\section{Maximum Permissible Exposure (MPE)}

The MPE is that level of laser radiation to which a person may be exposed without hazardous effect. For a visible beam this value depends on the beam intensity and the aversion response. The aversion response is the movement of the eyelid or head to avoid an exposure to bright light. This response can occur within 0.25 seconds, including the blink reflex time. The MPE for a $633 \mathrm{~nm}$ beam assuming a 0.25 second aversion response time is $2.5 \mathrm{~mW} / \mathrm{cm} 2$. Eye damage can occur, though, if someone deliberately stares into the beam.

4. Measured Power Densities

Beam intensity measurements were made with a coherent radiation laboratories model 212 power meter. A $7 \mathrm{~mm}$ limiting aperature was used according to section 9.2.2.1 of the ANSI standard. 


power density
$80 \mathrm{~mW} / \mathrm{cm} 2$
74
50
40
1.6
0.44
16
3.2

Lecation

at the laser aperature

through one turning mirror

on the alcove laser table

entering the horiz. laser

table

past one mirror on the horiz

laser table

vertical standpipe $1 / 9$ beam

vertical standpipe $1 / 36$ beam

transmitted through North 180

green safety glasses

transmitted through Sandia

solar visitors spectacles

\section{Beam Expander}

Previously the LTS system used a beam expander with a 10 um spatial filter on the He-Ne laser. The beam intensity at the aperature of the laser is $4 \mathrm{~mW} / \mathrm{cm} 2$. The hazard areas for this laser system would be located only on the laser table in the LTS alcove.

\section{Telescope}

The telescope that is used as an alignment aid views diffuse reflections from small reflectors put at distant points of the beam path. This activity poses no hazard; however, if a col1 imated beam was reflected back into the telescope, the focusing optics could greatly intensify the reflected beam and cause severe eye damage.

\section{CONCLUSIONS OR RECOMMENDATIONS:}

\section{Hazardous Locations}

All locations where the beam intensity is above $2.5 \mathrm{~mW} / \mathrm{cm} 2$ can be considered an intrabeam viewing hazard to personnel. At these locations the aversion response will not be fast enough to prevent damage to the eye. For $633 \mathrm{~nm}$ the damage will occur on the retina and could cause permanent vision reduction or total loss.

a. The 'entire beam path on the laser table inside the laser alcove can be considered hazardous.

b. The beam path on the horizontal laser table outside the laser alcove has beams above and below the MPE. This should be considered a hazardous location.

c. The beams in the vertical standpipes do not have sufficient 
beam Intensities to cause eye damage unless the beams are stared into. Staring into the $1 / 9$ beam for 1.6 seconds or the $1 / 36$ beam for 260 seconds will exceed the MPE and may cause eye damage.

\section{Control Measures}

The following control measures are in place and are sufficient to meet the provisions of the ANSI standard and provide eye safety.

a. laser controlled areas - the laser is supervised and operated by approved LTS operators and is separated from the non-laser areas of the alcove and the pit area. A blue welding curtain that transmits only 4 E-5 percent of the 633 $\mathrm{nm}$ beam separates the alcove area and a locked enclosure controls entry into the horizontal laser table. Visitors are asked to verbally acknowledge if it is safe to enter the alcove laser area prior to entry. There are also signs on the curtain specifying the presence of a class IIIb laser beam. It is recommended to post signs on the vertical laser tables in the pit warning persons not to stare into the laser beam (see attached design).

b. eye protection- the green safety glasses currently in use do not have sufficient transmission loss at $633 \mathrm{~nm}$ to provide eye protection for an intrabeam viewing of a hazardous beam or a mirrorlike reflection of a hazardous beam. These glasses should not be used for protection from the He-Ne beam.

CALCULATIONS:

$$
\begin{aligned}
& M P E=1.8(t)^{3 / 4} \mathrm{~mJ} / \mathrm{am}^{2} \\
& t_{\text {hayand }}=\left(\frac{1.8}{m \omega / \operatorname{mon}^{2}}\right)^{4}
\end{aligned}
$$

CROSS REFERENCE:

Environmental Monitoring:

Personnel Monitoring:

Personnel, Noise Monitoring:

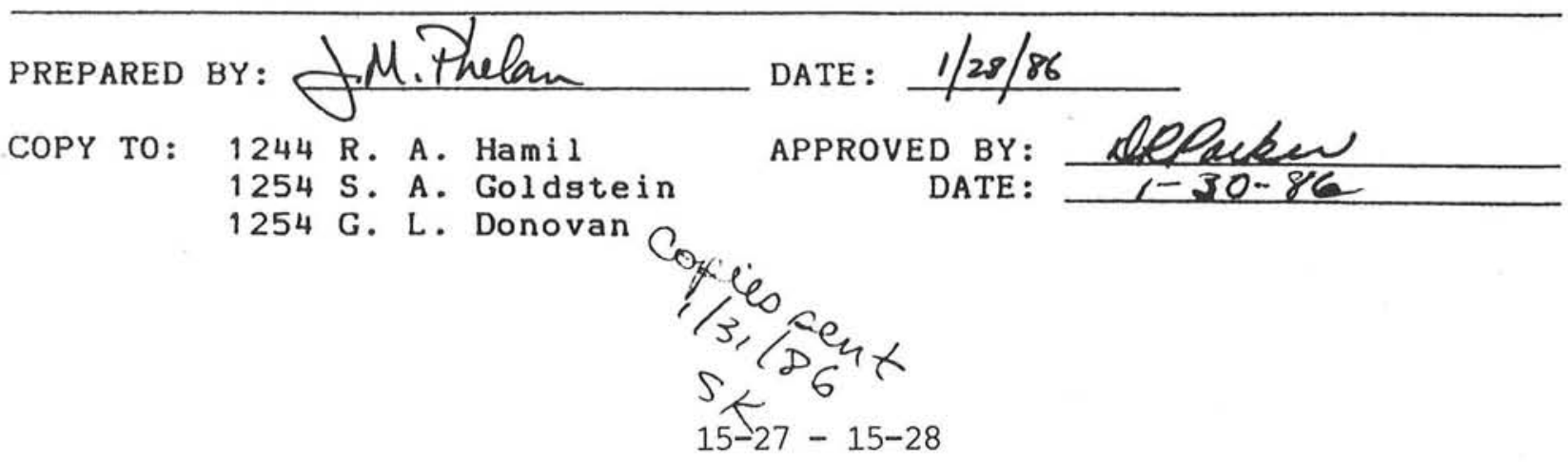




\section{SAFE OPERATING PROCEDURE FOR MAINTENANCE AND REPAIR \\ IN THE CENTER SECTION OF \\ PBFA II, BUILDING 983}

Appendix 16 


\section{Table of Contents}

Abstract . . . . . . . . . . . . . . 0

I. Introduction . . . . . . . . . . . . . . 1

II. Procedures for Entry into the Center Section . . 2

III. Appendices $\cdot \cdot \cdot \cdot \cdot \cdot \cdot \cdot \cdot \cdot \cdot \cdot \cdot \cdot 4$

A. Personnel Authorized for Center Section Access 4

B. High Voltage Equipment Safing Requirements . . 5

C. Procedures for Toxic Solvent Use . . . . . 6 
SAFE OPERATING PROCEDURE

FOR MAINTENANCE AND REPAIR

IN THE CENTER SECTION

$\mathrm{OF}$

PBFA II, BUILDING 983

\begin{abstract}
This SOP describes procedures for performing maintenance and repair operations in the center section of PBFA II, Building 983. Five major hazards are associated with maintenance activities in the center section of PBFA II:
\end{abstract}

1. Hazards associated with high voltage equipment.

2. Toxic vapor hazards associated with the use of organic solvents in the confined environment of the center section.

3. Hazards associated with the use of motive equipment.

4. Slips and falls while working within the center section.

5. Bump hazards due to the confined nature of the work space.

\begin{tabular}{ll}
\hline T. H. Martin, 1250 & date \\
\hline S. A. Goldstein, 1254 & date \\
\multicolumn{3}{l}{} \\
Distribution: \\
1236 & G. A. Zawadzkas \\
1250 & T. H. Martin \\
1254 & S. A. Goldstein \\
1254 & G. L. Donovan (2) \\
1254 & Division Members \\
3311 & D. R. Parker \\
3311 & J. M. Phelan \\
3316 & D. L. Rost \\
3316 & A. M. Fine
\end{tabular}

D. R. Parker, 3311 date

J. M. Phelan, 3311 date

D. L. Rost, 3316 date

A. M. Fine, 3316 date 
SAFE OPERATING PROCEDURE

FOR MAINTENANCE AND REPAIR

IN THE CENTER SECTION

OF

PBFA II, BUILDING 983

\section{Introduction}

Operation of the PBFA II Center section requires that maintenance operations be performed on a continuing basis. This section of PBFA II is classified as a confined workspace; the special procedures that apply to this class of work environment strictly limit entrance to authorized personnel (see Appendix A). Entry into the center section presents a number of potential hazards to personnel.

A. Three high voltage systems are associated with center section operation: the diode field bank, the plasma erosion opening switch system, and the diode utilities (e.g, active Lithium ion source, RF cleaning system, pulsed or biased diagnostics, etc.). Residual or active charges may be present on these systems should safing systems not be properly implemented. Personnel must verify that these systems have been properly safed and locked out before entry into the center section ( see Appendix B).

B. Freon TF and isopropyl alcohol based aerosols are routinely used in center section cleaning and refurbishment. The confined environment of the center section together with the toxic nature of these solvents can easily lead to overexposure and toxic effects if proper precautions are not taken. Industrial Hygiene, Division 3311, has monitored exposure levels during maintenance operations and outlined procedures for personnel protection (see Appendix C). These procedures shall be followed during all maintenance activities. Division 3311 shall be informed before any changes in type or quantities of solvents used so that additional protection may be implemented.

C. Center section maintenance involves extensive use of motive equipment to move personnel and large, heavy components. Proper procedures for the operation of 
SOP - Center Section Maintenance at PBFA II / page 2

motive equipment shall be followed at all times (ref. PBFA II Motive Equipment SOP), especially since much of the equipment must be moved over catwalks and other personnel traffic paths.

D. The potential for slips and falls in the center section is enhanced by its irregular geometry. Personnel entering the center section must be aware of this hazard at all times and wear appropriate non-slip footwear. Entry to the top of the center section shall be by ladder, Bosun's chair, or approved safety harness. At no time shall personnel enter this section by climbing down the toroid hardware. The number of personnel on the lower work platform shall not exceed five, with a maximum of two in any removable section.

E. The confined nature of the center section together with the high component density greatly increases the bump hazard to personnel. Objects dropped by personnel working overhead also adds to the potential for head injuries. Personnel entering the center section will be required to wear bump caps at all times. In addition, during disassembly operations, personnel are required to wear face shields for face and eye protection.

F. Flooding of the insulator stack may occur if the water section is filled and the center section tiedown structure is not compressed. Personnel shall not be allowed in or on the center section when the water section is filled unless the insulator stack is properly compressed.

G. Vacuum equipment shall be properly safed to prevent engagement during maintenance activities.

\section{Procedures for Entry Into the Center Section}

Before personnel enter the PBFA II center section for maintenance or repair activity, the following actions shall be performed:

A. Personnel not on the access authorization list posted at the center section handrails should contact either:

G.T. Holman, ph.\#4-2691 or pager \#142-357

Bobby Seals or Wayne Tanner,

ph.\#4-2954, 4-2956, 4-2957, or 4-1503

These personnel are aware of current hazard situations and are the only ones authorized to grant access authorization. 
B. The vacuum system and high voltage systems shall be placed in a "SAFE" state and the keys to enable these systems shall be properly locked out. The crew leader responsible for the team entering the Center Section shall verify the "SAFE" status before entry.

C. The two-man rule shall be followed whenever personnel enter the center section. Both members of the team shall be authorized by the Operations Division, 1254.

Upon completion of center section activity, personnel shall remove all tools, cleaning materials, and other equipment from the center section. Special care should be taken to monitor any small objects (e.g. pens, badges, etc.) that may have fallen into the stack. 


\section{Appendix A}

Personnel Authorized for Center Section Access

Name

Ball, Andrew

Holman, G.T.

Lake, Patrick

McDaniel, Dillon

Navarro, Mike

Parks, Phil

Petmecky, Don

Seals, Bobby

Tanner, Wayne

Vitro, Vicky

Wagoner, Tim org.

Signature

Date

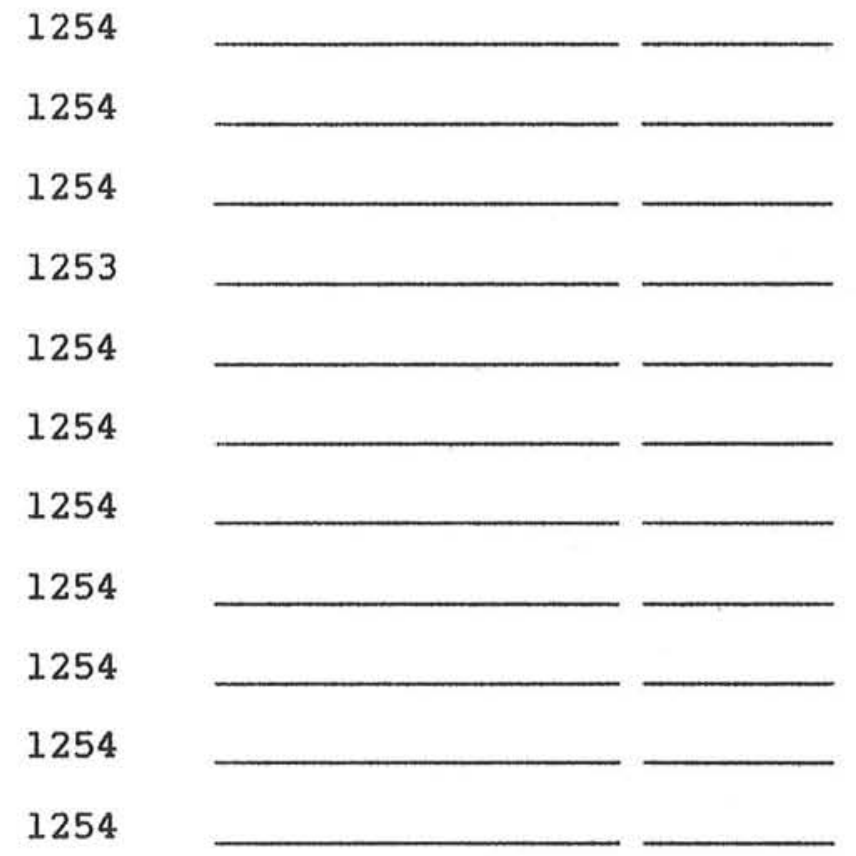


Appendix B

High Voltage Equipment Safing Procedures

Three systems are associated with operation of the PBFA II Center Section:

Diode B-Field Capacitor Bank

Plasma Erosion Opening Switch (PEOS) System

Diode Utilities Power Supply System

Before personnel are allowed access to the center section the safe condition of these systems must be verified and reported to the crew chief. Safing procedures are as follows:

Diode B-Field Capacitor Bank: Initial safing of this system is provided automatically from the Control/Monitor system by the deactivation of high voltage relays that short the bank output to ground. Proper operation of these relays should be checked before proceeding. After verifying operation of the safing relays, the output grounding sticks are secured to the bank output cables. Finally, the provided grounding straps shall be placed across the bank charging terminals. Grounding systems shall remain in place at all times bank operation is not required.

PEOS System and Diode Utilities: The PEOS and Diode utilities shall by placed in a "SAFE" condition before personnel enter the center section. The power to this system shall be locked out with a facility padlock until work is completed and personnel leave the center section. 
Appendix C

Procedures for the Use of Toxic Solvents During

Center Section Maintenance Operations

Section 1

Guidance to Develop SOP for Work in the VIS

(memo - J.M.Phelan to G.L.Donovan, 3/24/86)

Section 2

Freon Exposure During VIS Cleaning

(memo - J.M.Phelan to G.T.Holman, 3/24/86)

Section 3

Clarification of $3 / 24 / 86$ Memo

(memo - J.M.Phelan to G.T.Holman, 3/28/86)

Section 4

Action Levels for Chemical Exposure During Pre-Shot VIS Activities

(memo - J.M.Phelan to Distribution, 10/22/86) 
Sandia National Laboratories Albuquerque, New Mexico 87185

date: March 24, 1986

to: G. L. Donovan, 1254

from: J. M. Phelan, 3311

subject: Guidance to Develop SOP for Work in the Vacuum Insulator Stack

Ref: (1) Memo - Action Levels for Chemical Exposure During Pre-shot Vacuum Stack Activities; J. M. Phelan to Distn.; October 22, 1985.

(2) Memo - Freon Exposures During VIS Cleaning; J. M. Phelan to G. T. Holman; March 24, 1986.

Hazardous Operations.

An assesment of the work performed in the vacuum insulator stack has shown two types of operations where personnel may be exposed to hazardous air contaminants:

1. Pre shot cleaning and oiling operations -

Pre shot cleaning operations can generate significant exposures to freon for personnel in the VIS (ref 2). Oiling operations do not generate hazardous air contaminants but fresh air should be provided for personal comfort.

2. Post shot hardware removal and stack inspection The unusual odors coming from the VIS upon first opening have not been characterized, but from past experiences, these odors do not appear to contain significant hazardous components. After a lithium shot there may be lithium particulates that could be hazardous to personnel when removing hardware and inspecting the stack.

Recommended Procedures

* General

1. Air blowers should be made available for all operations that involve significant time in the VIS for odor and heat control.

* Pre shot cleaning 
2. Air blowers should be required for any freon cleaning operations in the VIS.

3. Air purifying respirators should be required for the freon cleaning operations in the VIS when the entire stack is to be cleaned (ref 2 ). Respirators need not be required for small scale cleaning operations.

4. Nitrile (NBR) gloves should be made available for those operations that involve skin contact with freon or other chemical solvents.

* Post shot work

5. Personnel should be provided eye protection, vinyl gloves, and disposable head covering when lithium can be a significant contaminant during post shot work. Further evaluation of this hazard will be performed as more experience is gained in the results of each shot and different diode configuations.

JMP $: 3311$

Copy to:

1254 S. A. Goldstein w/o ref

1254 R. R. Johnston w/o ref

1254 G. T. Holman w/o ref

3311 D. R. Parker w/o ref

3310 File w/o ref 
Sandia National Laboratories

Albuquerque, New Mexico 87185

date: March 24, 1986

to: G. T. Holman, 1254

from: J. M. Phelan, 3311

subject: Freon Exposures During Vacuum Insulator Stack Cleaning

\section{Investigation}

This report describes interim findings from two days of sampling for Freon $\mathrm{TF}$ and Aerodag components during operations within the vacuum insulator stack (VIS) of PBFA II. Samples were taken on 12/6/86 for Freon TF, Methylene Chloride, and Isopropyl Alcohol during the cleaning and aerodagging of the center torroid. On 12/9/86, samples were taken for Freon TF during a complete ring cleaning and oiling operation.

The samples for Freon TF taken during the ring cleaning operation were severely overloaded. The results from these samples are, therefore, poor estimates of the exposures during this operation and are most likely very conservative. There has not been another complete ring cleaning operation to date. These exposure estimates can be used with the understanding that the true exposures were likely to be much higher.

Table A tabulates the exposures to Freon TF, MeCl2, and IPA during the center torroid cleaning and aerodagging operation." These exposures were all within the exposure 1 imits and do not indicate a significant health threat to personnel performing this operation.

Table B tabulates the exposures during the complete freon TF cleaning of the VIS. The exposures of the top crew averaged $580 \mathrm{ppm}$ and the crew on the bottom averaged $615 \mathrm{ppm}$. The bottom crew had a higher average exposure due to the closed in nature of the workspace. When the work platform is raised up into the stack, the working area is an enclosed cylinder about 12 feet in diameter and 10 feet high. Access is through a trap door in the work platform. The top crew have an open top in their work area which allows for better dilution of air contaminants. While observing the top crew, it appeared that most of the Freon TF cleaning occurred in a 30 minute period. If the exposures were averaged over this 30 minute period rather than the entire sampling time, the exposures would then approach the $3000-5000$ ppm range. If one also considers that the Freon TF found on the samplers exceeded the rated capacity by 40 - 50 times, these exposures may have well 
exceeded $5000 \mathrm{ppm}$.

Since Freon $T F$ is nonflammable and has a relatively high allowable exposure $1 \mathrm{imit}$, it is one of the safest solvents to use in this situation. However, if control measures can not keep the exposure under this generous exposure limit, there are some acute health affects that put employees at a severe risk.

The exposure $1 \mathrm{imit}$ for 8 hours a day for a working 1 ifetime is $1000 \mathrm{ppm}$, below which no health effects would occur in normally healthy individuals. At levels greater than 1000 ppm biological effects appear as mild irritation, loss in ability to concentrate, and mild lethargy. When the exposure exceeds $5000 \mathrm{ppm}$ the heart can become sensitized to the effects of epinephrine. Epinephrine is produced by the body by marny mechanisms, including stress or fright producing situations. When a person is under stress and exposed to greater than 5000 ppm Freon TF, the heart muscle is more susceptable to epinephrine. The heart may beat with an irregular rhythm and otherwise function abnormally. This effect appears to have a threshold at about $5000 \mathrm{ppm}$ and becomes more pronounced as the exposure is increased.

Recommendations

The operations in the VIS that use significant quantities of chemical solvents have the potential to cause serious overexposures with significant health risks to personnel. It is important to keep close surveillance on those jobs using chemicals within the VIS. The following action items should be considered when activities are planned for the VIS.

1. Blowers - The coppus blowers should be used at all times that significant quantities of solvents are to be used in the VIS. One should be used on top and one for the bottom. These fans should be used to blow air into the working areas rather than sucking contaminated air out. The fans are much more effective at blowing air than pulling air.

a. If dust is considered to be a significant problem in the VIS, then a filter assembly should be designed by your people and installed on the intake of the fans. The use of the fans to provide fresh air to dilute air contaminants should be a primary action.

2. Monitoring - The next time a job similar to the complete ring cleaning occurs, division 3311 should be notified to evaluate exposures. This is very important in order to recommend the most effective control measures.

3. Respirators - Until we can get a better handle on the magnitude of exposures during the complete ring cleaning operation, half-face air purifying respirators should be required. Those people with beards or medical restrictions should not be performing this job. 
4. Gloves - Instead of the vinyl anti-c type glove currently used, a nitrile (NBR) style glove will provide better chemical resistance to the Freon TF. This will protect the skin from the oil removing and drying effect of the Freon TF.

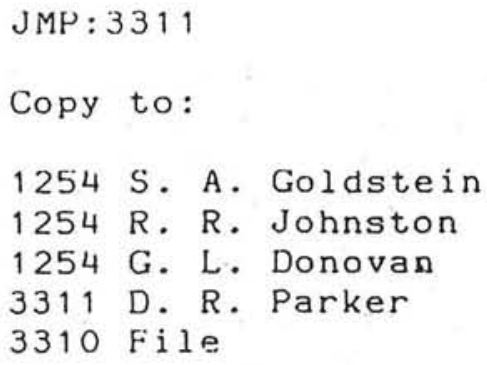


TABLE A

PBFA I I CENTER TORROID FREON CLEANING AND AERODAGGING MONITORING SUMMARY DECEMBER 6, 1985

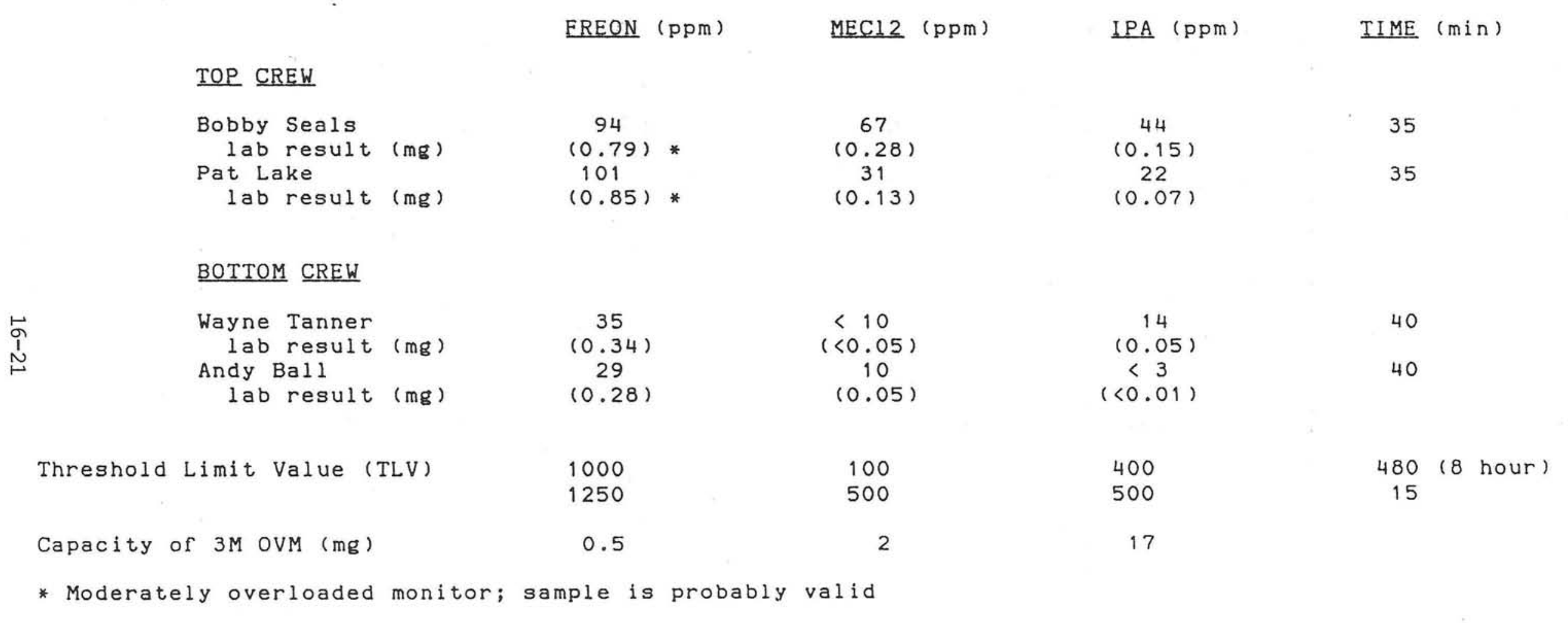


TABLE B

PBFA I I VACUUM INSULATOR STACK FREON CLEANING MONITORING SUMMARY DECEMBER 9, 1985

EREON (ppm) TIME (min) LAB RESULTS (mg)

TOP CREW

Bobby Seals

Pat Lake

495

180

$21.4 *$

634

170

25.9 *

Mike Navarro

629

170

$25.7 *$

--- Estimated exposure assuming all work performed in a 30 minute period -..

$\begin{array}{ll}\text { Bobby Seals } & 2967 \\ \text { Pat Lake } & 3591 \\ \text { Mike Navarro } & 3564\end{array}$

30
30

Mike Navarro

3564

30

$21.4 *$

$25.9 *$

25.7

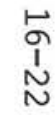

\section{BOTTOM CREW}

Wayne Tanner
Andy Ball
Phil Parks
Vicky Vitro

$\begin{array}{ll}594 & 140 \\ 704 & 140 \\ 647 & 135 \\ 517 & 140\end{array}$

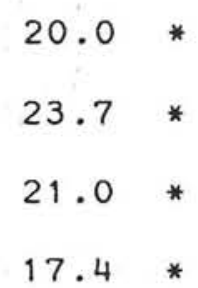

Threshold Limit Value (TLV) greatly underestimated actual exposure 
date: March 28, 1986

to: G. T. Holman, 1254

from: J M. Phelan, 3311

subject: Clarification of Memo

Ref: Memo - J. M. Phelan to G. T. Holman; Freon Exposures During Vacuum Insulator Stack Cleaning; March 24, 1986.

Your review of the referenced memo brought out several points of confusion. A clarification of these items include:

1. There have been other complete ring cleaning operations to date, but none have been performed solely with Freon TF. . These cleaning operations have used diffusion pump oil as the cleaning agent for a majority of the work with only small uses of Freon in difficult areas.

2. The reference to cleaning in a 30 minute period was for just that time period where Freon was used. The setup time and oiling time were in additions to this 30 minute period.

3. There does seem to be a significant concern over dust accumulating in the VIS. The use of blowers to blow air, even with a filter assembly, may increase the concerns/problems over dust. If large amounts of Freon are not being used to clean, the blowers could be used to pull air from the stack rather than blowing air into the stack. This will allow makeup air to bring the fresh air into the stack at a lower flow rate, maybe create less of a dust problem, and bring sufficient air into the work area.

4. The next time a complete ring cleaning operation is planned with Freon, division 3311 should be notified. Cleaning with. diffusion pump oil and small uses of Freon need not be monitored.

5. As an added precaution, personnel cleaning and aerodagging the center torroid ( $\# 4$ ) are presently using air purifying respirators to reduce exposures to as low as reasonably achievable. 
date: October 22, 1985

to: Distribution

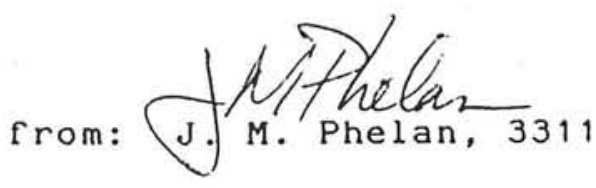

subject: Action Levels for Chemical Exposure During Pre-shot Vacuum Stack Activities

This memo has been written to inform you of the support the industrial hygiene group will provide for the PBFA II first shot.

Industrial hygiene will provide real time air monitoring to measure the levels of chemical vapors in the center stack during the cleaning, oiling and aerodagging operations prior to the first shot. This support is mandatory in light of the risks of high exposures to freon TF, methylene chloride, and isopropyl alcohol (methylene chloride and isopropyl alcohol are contained in Aerodag G). Freon TF is fairly non-toxic at lower levels, but at levels exceeding $0.5 \%$ the heart may become sensitized to epinephrine, increasing the likelihood of stress induced cardiac arrhythmias. Methylene chloride at higher levels of exposure has been implicated as an animal carcinogen and is the subject of regulatory action by the EPA. Isopropyl alcohol is extremely irritating to the eyes and respiratory tract at levels exceeding the 8 hour exposure 1 imit (400 ppm).

The measurements will be used to select the appropriate respiratory protection devices (provided by 3311). Since it is unknown whether an airline respirator will be feasible in the center section, work may have to be interrupted to allow natural or forced ventillation to decrease the concentrations. It is not likely that work will have to be suspended for very long periods of time during these operations, but careful monitoring is required. In other industries, deaths have occurred when unmonitored confined space work was performed with freon TF and methylene chloride.

The following table will be used as a guide for action based on the monitoring results found.

JMP : 3311

Copy to:

3311 D. R. Parker

3310 File 
TABLE 1

CHEMICAL CONCENTRATION AND ACTION REQUIRED

CHEMICAL

CONCENTRATION

Freon TF

to $1000 \mathrm{ppm}$

1000 to $5000 \mathrm{pPm}$

$>5000$ ppm

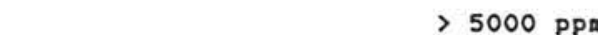

0 to $100 \mathrm{ppm}$

Methylene

Chloride

100 to $500 \mathrm{ppm}$

$>500 \mathrm{ppm}$

a frline resplrator requlred or work suspended unt1l level reduced by natural or forced vent1lation. ventilation. purifying respirator.

require half or full face alr purlfying resplrator. alrline resplrator recommended.
COMMENTS

recommend half or full face alr purifying resplrator.

require half or full face alr purlfying resplrator. alrline purirator recommended.

work suspended untll level

reduced by natural or rorced

1000 pp - 8 hr THA exposure

1 Imlt with no resplrator.

resplrator for exposure reduction Co ALARA and comfort.

$3000 \mathrm{ppm}-30 \mathrm{~m}$ In TWA exposure 1 Imlt with no respirator.

respirator for exposure reduction. may require rul

IDLH concentration. cardlac sensitization, heart attack possible. recomand half or full race air

recommend half or full face air purifylne resplrator.

Isopropy

Alcoho

0 to $400 \mathrm{pP}$

400 to 5000 ppa

TWA - time weighted average

IDLH - immediately dangerous to life and health

ALARA - as low as reasonably achievablè require full face air purifyine respirator. alrline respirator recommended.

airline respirator required or work suspended until level ventilation. reduced by natural or forced
$100 \mathrm{ppm}-8 \mathrm{hr}$ TWA exposure

11 ilt with no respirator.

respirator for exposure reduction o ALARA and comfort.

500 ppm - 15 min TWA exposure

$11 \mathrm{mit}$ with no respirator.

resplrator for exposure reduction.

eye irritation may require full

race resplrator.

poorly adsorbed by alr purlfy-

ing cartridges. possible anlmal

carcinogen at high conc.
$400 \mathrm{ppm}-8 \mathrm{hr} \mathrm{T}$ - $\mathrm{dA}$ exposure linit with no resplrator. respirator for exposure reduction to ALARA and comfort.

$500 \mathrm{ppm}-15$ mIn THA exposure 1 imit with no respirator. resplrator for exposure reduction. eye irritation requires full face resplrator use.

moderate narcotlc offects possible. severe eye and resplratory irritant. 


\section{SAFE OPERATING PROCEDURE \\ FOR THE \\ APPLIED-B DIODE CAPACITOR BANK \\ AT \\ PBFA II, BUILDING 983}

Appendix 17 
Table of Contents

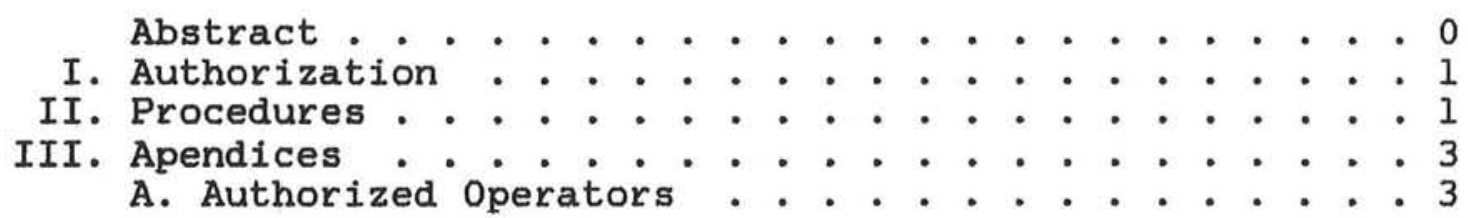




\title{
SAFE OPERATING PROCEDURE
}

FOR THE

\author{
APPLIED-B DIODE CAPACITOR BANK
}

AT

PBFA II, BUILDING 983

\begin{abstract}
This document outlines safe operating procedures for the 600 $\mathrm{kJ}, \quad 22 \mathrm{kV}$ Applied-B Diode capacitor bank located in Building 983. The high-voltage unit is located on the -25 foot level of Building 983 and the control console is located in the PBFA II Control/Monitor Room. Improper operation of this device could result in personal injury and electrocution.
\end{abstract}

T. H. Martin, 1250 date

S. A. Goldstein, 1254 date
D. L. Rost, 3316

date

A. M. Fine, 3316

date

Distribution:

1236 G. A. Zawadzkas

1254 S. A. Goldstein

1254 G. L. Donovan (2)

1254 Division Members

1264 P. A. Miller

3316 D. L. Rost

3316 A. M. Fine 
SAFE OPERATING PROCEDURE

FOR THE

APPLIED-B DIODE CAPACITOR BANK

AT

PBFA II, BUILDING 983

\section{Authorization}

Only personnel authorized by the Supervisor of the Pulsed Power Operations Division, 1254, shall be permitted to operate this device. Before being authorized these personnel shall:

A. Read and understand all pertinent documentation describing the bank's construction and operating features.

B. Familiarize himself/herself with the bank hardware including the high voltage unit, controls, interlocks, status displays, and safety features.

C. Demonstrate adequate familiarity with the hardware and operating procedures.

D. Be familiar with and understand the contents of this Safe Operating Procedure.

(see Appendix A for currently authorized personnel)

II. Procedures

A. Capacitor bank controls shall be locked in the "OFF" position at all times except when bank operation or testing is in progress. Keys shall be kept in the control of the Facility Manager to prevent unathorized operation. 
B. No operation of capacitor bank high voltage section shall take place unless either:

1. The Building 983 Access Control System is activated to prevent personnel access to the bank and load areas,

OR

2. Personnel access to the bank and load areas is prevented by use of facility personnel, under the direction of the bank operator, who have been instructed as to the hazards that exist and:

a. have visual control over all approach paths to the bank and load areas, and

b. are in communication with the bank operator.

C. The capacitor bank high voltage section shall not be operated with any interlocks or status display features inoperative.

D. Testing of bank sub-systems (cooling water, heaters, control indicators, etc.) shall be allowed without compliance with "B" above providing that all high voltage circuitry is disabled and the main control console is locked in the "OFF" position.

E. After each session of capacitor bank operation, the bank operator shall ensure that:

1. The bank has been dumped

2. the console has been locked in the "OFF" position

3. The internal shorting circuits have been visually inspected for engagement and proper condition

4. All external manual shorting devices have been engaged.

F. If, in the opinion of the operator, any test cannot be completed safely, then he/she shall not begin the test sequence or shall discontinue the test if already in progress. The operator shall then bring this concern to the attention of the Building 983 Facility Manager. The Facility Manager shall be responsible for resolving this concern through Division 1254 Supervision, the Organization 1200 Experimental Safety Committee, or Safety Engineering Division 3316, before testing proceeds. 


\section{Appendix A}

Authorized Applied-B Diode Capacitor Bank Operators

$\begin{array}{lll}\text { Name } & \text { Org. } & \text { Signature } \\ \text { Cleary, Richard } & 1254 & \\ \text { Devlin, Gary } & 1254 & \\ \text { Holman, G.T. } & 1254 & \\ \text { Nations, Dennis } & 1254 & \\ \text { Navarro, Mike } & 1254 & \\ \text { Seals, Bobby } & 1254 & \\ \text { Tanner, Wayne } & 1254 & \end{array}$




\section{SAFE OPERATING PROCEDURE \\ FOR \\ WELDING, CUTTING, AND HOTWORK \\ IN}

TECH AREA IV

Appendix 18 


\section{Table of Contents}

Abstract.................... . . 0

I. Introduction . . . . . . . . . . . . . . . . . 1

II. Description of Relevant Hazards . . . . . . . . 2

A. Toxic By-Products . . . . . . . . . . . . . 2

1. Metal Fumes . . . . . . . . . . . . 2

2. Toxic Gases . . . . . . . . . . . 3

3. Ultraviolet Radiation . . . . . . . . 3

B. Equipment Related Hazards . . . . . . . . . . 3

1. Compressed Gas Cylinders . . . . . . . . 3

2. Electrical Shock... . . . . . . . . 3

3. Fire....... . . . . . . . . 4

III. Hazard Control Procedures . . . . . . . . . . . 4

A. Control of Toxic By-Products . . . . . . . . . 4

1. Ventilation Control Measures . . . . . . . 4

2. Personal Protective Equipment . . . . . . 4

a. Supplied Air Respirators . . . . . . . . 4

b. Eye Protection . . . . . . . . . . . 5

c. Protective Clothing . . . . . . . . 5

B. Compressed Gas Cylinders . . . . . . . . 6

1. Storage ............... . 6

2. Handling . . . . . . . . . . . . 6

3. Cylinder Use . . . . . . . . . . . 6

C. Electrical Shock . . . . . . . . . . . 7

D. Fire Prevention . . . . . . . . . . . . 7

1. SNLA Procedures . . . . . . . . . . . 7

2. Tech Area IV Procedures . . . . . . . . . . 7

IV. Appendices . . . . . . . . . . . . . . . . . 9

A. Fire Protection Procedure . . . . . . . . . 9

B. Sandia Welding Permit, SA 2013-B . . . . . 21

C. TA-IV Welding Checklist . . . . . . . . 22 
SAFE OPERATING PROCEDURE

FOR

WELDING, CUTTING, AND HOTWORK

IN

TECH AREA IV

\begin{abstract}
This SOP describes safety considerations and procedures for obtaining welding and cutting permits for work done in and around all accelerator facilities in Tech Area IV by members of the 1200 orqanization. Three major hazards are associated with these activities:
\end{abstract}

1. Toxic by-products, such as metal fumes, toxic gases, and ultraviolet radiation.

2. Dangers associated with welding equipment, such as electrical shock and compressed gas hazards.

3. Fires resulting from ineffective safety procedures.

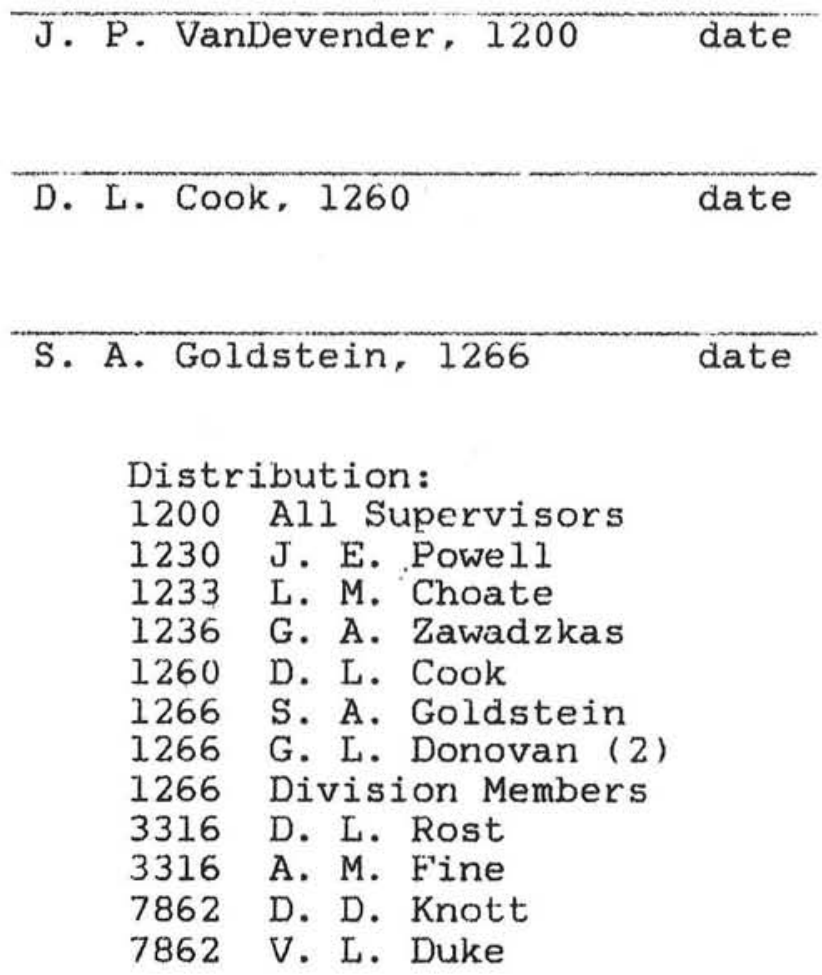

D. L. Rost, 3316 date

A. M. Fine. 3316 date

D. D. Knott, 7862 date

V. L. Duke, 7862 date 
SAFE OPERATING PROCEDURE

FOR

WELDING. CUTTING, AND HOTWORK

IN

TECH AREA IV

I. Introduction

This document addresses the hazards associated with welding, cutting and other hotwork in and around the accelerator facilities in Tech Area IV. Procedures to minimize risks and improve safety are presented.

This type of metal work falls into three classes:

A. Weld Shop Work

This work includes welding, cutting, brazing, flame soldering, and other hotwork performed by 1200 personnel in areas specifically designed as "Weld Shops". Whereas the environment of these areas can be closely controlled, hazard risks are less than those in other areas. These lower risk areas may be issued a long term renewable welding permit, though the procedures specified herein must still be followed.

B. Accelerator Tank or Structural Work

This work includes modifications to metal components or structures performed by 1200 personnel outside of established weld shop areas. The presence of transformer oil, solvents and other flammable materials within Area IV facilities require strict adherence to the provisions of this SOP.

C. Welding by Construction Contractors or Plant Engineering Personnel

This work is similar to cateqory B above, but covers work performed by non-1200 personnel. DOE or Plant Engineering Divisions are responsible for establishing and monitoring procedures and issuing permits for these operations. Permits issued to non-1200 personnel by Plant Engineering shall be countersigned by the appropriate 1200 permit issuer before work begins to ensure local safety aspects have been considered. In addition, 1200 personnel should monitor this work and 
SOP - Welding, Cutting, and Hotwork in TA-IV / page 2

report violations or unaddressed hazards to the proper authorities (Plant Inspectors. Fire Protection, DOE, etc.). All personnel should be prepared to stop anyone performing hazardous operations.

II. Description of Relevant Hazards

A. Toxic By-Products

Metal fumes, toxic gases, and ultraviolet radiation may be produced by welding and cutting operations. Personnel should be aware of these potential hazards before performing work of this type.

1. Metal Fumes

The type of metal fume qenerated depends upon the type of metal being welded and the weld rod used. Different metal fumes have different orders of toxicity.

Cadmium and lead fumes are extremely toxic. Overexposure to fumes from these metals may result in death. Both lead and cadmium can be found in combination with other metals as alloys which are just as hazardous in this regard. The following lists some common materials which contain lead or cadmium :

a. Lead is a component in some brasses and bronzes.

b. Lead fumes can be generated from welding materials coated with lead base paints.

c. Lead fumes may be generated by continuous soldering operations or from plumber's lead pots.

d. Cadmium is used extensively as a corrosion resistant coating on iron and steel.

e. Cadmium plating is used to protect many types of casters, cabinet harware, lock hasps and other hardware.

f. Cadmium is an ingredient in many solders and brazing wires.

The fumes from antimony, chromium, cobalt, copper, magnesium, nickel, zinc, tin and stainless steel are moderately toxic. Zinc is found in all galvanized metals. Overexposure to these metal fumes results in a malaria-like illness called metal fume fever. Chills, fever, nausea, headache and dry cough begin a few hours after exposure and usually last about a day. 
SOP - Welding, Cutting, and Hotwork in TA-IV / page 3

\section{Toxic Gases}

Electric arc welding operations result in the production of toxic gases. The electric arc, in passing through air, produces ozone, carbon monoxide, and oxides of nitrogen which are highly toxic. An electric arc or intense flame may cause chlorinated hydrocarbons such as trichloroethylene, freon, and some dye penetrants to decompose into toxic products. Welding and cutting is not permitted in areas where chlorinated hydrocarbons or their vapors are present.

3. Ultraviolet Radiation

Welding and cutting operations, particularly electric arc welding, produce intense light in the visible, infrared, and ultraviolet wavelengths. This radiation may cause severe burns to the skin and eyes. Ultraviolet radiation also causes the production of ozone in the vicinity of the operation.

B. Equipment Related Hazards

The major hazards associated with welding and cutting equipment are fire, electrical shock and hazards related to compressed gases.

1. Compressed Gas Cylinders

High pressure gases present both mechanical and chemical hazards. Mechanical hazards associated with these cylinders include any action which may cause damage to the bottle resulting in the rapid release of gas. A falling cylinder or one damaged by nearby equipment may result in severe explosions. Chemical hazards may also result depending upon the gases being used. Oxygen can be very dangerous in this regard. Proper handling, storage, lubrication, cleaning and operation of all equipment is required.

2. Electrical Shock

Electrical shock is a hazard associated with electric arc welding operations. Voltages required for arc welding are typically too low to cause injury or severe shock, however, under some circumstances these voltages may be dangerous to life. Line voltages are present within welding units and may be hazardous as well. 
SOP - Welding, Cutting, and Hotwork in TA-IV / page 4

3. Fire

The possibility of fire is the most obvious hazard associated with welding and cutting in both flame and electric arc operations. The combustible most likely to be involved in such fires is transformer oil in the area of the welding operation. This oil does not burn readily in bulk for its relatively high flashpoint, but wicking or atomization aids significantly in the ignition process. Oil soaked materials such as cables, rags, Zorb-all, and others must be considered as flammables. Virtually any flammable material can be ignited by hot slag from welding operations.

\section{Hazard Control Procedures}

A. Control of Toxic By-Products

Adequate ventilation and use of personnel protective equipment are the most commonly employed safeguards against welding hazards. Proper ventilation of the welding area is the most important control measure to ensure personnel safety. The following is a description of types of ventilation control and personnel protective equipment useful in controling welding hazards :

1. Ventilation Control Measures

a. Good general room ventilation must be supplied for any welding operation.

b. Work in confined spaces requires local exhaust ventilation for operations that generate toxic fumes or gases. Welding of any of the metals mentioned above requires local exhaust ventilation. Local exhaust ventilation is generally required for electric arc welding operations as oxides of nitrogen and ozone are always produced. Local exhaust should also be considered to prevent contamination of surrounding areas by welding by-products.

2. Personal Protective Equipment

a. Supplied Air Respirators

Supplied air respirators are required any time normal ventilation methods do not provide sufficient protection to personnel, for example: 
1. When welding or cutting operations produce toxic by-products and local exhaust ventilation is not available.

2. Whenever extremely toxic by-products are generated such as cadmium or lead.

3. Whenever local exhaust ventilation is unable to keep toxic by-product concentrations below acceptable safe limits.

b. Eye Protection

Welding helmets shall be used for all electric arc welding operations. Helmets or goggles shall be used for all gas welding and oxygen cutting operations.

The lense shade number used in welding and cutting depends upon the type of operation to be performed. The following is a general guideline:

Type of Operation Shade Number

\section{Cutting}

Gas Welding

Arc Welding

$$
\begin{aligned}
3 & \text { to } 6 \\
4 & \text { to } 8 \\
10 & \text { to } 14
\end{aligned}
$$

All persons in close proximity to welding or cutting operations shall wear protective goggles or spectacles. All welding operations shall be properly screened for the protection of passers-by or other personnel working in the area. Shields shall be standard non-reflective weld screens.

c. Protective Clothing

All welders shall wear flame-proof gauntlet gloves. This requirement is mandatory for electric arc welding or cutting operations. Flame-proof aprons or leathers are also recommended for protection against radiation and sparks.

Dark clothing is preferable to reduce reflected radiation. Burns on areas of exposed skin are possible from reflected radiation during gasshielded arc welding operations. Effort should be made to keep all skin surfaces covered while welding. Shirt sleeves should be kept rolled down at all times. $0 i l$ soaked clothing will support combustion and represents a fire hazard. 
B. Compressed Gas Cylinders

1. Storage

a. Cylinders should be protected from weather extremes. They may be stored in the open, but should be protected from continuous sunlight. Cylinder temperatures should never be allowed to exceed 125 degrees $\mathrm{F}$.

b. Cylinders should be secured using chains, bars or approved straps in an upright position in an area specified for their storage. Valve protection caps must be kept in place when bottles are not in use.

c. Oxygen cylinders should not be kept in close proximitry to fuel gas or other flammable materials. When sufficient separation is not possible, a fire resistant partition should be placed between oxygen and fuel gas cylinders.

d. Full cylinders should be kept seperate from empty ones.

e. Cylinders should be stored such that the may be used in rotation as new ones are delivered.

2. Handling

a. Cylinders shall not be transported without valve protection caps in place.

b. When moving cylinders by hand, tilt and roll the bottom edge. Do not drag, slide or roll on the side.

c. Cylinders should not be handled roughly, dropped, or subjected to other physical shock.

d. Cylinders should be lifted with a suitable fixture designed for this purpose. Never lift cylinders with slings, electromagnets, or by attachments to their protective caps.

e. No attempt should be made to repair, paint, or alter cylinders or their valves.

f. Never attempt to fill or mix gases within cylinders.

3. Cylinder Use

a. Do not pressurize low pressure containers with cylinders unless a regulator is used to reduce pressure to proper level. 
SOP - Welding, Cutting, and Hotwork in TA-IV / page 7

b. Check valves should be installed on the inlet side of all regulators in manifold systems.

c. Relief valves should be used on the downstream side of all regulators to protect from overpressure should a failure occur.

d. Before connecting a regulator to a cylinder valve, open the valve slightly to clear the valve of dirt or debris. Close the valve immediately.

C. Electrical Shock

Precautions applicable to all electrical devices should be observed. Ensure that circuit grounding is adequate. Operators should never allow the live metal parts of an electrode holder to come in contact with his skin. Clothing damp from perspiration or wet working conditions enhance the dangers of electrical shock.

Electrode holders must not be cooled by immersion in liquid. Water cooled holders must not be used if leaks occur.

To prevent unnecessary accidents, welding equipment should be unplugged when not in use. Metal and carbon electrodes should be removed from, retracted within or cut off from electrode holders when not in use to eliminate accidental electrical contact.

D. Fire Prevention

1. SNLA Procedures

Specific requirements for cutting, welding, roofing and other hotwork that apply throughout the Laboratory are identified in Fire Protection Procedure FPP-E-4 (see Appendix A). These procedures must be followed by personnel within and outside the 1200 organization when welding or cutting in TA-IV.

2. Tech Area IV Procedures

a. Memo of Policy

Accountability for establishing Area IV welding safety policies and issuing Sandia welding permits has been delegated to specific Operations Divisions within SNLA Area IV. This delegation is documented in a memo from V. L. Duke to Distribution (see Appendix A). 
b. Personnel Authorized to Issue Weld Permits

The following personnel are authorized to issue welding, cutting and hotwork permits for work performed within their respective facilities:

Building 970:

Leonard Torrison, 1236

Ken Mikkelson, 1236 (Alternate)

Building 981:

Bill McAtee, 1233

Arthur Sharpe, 1233 (Alternate)

Building 983 and All other TA-IV, Organization 1200 Hot Work:

Bob Johnston, 1266

Bob Clevenger, 1266 (Alternate)

The permit form, SA2013-B (see Appendix B), should be completely filled out, including work site supervisor signature, before consulting the permit issuer. Permit issuer alternates shall have authority only in the absence of the primary issuer. In the event both issuers from a facility are absent, authority for issuance may be delegated to an authorized issuer from another facility to cover the time of absence.

c. Checklist Addendum to FPP-E-4

The attached checklist (see Appendix C) details requirements for welding in or near accelerators and other TA-IV equipment. The provisions of this checklist must be followed in order to receive an Area IV permit. 
Appendix A

1. Memo, V.L.Duke to Distribiution, 8/29/86, "Welding Safety in TA-IV"

2. Fire Protection Procedure, FPP-E-4 
SANDIA NATIONAL IABORATORTES

Albuquerque, New Mexico 87185

Date: $A U G 2$ \& 1986

To: Distribution

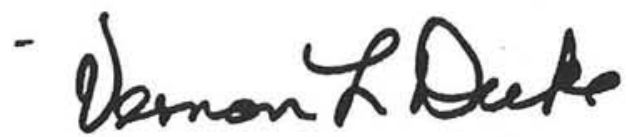

From: V. L. Duke, 7862

Fire Protection Engineering

Re: Welding Safety in TA-IV

Enclosed is a revised Fire Protection Procedure, FPP-E-4 "Cutting, Welding, Roofing, and Hotwork Permit Program," dated August 25, 1986. The following pertain to the TA-IV welding safety program:

o All welding operations involving electric or gas cutting and welding require a permit.

- The Organization 1200 "Safe Operation Procedure for Welding, cutting, and Hotwork in TA-IV" will authorize one primary and one alternate welding permit issuer for Buildings 970, 981, and 983.

- If both the primary and alternate permit issuers for a building are absent, or if welding is needed in a building other than 970, 981, or 983, the Building 983 permit issuers are authorized to issue a permit after visiting the site and evaluating the hazard.

- The authorized permit issuers may issue permits, in accordance with FPP$\mathrm{E}-4$ and the TA-IV SOP, to:

- 1200 Personnel

- 1200 Contract Personnel

- 7800 Plant Maintenance Personnel

- 7800 Contractors (Subject to counter signature by 7833 construction Inspection)

o Specifically designed permanent welding shop work areas. Such welding shop permits are valid for a period of six months.

- In the event that a Building 983 permit issuer is unavailable, permits may still be issued by Division 7862, Fire Protection Engineering subject to counter signature of operational organization personnel. 
- Any person observing an unsafe operation involving flames, sparks, or hot slag should halt the operation and immediately notify the permit issuers, the appropriate 1200 division supervisor, or 7862 Fire Protection

- Engineering.

- When desired, the authorized permit issuer may request a Division 7862 Fire Protection Engineer visit the site prior to issuing the permit.

I believe the above will allow timely response to Organization 1200 's needs, while assuring a level of fire protection required by the Department of Energy. If you have any further concerns, please call me at 6-1800.

VLD:7862:mm

Copy to:

1230 J. Powell

1233 L. M. Choate

1233 A. W. Sharpe

1233 W. H. McAtee

1236 G. A. Zawadzkas

1236 K. Mikkelson

1236 L. Torrison

1250 T. H. Martin

1254 S. A. Goldstein

1254 R. Clevenger

1254 G. L. Donovan

1254 R. R. Johnston

7862 File

7862 V. L. Duke 
FPP-E-4

August 25, 1986

cutting, welding, Roofing, and Hot Work Permit Program

cutting and welding operations produce many potential ignition sources, in the form of sparks and globules of molten metal, which often scatter widely. These may pass through cracks, pipe holes or other small openings in floors and partitions, starting fires which reach serious proportions before being noticed. Electric arcs, oxygen-fuel gas flames and hot metal being cut or welded may ignite nearby combustible materials. Serious fires are most frequent in areas not specifically designated for welding.

Iikewise, roofing fires are commonly caused by overheating the asphalt or coal tar pitch, applying it to a low ignition temperature material, using flammable liquids to clean laps for cemented joints in membranes, using torches to soften coverings, and spontaneous combustion of hot tar mops.

This Fire Protection Procedure provides guidance for gas and electric cutting and welding operations, open flame work at explosives handling sites, and the use of tar kettles. This procedure covers work performed by Sandia personnel or outside contractors at Sandia National Iaboratories Albuquerque (SNLA). Excluded is work performed by contractors working under DOE contracts in areas separated from Sandia facilities. In these cases, the prime contractor is responsible for establishing a welding safety program. However, when welding is performed in or near existing Sandia buildings, facilities, or utilities, the DOE contractor will obtain a Sandia welding permit.

Silver soldering, sweat soldering, etc., does not require a permit, except at explosive handling sites; however, a fire extinguisher is still required. 
Welding Permit. A permit (Form SA 2013-B) issued by the SNLA Fire Protection Engineers authorizing specific cutting or welding work at a specified location, open flame work at explosives handling sites, or tar kettle use.

Fire Watch. One or more persons knowledgeable in the use of fire extinguishers and who viewed Sandia's welding safety videotape, in constant attendance during cutting and welding work (when required), who have no other duties which would interfere with their ability to monitor the cutting and welding work, and who are immediately available to extinguish a fire or take other effective action if needed.

DUTIES OF ORERATIONS ENGINEERING DIVISION, FIRE PROTECTION GROUP, 7862

Division 7862, where warranted, inspects the location where the work is to be performed, and issues Permit Form SA 2013-B after determining the locations are safe. The permit is signed by all welders or the roofing foreman, the construction inspector, and by Division 7862. Where contractors, not inspected by Division 7831, and Sandia maintenance personnel are welding in buildings, they have the Division Supervisor who is responsible for the area where the work is to be performed, sign the permit. This will assure that the using organization is aware of the work being done in its area and provide the opportunity to advise the welder of any hazard near the worksite. Welding or cutting operations at outdoor locations which are 35 feet from the nearest fuel tank, manhole, building, or structure do not require a permit.

Division 7862 reserves the right to make subsequent inspections during progress of the job, and to stop the work if conditions have changed such that the work location is no longer safe.

Division 7862 determines whether

* additional person(s) are required to act as fire watch

* work is to be relocated to a safe location

* combustibles are to be removed

* fire resistive blanket is needed to protect adjacent combustibles or vulnerable equipment

* additional fire extinguishing equipment is required

* procedures for draining fuel tanks on vehicles are required

* used vessels which formerly contained flammable materials may be welded, and the precautions to be taken

* Fire Department standby is necessary. 
Instructions for Filling out Permit

Time Iimit for Welding Permit

Remote Areas
Division 7862 inserts the following on permit

* the type of work the permit covers

* the date, organization or contracting firm, building number, and location

* a brief description of the job

* the precautions required for the job

* the starting and expiration date and time

The permit must be signed by

* each welder or roofing foreman doing the work

* the construction inspector or the Division supervisor of the work site

* Division 7862, Fire Protection Engineering

Each person signing the permit agrees to the safety of the operation.

Pemits are issued for:

* limited period decided by 7862 , or

* indefinite period, only for permanently designated welding areas.

NOTE: Cutting, welding, or other hot work to be performed on any container which previously contained flammable substances requires a separate permit, even in permanent welding areas.

Division 7862 delegates the Remote Areas Maintenance and Test Support Division, 7818, to conduct the hot work safety program in Technical Areas III, V, and coyote Test Field, and to issue all permits, except for Division 7831 construction contracts.

Division 7862 delegates the Pulsed Power Systems Operations Divisions, 1233, 1236, and 1254, to conduct the hot work safety program in Technical Area IV, and to issue all permits, except for Division 7831 construction contracts.

Division 7862 delegates the Central Receiver Test Facility Division, , to conduct the hot work safety program at the Central Receiver Test Site, and to issue all permits, except for Division 7831 construction contracts.

Division 7862 delegates the Senior Fire Office of Advance Security to conduct the hot work safety program at the Tonopah Test Range, and to issue all permits. 
DUTIES OF INDUSTRIAL HYGIENE DIVISION, 3311

Division 3311 serves as consultant to 7862. They

* prescribe eye protection to prevent damage from light emission. during welding,

* prescribe respiratory protection to prevent inhalation of toxic fumes, and

* approve location, ventilation, and protective equipment by signing welding permit, where applicable.

DUTIES OF SAFETY ENGINEERING DIVISION I, 3315, OR DIVISION II, 3316

Divisions 3315 and 3316 serve as consultants to 7862 . They

* verify that equipment exposed to explosives is not contaminated, and

* approve welding locations adjacent to explosives by signing welding permit, where applicable.

RESPONSIBILITIES OF CONTRACTORS

Contractors are responsible for performing all cutting, welding, hot work at hazardous sites, or roofing in compliance with the precautions in Appendix A of this document and are responsible for all damages resulting from failure to comply. Contractors are to provide their own fire extinguishers, hose, pails, welding blankets, any required fire watch, and take all required precautions where and as directed.

Contractors are to comply with all applicable laws, which take precendence over this document. 
Welders are to

* read, understand, and be familiar with the provisions of Appendix A of this document that is given to contractor representatives at the preconstruction conference

* view annually the Factory Mutual Engineering Corporation film, "Preventing Cutting and Welding Fires." Division 7862 will maintain a record of welders who have viewed-this safety film, and the date of viewing

* obtain a welding permit before starting to cut or weld. The permit must be posted on the job site until the work is completed * use appropriate personal protective equipment when starting to cut or weld

* not cut or weld where conditions are not safe

* continue to cut or weld only as long as conditions remain unchanged from those under which approval was granted.

Welding equipment is to conform to the conditions specified in OSHAct Articles 1926.350 and 1926.351.

Fire watch is to

* have fire extinguishing equipment readily available and be familiar with its use. Fire extinguisher is to be fully charged and have a current tag attached showing the dates the extinguisher was last inspected, recharged, and hydrostatically tested.

* know how to summon the Fire Department and evacuate the building * stop or correct any condition that might lead to a fire and notify the construction inspector as soon as practical * monitor the cutting and welding operation and be on the alert for signs of fire * try to extinguish fires before turning in an alarm only when obviously within the capacity of extinguishing equipment. Otherwise, immediately turn in a fire alarm

* report any fires they have put out

* remain on the work site while work is performed and check for smoldering fires at least 30 minutes (or longer, if so specified on the welding permit) after the work is completed or any time welders leave the immediate area. 
RESPONSIBILITIES OF ROOFERS

Roofers are to

* read, understand, and be familiar with the provisions of Appendix A of this document that is given to contractor representatives at the preconstruction conference

* obtain a roofing permit before starting job. The permit must be posted on the job site until the work is completed

$-6-\quad 18-23$ 
FPP-E -4

Appendix A

August 25, 1986

cutting, Welding, Roofing, and Hot Work Permit Program

FIRE PREVENTION PRECAUTIONS

Permit Considerations
Welding Permit. Cutting or welding is permitted at SNLA only in designated areas, or such other areas where it has been determined safe by Division 7862 , as indicated by the issuance of a welding permit. The permit will be issued only to the operator (welder) and is good only for the operation and location specified. The permit is not valid until cosigned by the welder and construction inspector or using organization supervisor.

Alternate options to Cutting and Welding. In recognition of the fire hazard of cutting and welding operations, alternate methods of dismantling or joining are to be considered before deciding that a job can be accomplished only by cutting or welding. Saws, pipe cutters, and mechanical pipe couplings are examples of such alternatives.

Fire Extinguishers. Provide the fire extinguishing equipment specified on the welding permit. Contractors are required to supply their own fire extinguishers, hose, pails, welding blankets, etc.

Fire Watch. A fire watch is to be maintained whenever specified on the welding permit. Where the operation may introduce a fire hazard to an adjacent area, a fire watch may be warranted on both sides of a wall, floor, or ceiling. The fire watch is to be maintained for at least one-half hour after completion of cutting or welding operations (or longer at the discretion of the Fire Protection Engineers), in order to detect and extinguish possible smoldering fires. The fire watch shall immediately stop any cutting or welding operation if sparks or hot slag are contacting combustibles. If the fire watch leaves for any reason, cutting and welding is to cease inmediately. The welder is then to act as fire watch for the period of time specified on the welding permit. Cutting or welding is not to be started again until the fire watch is re-established.

Work Stoppage. When cutting and welding is suspended for a substantial period of time, such as a lunch break, or overnight, arc welding machines shall be de-energized, electrodes removed from holders, and the holders placed so that accidental contact cannot occur. The torch and supply valves of gas equipment are to be closed.

Confined spaces. When cutting and welding in a confined space (e.g. manholes, tanks, very small rooms), all gas and oxygen cylinders and manifolds are to be located outside the confined space. When work is stopped for any substantial period of time, if practical, the torch and hoses are to be removed from the confined space. Industrial 
Occupancy Considerations
Construction Area Considerations
Hygiene, Org. 3311, will determine whether portable fans, blowers, or monitoring equipment are required to prevent the inhalation of toxic fumes or suffocation.

Arc Welding Operations. Where other personnel may pass through the area of an arc welding operation, the arc is to be shielded.

Relocation of Combustibles. Where practical; combustibles are to be relocated a least 35 feet from the work site. Where relocation is impractical, combustibles are to be shielded by noncombustible covers, metal or fire-resistant guards or curtains. Edges of covers at the floor are to be tight to prevent sparks from going under them. This precaution is also important at overlaps where several covers are used.

Flammable Liquids. Flammable liquids and motor vehicles are to be at least 50 feet from the work site. Welding is not to be performed in rooms or on equipment which may contain flammable liquids or fumes or explosives unless additional precautions are taken. Refer to Org. 7862 and Org. 3415 or 3416 for guidance.

Used Containers. No cutting, welding, or other hot work is to be performed on used drums, barrels, tanks, or other containers until they have been cleaned in accordance with NFPA 327 to remove flammable materials or any substances such as greases, tars, acids, or other materials which when subjected to heat, might produce flammable or toxic vapors. Any pipes or connections to the drum or vessel are to be disconnected or blanked. The container is then to be vented to permit the escape of air or gases before preheating, cutting, or welding. As a further precaution, it is advisable to fill the container with water and/or purge with carbon dioxide or other inert gas, or take additional precautions to be prescribed by Organization 7862 .

Demolition. In demolition work, combustibles are to be removed before cutting operations are begun.

Noncombustible walls. If cutting or welding is done on a metal wall, partition, ceiling, or roof, precautions are to be taken to prevent ignition of combustibles on the other side. Where combustibles cannot be relocated, a fire watch on the opposite side from the work is to be provided.

Combustible Cover or Sandwich-Type Walls. Cutting or welding is not to be attempted on a metal partition, wall, ceiling, or roof having a combustible covering, nor on walls or partitions of combustible sandwich-type panel construction unless additional precautions are taken. Refer to Org. 7862 for guidance. 
Pipes. Cutting or welding on pipes or other metal in contact with combustible walls, partitions, ceilings, or roofs is not to be undertaken if the work is close enough to cause ignition by conduction unless additional precautions are taken. Refer to Org. 3662 for guidance.

Ducts. Ducts or other systems that might carry sparks to distant combustibles are to be suitably protected or shut down.

Combustible Walls. Where cutting or welding. is done near walls, partitions, ceiling or roof of combustible construction, fireresistant shields are to be provided to prevent ignition.

Duct linings. Combustible duct lining or insulation is to be removed prior to cutting or welding ductwork.

Floor Openings and Cracks. Wherever floor openings or cracks in the flooring cannot be closed, precautions are to be taken so that neither personnel nor combustible materials on the floor below will be exposed to sparks which might drop through the floor. The same precautions are to be observed with regard to cracks or holes in walls, open doorways, and open or broken windows.

Floors. Where combustible materials such as paper, wood shavings, etc., are on the floor, the floor is to be swept clean for a radius of 35 feet. Combustible floors may be kept wet, or otherwise protected by fire resistant shields. Where floors have been wet down, personnel operating electric arc welding or cutting equipment are to be protected from possible shock.

Tar Kettles Tar Kettles. Tar kettles are to be dedicated for use of either asphalt or coal tar pitch. Locate tar kettles at least 15 feet from windowless masonry building walls, 20 feet from any door, window, or ventilation opening, and 25 feet from any wood frame building or yard storage of materials. Tar kettles are prohibited inside buildings or on roofs.

Kettle Temperature. Operators are to monitor the temperature of the tar kettle to preyent overheating. Kettles containing asphalt are not to exceed $425^{\circ} \mathrm{F}$, and those containing coal tar pitch are not to exceed $350 \mathrm{~F}$.

Fueling Tar Kettles. Tar kettles are to be fueled at a remote site approved by Sandia. Drums of fuel are not permitted at the roofing site. UL approved safety cans may be used if properly maintained.

Tar Mops. Remove tar mops from buildings and roofs when not in actual use-they can ignite spontaneously. Before leaving for the day, mops are to be submerged in a pail of water, a safe distance from the tar kettle, buildings, and other materials. 
Fire Extinguishers. One dry chemical fire extinguisher, rated 60B:C and a charged 3/4-inch garden hose with an adjustable spray nozzle in the shut-off position are to be kept near the tar kettle. Three 5gallon pails full of water are to be provided where a water supply for a hose is unavailable. 
Appendix B

Sandia Welding Permit, Form SA 2013-B

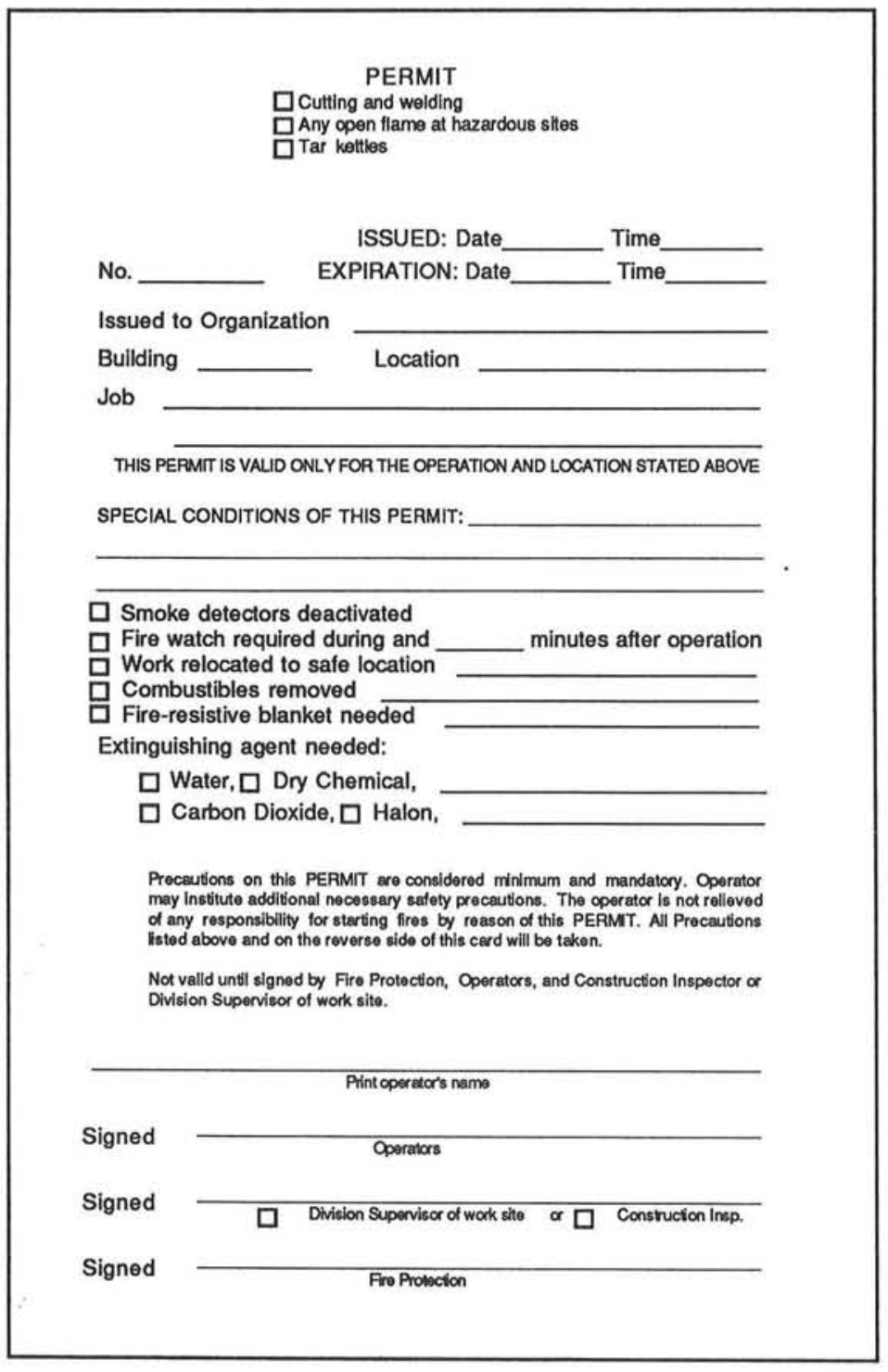


Appendix C

TA-IV Welding Checklist

Personnel shall not weld, cut or perform other hotwork operations outside designated welding areas until the following precautions are taken.

All items should be checked before starting job

* All pertinent information has been provided on welding permit

* All instructions on the reverse side of the weld permit have been read and followed

* The permit has been signed by the operator(s), the Division Supervisor responsible for the worksite (or delegate), and the appropriate facility permit issuer (or Division 7862 fire protection personnel)

* Where applicable, smoke detector systems have been deactivated through Fire Protection, Division 7862

* The building sprinkler system has been verified to be operational by the permit requestor

* All possible flammable materials and all solvents have ben removed from the work area

* All remaining flammable materials have been protected with fire-resistant blankets or other approved shielding

* Adequate portable fire extinguishing equipment is close at hand

* All wall and floor openings near the weld sight have been tightly covered

* Floor trenches near the weld site have been completely covered or cleaned of all trash, Zorb-all or other potentially flammable material

* All signal, control, utility or other types of cables have been removed from the area or otherwise properly shielded from sparks and/or hot metal 
* Responsible fire watch personnel have been assigned to watch for hazardous sparks or hot materials in the area

* Arc shields have been placed to appropriately shield passers-by and other workers

* Arrangements have been made, where appropriate as determined by the permit issuer, to patrol the weld area (including areas adjacent to or below) for at least one half hour after the weld operation to check for smoldering materials

FOR WORK WITHIN OR ABOVE OIL SECTIONS OR TANKS:

* Oil has been drained to the extent that the weld area is clear of free-standing oil

* Shielding has been provided to protect any oil covered components adjacent to or below the weld operation

* All materials capable of wicking oil have been moved out of range of sparks or slag spatter

* The results of this checklist have been reviewed by the operators and the Area IV permit issuer. Any questionable areas must be resolved through a site visit by the responsible permit issuer prior to approval of the welding permit

* Fire protection has been informed immediately following job completion and informed to restore smoke detection system to operational status 


\section{SAFE OPERATING PROCEDURE FOR \\ OPERATOR TRAINING AND CERTIFICATION \\ AT}

PBFA I I, BUILDING 983

Appendix 19 
Table of Contents

Abstract ................ . . 0

I. Introduction ................ I

II. Personnel Classifications ........... I

III. Command Structure . . . . . . . . . . . . . 2

IV. Types of Operational Training . . . . . . . . . 2

A. General Orientation . . . . . . . . . 2

B. Technical Training in Pulsed Power Technology . 3

C. Facility Safe Operating Procedures . . . . . 3

D. Subsystem Operating Procedures . . . . . . . 3

E. On-The-Job Opportunities and Methods . . . . . 4

v. Authorization and Certification Requirements . . . 4

A. Consideration for Authorization . . . . . . . 4

1. Personnel Authorized as Operators . . . . 5

2. Personnel Authorized to Fire PBFA II . . . . 6

B. Certification Requirements .........6 6

1. Prior Operational Experience . . . . . . 6

2. Specific Training Program ........ 6

3. Simulation and Practice . . . . . . . . 7

4. Operator Time Under Observation . . . . . . 7

VI. Appendices . . . . . . . . . . . 8

A. Description of PBFA II Functional Personnel . . 8

B. PBFA II Operational Command Structure . . . 13

C. Personnel Training Materials ........ 14

1. Newhire Orientation Checklist . . . . 15

2. Technical Training Materials ...... 24

3. Available Classes in Pulsed Power . . . . 24

4. Personnel Safety Training Program . . . . 25

D. Facility Safe Operating Procedures . . . . 29

E. Subsystem Operating Procedures ... . . 65 
SAFE OPERATING PROCEDURE

FOR

OPERATOR TRAINING AND CERTIFICATION

AT

PBFA II, BUILDING 983

\begin{abstract}
This SOP covers the training of PBFA II facility operating crews in both technical and safety areas, and the certification of personnel in the operation of various accelerator subsystems. Ineffective training in technical and safety procedures and undocumented operator certification could result in an unacceptable number of avoidable operating errors, increased hardware damage, and an increased risk to personnel exposed to accelerator hazards.
\end{abstract}

T. H. Martin, 1250 date

$\overline{\text { s. A. Goldstein, } 1254 \text { date }}$
D. L. Rost, 3442 date

A. M. Fine, 3442 date

Distribution:

1236 G. A. Zawadzkas

1250 T. H. Martin

1254 S. A. Goldstein

1254 All Personnel

1254 G. L. Donovan (2)

3442 D. L. Rost

3442 A. M. Fine 
SAFE OPERATING PROCEDURE

\author{
FOR \\ OPERATOR TRAINING AND CERTIFICATION
}

AT

PBFA II, BUILDING 983

I. Introduction

This SOP outlines the training of PBFA II facility operating crews in technical and safety areas, and the certification of these personnel. Ineffective training or undocumented operator certification could result in higher numbers of avoidable operating errors, increased hardware/property damage, and an increased risk to facility personnel. Because of the size and complexity of PBFA II and its support subsystems, technical and safety training is required for all members of PBFA II Operations. However, since PBFA II is an R\&D facility, operating personnel perform rather specialized job functions, with mobility across these job functions being very infrequent. Rather than providing extensive general training to all personnel, the specific type and amount of training an individual requires will depend both on prior background and actual assignment on the PBFA II crew.

The operation of PBFA II is unlike the more familiar environments of conventional power plants or nuclear generating stations in which continuous processes are involved. The intermittant operation of the accelerator and the controlled conditions of the experiments act to minimize the impact of operating errors compared to these other facilities. Therefore, accelerator operator certification of a formal nature will be required only for those individuals who perform hands-on duties in preparing, firing, and safing the more high-risk accelerator systems.

\title{
II. Personnel Classifications
}

A listing of the various positions within PBFA II Operations are shown in Table 1. The workforce is comprised of a mixture of Sandia Laboratories personnel and electromechanical contractor technicians recruited from the Albuquerque business community. A list of descriptions and qualifications for these positions is provided in Appendix A. Descriptions are taken from Chapter F of the SNL Personnel Manual, Section C of SNLA Contract \#96-6400, and the PBFA II Final Safety Analysis Report. 
Sandia Laboratories Electromechanical Contractor Personnel Classifications Technical Personnel Classifications

Members of Technical Staff Technical Staff Associates Lead Pulsed Power Technician Senior Technical Aides Technical Aides

Senior Pulsed Power Technician

DAS Operator Technician

DAS/CM Programmer Technician

Control Room Operator Technician

Special Tasks Pulsed Power Technician

Mechanical/Experimental Technician

Table 1. PBFA II Personnel Classifications

\section{Command Structure}

The present operational command structure for the PBFA II crew is diagrammed in Appendix B. Since the Pulsed Power Operations Division Supervisor maintains overall responsibility for establishing safety procedures for the PBFA II crew and facility work areas, he also authorizes a limited number of division personnel to perform certain tasks associated with the operation of the facility and firing of the accelerator. This authority is delegated through the Technical Manager to appropriately selected Section Coordinators. These individuals assure that the operating procedures (OP's), safe operating procedures (SOP's), facility and subsystem checkoff lists and daily inspections, and general administrative procedures are adhered to by Operations Division members and others working in the PBFA II facility.

\section{Types of Operational Training}

Many types of training are required for PBFA II personnel depending upon job responsibilities and work areas. Materials used in training facility personnel are outlined in Appendix C. General descriptions of the types of training required are listed below.

\section{A. General Orientation}

A general orientation to Pulsed Power Operations Division philosophy and methods is given to all contractors and Sandia personnel within one week upon arrival into the division (see Appendix $C$ ). Material on programmatic goals, technical and safety issues, and operational guidelines is continually updated through division planning meetings, bi-annual safety meetings, and vari- 
SOP - PBFA II Operator Training and Certification / page 3

ous safety training sessions and workshops. The attendance of these safety meetings is documented in the division files.

The types of safety training courses which apply to various job functions and hazards, their administration, and required training frequency are outlined in Appendix C.

B. Technical Training in Pulsed Power Technology

Short pulse, high voltage technology, being an emerging research area, involves practices and theories not widely available in the academic or industrial environment. Much of the technical training in pulsed power is conducted locally utilizing applicable information collected from specialized sources, many internal to Sandia.

The extent and areas of technical training division members receive is dependant on an individual's specific assignments and his/her depth of prior knowledge. A list of reference materials typically used for both technical and high voltage safety training appears in Appendix C.

C. Facility Safe Operating Procedures

Safe Operating Procedures serve as formal documentation of potentially hazardous operations, materials, or equipment present within the work environment at PBFA II. These documents outline specific procedures facility personnel must follow to minimize hazards to personnel and property. A list of PBFA II Safe Operating Procedures that are in effect or under development is provided in Table 2. Copies of PBFA II S.O.P. abstracts and tables of contents are provided in Appendix D. All division personnel are required to read and acknowledge that they understand the contents of these SOP's.

D. Subsystem Operating Procedures

Facility operating procedures are used to establish a standard methodology with respect to facility subsystem operation. Once procedures have been established through interactions between design engineers, safety organizations, operational personnel, etc., 0.P.'s ensure that important aspects of subsystem operation are documented and followed. A listing of procedures being developed during the operational phase of PBFA II appears in Appendix E. 


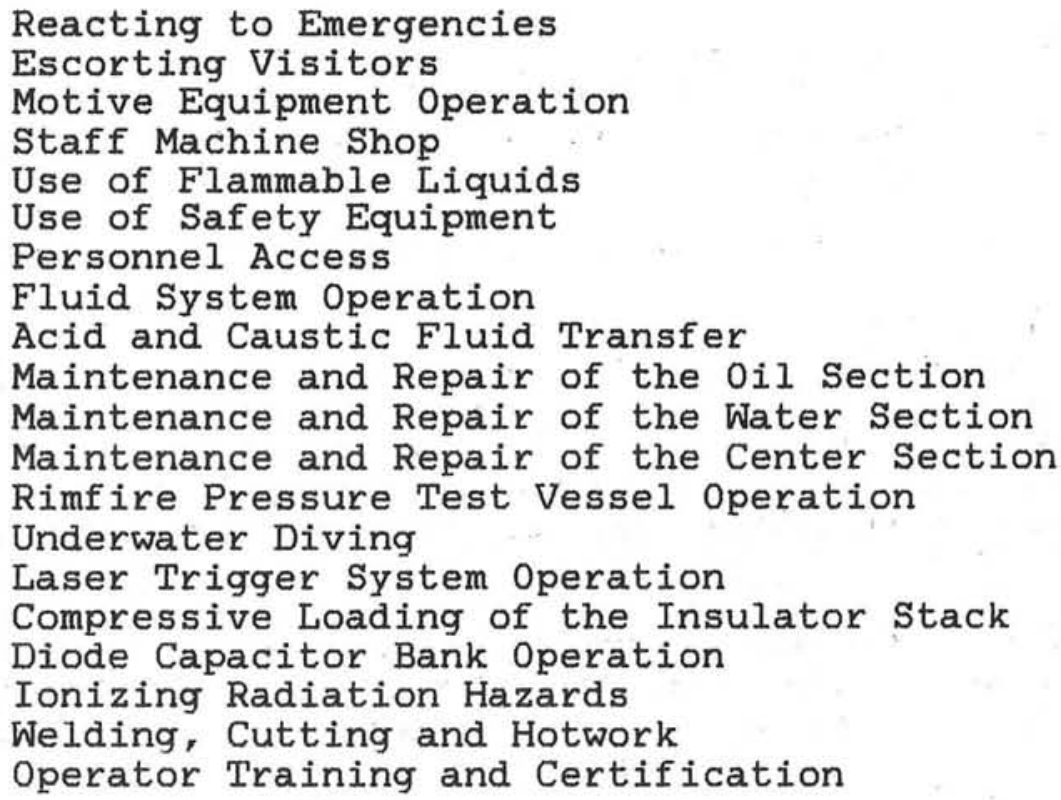

Table 2. PBFA II Safe Operating Procedures

E. On-The-Job Opportunities and Methods

Since much of the PBFA II operational technology, techniques, and procedures are being developed on site and are continually emerging, the transfer of information through on-the-job interactions between senior and junior division members frequently is used as a safety and technical training aid. While this type of training by itself is somewhat informal, in conjunction with $O P^{\prime} s$ and $S^{\prime} P^{\prime} s$, it is useful in transferring the Operations Division's corporate memory to new individuals as they learn to perform their job functions.

V. Authorization and Certification Requirements

\section{A. Considerations for Authorization}

Many duties of the operating crews, such as those not involving hazardous or specialized subsystems, do not require authorization to perform as long as the proper $0 P^{\prime} s, S O P^{\prime} s$, and checkoff lists are read, acknowledged, understood, and followed. Other job functions, such as the exercising of subsystems for tests/shots or the preparation and operation of an entire accelerator section for a shot, do require authorization from the Pulsed Power Operations Divi- 
SOP - PBFA II Operator Training and Certification / page 5

sion Supervisor and certification that the responsible person has demonstrated the capability of performing that function correctly and safely.

\section{Personnel Authorized as Accelerator Operators}

Those accelerator operator job functions requiring Division Supervisor authorization and the present certified incumbents are as follows:

Operator Position

Authorized Personnel

$\begin{array}{ll}\text { a. Technical Manager } & \text { G. D. Peterson } \\ \text { b. Shot Coordinators } & \text { D. R. Nations } \\ \text { c. Facility Supervisor } & \text { G. L. Donovan } \\ \text { d. Control/Monitor Coordinator } & \text { R. R. Johnston } \\ & \text { G. L. Devlin } \\ \text { e. Data Acquisition Coordinator } & \text { D. R. Nations } \\ & \text { C. A. Bouchier } \\ \text { f. Process Systems Coordinator } & \text { R. R. Mattson } \\ \text { g. ESS Coordinator } & \text { D. O. Jobe } \\ \text { h. PFS Coordinator } & \text { R. R. Johnston } \\ \text { i. Center Section Coordinator } & \text { H. D. McGovern } \\ & \text { G. T. Holman } \\ & \text { G. D. Peterson }\end{array}$

Table 3. Authorized PBFA II Operators

The above persons are authorized to operate the major subsystems within their sections and to train other individuals, both Sandians and contract personnel, to assist them in their functions. They may also delegate qualified crew members to substitute for them as section coordinators during their absence or their temporary assignment to other duties. The Division Supervisor shall be notified of such delegations. 
2. Personnel Authorized to Fire PBFA II

By virtue of their specialized training and global familiarity with PBFA II components and subsystems, a limited number of individuals are authorized to execute integrated accelerator subsystem tests, especially those involving hazards such as high voltage and stored electrical energy, and to fire 36 module accelerator shots. The authorized personnel are:

Position Authorized Person

$\begin{array}{ll}\text { a. Division Supervisor } & \text { S. A. Goldstein } \\ \text { b. Technical Manager } & \text { G. D. Peterson } \\ \text { c. Shot Coordinators } & \text { D. R. Nations } \\ & \text { G. L. Donovan } \\ \text { d. Control/Monitor Coordinator } & \text { R. R. Johnston } \\ \text { e. Experiment Design Team Leader } & \text { J. M. Devlin }\end{array}$

Table 4. Personnel Authorized to Fire PBFA II *

* A minimum of two of the above persons must be present to fire the PBFA II accelerator.

B. Certification Requirements

Accelerator operators and their alternates shall be considered certified when they have satisfied the following requirements:

1. Prior Operational Experience

All operators shall have at least 2 years prior experience in the operation of large $R \& D$ facilities involving systems similar to those on PBFA II.

2. Specific Training Program

All operators shall have completed either all or a critical fraction of the specific training requirements program as outlined in Appendix C. The training each operator receives will depend on the particular operational position for which he/she is being certified. Progress toward completion of this training program shall be documented in the division training files. 
3. Simulation and Practice

All operators shall have participated in simulations, dry runs, and practice exercises of their subsystems to assure that they are completely familiar with the system characteristics, OP's and SOP's, checkoff lists, fault modes, and integration requirements with other subsystems, especially from a safety viewpoint. The scope of these simulations, dates of execution, and a list of participating personnel shall be documented as part of the division's training records.

4. Operator Time Under Observation

Prior to receiving certification and permanent appointment to a position, all operators shall demonstrate competant, qualified performance of their job functions while being observed by the Pulsed Power Operations Division Supervisor. 
Appendix A

Description of PBFA II Functional Personnel

Descriptions are taken from Chapter $F$ of the SNL Personnel Manual, Section C of SNLA Contract \#966400, and the PBFA II Final Safety Analysis Report. These descriptions outline personnel responsibility and capability levels.

\begin{tabular}{|c|c|c|}
\hline POSITION & DUTIES . & EDUCATION/TRAINING \\
\hline $\begin{array}{l}\text { Staff Members } \\
\text { (Technical Staff and } \\
\text { Laboratory Staff) }\end{array}$ & $\begin{array}{l}\text { The technical staff provides } \\
\text { research, development, and } \\
\text { engineering. They are sup- } \\
\text { ported by the laboratory staff } \\
\text { who provide an information } \\
\text { system and technical and } \\
\text { administrative work. }\end{array}$ & $\begin{array}{l}\text { Ph.D., M.S., or M.A. degree in } \\
\text { appropriate field, or an equiva- } \\
\text { lent combination of academic } \\
\text { training, accomplishments, and } \\
\text { practical professional experience } \\
\text { relevant to work. }\end{array}$ \\
\hline Technical Staff Associates & $\begin{array}{l}\text { Engaged in scientific, engineer- } \\
\text { ing, design or information sys- } \\
\text { tems activity that supports the } \\
\text { basic research and development } \\
\text { mission. }\end{array}$ & $\begin{array}{l}\text { Require special training, experi- } \\
\text { ence, and knowledge in specific } \\
\text { fields and have considerabie } \\
\text { latitude for discretion and } \\
\text { judgement. }\end{array}$ \\
\hline Senior Technical Aides & $\begin{array}{l}\text { Provide research, design, devel- } \\
\text { opment, documentation, prod- } \\
\text { uct engineering, and testing } \\
\text { support. }\end{array}$ & $\begin{array}{l}\text { Bachelor degree in electronics, } \\
\text { mechanics, chemistry, physics, } \\
\text { design-drafting, mathematics, } \\
\text { engineering technology, etc., } \\
\text { from a college or university, or } \\
\text { the equivalent in education and } \\
\text { experience in theory and } \\
\text { practices relevant to work. }\end{array}$ \\
\hline Technical Aides & $\begin{array}{l}\text { Provide research, design, } \\
\text { development, documentation, } \\
\text { product engineering and testing } \\
\text { support. }\end{array}$ & $\begin{array}{l}\text { Requires completion of an } \\
\text { associate degree in electronics, } \\
\text { mechanics, chemistry, physics, } \\
\text { design-drafting, mathematics, } \\
\text { engineering technology, etc., } \\
\text { from a technical institute, or the } \\
\text { equivalent in education and } \\
\text { experience in theory and } \\
\text { practices relevant to work. }\end{array}$ \\
\hline
\end{tabular}


TECHNICIAN POSITION SPECIFICATIONS :

\begin{tabular}{|c|c|c|}
\hline POSITION & FORMAL TRAINING & TECHNICAL EXPERIENCE \\
\hline $\begin{array}{l}\text { Lead Pulsed Power } \\
\text { Technician }\end{array}$ & $\begin{array}{l}\text { Graduate fro a two-year resident course at a } \\
\text { technical institute, or have technical institute } \\
\text { equivalency. Formal coursework in electronic } \\
\text { technician fundamentals including basic } \\
\text { electrical circuit theory, test equipment } \\
\text { operation and repair, basic algebra, chassis } \\
\text { wiring from electrical schematics or drawings, } \\
\text { transmission line theory, and introduction to } \\
\text { mechanical drafting techniques. }\end{array}$ & $\begin{array}{l}\text { Must have sufficient on the job experience to have an intimate } \\
\text { technical understanding of procedures and maintenance required } \\
\text { for successful operation of the facility on which he will be a working } \\
\text { member of the crew. } \\
\text { Must be capable of efficiently directing the manpower of con- } \\
\text { tractor's furnished crew members to perform both routine and } \\
\text { specialized tasks required for operating and conducting } \\
\text { experiments on the facility. } \\
\text { Must be sufficiently aware of both routine and unique fault modes } \\
\text { in facility operation or in experiments performed on the facility by } \\
\text { Sandia staff to rapidly correct these faults and to assist in their } \\
\text { future prevention. } \\
\text { Must be capable of working in an independent fashion in solving } \\
\text { hardware and logistics problems associated with the facility. } \\
\text { Must have the initiative to independently devise methods for up- } \\
\text { grading the electrical, electronic, mechanical, and vacuum systems } \\
\text { supporting the facility, and improving diagnostic monitors and data } \\
\text { acquisition techniques. Implementation of all such methods is } \\
\text { subject to Sandia approval. } \\
\text { Must be able to interface with all facility users in a mature and } \\
\text { cooperative fashion. }\end{array}$ \\
\hline $\begin{array}{l}\text { Senior Pulsed Power } \\
\text { Technician }\end{array}$ & $\begin{array}{l}\text { Graduate from a two-year resident course in } \\
\text { electronics at a technical institute or have } \\
\text { equivalent technical experience in the area of } \\
\text { pulsed power. }\end{array}$ & $\begin{array}{l}\text { - A minimum of two years recent employment experience where } \\
\text { primary duties were in the following areas: } \\
\text { Assembling, operating, maintaining, setting up and performing } \\
\text { experiments on high voltage equipment, particle beam gener- } \\
\text { ators or EMP simulators. The technician must have obtained a } \\
\text { good understanding of high voltage safety procedures related } \\
\text { to capacitor banks, power supplies and high voltage experi- } \\
\text { ments. A knowledge of the function and use of high voltage } \\
\text { capacitors, spark gaps, high voltage power supplies and pulse } \\
\text { conditioning networks is necessary. }\end{array}$ \\
\hline
\end{tabular}


TECHNICIAN POSITION SPECIFICATIONS

(continued)

\begin{tabular}{|c|c|c|}
\hline POSITION & FORMAL TRAINING & TECHNICAL EXPERIENCE \\
\hline $\begin{array}{l}\text { Senior Pulsed Power } \\
\text { Technician (concluded) }\end{array}$ & & $\begin{array}{l}\text { Nanosecond instrumentation techniques including setting up } \\
\text { and operating fast pulse devices to obtain data from single } \\
\text { pulse events. The technician must have experience operating } \\
\text { oscilloscopes, e.g., Tektronix } 485,454, \text { and } 7000 \text { series, and be } \\
\text { able to integrate a variety of commercial equipment into a } \\
\text { compatible instrumentation system. } \\
\text { On the job work experiences and/or training in at least one of } \\
\text { the following areas: } \\
\text { Design and illustration of mechanical support fixtures, jigs and } \\
\text { similar metal or plastic pieceparts such that a machinist could } \\
\text { fabricate these items. The technician must be capable of } \\
\text { fabricating and assembling such items him/herself by the use of } \\
\text { a drill press, metal lathe and will, and other standard metal shop } \\
\text { devices. } \\
\text { Vacuum and pressure systems including the use of vacuum } \\
\text { pumps, vacuum gauges and pressure gauges. } \\
\text { Assembly procedures, such as soldering simple structures } \\
\text { together using silver solder techniques and oxygen-acetylene } \\
\text { torch. } \\
\text { Test equipment operation, mainteriance, and repair. } \\
\text { Experimental data reduction to tabular or graphical form. } \\
\text { The fabrication of high voltage (multi-kV to multi-MV), fast } \\
\text { (2-5 nsec) pulse circuits. } \\
\text { The technician must be able to perform tasks indicated in the } \\
\text { statement of work with a minimum of direct supervision. The } \\
\text { technician must be able to work independently or harmoniously } \\
\text { as part of a large group. }\end{array}$ \\
\hline
\end{tabular}


TECHNICIAN POSITION SPECIFICATIONS

(continued)

\begin{tabular}{|c|c|c|}
\hline POSITION & FORMAL TRAINING & TECHNICAL EXPERIENCE \\
\hline $\begin{array}{l}\text { Data Acquisition System } \\
\text { Operator Technician }\end{array}$ & $\begin{array}{l}\text { Graduate from a two-year resident course in } \\
\text { electronics at a technical institute or have } \\
\text { equivalent technical experience in the area of } \\
\text { digital electronics. }\end{array}$ & $\begin{array}{l}\text { - A minimum of two years recent experience where duties were } \\
\text { in the following areas: } \\
\text { Setup, calibration, operation, and maintenance of banks of fast } \\
\text { oscilloscopes (e.g., Fairchild 757, Tektronix } 7000 \text { Series, using } \\
\text { vertical amplifier plug-ins and horizontal time base plug-ins) } \\
\text { and trigger and time marker generators. } \\
\text { Setup, operation, and troubleshooting of banks of computer } \\
\text { controlled digitizers, such as Tektronix R7912 or 7912AD. } \\
\text { Fabrication of cables, timing of cables using TDRs, tracing } \\
\text { cabling and termination problems, repair of cable connectors, } \\
\text { and calibration of signal attenuators. } \\
\text { Work with experimentalists setting up various types of transient } \\
\text { electrical diagnostics, and calibration of various monitors, e.g., } \\
\text { CVRs, B-dot loops, copper sulfate voltage dividers. } \\
\text { Technical course work or recent experience with digital } \\
\text { computers and computer programming, with emphasis on } \\
\text { simple machine languages, FORTRAN, and SBS Basic. }\end{array}$ \\
\hline $\begin{array}{l}\text { Data Acquisition } \\
\text { System/Control Monitor } \\
\text { System Programmer } \\
\text { Technician }\end{array}$ & $\begin{array}{l}\text { Graduate from a two-year resident course in } \\
\text { electronics at a technical institute or have } \\
\text { equivalent technical experience in the area of } \\
\text { computer science. }\end{array}$ & $\begin{array}{l}\text { Previous experience with applications and system type program- } \\
\text { ming on mini-computers is required. Experience with MODCOMP } \\
\text { Classic, HP } 1000 \text { Series, and D.G. MV/8000 Series computers, and } \\
\text { Tektronix and LeCroy computer-controlled digitizers is desirable. }\end{array}$ \\
\hline $\begin{array}{l}\text { Control Room Operator } \\
\text { Technician }\end{array}$ & $\begin{array}{l}\text { Graduate from a two-year resident course in } \\
\text { electronics at a technical institute or have } \\
\text { equivalent technical experience in the area of } \\
\text { digital electronics. }\end{array}$ & $\begin{array}{l}\text { Previous experience in the operation of computer controlled } \\
\text { systems in industrial or similar environment. Experience in pro- } \\
\text { gramming microprocessors and minicomputer systems., Familiarity } \\
\text { with languages such as Fortran } 77, C \text {, and } Z 80 \text { microprocessor } \\
\text { assembly codes; experience with HP } 1000 \text { Series computers } \\
\text { employing an RTE-A operating system. Familiarity with computer } \\
\text { interfacing of electrical and mechanical process transducers such as } \\
\text { pressure and vacuum gauges, level indicators, position sensors; } \\
\text { some knowledge of high voltage pulse monitoring technology } \\
\text { would be helpful. }\end{array}$ \\
\hline
\end{tabular}


TECHNICIAN POSITION SPECIFICATIONS

(concluded)

\begin{tabular}{|c|c|c|}
\hline POSITION & FORMAL TRAINING & TECHNICAL EXPERIENCE \\
\hline $\begin{array}{l}\text { Special Tasks Pulsed } \\
\text { Power Technician }\end{array}$ & No formal training required. & $\begin{array}{l}\text { Experience in electro/mechanical support of Research and } \\
\text { Development activities. }\end{array}$ \\
\hline $\begin{array}{l}\text { Mechanical/Experi- } \\
\text { mental Technician }\end{array}$ & $\begin{array}{l}\text { Graduate from a two-year resident course at a } \\
\text { technical institute, or have the equivalent } \\
\text { technical experience. Formal coursework in } \\
\text { mechanical technician fundamentals including } \\
\text { drafting, survey of engineering materials, } \\
\text { engineering graphics, manufacturing processes, } \\
\text { thermodynamics, basic physics, basic electricity, } \\
\text { and mathematics (algebra, trigonometry, and } \\
\text { geometry). }\end{array}$ & $\begin{array}{l}\text { - A minimum of two years recent employment experience where } \\
\text { primary duties included the following areas: } \\
\text { Interpretation of engineering blueprints, interfacing with } \\
\text { industrial fabricators (machine and welding shops), design or } \\
\text { repair of electrical and mechanical utility equipment, materials } \\
\text { component research, design or maintenance of mechanical } \\
\text { control systems, system design using mechanical instrumenta- } \\
\text { tion and electromechanical sensors (pressure, temperature, flow } \\
\text { strain). } \\
\text { On the job work experience or training in the following areas: } \\
\text { Mechanical skills similar to those outlined in Senior Pulsed } \\
\text { Power Research Technician. } \\
\text { Familiarity with types of motive equipment, material handling } \\
\text { equipment, industrial fixtures and positioning devices. } \\
\text { Hands-on familiarity with metal machine shop tools, welding, } \\
\text { brazing, and soldering techniques. } \\
\text { Inspection and quality assurance of fabricated parts. }\end{array}$ \\
\hline
\end{tabular}




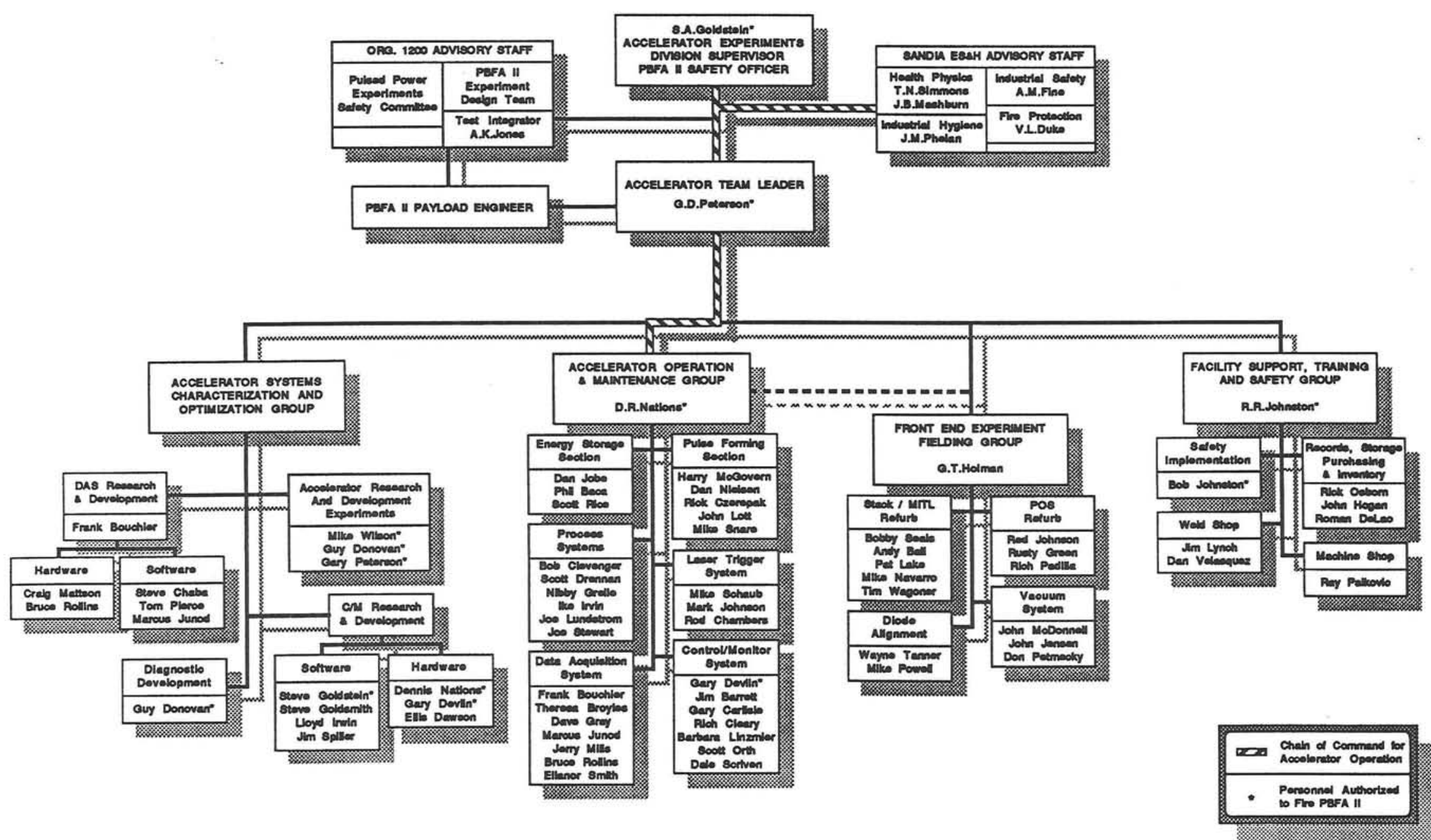




\section{Appendix C}

\section{Personnel Training Materials}

Section 1 shows the orientation checklist to be used for new Operations personnel orientation. The use of such documentation ensures that personnel recieve neccesary background information before beginning work at PBFA II.

Section 2 outlines materials used to instruct facility personnel in the area of Pulsed Power Technology. This documentation has been generated through past work within the Pulsed Power community.

Section 3 lists available classes in Pulsed Power and related technologies.

Section 4 outlines personnel safety training programs utilized by the PBFA II Operations Division and required retraining. 


\section{Section 1 / Newhire Orientation Checklist}

The following is an orientation checklist used to acquaint new Operations personnel to Division policies and procedures, and to relay pertanent background information. 
Contractor and New Hire Orientation Checklist Division 1254

A. Paperwork and Forms

1. Dosimeter

2. Add to Contract (Contract Personnel)

3. Request Clearance

4. Material Pass (if applicable)

5. Sandia I.D.. Dept. roster, etc.

6. Stores withdrawal authorization submitted

7. Add to training lists (CPR, First Aid, etc.)

8. Add to Fire Team

B. Orientation to PBFA II Policies

1. Structure

a. Chain of command

b. Who to take orders from

c. Who not to take orders from

d. Task Leader philosophy

e. Lead Tech/Section Coordinator function

f. Job functions

2. Where to ask questions/resolve problems

3. Reporting sick leave

4. Vacation requests

5. Leave $W / 0$ pay policy

6. Lunch and coffee breaks

7. Telephone - personal use and incoming calls 
8. Use of shop or tools for personal use

9. Machine shop policy

10. Philosophy of cleaning up after ourselves

11. What to do when others violate our policies

12. Operations relationships to others (e.g. Experimenters, Plant Engineering, outside contractors, light lab personnel, etc.)

13. Log books

14. Ordering - $P R^{\prime} s$ and $M R^{\prime} s$

15. Sandia Security

a. Guards

b. Access to other Tech Areas

16. Locker, secretarial supplies, hard hat, coveralls, showers, frig., microwave, K.P., coffee fund

C. Orientation to Safety Policies

1. Give a general policy statement

2. Issue SOP's, assign time to read and schedule a question/answer session.

a. Areas requiring specialized training before working in:

Marx Generators - stay away!!! Do not work on until proper training has been given.

_ $0 i 1$ Section - Same as above!!!

_- Crane usage

Motive Equipment usage (drivers

license required for forks)

High Voltage Equipment - power supplies, trigger systems, etc.

b. Show location of breakers and explain facility policy on electrical breakers c. Demonstrate alarms and explain usage 
d. Explain purpose of Access Control system

$$
\text { H.V. test alert }
$$

Limited Full Alert

$$
\text { Unlimited Full Alert }
$$

e. Explain our fire protection system and policy - assign to team; explain team job function, how to react, when to fight fires, when not to, etc. Oil tank fire possibility

f. SF6 hazards - Water Section and Center Section as "confined workspaces"

g. Safety belts and lanyards

h. Hard hat areas

i. No smoking areas (what to do when others are smoking)

j. Buddy system philosophy

$$
\text { High voltage }
$$

Hazardous work areas

Diving activity

k. Entry into Pulse Forming Section

Belts

Checking air quality

_ Buddy

- SF6 pressure in gas switches

1. Entry into Energy Storage Section

Breakers, lock-outs, tags-outs

oil fill, lock-outs, tag-outs

Safety belts

Boots 


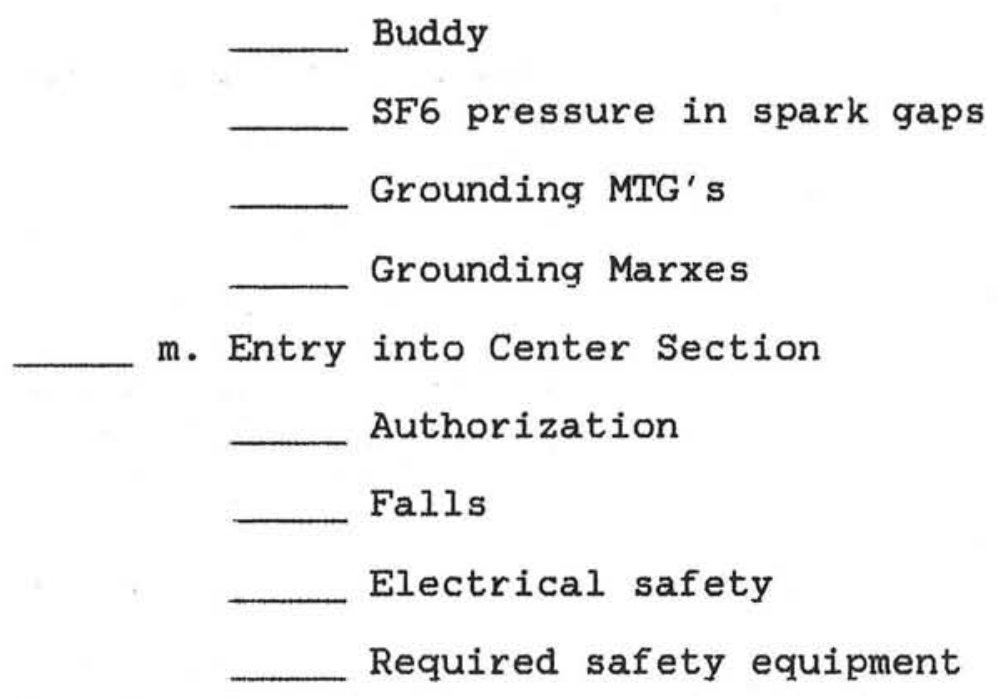

n. Solvents

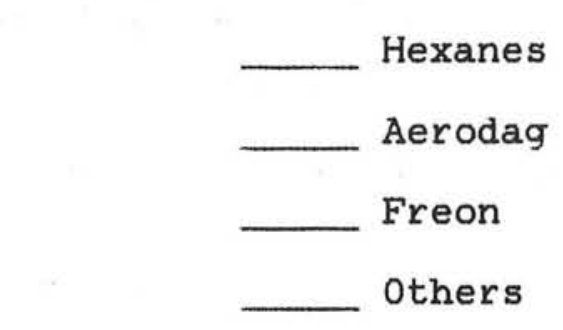

o. High pressure gas

Gas cylinders
Dive air bottles

p. Show safety films

D. Orientation to Tech Training

1. Issue Pulsed Power Training Manual

a. Assign time to read priority articles

b. Schedule question and answer period

2 . Issue $O P^{\prime} s$ to components and subsystems

a. Assign time to read

b. Schedule question and answer period

c. Introduce to PBFA II shot procedures 
3. Give explaination of PBFA II operation

a. Energy Storage Section

Power supplies, charge buss, dump relay

+ and - charging MTG trigger system, $500 \mathrm{kV}$ output to trigger 4 Marxes each Transfer switches (MTG, Marx) Dummy loads Marx erection Equivalent circuit (RLC) Spark gaps

b. Pulse Forming Section

Pulse forming lines Pin switches Rimfire switches Energy Diverter Switches

c. Vacuum interface Lucite stack.

d. Power flow section MITL's

e. Diodes

f. Monitors

B dots, V dots, CVR's, dividers

4. DAS system

5. Control/Monitor system

a. Brief discussion and walkthrough 
6. Associated subsystems

a. Vacuum

b. Process system walkthrough

Discuss procedures
Storage, transfer, processing

c. Pneumatic system

d. SF6 - use, piping, reclaimer, etc.

7. Other accelerators

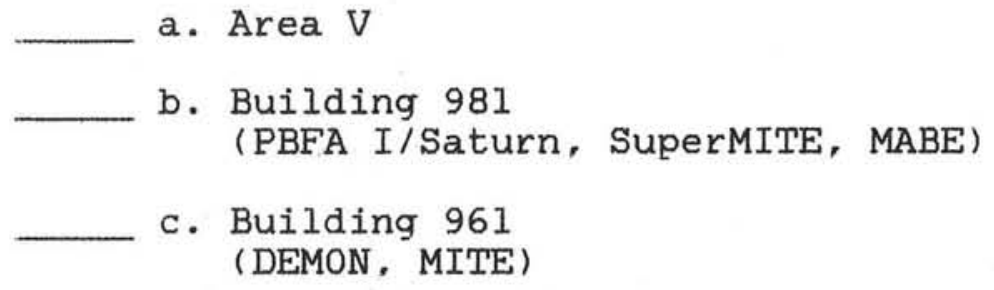

8. Training Program

a. Literature

b. Classes

c. Video tapes

d. Lectures

E. Operations Philosophy Pep Talk

1. Job Function

a. Setup experiment and shoot

b. Maintenance - preventative and fault mode

c. Upgrade, improve

d. Establish new technology

e. Trouble shoot

f. Suggest

g. Document ( $\log$ books) 
Division 1254 Newhire Orientation checklist / page 7

2. Quality control (pretend its yours!)

a. Attention to detail (rigor) b. Try to be right the first time!

c. If you don't know - ASK!

d. Quality vs. quantity

e. The time element

f. Alertness

g. Eggshells and sledge hammers

3. Training (continuing education)

4. Reputation

5. Information exchange with others

a. Pulsed Power Research Group

b. Engineering Group

c. Projects Group

6. Dependence on crew

7. Money

a. Available to buy equipment

b. Not available to waste! 
Employee Name

Review Date

Reviewer

Initial

Employee Reviewer 
* PBFA II Papers delivered at the 5th I.E.E.E. Pulsed Power Conference, Arlington Virginia, June 10-12, 1985

* A collection of Publications on Sandia Laboratories Particle Beam Fusion Research Program I (1979) and II (1982)

* Pulsed Power Operations Division Technical Training Manual (1981)

* PBFA I Pulsed Power Manual, P. J. Skogmo \& J. F. Seamen, SAND 81-1770, August 1981

* Pulsed Power Equations, Formulas, and Rules of Thumb, SNLA Division 1252, December 1985

* The PBFA II Demonstration Experiment (DEMON) Project Documentation, SNLA Division 1252, December 1985

* AFWL Pulsed Power Lecture Series course documentation

* (On The Job Training)

Section 3 / Available Classes in Pulsed Power

UNM / SNLA Pulsed Power Technology Course I \& II

K-Tech Pulsed Power Technology Course 
The following tables outline training programs utilized by the Pulsed Power Operations Division.

Table 1 summarizes the general training areas which address the hazards present at PBFA II. It lists the type of training program, the administration of the program and organizations at Sandia responsible for conducting the training sessions, and required retraining frequency.

Table 2 identifies the general training requirements for operations personnel having specific job categories in various sections of the accelerator and facility. These recommended training areas match the hazards typically associated with the daily job functions indicated in the JOB ASSIGNMENT column.

Table 3 details the specific training record for all operations personnel and documents the dates by which training must be accomplished and on which retraining is required. This record will be documented and kept current on a computer generated database, and is part of the division training file.

Since the Pulsed Power Operations Division trining program is still evolving, it is not possible with the present resources to provide the full compliment of training to each division member immediately upon hiring into the division. In general, programs most critical to the safety of each individual, as determined by job assignment, will be accomplished no later than a six month period after arrival to PBFA II. 


\section{Personnel Training}

\begin{tabular}{|c|c|c|}
\hline $\begin{array}{l}\text { Cardiopulmonary } \\
\text { Resuscitation (CPR) }\end{array}$ & $\begin{array}{l}\text { Instruction is given to all personnel by instructors who are certified by the Heart } \\
\text { Association through the Sandia Medical Department. }\end{array}$ & Required yearly \\
\hline First Aid & $\begin{array}{l}\text { Instruction is given to all personnel by the Heart Association through the Sandia } \\
\text { Medical Department. }\end{array}$ & Required every two years \\
\hline Air Pack & Training is given to all personnel by Sandias Environmental Health Department. & Review required every two years \\
\hline Scuba & Each diver must have at least a basic certification by a nationally accredited school. & $\begin{array}{l}\text { Certified divers should dive every } \\
\text { six months to maintain skills }\end{array}$ \\
\hline Crane & $\begin{array}{l}\text { Crane operators will be shown safety training films and/or trained by a visiting } \\
\text { instructor. }\end{array}$ & Review reuired every two years \\
\hline Rigging & $\begin{array}{l}\text { Rigging operators will be shown safety training films and/or trained by a visiting } \\
\text { instructor. }\end{array}$ & Review required every two years \\
\hline Forklift & $\begin{array}{l}\text { Forklift operators will be shown safety training films and/or trained by a visiting } \\
\text { instructor. }\end{array}$ & Review required every two years \\
\hline Respirators & $\begin{array}{l}\text { Personnel required to handle toxic materials will be fitted with individual } \\
\text { respirators through the direction of Sandias Environmental Health Department. }\end{array}$ & $\begin{array}{l}\text { Fittings should be checked as } \\
\text { necessary or every two years }\end{array}$ \\
\hline Fire Extinguishers & $\begin{array}{l}\text { All crew members will be trained how to operate fire extinguishers by a member } \\
\text { of Sandias Fire Protection Team. They also will be shown where they are located } \\
\text { in the area assigned, the different types of fire extinguishers at their disposal, and } \\
\text { what types of fires they are used to extinguish. }\end{array}$ & Review required every two years \\
\hline Safety Meetings & $\begin{array}{l}\text { Safety meetings and a facility walk through are conducted under the supervision } \\
\text { of the Operation Engineering Division. }\end{array}$ & Required at least twice a year \\
\hline Fire Protection & $\begin{array}{l}\text { Fire protection training will be conducted under the supervision of the Fire Safety } \\
\text { Engineering Division. This will include the use of dry chemical, carbon dioxide, and } \\
\text { Halon extinguishers as well as the AFFF firehose systems. }\end{array}$ & Required at least twice a year \\
\hline $\begin{array}{l}\text { Craft, Process, and } \\
\text { Job Training }\end{array}$ & & On the job training as required \\
\hline $\begin{array}{l}\text { Emergency Organization } \\
\text { Training }\end{array}$ & $\begin{array}{l}\text { The emergency Preparedness System is administered by the Security Plans and } \\
\text { Training Division. }\end{array}$ & \\
\hline Laser Safety Training & Administered by Industrial Hygiene Division. & No retraining required \\
\hline High Voltage Training & Administered locally by project groups. & As required by personnel changes \\
\hline Pressure Safety & Administerd by Safety Department. & No retraining scheduled \\
\hline Materials Handling & Plant Engineering, Safety Department for Explosives & As required for project personnel \\
\hline $\begin{array}{l}\text { Radiation Safety } \\
\text { Orientation }\end{array}$ & Health Physics Division & As required \\
\hline
\end{tabular}




\begin{tabular}{|c|c|c|c|c|c|c|c|c|c|c|c|}
\hline JOB ASSIGNMENT & $\mathrm{CPR}$ & $\begin{array}{c}\text { First } \\
\text { Aid }\end{array}$ & $\begin{array}{c}\text { Air } \\
\text { Pack }\end{array}$ & Scuba & $\begin{array}{c}\text { Respir- } \\
\text { ators } \\
\end{array}$ & $\begin{array}{r}\text { Fork } \\
\text { Lift } \\
\end{array}$ & \begin{tabular}{|l} 
Crane \& \\
Rigging
\end{tabular} & $\begin{array}{l}\text { Fire } \\
\text { Ext. }\end{array}$ & $\begin{array}{l}\text { Laser } \\
\text { Safety }\end{array}$ & $\begin{array}{c}\text { HV } \\
\text { Safety }\end{array}$ & $\begin{array}{c}\text { Rad } \\
\text { Safety } \\
\end{array}$ \\
\hline ENERGY STORAGE SECTION & $x$ & $x$ & $\mathrm{x}$ & & $x$ & $x$ & $\mathrm{x}$ & $\mathrm{x}$ & & $x$ & \\
\hline PULSE FORMING SECTION & $x$ & $x$ & $x$ & $\mathrm{x}$ & $x$ & $x$ & $x$ & $x$ & & & \\
\hline $\begin{array}{l}\text { CENTER SECTION } \\
\text { Hardware Refurb \& Install } \\
\text { POS Fabrication \& Prep }\end{array}$ & $\begin{array}{l}x \\
x\end{array}$ & $\begin{array}{l}x \\
x\end{array}$ & $x$ & & $\begin{array}{l}x \\
x\end{array}$ & $\begin{array}{l}x \\
x\end{array}$ & $\begin{array}{l}x \\
x\end{array}$ & $\begin{array}{l}x \\
x\end{array}$ & & $\begin{array}{l}x \\
x\end{array}$ & $\begin{array}{l}x \\
x\end{array}$ \\
\hline VACUUM SECTION & $x$ & $x$ & & & $\mathrm{x}$ & $x$ & $x$ & $x$ & & & $x$ \\
\hline $\begin{array}{l}\text { CONTROL MONITOR SECTION } \\
\text { System Programmer } \\
\text { Operator Technician }\end{array}$ & $\begin{array}{l}x \\
x\end{array}$ & $\begin{array}{l}x \\
x\end{array}$ & & & & $\mathrm{x}$ & $x$ & $\begin{array}{l}x \\
x\end{array}$ & & $x$ & \\
\hline $\begin{array}{l}\text { DATA ACQUISITION SECTION } \\
\text { System Programmer } \\
\text { Operator Technician }\end{array}$ & $\begin{array}{l}x \\
x\end{array}$ & $\begin{array}{l}x \\
x\end{array}$ & & & & $x$ & $\mathrm{x}$ & $\begin{array}{l}x \\
x\end{array}$ & & & \\
\hline PROCESS SYSTEMS & $\mathrm{x}$ & $x$ & $\mathrm{x}$ & $\mathrm{x}$ & $\mathrm{x}$ & $\mathrm{x}$ & $x$ & $x$ & & & \\
\hline SUPPORT SHOPS & $x$ & $x$ & & & & $\mathrm{x}$ & $x$ & $x$ & & & $x$ \\
\hline $\begin{array}{l}\text { LOGISTICS } \\
\text { Software Development } \\
\text { Purchasing, Inventory \& } \\
\text { Material Moving }\end{array}$ & $\begin{array}{l}x \\
x\end{array}$ & $\begin{array}{l}x \\
x\end{array}$ & & & & $x$ & $x$ & $\begin{array}{l}x \\
x\end{array}$ & & & $x$ \\
\hline LASER TRIGGER SECTION & $x$ & $x$ & $x$ & & $x$ & $x$ & $x$ & $\mathrm{x}$ & $\mathrm{x}$ & $x$ & \\
\hline
\end{tabular}




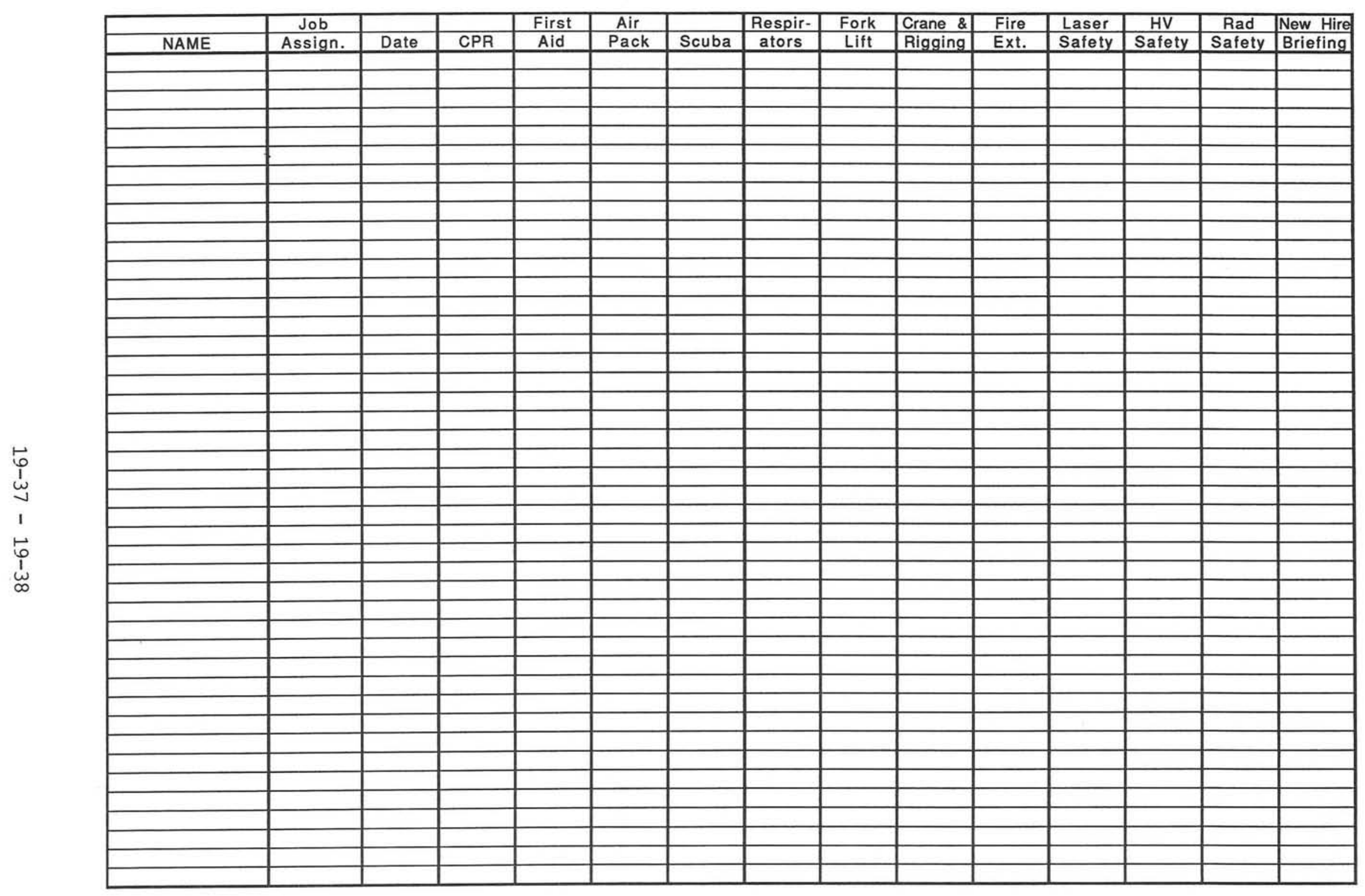


Appendix D

Facility Safe Operating Procedures

Safe Operating Procedures serve as formal documentation of potentially hazardous operations, and outline specific procedures facility personnel must follow to minimize hazards. The following is a compilation of PBFA II S.O.P. abstracts and tables of contents. 
SAFE OPERATING PROCEDURE

\author{
FOR \\ ESCORTING VISITORS \\ AT \\ PBFA II, BUILDING 983
}

\begin{abstract}
This SOP outlines proper procedures for conducting tours through the PBFA II complex in Area IV, building 983. Poor coordination of tours in this facility may expose visitors and/or resident personnel to unnecessary safety hazards and may result in lost time to the operation of the facility.
\end{abstract}




\section{Table of Contents}

Abstract . . . . . . . . . . . . . . . 0

I. Introduction .. . . . . . . . . . . . . . . 1

A. General . . . . . . . . . . . . . . 1

B. Phases of the PBFA II Project. . . . . . . . . 1

C. Types of Visitor Access . . . . . . . . . . 2

1. Tours . . . . . . . . . . . ...2

2. Visits . . . . . . . . . . . . . 2

D. Required Authorizations . . . . . . . . 3

1. Tours . . . . . . . . . . . . 3

2. Visits . . . . . . . . . . . . . 3

E. Indoctrination Required for Visitor Escorts . 3

II. Hazards and Safety Considerations . . . . . . 5

A. Flammable and Combustable Materials . . . . . 5

1. List of No Smoking Areas . . . . . . . . . 5

B. Motive Equipment and Mechanical Hazards . . . 5

C. Slips and Falls. . . . . . . . . . . . . 6

D. Stairs, Ladders, Gratings and Catwalks . . . 6

E. Electrical Hazards . . . . . . . . . . 6

F. Hard Hat Areas . . . . . . . . . . . . . 7

G. Warning Lights and Audible Alarms . . . . . 7

H. Locked Doors . . . . . . . . . . . . . 8

III. Action in case of Emergency or Injury . . . . . . 9

A. Evacuation in Case of Fire . . . . . . . . . . 9

B. Injury or Emergency . . . . . . . . . . . . . . 9

1. List of Emergency Telephone Numbers . . . 9

IV. Appendices . . . . . . . . . . . . . . . . 11

A. 1200 Tour Information Sheet . . . . . . . . 11

B. Building Access Routes and No Smoking Areas . 12 


\title{
SAFE OPERATING PROCEDURE
}

FOR THE

STAFF MACHINE SHOP

AT

PBFA II, BUILDING 983

\begin{abstract}
This SOP outlines techniques for safely using the equipment in the Staff Machine Shop in Building 983. Poor shop practices may result in personal injuries and/or damage to equipment and material.
\end{abstract}




\section{Table of Contents}

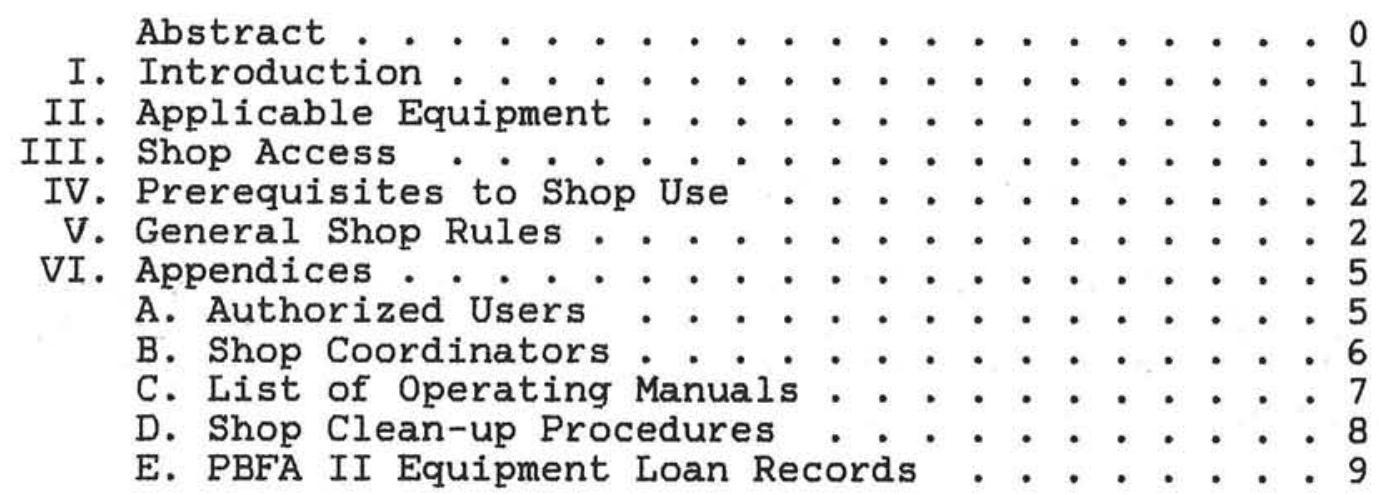


SAFE OPERATING PROCEDURE

FOR OPERATION, MAINTENANCE AND REPAIR

OF THE TESTBED FACILITY

AT

PBFA II, BUILDING 983

\begin{abstract}
This document covers procedures for operation, maintenance and repair at the PBFA II testbed facility. Two major hazards are associated with these operations:

1. High voltage, resulting from either active or residual charge left on the Marx Trigger Generator (MTG) or Marx Generator.

2. Slips and falls resulting from residual oil on the floor or testbed components.
\end{abstract}


Table of Contents

Abstract .. . . . . . . . . . . . . . 0

I. Introduction . . . . . . . . . . . . . . . 1

II. Testbed Operation . . . . . . . . . . . . . . 1

III. Testbed Hazards . . . . . . . . . . . . . . 2

IV. Procedures for Entry into the Testbed . . . . . . 3

V. Procedures for Working Within the Testbed . . . . 4

VI. Personnel Training . . . . . . . . . . . . . . 4

VII. Appendices . . . . . . . . . . . . . . . 5

A. Authorized Testbed Operators . . . . . . . 5

B. Energy Storage Device Safing Techniques . . . 6

C. Oxygen Deficient Environment Procedures . . 12 
SAFE OPERATING PROCEDURE

FOR

REACTING TO EMERGENCIES

AT

PBFA II, BUILDING 983

\begin{abstract}
This SOP outlines procedures for reacting to emergency situations within the PBFA II complex. Improper response to emergencies may result in area residents being subjected to higher than necessary risks and/or increased damage to equipment.
\end{abstract}


Table of Contents

Abstract . . . . . . . . . . . . . . . 0

I. Introduction . . . . . . . . . . . . . . . . 1

A. Emergency Response Duties . . . . . . . . . . 1

1. List of Emergency Telephone Numbers . . . . 1

II. Fire Control Procedures . . . . . . . . . . . . 2

A. Building Fire Team . . . . . . . . . . . . 2

B. Fire Team Personnel . . . . . . . . . . . 2

C. Safety Drills... . . . . . . . . . . . 2

III. Procedures for Personnel Injury Response . . . . 2

A. Slips and Falls . . . . . . . . . . . . . . 2

B. Asphyxiation or Potential Drowning . . . . . 2

C. Electrocution . . . . . . . . . . . . 3

D. Documentation .. . . . . . . . . . 3

IV. Emergency Preparedness . . . . . . . . . . . 3

V. Appendices . . . . . . . . . . . . . . . . 4

A. Fire Team Responsibilities . . . . . . . . 4 4

1. Building Fire Captain . . . . . . . . . 4

a. Fire Captain Checklist . . . . . . 6

2. Zone Officer . . . . . . . . . . . 7

a. Zone Officer Checklist . . . . . . . 9

3. Evacuation Squad . . . . . . . . 10

4. Extinguisher Squad . . . . . . . . . . 11

5. Annunciator Panel Monitor . . . . . . 12

6. Building Perimeter Observer . . . . . . 13

7. Sprinkler Valve Guard . . . . . . . . 14

8. Radio Dispersers . . . . . . . . . . 15

B. Building 983 Fire Team Personnel . . . . 16 
SAFE OPERATING PROCEDURE

FOR

MOTIVE EQUIPMENT OPERATION

AT

PBFA II, BUILDING 983

\begin{abstract}
This SOP outlines proper use of devices to move personnel and materials in and around Building 983. Improper techniques can result in personal injury and destruction of property.
\end{abstract}


Table of Contents

Abstract .................... . 0

I. References... . . . . . . . . . . . . . . 1

II. Introduction . . . . . . . . . . . . . . . . . 1

III. Applicable Equipment . . . . . . . . . . . . . 1

IV. Hazards . . . . . . . . . . . . . . . . . 2

V. Handling Precautions . . . . . . . . . . . . . . 2

VI. Motive Equipment Operational Procedures . . . . . 2

A. Cranes and Hoists . . . . . . . . . . . . 2

B. Material Handling Equipment . . . . . . . . . 4

C. Personnel Motive Equipment . . . . . . . . . . 4

D. slifting Fixtures . . . . . . . . . . . . . 4

VII. Specific Operational Procedures . . . . . . . 5

A. 10-ton Highbay Bridge Crane . . . . . . . . 5

B. 10-ton Highbay Gantry Cranes . . . . . . . . 5

C. 1/2-ton Highbay Jib Cranes . . . . . . . . . . 6

D. 1/2-ton Test Tank Rail Crane . . . . . . . . . 6

E. Facility Material Handling Equipment . . . . 6

VIII. Appendices . . . . . . . . . . . . . . . . . 7

A. Training Requirements and Procedures . . . . 7

B. Operating Manuals . . . . . . . . . . . 8

C. Material Handling Equipment Access . . . . . . 9

D. Rigging Considerations . . . . . . . . . . .10

E. SAND81-1807, Revision A, Section 4.6 .3 . . . 12 
SAFE OPERATING PROCEDURE

FOR

THE USE OF FLAMMABLE LIQUIDS

AT

PBFA II, BUILDING 983

\begin{abstract}
This SOP outlines proper procedures for use and disposal of flammable liquids in and around Building 983. Improper handling of these materials can result in fires that could cause injury and destruction of property.
\end{abstract}


Table of Contents

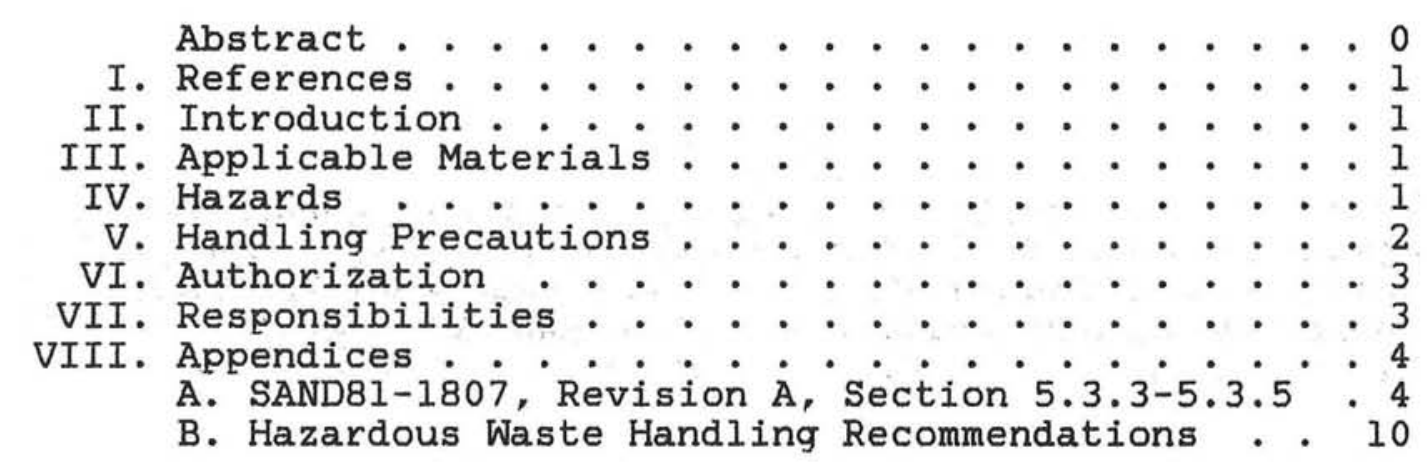


SAFE OPERATING PROCEDURE

FOR THE

USE OF SAFETY EQUIPMENT

$\mathrm{AT}$

PBFA II, BUILDING 983

\begin{abstract}
This SOP outlines proper procedures for use of safety equipment within Building 983. Failure to use this equipment properly will cause personnel to be exposed to unnecessary risk and may result in falls or other personal injury.
\end{abstract}


Table of Contents

Abstract . . . . . . . . . . . . . 0

I. Introduction ................. 1

II. Applicable Equipment . . ............. . I

III. Procedures ... . . . . . . . . . . . . . . . . I

IV. Inspection and Maintenance .......... 3

V. Appendices .............. 5

A. SAND81-1807, Revision A, Section 4.2.4.8..5

B. Scott Air Pack Authorized Users . . . ... 6 
SAFE OPERATING PROCEDURE

FOR

PERSONNEL ACCESS

T0

PBFA II, BUILDING 983

\begin{abstract}
This SOP describes the Access Control System and access procedures at PBFA II, Building 983. This system is used to limit personnel access to areas of the 983 complex during accelerator testing or other potentially dangerous activity. The hazards involved with improper access controls include personnel exposure to intense electromagnetic fields, ionizing radiation, high energy laser radiation, high level accoustical noise, and hazards associated with high voltage equipment.
\end{abstract}


Table of Contents

Abstract ................. 0

I. Introduction ................. I

II. System Description . . . . . . . . . . . . . . . I

III. Operating Mode Descriptions ... . . . . . . . 2

A. Full Access . . . . . . . . . . . . 2

B. Laser Trigger Alert. . . . . . . . . . . . 2

C. High Voltage Alert .. . ... . . . . . . 2

D. Full Alert ...............2

E. High Voltage on/off .......... 3

IV. Facility Evacuation Criteria . . . . . . . . 3

A. Laser Test Alert Status . . . . . . . . 3

B. High Voltage Alert Status . . . . . . . 3

C. Full Alert Status . . . . . . . . . . . . . 3

V. Emergency Access . . . . . . . . . . . . . . . . 4

VI. Roof Access . . . . . . . . . . . . . . . . . . 4

VII. System Testing . . . . . . . . . . . . . . . . 4

VIII. Appendices . . . . . . . . . . . . . . . . . 5

A. Access Control Evacuation Procedures . . . . . 5

1. High Voltage Test Alert . . . . . . . . 5

2. Laser Test Alert............ 6

3. Full Alert .............. . 8

a. Limited Full Alert . . . . . . . . 8

b. Unlimited Full Alert . . . . . . 10

B. Facility Warning Beacon Identification . . . 12 


\title{
SAFE OPERATING PROCEDURE \\ FOR MAINTENANCE AND REPAIR
}

IN THE OIL SECTION

OF

PBFA II, BUILDING 983

\begin{abstract}
This SOP describes procedures for performing maintenance and repair operations in the oil section of PBFA II, Building 983. Three major hazards are associated with entry into the oil section of PBFA II:
\end{abstract}

1. Hazards associated with high voltage equipment

2. Slips and falls resulting from residual oil in the tank

3. Bump hazards due to the confined nature of the work space and numerous components 
Table of Contents

Abstract . . . . . . . . . . . . . . 0

I. Introduction . . . . . . . . . . . . . . . . . 1

II. Prodcedures for Entry into the 0il Section . . . . 2

III. Procedures for Working Within the 0il Section . . 2

IV. Personnel Training . . . . . . . . . . . . . 3

V. Appendices . . . . . . . . . . . . . . . . . . . 4

A. Oxygen Deficient Environment Procedures . . . . 4

B. Energy Storage Device Safing Techniques. . . . 5 
SAFE OPERATING PROCEDURE

FOR

FLUID SYSTEMS OPERATION

AT-

PBFA II, BUILDING 983

\begin{abstract}
This SOP describes the hazards involved with work in and around the PBFA II fluid systems. Improper safety practices can result in personal injury, destruction of property, and disruption of facility activities.
\end{abstract}




\section{Table of Contents}

Abstract . . . . . . . . . . . . . . 0

I. References.................... . . 1

II. Introduction . . . . . . . . . . . . . . . . . 1

III. System Hazards . . . . . . . . . . . . . . . . . . 1

A. Transformer 0il Processing System . . . . . . 1

B. Technical Water Processing System . . . . . . 2

IV. Appendices . . . . . . . . . . . . . . 4

A. Authorized Fluid System Operators . . . . . : 4

B. Fluid System Emergency Response Procedures. . 5 


\title{
SAFE OPERATING PROCEDURE \\ FOR MAINTENANCE AND REPAIR \\ IN THE WATER SECTION
}

$\mathrm{OF}$

PBFA II, BUILDING 983

\begin{abstract}
This SOP describes procedures for performing maintenance and repair operations in the water section of PBFA II, Building 983, when water is out of the machine ( reference PBFA II SOP for Underwater Diving for underwater operations). Three major hazards are associated with entry into the water section of PBFA II:

1. An oxygen deficient environment may occur in the tank from an SF6 gas leak.

2. Slips and falls resulting from residual water in the tank.

3. Bump hazards due to the confined nature of the work space and numerous components.
\end{abstract}


Table of Contents

\begin{abstract}
. . . . . . . . . . . . . . 0
I. Introduction . . . . . . . . . . . . . . . . 1

II. Procedures for Entry into the Water Section . . . 2

III. Procedures for Working Within the Water Section . 2

IV. Appendices . . . . . . . . . . . . . . . 3

A. Oxygen Deficient Environment Procedures . . . 3
\end{abstract}




\title{
SAFE OPERATING PROCEDURE
}

FOR THE

GAS SWITCH PRESSURE TEST VESSEL

AT

PBFA II, BUILDING 983

\begin{abstract}
This document outlines safe operating procedures for the Rimfire Gas Switch pressure test vessel at PBFA II, Building 983. Improper use of this device could result in personal injury.
\end{abstract}




\section{Table of Contents}

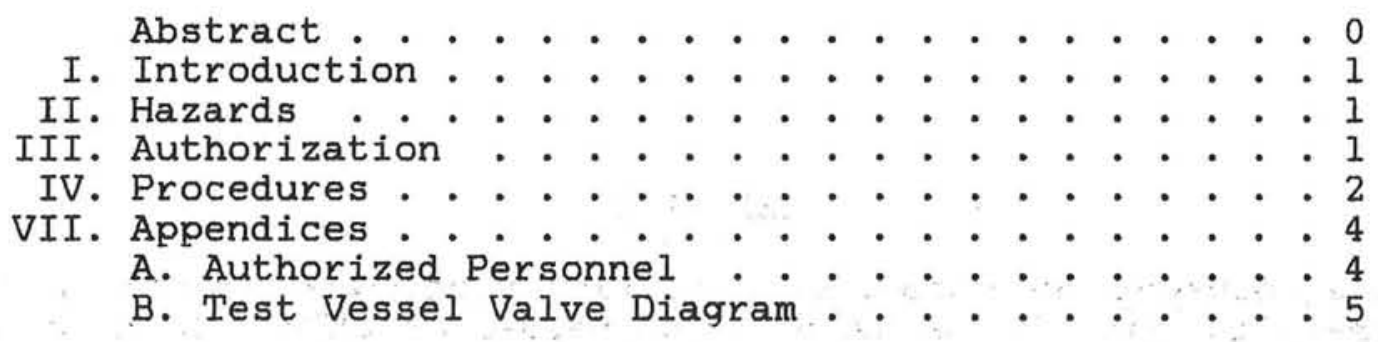


SAFE OPERATING PROCEDURE

FOR

IONIZING RADIATION HAZARDS

AT

PBFA II, BUILDING 983

\begin{abstract}
This SOP outlines procedures for minimizing hazards from ionizing radiation at PBFA II, Building 983. Failure to follow proper procedures can result in personnel exposure to high levels of radiation.
\end{abstract}




\section{Table of Contents}

Abstract . . . . . . . . . . . . . . 0

I. Introduction . . . . . . . . . . . . . . . 1

II. Operator Authorization . . . . . . . . . . . . 1

III. Operating Parameters . . . . . . . . . . . . . . 1

IV. Radiation Safeguards . . . . . . . . . . . . . 2

V. Operating Procedures . . . . . . . . . . . . 2 


\title{
SAFE OPERATING PROCEDURE
}

FOR

UNDERWATER DIVING

AT

PBFA II, BUILDING 983

\begin{abstract}
This SOP outlines procedures for underwater diving operations at PBFA II, Building 983. The hazards involved include personal injury and drowning.
\end{abstract}




\section{Table of Contents}

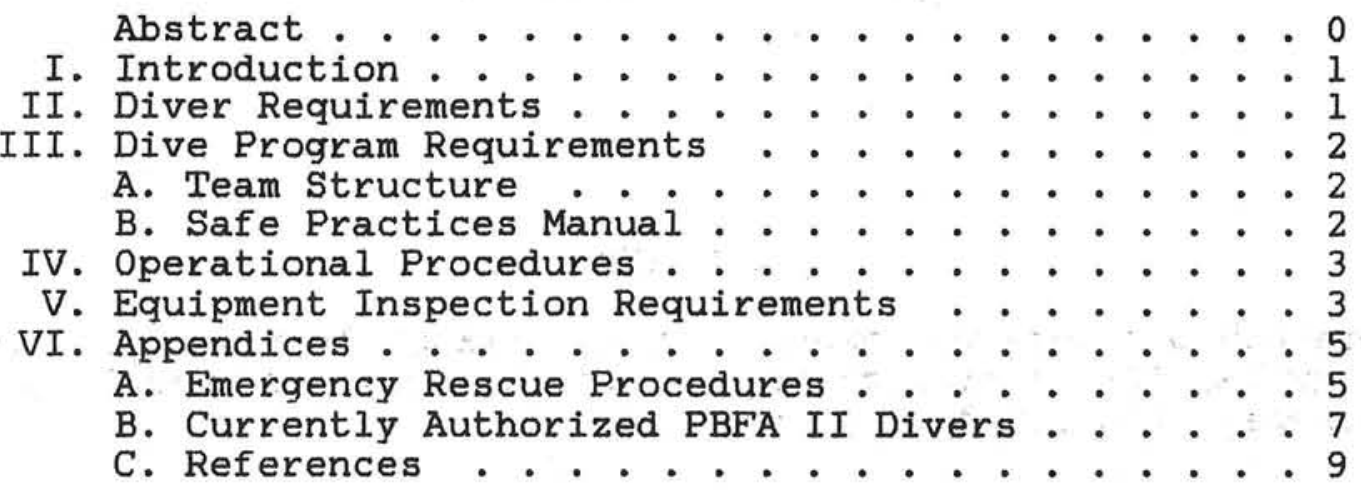


SAFE OPERATING PROCEDURE

FOR

LASER TRIGGER SYSTEM OPERATION

AT

PBFA II, BUILDING 983

\begin{abstract}
This SOP describes procedures for operation of the Laser Trigger system at PBFA II, Building 983. Three major hazards are associated with LTS operation:

1. Hazards associated with operation of high voltage equipment.

2. Hazards associated with exposure to Laser radiation.

3. Hazards associated with the handing of toxic gas.

Failure to operate this system properly could result personal injury and destruction of property.
\end{abstract}




\section{Table of Contents}

Abstract . . . . . . . . . . . . . . 0

I. Introduction . . . . . . . . . . . . . . . . 1

II. Operational Precautions . . . . . . . . . . . 2

1. High Voltage Systems . . . . . . . . . . . 2

2. Laser Systems . . . . . . . . . . . . . . . 2

3. Toxic Gas Hazards . . . . . . . . . . . 3

III. Operational Procedures . . . . . . . . . . . 3

A. Access Control to the LTS Alcove . . . . . . . 3

B. Control of High Voltage Keys . . . . . . . 3

C. Beacons and Warning Systems . . . . . . . 3

D. Alcove Fire Control System . . . . . . . . 4

E. LTS Alcove Vent System . . . . . . . . . . . . 4

F. Authorized LTS Operators . . . . . . . . . 4

G. Local and Remote Control Operations . . . . 4

IV. Appendices . . . . . . . . . . . . . . . . . 5

A. Authorized LTS Operators . . . . . . . . 5

B. References . . . . . . . . . . . 6 


\title{
SAFE OPERATING PROCEDURE \\ FOR MAINTENANCE AND REPAIR
}

IN THE CENTER SECTION

OF

PBFA II, BUILDING 983

\begin{abstract}
This SOP describes procedures for performing maintenance and repair operations in the center section of PBFA II, Building 983. Five major hazards are associated with maintenance activities in the center section of PBFA II:
\end{abstract}

1. Hazards associated with high voltage equipment.

2. Toxic vapor hazards associated with the use of organic solvents in the confined environment of the center section.

3. Hazards associated with the use of motive equipment.

4. Slips and falls while working within the center section.

5. Bump hazards due to the confined nature of the work space. 


\section{Table of Contents}

Abstract . . . . . . . . . . . . . . 0

I. Introduction . . . . . . . . . . . . . . . . 1

II. Procedures for Entry into the Center Section . . . 2

III. Appendices . . . . . . . . . . . . . . . . 4

A. Personnel Authorized for Center Section Access 4

B. High Voltage Equipment Safing Requirements . . 5

C. Procedures for Toxic Solvent Use . . . . . 6 


\author{
SAFE OPERATING PROCEDURE \\ FOR THE \\ APPLIED-B DIODE CAPACITOR BANK \\ AT
}

PBFA II, BUILDING 983

\begin{abstract}
This document outlines safe operating procedures for the 600 $\mathrm{kJ}, 22 \mathrm{kV}$ Applied-B Diode capacitor bank located in Building 983. The high-voltage unit is located on the -25 foot level of Building 983 and the control console is located in the PBFA II Control/Monitor Room. Improper operation of this device could result in personal injury and electrocution.
\end{abstract}


Table of Contents

Abstract ................... . . 0

I. Authorization . . . . . . . . . . . . . . 1

II. Procedures . . . . . . . . . . . . . . . . . I

III, Appendices . . . . . . . . . . . . . . . . 3

A. Authorized Operators . . . . . . . . 3 


\title{
SAFE OPERATING PROCEDURE
}

FOR

WELDING, CUTTING, AND HOTWORK

IN

TECH AREA IV

\begin{abstract}
This document covers safety considerations and procedures for obtaining welding and cutting permits for work done in and around all accelerators in Area IV by members of the 1200 Organization. The major hazards associated with this work are:

1. Toxic by-products, such as metal fumes, gases, and ultraviolet radiation.

2. Dangers associated with the equipment, such as electrical shock and explosion of compressed gases.

3. Fire.

Failure to address the above hazards correctly could result in injury to the welder and co-workers and damage to Area IV facilities ranging from minor problems to destruction of major equipment.
\end{abstract}


Table of Contents

Abstract . . . . . . . . . . . . . 0

I. Introduction ............... 1

II. Description of Relevant Hazards . . . . . . . 2

A. Toxic By-Products . . . . . . . . . . . . . 2

1. Metal Fumes ............ 2

2. Toxic Gases ............ 3

3. Ultraviolet Radiation ........ 3

B. Equipment Related Hazards . . . . . . . . . 3

1. Compressed Gas Cylinders . . . . . . . . . 3

2. Electrical Shock........... 3

3. Fire . . . . . . . . . . . 4

III. Hazard Control Procedures ...........4

A. Control of Toxic By-Products . . . . . . . . . 4

1. Ventilation Control Measures . . . . . . 4

2. Personal Protective Equipment . . . . . 4

a. Supplied Air Respirators . . . . . . 4

b. Eye Protection ........... 5

c. Protective Clothing ... . . . . . 5

B. Compressed Gas Cylinders ... . . . . . 6

1. Storage . . . . . . . . . . 6

2. Handling . . . . . . . . . . 6

3. Cylinder Use . . . . . . . . . . . . 6

C. Electrical Shock . . . . . . . . . . 7

D. Fire Prevention ............ . 7

1. SNLA Procedures ............7 7

2. Tech Area IV Procedures . . . . . . . . 7

IV. Appendices . . . . . . . . . . . . . . . . 9

A. Fire Protection Procedure . . . . . . . . . . 9

B. Sandia Welding Permit, SA 2013-B ..... 21

C. TA-IV Welding Checklist......... 22 


\author{
SAFE OPERATING PROCEDURE \\ FOR \\ OPERATOR TRAINING AND CERTIFICATION \\ $\mathrm{AT}$
}

PBFA II, BUILDING 983

\begin{abstract}
This SOP covers the training of PBFA II facility operating crews in both technical and safety areas, and the certification of personnel in the operation of various accelerator subsystems. Ineffective training in technical and safety procedures and undocumented operator certification could result in an unacceptable number of avoidable operating exrors, increased hardware damage, and an increased risk to personnel exposed to accelerator hazards.
\end{abstract}


Table of Contents

Abstract . . . . . . . . . . . . . 0

I. Introduction . . . . . . . . . . . . . . 1

II. Personnel Classifications . . . . . . . . . . . I

III. Command Structure . . . . . . . . . . . . . . 2

IV. Types of Operational Training . . . . . . . . . . 2

A. General Orientation . . . . . . . . . . . 2

B. Technical Training in Pulsed Power Technology . 3

C. Facility Safe Operating Procedures . . . . . 3

D. Subsystem Operating Procedures .. . . . . . 3

E. On-The-Job Opportunities and Methods . . . . . 4

V. Authorization and Certification Requirements . . . 4

A. Consideration for Authorization . . . . . . . . 4

1. Personnel Authorized as Operators . . . . 5

2. Personnel Authorized to Fire PBFA II . . . 6

B. Certification Requirements . . . . . . . 6

1. Prior Operational Experience . . . . . . 6

2. Specific Training Program . . . . . . 6

3. Simulation and Practice . . . . . . . 7

4. Operator Time Under Observation . . . . . 7

VI. Appendices . . . . . . . . . . . . . . . 8

A. Description of PBFA II Functional Personnel . 8

B. PBFA II Operational Command Structure . . . 13

C. Personnel Training Materials . . . . . . . 14

1. Newhire Orientation Checklist . . . . . 15

2. Technical Training Materials . . . . . 24

3. Available Classes in Pulsed Power . . . . 24

4. Personnel Safety Training Program . . . 25

D. Facility Safe Operating Procedures . . . . . 29

E. Subsystem Operating Procedures . . . . . . 65 
Appendix E

Subsystem Operating Procedures

Facility operating procedures are used to establish a standard methodology with respect to facility subsystem operation. O.P.'s ensure that important aspects of subsystem operation are documented and followed. The following is a listing of procedures being developed during the operational phase of PBFA II.

Shot Related O.P.'s:

PBFA Shot Procedures

Shot Description

Shot Coordinator Shot Duties

Philosophy of Highbay Evacuation

Access Control System Procedures

PA Operator Announcement Guide

Marx Charge Operating Procedure

MTG Charge Operating Procedure

LTS Charge Operating Procedure

POS Charge Operating Procedure

Diode Capacitor Bank Operating Procedure

Mechanical Room Shot Procedure

Walkie-Talkie Stations

Manpower Requirements for Shot Activities 
Appendix E (cont.)

Systems/Maintenance Related O.P.'s:

Morning Inspection Sheet Evening Inspection Sheet Weekend Inspection Sheet Monday Inspection Sheet

Water Transfer System Operating Procedure Oil Transfer System Operating Procedure SF6 System Operating Procedures Marx Generator Rebuild Procedures Rimfire Switch Rebuild Procedures Vacuum System Operating Procedures Energy Storage Section Full Inspection Pulse Forming Section Full Inspection Power Flow Section Full Inspection

Vacuum Interface Procedures Vacuum Convolute Procedures Vacuum System Maintenance Procedures Emergency Generator Maintenance Procedures 


\section{SAFE OPERATING PROCEDURE \\ FOR \\ HIGH VOLTAGE MONITOR CALIBRATION \\ AT \\ PBFA II, BUILDING 983}

Appendix 20

$20-1-20-2$ 
Table of Contents

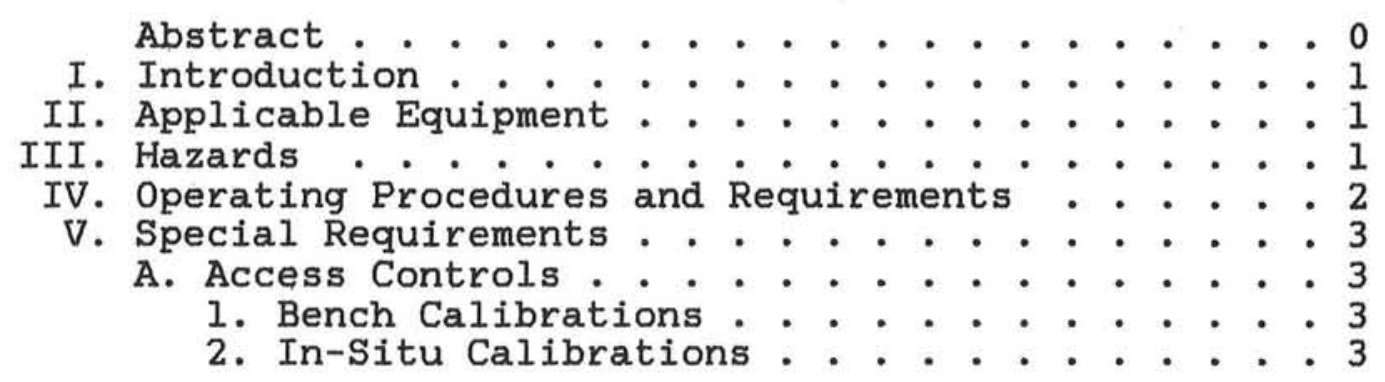


SAFE OPERATING PROCEDURE

FOR

HIGH VOLTAGE MONITOR CALIBRATION

$\mathrm{AT}$

PBFA II, BUILDING 983

\begin{abstract}
This SOP outlines procedures for high voltage monitor calibration operations within Building 983. Improper use of this equipment could result in personal injury and electrocution.
\end{abstract}

\begin{tabular}{lllll}
\hline T. H. Martin, 1250 & date & & D. L. Rost, 3316 & date \\
\cline { 1 - 2 } S. A. Goldstein, 1254 & & date & A. M. Fine, 3316 date
\end{tabular}


SAFE OPERATING PROCEDURE

FOR

HIGH VOLTAGE MONITOR CALIBRATION

$\mathrm{AT}$

PBFA II, BUILDING 983

I. Introduction

This SOP defines procedures for high voltage calibration operations associated with the PBFA II facility. Monitor calibrations occur on a continual basis and involve a variety of devices that diagnose accelerator performance and experimental results. High voltage pulse generators are required to properly calibrate monitors designed to measure high amplitude signals. Calibrations may take place in situ within the accelerator tank, or on test benches in other areas of the facility.

\section{Applicable Equipment}

A number of high voltage pulser units are employed at PBFA II depending upon the calibration performed. These pulsers range from 10 to 50 kilovolt output, with up to 30 Joules of stored energy. Procedures specified in this document are to be followed for all pulsers used at PBFA II.

III. Hazards

The Primary hazard associated with calibration is personnel injury through electric shock, either from the shock itself or a resultant fall. Situations which increase the risk involved in these operations are listed below:

A. The amounts of stored electrical energy involved in monitor calibrations, though potentially lethal, is not sufficient to automatically require activation of the facility access control system. Strict local controls must be employed to limit personnel access to areas of risk during these operations.

B. Personnel used to working with large amounts of stored energy may become complacent around small pulser units. Calibration team members must guard against this potentially lethal attitude. 
C. Calibrations performed in situ routinely require personnel to adjust or move cabling between shot sequences. Calibration team members must ensure that all equipment is safed before approaching high voltage cables or devices (or allowing others to approach!).

D. In situ calibrations in the water section of ten require divers to move or adjust cabling. Procedures described in the PBFA II Underwater Diving SOP must be followed during these operations.

E. During bench calibration operations, energized equipment is susceptable to accidental contact by operator personnel. Persons performing bench calibrations shall maintain well organized setups and guard against this hazard.

F. The pulser units employed at PBFA II are susceptable to internal breakdowns or unpredictable self-triggering. No calibration equipment shall be energized until personnel are clear of areas of risk. Any troubleshooting or setup changes are to occur only after systems have been properly and completely safed.

\section{Operating Procedures and Requirements}

Any personnel observing unsafe practices or test setups should request an immediate cessation of testing until such conditions are rectified. Such occurances shall be reported to the PBFA II Facility Supervisor and the Division Supervisor, PBFA II Operations.

A. Only personnel meeting the following requirements shall be authorized to perform high voltage calibrations within the PBFA II facility:

1. Personnel shall be familiar with this and all other pertinent Safe Operating Procedures.

2. Personnel shall have prior experience with calibration equipment and understand the risks involved.

3. Personnel shall understand the normal response of devices being calibrated in order to identify operational abnormalities.

B. The two man rule shall apply during all calibration procedures within building 983. Whenever troubleshooting or setup changes are required, both personnel must be present.

C. Two personnel trained and certified in CPR must be present within the facility during high voltage calibration operations. 
D. During pulsing runs, at least one person authorized under this SOP must remain in the proximity of the test setup while equipment is energized. This person shall be responsible for limiting access to any hazardous equipment and posess the means to immediately contact personnel in DAS or C/M in case of emergency.

E. Before each use, all equipment used in calibration operations (pulser units, cables, etc.) shall be inspected for signs of wear, breakage or other unsafe conditions. Equipment showing signs of damage shall be removed from service immediately.

F. Deviations from the procedures outlined in this document must receive prior approval by the Division Supervisor of PBFA II Operations.

V. Special Requirements

A. Access Controls

During high voltage calibration procedures, access to all hazardous equipment or components shall be adequately restricted to prevent contact by facility personnel or visitors.

At least one person authorized under this SOP shall stay in proximity of the calibration setup and be responsible for personnel access controls during high voltage operations. Where this is not adequate (because of large areas involved, etc.) and localized lockout measures are not possible, the Facility Access Control system shall be activated.

\section{Bench Calibrations}

Areas containing high voltage components shall be roped off with perimeters extending at least four feet from hazardous areas or components. An active caution beacon and "High Voltage" warning sign shall be prominently displayed during all high voltage activities. Warning signs and beacons shall be situated such that personnel approaching the setup from any direction shall be informed of the hazard.

\section{In-Situ Calibrations}

No high voltage calibration equipment shall be energized while personnel are in areas of risk. During oil section calibrations, personnel shall be restricted from access within five modules of ANY high voltage activity. Calibrations within the water section $\underline{O R}$ center section shall require evacuation of $\mathrm{BOTH}$ of these accelerator sections before equip- 
SOP - High Voltage Monitor Calibration Bldq. 983 / page 4

ment is energized. Any high voltage activity which involves more than one section shall follow ALL applicable procedures.

Calibration equipment which extends outside of the accelerator tank (pulsers, pulser cables, etc.) shall be roped off and labeled as in 1 above. 